\title{
REPRODUCING UNEVEN DEVELOPMENT ON THE HUNGARIAN HOUSING MARKET
}

\section{Zsuzsanna Pósfai}

$\mathrm{PhD}$ dissertation in partial fulfilment of the requirements

of the Marie Curie ITN "RegPol ${ }^{2}$ - Socio-economic and Political

Responses to Regional Polarisation in Central and Eastern Europe",

and of the Doctoral School of Geosciences

Department of Economic and Social Geography,

Faculty of Science and Informatics, University of Szeged.

Supervisors:

Dr. Erika Nagy: Centre for Economic and Regional Studies, Hungarian Academy of Sciences Dr. Zoltán Kovács: Department of Economic and Social Geography, University of Szeged

Szeged, 2018

The research leading to these results was conducted in the frame of the project "Socioeconomic and Political Responses to Regional Polarisation in Central and Eastern Europe" (RegPol$\left.{ }^{2}\right)$, coordinated by the Leibniz Institute for Regional Geography, Leipzig/ Germany. The project received funding from the People Programme (Marie Curie Actions) of the European Union's Seventh Framework Programme FP7/2007-2013/ under REA grant agreement $n r .607022$. 
Table of Contents

Introduction

Chapter 1. Theoretical propositions for investigating uneven development on the Hungarian

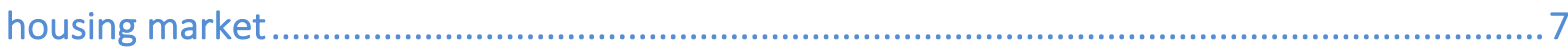

1.1. Crisis pushes critical approaches to the fore: tracing theoretical trajectories ...............................

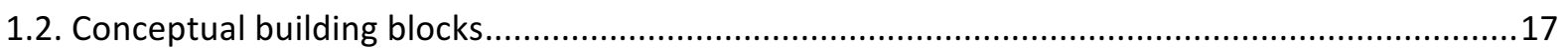

1.3. Existing research on housing and uneven development in Hungary .........................................34

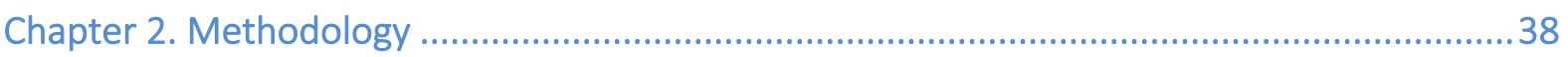

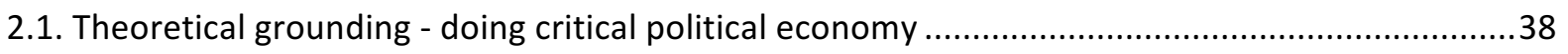

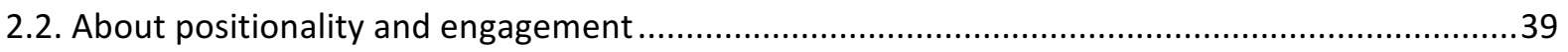

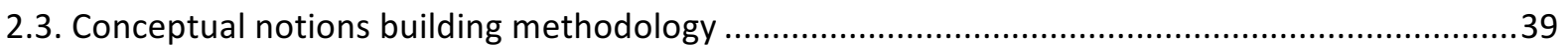

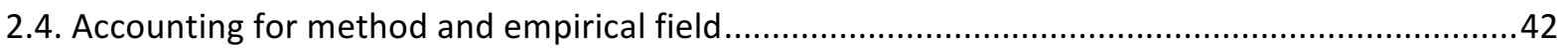

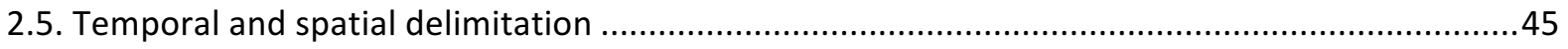

Chapter 3. A framework of uneven development on various scales of the housing market ...47

3.1. A brief chronology of channelling capital into housing in Hungary since the late 1990s ..............47

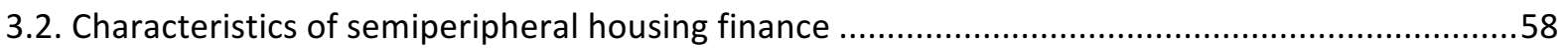

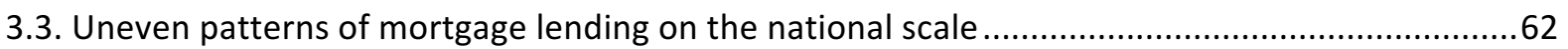

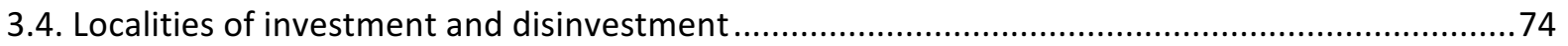

Chapter 4. Mapping firms of the housing market and how crisis reshuffles them ................81

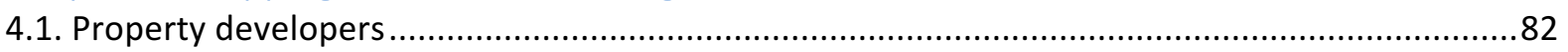

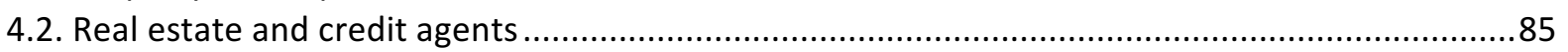

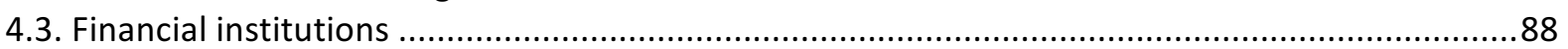

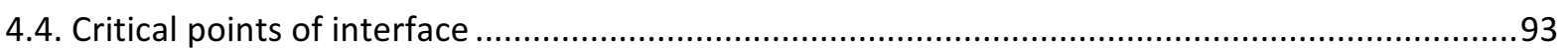

Chapter 5. Key mechanisms of reproducing uneven development on the housing market..100

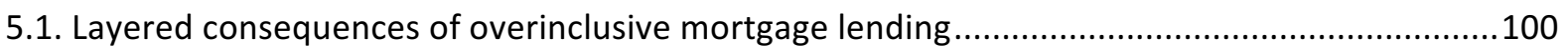

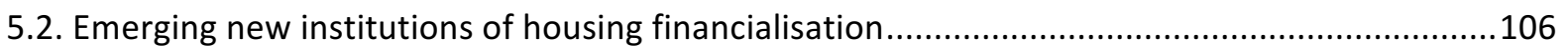

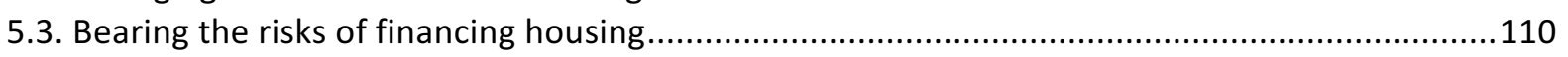

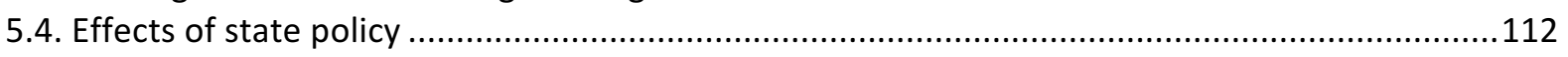

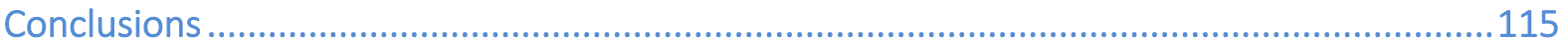

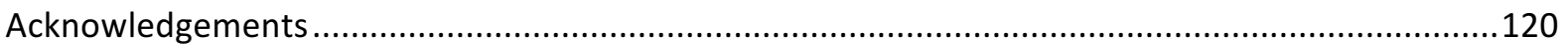




\section{INTRODUCTION}

The economic crisis of 2008 brought the inherent links of global capitalism and housing to the surface. Following this turning point, a number of studies critically engaging with the political economy of housing emerged in various contexts around the globe. My research can also be considered one of these. In my analysis of the Hungarian housing market, I accord particular attention to the spatial dimensions of investment in housing, and to how corporate actors navigate and reproduce this inherently uneven field. I conceptually position my research in relation to the notion of uneven development, and thus approach my study through the lens of understanding patterns of homogenisation and differentiation. This approach supports a relational understanding of cores and peripheries, as well as a focus on the mechanisms underlying the production of socio-spatial unevenness in housing, rather than merely giving an empirical observation of the existence of these inequalities.

\section{Relating to a broader research agenda}

I have conducted the research leading up to this $\mathrm{PhD}$ dissertation in the framework of a Marie Curie Initial Training Network, as part of a research project entitled "RegPol ${ }^{2}$ - Socioeconomic and Political Responses to Regional Polarisation in Central and Eastern Europe". This has determined some of the main guiding elements of my research, most notably the focus on the mechanisms how subnational socio-spatial inequalities are reproduced in Central and Eastern Europe. The research agenda proposed by the RegPol ${ }^{2}$ research project was one of peripheralisation; examining uneven development principally from the perspective of peripheral areas, inquiring about their trajectories of development. However, as argued in the introduction to an edited volume linked to this research network, "peripheralization implies processes of centralization and thus forms of socio-spatial polarisation at various scales" (PoSCoPP 2015, p1, own highlight). I strongly build on this relational and scalar approach to cores and peripheries, understanding the formation of cores and peripheries in a dynamic, overlapping way. That is, I see processes of peripheralisation as inherently linked to those of centralisation, and the relation between the two is central in my analysis. I integrate this approach with that proposed by scholars of world systems and dependency theories, who emphasise the hierarchical and dependent nature of this relation; arguing that the dynamic tension between cores and peripheries is the main driving force of uneven development (Gowan 2000).

Being part of the $\mathrm{RegPol}^{2}$ research project also meant that my research was inherently comparative - even if my concrete empirical material finally only focused on the case of Hungary. The continuous exchanges with fellow researchers and constant reflection on the broader framework of uneven development and peripheralisation in Central and Eastern Europe always kept the perspective of regional and European comparison before me. Although this regional comparison does not explicitly appear in the dissertation; the conceptual understanding of situating Hungary as a semiperiphery within the European and global economy opens a meaningful space for understanding this particular case in a broader regional context.

\section{Conceptual positioning}

Conceptually, I position myself in relation to research traditions of critical political economy and economic geography, drawing especially on studies that have emerged following 
the 2008 crisis and represent critical / more macroscopic approaches to understanding contemporary capitalist development. Within these disciplinary approaches I especially mobilise notions that can be related to the development of the housing market within this frame. This directs my attention to scholarly work that focuses on the ways how capital is invested in housing. Thus, I draw on the literature relating to the variegated financialisation of housing (linked to new developments in financial geography), and on studies of residential varieties of capitalism (in political science and political economy). I claim that households are included in the extractive logic of financial capitalism primarily through household credit - especially in the context of housing regimes extremely dominated by individual homeownership (which is the case of Hungary). I believe that financial mechanisms available to the development of housing fundamentally determine what type of actors will be present on the housing market, and also to whom and under what conditions housing is accessible. Furthermore, in line with the tradition of critical political economy, I see crisis as an instance that reveals underlying mechanisms of channelling capital from the peripheries to the cores - thus, I continuously come back to the analysis of the turning point of the recent economic and financial crisis. In my view, the development of the Hungarian housing market in recent decades cannot be understood independently from broader relations of dependent integration in the European and global economic space. Thus, I strongly draw on scholars of dependency theories, particularly those who have employed this frame of thought to contemporary Europe.

I also understand the issue of subnational socio-spatial disparities in relation to these external dependencies, and argue that internal fragmentation within Hungarian society, economy, or in the spatial structure of the housing market can be linked to the semiperipheral position Hungary takes up in the global economy. I believe that inquiries about increasing spatial unevenness within peripheral European countries, and about the increasing marginalisation of certain local spaces will not have the necessary explanatory force without considering the broader logic of European integration they are embedded in. I propose a research agenda for such a multiscalar understanding of uneven and dependent development. The housing market is a very apt empirical field for understanding how these extractive mechanisms play out on various scales.

In my analysis, I focus on corporate actors as the concrete conveyors of capitalist processes on the housing market. I am interested in how firms themselves are embedded in core-periphery relations, and on the other hand how they (re)produce socio-spatial patterns of unevenness. I aim to shed light on how corporate-level strategies are translated into uneven development. In this, I build on conceptual approaches that link corporate governance strategies to macroeconomic processes.

\section{Research questions}

Under a capitalist housing regime it can, in the end, be seen as necessary - or, at the least, unsurprising - that the housing market should be geographically uneven: housing makes the inherently unequal spatial logic of capitalism explicit. A structuralist / marxist understanding of housing under capitalism suggests that patterns of unevenness and inequality will continue to be reproduced. While I adhere to this structuralist approach and emphasise the need to uncover the broader economic context in which housing develops locally, I think this approach can be brought into a productive tension with an understanding of the agency of actors engaged in this field. In the end, it is always concrete firms and concrete public institutions that create the circumstances for capital investment in housing, and they also have certain capacity to mitigate or alter these processes. Thus, I find it highly relevant to uncover the concrete 
mechanisms through which capital is fixed in housing and the ways in which corporate actors and the state intervene in the development of national and local housing markets.

The concrete research questions guiding my inquiry are thus, (1) on the one hand, related to where the money comes from that is invested in housing in Hungary? I will trace what the institutional and spatial patterns of this investment are, and how this lays out a structure of uneven development on the housing market. (2) Second, I aim to understand how corporate actors of the housing sector are themselves embedded in core-periphery relations, and how they navigate this uneven structure. (3) Third, I am interested in what consequences the institutional structure and corporate strategies of these firms have on the reproduction of socio-spatial unevenness? (4) Finally, (as a crosscutting question to the above themes), I focus on how the whole of this system is constantly shifting over time, in resonance with the cyclical development of capitalism. Thus, I will pay particular attention to what the condensing and turning moment of crisis in 2008 can uncover about the underlying mechanisms of unevenness and extraction through housing.

\section{Empirical directions}

In the dissertation, I argue that capital is being systematically transferred from the peripheries to cores on various scales through housing. This can be observed on a European, national and local scale, and can be grasped in the concrete strategies of various types of actors of housing (such as financial institutions, developers or agents). Examples for this process include how Western European financial institutions entered Central and Eastern European (CEE) markets before the crisis and channelled capital towards cores on a European scale; or how individual mortgages and project-financing credit are allocated with much more favourable conditions in core areas on a national scale; or through the fact that investor- buyers from all over the country prefer to invest in prime real estate locations in the capital city. The capital-intensive and investment-oriented segment of the housing market - where economic actors prefer to intervene - is thus increasingly concentrated in core areas (which often produces inequalities and displacement locally), while in peripheral areas the provision of housing is left to the responsibility of individual households (relying on their own resources or on credit to secure housing).

In my research I have empirically focused on corporate actors of the housing market; understanding their logic of intervention and the socio-spatial effects this has. Households and state institutions have only indirectly been included in the research, and my point of entry has deliberately been from the perspective of firms. Understanding firm strategies has been a way to grasp how finance and sptial unevenness are linked through housing.

In terms of housing finance there has been an important shift following the crisis from international to domestic sources of housing finance in Hungary. It remains to be seen whether this new structure can create future avenues for more stable and long-term forms of housing finance. What is already clear from the current reorganisation of housing finance is that the institutional hierarchy of actors involved in the housing market has shifted, benefiting an emergent new national capitalist class.

The availability of capital, the internal firm strategies balancing profit seeking and risk management, as well as instances of public intervention interact to produce cycles of ebbs and flows of investment and disinvestment on the housing market. The socio-spatial patterns of how capital spreads out and then how it is reconcentrated overlap, showing how homogenisation and differentiation under uneven development coexist and mutually reinforce each other. I analyse this process through the intervention of corporate actors in the field, 
claiming that risk management on a company scale translates into uneven socio-spatial development on a broader scale; and that because of this the concrete mechanisms through which uneven development can be practically grasped on the scale of the everyday functioning of the housing market are articulated in the terminology of corporate governance.

Currently, housing in Hungary is undergoing important shifts (this volatility is, in part, a necessary characteristic of a semiperipheral housing market), which makes research in this field difficult and subject to a potentially quick loss of relevance. For this reason, I do not consider the value of my research to be in the empirical description of the precise current situation on the housing market, rather in the way I sought to uncover systematic tendencies and characteristic mechanisms of how the unevenness of housing is (re)produced in Hungary.

\section{Structure and aims of the dissertation}

In the dissertation, I first outline the main theoretical lines of thought I draw on in the related disciplines of critical political economy and economic geography (chapter 1.1). Based on this, I determine three main conceptual reference points that will guide my analysis (chapter 1.2). These are related to (1) the role of housing in political economy more generally and in the spatial understanding of capitalism; (2) to core-periphery relations on various scales, understood in the framework of dependent development; and (3) to the role of firms in concretely translating these processes of capitalist development. Furthermore, I give an overview of existing empirical research about the Hungarian context which I draw on in my analysis (chapter 1.3). Following the setup of my methodological approach (chapter 2), I first propose a framework of how the uneven structure of housing is articulated on various scales; focusing on mechanisms of housing finance (chapter 3); then I give an overview of how economic actors are embedded in this uneven structure (chapter 4); and finally I give an analysis of various points of juncture where the unevenness of the housing market is reproduced (chapter 5). 


\section{CHAPTER 1}

\section{THEORETICAL PROPOSITIONS FOR INVESTIGATING UNEVEN DEVELOPMENT ON THE HUNGARIAN HOUSING MARKET}

Housing plays an important role in spatially anchoring broader processes of capitalist development, especially during cycles of financialisation. In order to grasp how this concretely happens I will investigate corporate actors which are - through their everyday mechanisms of doing business - the agents practically channelling money into housing. I claim that increasing spatial inequalities (or polarising core-periphery relations) on the Hungarian housing market are not a coincidence, but a consequence of how capitalism spatially unfolds in a dependent and uneven way. In this process, it is crucial to consider the role the CEE region fills in the interdependent and hierarchically structured global economic system (and specifically within the European economic space).

In order to understand the disciplinary trajectories from which these conceptual considerations come from, I will first give a brief overview of recent developments in the field of economic geography and critical political economy (in both of these disciplinary fields, the economic crisis of 2007/2008 brought the revival of structuralist approaches), highlighting the notions and theoretical approaches that have informed my analysis (chapter 1.1).

Then, I will propose three large "conceptual building blocks", drawing on the disciplinary developments previously outlined (chapter 1.2). In my study, I aim to link (1) a currently growing body of literature about the role housing plays in anchoring macroeconomic processes in space, and about the general role of housing in contemporary political economy; with a focus on Central and Eastern Europe (see e.g. Aalbers 2017, Bohle 2017, Sokol 2017); (2) notions of dependency and socio-spatial fragmentation on various scales (see eg. Becker et al. 2015, Hürtgen 2015); (3) literature disentangling how enterprises become conveyors of macroeconomic processes, how they are tied to uneven spatial development under financialisation (see eg. Dixon 2010, Vliegenthart-Overbeek 2007).

Furthermore, since most of the academic work I conceptually build on does not relate specifically to the field of housing or to the Hungarian context, I found it pertinent to give an overview of research done in Hungary in relation to the spatial inequalities of housing (chapter $1.3)$.

The conceptually integrating frame in which I bring these issues together is that of uneven development. This frame allows me to link macroeconomic processes to corporate actors operating on various scales, and also to material, locally specific housing realities. My analysis will be guided by a specific attention to the simultaneous dynamics of homogenisation and differentiation, and on how these dynamics produce patterns of capital investment and capital extraction between cores and peripheries. 


\subsection{Crisis pushes critical approaches to the fore: tracing theoretical trajectories}

Following the financial crisis of 2008, which shed light on global economic interconnectedness, there has been a revival of more macroscopic-structuralist explanations and theoretical approaches both in the field of geography and political economy. After a period of rather fragmented interpretations focusing on differentiation within capitalism, we are currently witnessing a return to understandings of capitalism in the singular. Common to these approaches is that they claim that there is one capitalism which, however, is articulated in a differentiated (variegated, or uneven) way across different contexts. The stake of research conducted in this frame is to understand the empirical richness of historically-institutionally concrete and diverse realities through their embededness in broader social and economic processes.

It is important to see how these theoretical shifts are the consequences of material shifts in the societal and economic contexts the "producers of theory" are situated in (Ebenau et al. 2015). That is, the revival of marxist-structuralist explanations is not independent from the unfolding recent economic and financial crisis. This shift in academic attention can be traced in the disciplinary fields of both geography and political economy, and was, in many cases, triggered by the devastating effects of the crisis on the housing market, and resulted in new conceptual propositions about the global linkages of housing. As Smith put it, for instance: "The central argument I would still like to make is that we need to understand the varied patterns and processes of uneven development across geographical scales. Nowhere was this more obvious than in the ways that a mortgage crisis in the United States became almost immediately a global economic and financial meltdown" (Smith, 2011, p. 264).

Although the fields of economic geography and political economy cannot be strictly separated: while the first has a disciplinary focus, the latter is rather a conceptual approach that has influenced various disciplines (among them, geography), I will nevertheless follow a somewhat mechanical separation of these two branches in the following section. At times, the authors discussed under the "political economy" line of thought could probably rather be considered as disciplinarily belonging to political science - in the framework of which they adapt a political economy approach. The disciplinary boundaries in social sciences are increasingly porous (as my own scientific-professional trajectory also illustrates), and my objective is not to give a comprehensive overview of the disciplinary developments in economic geography and political science in the past few decades. Rather, I seek to understand the roots of concepts that I mobilise in order to understand my empirical field; and in this process I give a narrative of how specific segments of these two disciplines transformed over the years. I employ a political economy approach and build strongly on geographical notions of space, as well as on an analysis of institutions (concretely, firms) operating on various scales.

An important point to pin down is that the following overview is dominated by contemporary critical theory elaborated in the core of global academia and of the global economy. Although I will link and contrast this narrative with academic work coming from (semi)peripheral contexts, I recognise that the entire theoretical lineage could be drawn up from the latter perspective (which would most likely highlight different turning points). This is not done in the present dissertation for various reasons. Contemporary debates in the field of critical theory relating to housing are dominated by academic work coming from core / globally dominant universities and research institutes, and it is inevitable to be able to converse with this body of work. Furthermore, due to the internal logic of academic publishing, "core" academic work is much more easily accessible, and has also constructed its own disciplinary 
narratives (see eg. the volume edited by Ebenau et al. 2015). Constructing different disciplinary narratives requires a much bigger effort of research and conceptualisation, and (from my perspective) cannot be done in the frame of a doctoral dissertation, but has to be a collective process. Thus, the narrative I partially reconstruct here will dominantly be from the perspective of the wave of post-crisis critical thought which has gained momentum in recent years in core institutions of academia.

One of the main concerns of recently emerging new macro-focused approaches is the consolidation of structuralist explanations and "local specificities". Disconsidering the specificities of different contexts is the ever-existing critique towards structuralist approaches. One of the ways in which contemporary critical research aims to overcome this issue is through empirically rich (and often comparative) research projects, while theoretically tackling this challenge by incorporating (more micro-focused) disciplinary developments of the 1990s and early 2000s. During this period, both in geography and in political economy more institutionally focused, fragmented theories become dominant, supporting the idea of capitalist convergence and focusing on local institutional diversity (Ebenau et al. 2015). These approaches produced certain empirical detail and methodological tools to investigate the concrete functioning of enterprises, or to open the box of the national scale in spatial analyses. These insights are now incorporated by contemporary proponents of more macroscopic explanations (who mainly focus on large questions of how capitalism functions), and these are conceptual tools that I have also applied in my research. Comparative and scalar approaches (that have conceptual but also methodological consequences) are also often mobilised in research aiming to account for local specificities and structural pressures at the same time.

In the following sections I will briefly trace the disciplinary developments in geography and critical political economy relating to various ways of investigating diversity within capitalist development. Although in this first section I do not make many explicit links to my empirical findings, the concepts I highlight here all informed and built my approach. The scheme at the end of this subchapter gives an overview of the notions that are most important from these disciplinary developments from the perspective of my conceptualisation.

\subsubsection{Disciplinary developments from the 1970 s to the 2008 crisis}

\subsubsection{Systemic critique in the $1970 \mathrm{~s}$ and $1980 \mathrm{~s}$}

In the 1970 and 1980s, as a response to the crisis following the macroeconomic shifts of the early 1970s, geographers turned towards the broader questions of capitalism and its spatial articulations (Hudson 2015). In this field, a body of literature in critical geography emerged, which is until today determinant in thinking about the spatiality of capitalism. The work of David Harvey and Neil Smith are key reference points in this literature, which are mobilised in the recent turn towards more critical and structuralist approaches in geography and political economy. The key notion I build on is that of uneven development (Smith 1984), as well as the idea of a spatial fix, and reflections on the function of real estate and housing as such a fix for surplus capital (Harvey 1982). Inherent to the notion of uneven development is the idea that the spatially uneven patterns of investment are more than just an indicator of inequalities under capitalism - they are actually a central driving force of capitalist development (Smith 1984). Smith describes the patterns of homogenisation and differentiation as central mechanisms in this process. Homogenisation here refers to the universalising tendency of capital, producing globally similar patterns of investment and of the exploitation of labor (ibid.). Differentiation in Smith's work refers to the spatial articulation of the division of labor and capital; it is about 
how capital moves around spatially looking for higher yields and transforming space in the process. The differentiating mechanism is the element of uneven development that produces inequalities and which also allows to account for the different paths and historically contingent institutional setups that develop in different contexts. Processes of homogenisation and differentiation happen in an intertwined and mutually dependent way.

Parallel to this, "the global economic crisis of the 1970s also brought a change in mainstream economic thinking" (Becker-Weissenbacher 2015). Economists focusing on issues of unequal relations of trade (mostly building on the experience of Latin-American countries) and on the systematically hierarchical structure of the global economy developed dependency and world systems theories (Frank 1967, Wallerstein 1976). These approaches criticised modernisation theories and mainstream theories of development, which promoted a catching up of "underdeveloped" parts of the world through more integration into a liberalised global economic order. Authors of dependency and world systems theories engaged in an explanation of persistent global inequalities by shedding light on how the international division of labor creates a rather rigid hierarchical system of global dependencies, where different places fulfil unequal roles in a global process of capital accumulation (Frank 1967, Arrighi 1994). In this hierarchically structured system capital is extracted from peripheries and is channeled towards the core of the global economy. Beside the notions of core and periphery (which are structuring elements of world systems theory), Wallerstein also developed the idea of the semiperiphery which will be especially interesting to mobilise in the context of Central and Eastern Europe (CEE). Semiperipheral countries (such as those of CEE) fulfil a specific function in the world economy both politically and political-economically (Wallerstein 1976, Arrighi 1990). Concerning the first aspect, the function of these places is to avoid extreme polarisation and thus dampen social unrest and avoid a broad coalition of the poor (also through the sustained promise of the semiperiphery being able to catch up to the core); while the latter function is to serve as markets for capital investment from the core countries, while providing cheap labor force (ibid). The approach of dependency and world systems theories is important in guiding my approach, but I will not employ this as an all-encompassing concenptual frame. I do, however, strongly build on more recent theoretical propositions rooted in this approach.

\subsubsection{A more microscopic focus in the 1990s and 2000s}

By the end of the 1980s, with various mechanisms put in place for handling the US crisis of overaccummulation (Brenner 2004) and of hegemony (Arrighi 1994), with the collapse of the Soviet Union and of the state socialist regimes of Central and Eastern Europe, theory also turned away from concerns of unevenness and inequality, and towards notions of convergence. Views claiming (hoping?) that the whole world would sooner or later adapt the AngloAmerican way of "doing" "proper" capitalism became predominant. However, when general convergence could not be empirically observed and significant differences were seen to persist, lines of thought focusing on institutional difference and historical path-dependency emerged in political science and economic geography.

In this vein, geography turned towards more fragmented analyses about the spatiality of capitalism in the 1990s, focusing on regional specificities and competitiveness, as well as on the functioning and governance structure of enterprises (Coe et al. 2007). In this period, two strands of literature developed within geography aiming to "link globalization dynamics and notions of regional development" (Coe et al. 2004). The first focused on endogenous institutional structures, while the other on inter-firm networks and global commodity / value chains (GCCs/GVCs). This work, along with the perspective of global production networks, aims to redefine regional development as relational and interdependent; going beyond the 
endogenous explanatory factors common to mainstream geography by connecting to global economic processes. The empirical vehicle through which this connection is made is the firm (Coe et al. 2004). However, in the body of literature on GVCs / GPNs the recognition of interconnectedness on a global scale is often done in an uncritical way; thus sometimes becoming a "network inclusion literature", without much reflection about how inclusion in hierarchically structured economic systems can actually have extractive consequences for certain regions (Werner 2016). (This extractive nature of inclusion is an argument that is often made in relation to housing finance systems, and strongly emerges from my research as well.)

In political economy during the 1990s priority was given to accounting for locally specific forms in which contemporary capitalism is articulated, and the possibilities of catching up in these various cases was debated. One such debate was that on post-socialist transition and when it would be over. (For a critique of this perspective and for studies of post-socialism linked to global processes see the edited volume Hann 2002, or Gille 2010.) In this context the school of "varieties of capitalism" (VoC) emerged at the end of the millennium, using the approach of heterodox political economy (Hall-Soskice 2001). At that point, this body of literature took up a critical position vis-à-vis the convergence-euphoria of the 1990s, and - in spite of its rather careful structuralism - represented some kind of a counterpoint to mainstream neoliberal economics (Ebanau et al. 2015). The varieties of capitalism approach links national economic systems to the global economy conceptually, but is still limited by methodological nationalism and by a rather static comparative approach, remaining unsensitive to the notion of scale, and underlining differences of container-like national systems (Coates 2015). In this school and the numerous studies it inspired, theoretical emphasis was put on exploring differences among various national economies, with a strong empirical focus on firms and on how they interact with local regulatory environments (Ebenau et al. 2015). Politically, this also fell in line with supporting projects of social democracy in various European countries through the emphasis put on the influence national regulatory regimes can have (ibid). Adopting the $\mathrm{VoC}$ approach to Central and Eastern European countries was one of the newer developments within this school, which mainly developed in the post-crisis context.

Thus, both in geography and in political economy, from the early1990s the conceptual focus was shifted to firms and the different strategies they employ in various contexts. This institutional focus is a methodologically very valuable field of knowledge that should not be underestimated even when turning to more structuralist explanations (see eg. Werner 2016, Dixon 2010).

\subsubsection{Post-crisis critical thought}

Following the crisis, there was a resurgence of more macroscopic, structuralist explanations both in geographical and political economy approaches. These new analyses go back to understanding capitalism in the singular, and aim to explain systemic pressures while remaining sensitive to local specificities. This dual focus is often motivated by the shock of how quickly the crisis of 2008 spread globally and hit in very specific ways locally - also often through the housing market (Aalbers-Christophers 2014). This dual concern of (1) aiming to contextually understand local institutional and economic specificities while at the same time (2) emphasising the role of systemic pressures coming from an interlinked, global system has produced a number of new theoretical approaches such as variegated capitalism (PeckTheodore 2007, Jessop 2014) or has triggered the re-theorisation of old concepts such as that of uneven development (Hudson 2016, Dunford-Liu 2017). 
In both disciplinary fields I will highlight new conceptual developments relating to the recognition that "there is one system", but articulated in a varied way on different points of the global economy; to reflections on spatiality and subnational spatial inequalities; as well as to conceptual approaches to the firm. Starting from my empirical focus on housing finance, spatial inequalities and firm-level strategies, I reflect on Schwan's call that in spite of recent developments both within political economy and economic geography deepening understanding on the role of finance and regions, there are relatively few studies that would inherently link the two (Schwan 2017).

\subsubsection{Economic geography}

In economic geography, the post-crisis shift towards more structuralist approaches can be well grasped by the dominance of the global perspective in the Sage handbook of economic geography from 2011 (Leyshon et al 2011). Compared to earlier volumes overviewing the position of the discipline (see eg. Coe et al 2007), where issues of corporate management, company structuring strategies or individual-scale practices and analyses of cultural embeddedness were much more dominant; the handbook from 2011 clearly focuses on connecting the global and local, and on coming back to broader questions about the spatiality of capitalism. Capitalism is once again dominantly analysed as one interconnected system, while the spatial inequalities it produces are handled almost as common sense: "Globalization is not spatially homogenising, but instead depends upon and contributes to uneven geographical development on various scales." (Coe 2011, p 99). Authors of this volume go back to writings in critical geography from the 1980s (eg. Harvey 1982) in order to bring back ideas of scale, to gain analytical tools to connect to the global without losing the empirical richness of the local (Jones 2011). Brenner explicitly brings the notion of uneven development back to the fore, claiming that "late modern capitalism is premised on the intensification of differences among places and territories" (Brenner 2011, p.135) - while taking the specific geographies of uneven development apart into empirically workable entities (place, territory, scale, networks).

While the above-cited work gives useful, empirically workable notions for connecting contextual specificities and systemic frames, there are also new propositions for a wider retheorisation of uneven development (Dunford-Liu 2017, Hudson 2016, Peck 2016). The notion of uneven development is currently gaining new prevalence after several decades of being somewhat sidelined. Common to these propositions is that they reach back to macroscopic perspectives developed in the crisis cycle of the 1970s, and understand contemporary capitalism as one dominant economic system, which, however, is articulated in varied concrete forms across different institutional and historical contexts. Recent work in the field of economic geography has made important steps in employing the notion of uneven development to concrete institutional developments, individuals' and firms' strategies and to a variety of spatial scales (Hadjimichalis-Hudson 2014, Hudson 2016). These approaches help in understanding homogenisation and differentiation both in institutional and spatial terms; showing how uneven development concretely unfolds through inherently spatial processes of investment and disinvestment (Hardy 2014, Hudson 2015). This line of thought, along with how it can be employed in my investigation of the Hungarian housing market will be further developed in the following section.

From the point of view of this dissertation, there are further valuable conceptual elements in the newly emergent critical line of economic geography. One is the shifting focus to the role of finance in spatial processes (building on the tradition of geographies of money and finance). While economic geography traditionally focused on the productive sector and on relations of 
trade, understanding the role of finance in linking global processes to concrete space becomes crucial under contemporary financial capitalism. As Sokol (2013) argues, financialisation is a fundamentally spatial process, and all the phenomena that are investigated in various segments of the rapidly growing financialisation literature (Engelen 2012) could be seen as various forms of growing amounts of surplus capital looking for a spatial fix (Sokol 2013). There have also been a number of contributions from the field of economic geography in recent years focusing on the role of finance on the scale of/ in relation to regions. These are studies "dealing with questions of how to systematically incorporate finance (Pike - Pollard 2010; Sokol 2013, 2017), avoid "fetishizing the national scale" (Christophers 2012) or trace the geographical spread of finance as essential component of its development (Leyshon and Thrift 1997)" (Schwan 2017, p5).

However, there is also critique from within economic geography arguing that the understanding of processes of financialisation are still not geographical enough (Sokol 2017). Sokol draws attention to the fact that to date there are very few studies or conceptual approaches that would explain how financialisation produces uneven development (ibid). In order to bring spatiality into contemporary critical analysis of capitalism - specifically in a (semi-)peripheral context! - he proposes the notion of financial chains, which adapts the economic geography tradition of a firm-centered, networked-relational analysis to the context of financial capitalism (ibid). Similarly, Schwan argues that "despite all progress, there are still many blind spots given the centrality of both regions and finance for contemporary capitalism" (Schwan 2017, p. 6).

Previous work in economic geography on global networks of firms (conducted in the conceptual frames of global value chains and global production networks) generally provides a valuable methodological toolbox for new structuralist approaches in geography, which at the same time aim to understand concrete spatial articulations. Marion Werner, for example, proposes to couple the approach of global production networks with that of uneven development in order to have more conceptual tools to deal with the inherently unequal nature of international corporate networks (Werner 2016). As she puts it in a previous article, "The interdisciplinary appeal of the chain heuristic lies in its ability to ground abstract-prone analysis of economic globalization in the everyday practices of firms, workers, households, states, and consumers." (Werner-Bair 2011, p. 998). Werner proposes to return to the original, critical position of GPN as it was used in the 1980s by world systems analysis (Werner 2016, WernerBair 2011). This approach is gaining ground, supporting a systemic understanding of how contemporary industrial production is embedded in global core-periphery relations (see eg. Geröcs-Pinkasz 2018). It is, however, seldom used in the context of financial relations. Whereas applying the "chain heuristic" to financial flows could be a helpful tool to spatially ground understandings of financialisation (Sokol 2017).

Financialisation is often understood in terms of how it transforms specific segments of the economy and society - such as enterprises or households or the state. I adhere to authors who claim that what is needed is a systematic theoretical proposition about how financialisation becomes the contemporary infrastructure for global relations of dependency (Heires-Nölke 2014, specifically Becker 2014 in this volume). Consistent with this approach, I understand financialisation as a new regime of accumulation (Brenner 2004), and as a historical point when cyclical shifts of hegemony are happening (Arrighi 1994). In such an approach, financialisation is not the specific characteristic of the past four decades, but is a cyclically returning period relating to declining rates of profitability in the productive sector and structural transformations in the global economy. In this approach, financialisation can be understood as the structuring mechanism of core-periphery relations on various scales today. For this, we need to combine 
the geographical understandings of financialisation with those proposed by the contemporary "new-structuralist" theorists in the field of political economy.

\subsubsection{Critical political economy}

In their large-scale proposition about new directions in comparative capitalism research, Ebenau et al. claim that in cutting-edge political economy research, the subject is shifted back from institutions to capitalism itself (Ebenau et al 2015); signalling the post-crisis analytical shift of the discipline towards understandings of capitalism as one interdependent and hierarchical system. They claim that neoinstitutionalist approaches to comparative capitalism research (such as varieties of capitalism and related schools) usually do not manage to make this shift, and have little engagement with examining "specific institutional configurations in the broader analysis of the development of capitalism" (ibid, p 36). Thus, their proposed research agenda is to move towards this broader analysis in order to "advance the project of an institution-centered analysis of capitalist diversity" and to "redefine the comparative capitalism research agenda towards what we call a critical, global Comparative Political Economy" (ibid, p.34).

One of the issues inherent to this research agenda is to acknowledge global relations of dependency and make a shift away from the usual eurocentrism of political economy analyses; highlighting how the functioning of the capitalist system is inherently based on the extraction of resources from the peripheries towards the centres (Wehr 2015). Equally important is to acknowledge the hierarchically structured nature of the global economy, in which strong dependencies exist (Arinci et al. 2015), resulting in inequalities between the different "varieties" of capitalism (Jessop 2015).

Within the $\mathrm{VoC}$ perspective, claims for a post-socialist variety of capitalism emerged (Bohle-Greskovits 2012) explaining different trajectories post-socialist countries followed in the context of their integration in the global economy and specifically in the EU. Bohle and Greskovits highlight the role of transnational corporations in how the region's economic integration happened, and also underline that the region's neoliberal regimes supported a financialised growth regime where capital was mainly channeled through credit into nonproductive sectors through a dominantly foreign-owned banking sector. This led to a situation where "a virtous circle of consumer credits, mortgage lending, and a construction and housing boom reinforced each other" (Bohle-Greskovits 2012, p. 91), while productive sectors were dominated by western TNCs expanding into the region for reasons of cost efficiency (ibid). Thus, they construct a new category within the $\mathrm{VoC}$ school in an inherently globally interlinked way.

The notion of variegated capitalism is gaining ground in the field of political economy, putting emphasis on the idea of one system articulated in a locally variegated way (Ebenau et al 2015). According to this approach, the concrete articulation of capitalist processes in a given place depends on an interaction between macroeconomic processes on the one hand and local institutions, class structures, etc. on the other. This creates variegated trajectories within the same system, which is globally heading in the same direction. Peck and Theodore, in their agenda-setting paper, argue for the reintroduction of a geographical and structural perspective in the analysis of difference under capitalist development (Peck and Theodore 2007). Their framework is also sensitive to the analysis of institutional strategies and regional disparities, providing a frame which is more applicable to empirical research on different scales. They also accord specific attention to the transformation of enterprises under financial capitalism (recognising that in order to meaningfully go beyond the varieties of capitalism approach, the 
scale of the firm - which is generally considered to be the strength of $\mathrm{VoC}$ - must also be tackled in an empirically sound way). Translating this approach to my research means that, for instance, instead of considering particular institutional articulations of the Hungarian housing market as something stemming from national characteristics or a Central and Eastern European type of capitalism, I situate the Hungarian experience in a wider, systemic understanding of housing under contemporary capitalism.

The way the notion is proposed by Peck and Theodore is very much a disciplinary positioning as well: they aim to put the more political science approach of varieties of capitalism in conversation with economic geography's approach of uneven development which strongly relates it to the conceptual frame I am striving to set up for the present dissertation. Their call is to move beyond the methodological nationalism of the VoC approach by employing a multiscalar analysis, and of accounting for systematic convergence as well, and not only divergence. ${ }^{1}$ In this dynamic understanding of divergence and convergence they argue for not several capitalisms, but capitalism in the singular - which is, however, articulated in different ways in different contexts. This understanding of a dual dynamic is closely in line with the idea of uneven development.

The analysis of how local historical trajectories, institutional setups and class relations interact with international capital, producing concrete forms of dependent development is already present in the work of later generations of the dependency school (eg. Gereffi-Evans 1981); and reemerges in contemporary applications of this approach to the European context (e.g. Becker et al 2015, Vliegenthart 2010). Historically, this new disciplinary branch builds on the European dependency school of the 1970s (Weissenbacher 2017), who had developed this approach in their quest to explain increasing spatial inequalities in the wake of the crisis of the '70s. In its contemporary application, questions of debt become central and the institutional structures of the EU are analysed from the perspective of the core-periphery relations they sustain - while taking the global economic hierarchy seriously. This is also a product of the 2008 crisis in the sense that one of the central arguments is how crisis management in the EU is systematically pushed from the cores to the peripheries (Becker et al 2015).

In contemporary political economy there is a strong intention not to fall in the trap of overly generalising structuralist explanations - that Marxist approaches are often accused of. Two important ways of "breaking it down" are to take the analysis to finer geographical and social scales, and to employ it to the institutional and firm level. Along the first line, studies on internal fragmentation and structural heterogeneity are emerging, arguing that external economic growth systematically relies on increasing internal polarisation - especially in (semi)peripheral economies (Hürtgen 2015). In terms of the second, institutionalist concern, a field of new corporate governance has emerged, which aims to understand the institutional, management decisions of firms in relation to their broader context (Vliegenthart-Overbeek 2007).

\subsubsection{Linking political economy and economic geography}

From both the political economy and economic geography strands of literature I bring the recognition that macro-scale explanations have to take into account the concrete articulations of capitalist processes - articulated by and through institutions, enterprises, and subnational

\footnotetext{
${ }^{1}$ Peck and Theodore use the terms of convergence and divergence in spite of the fact that they build on the tradition of uneven development - however, in my understanding they use these former terms in a sense very similar to the notions of homogenisation and differentiation central to uneven development.
} 
spatial entities. Thus, in my research I position economic actors and their relations to each other on various spatial scales as central entities of analysis, even though I seek to understand them as conveyors/ articulators of macro processes. I am interested in how they integrate in these macro-scale processes, and in what relations they have with each other rather than analysing firm-level processes in a bounded way.

Although, for analytical purposes, "economic geography" and "critical political economy" appear here as two separate domains, it should be stated that this is of course not the case, and the two approaches are intertwined on various points, and there are a growing number of explicit calls to link theoretical developments in the two fields. For instance, in their agendasetting article on variegated capitalism, Peck and Theodore (2007) argue for the reintroduction of a geographical and structural perspective in the analysis of difference under capitalist development. The terms of "convergence" and "variation" used by them (based on the political economy tradition) could also be easily translated to those of "homogenisation" and "differentiation" used by the geographical literature of uneven development (ibid). As a response to their call, Dixon (coming from the field of economic geography) reflects on how geography could take example from what the idea of variegated capitalism does in the field of political economy. He suggests that following the propositions of scholars of variegated capitalism, "the work done by economic geographers in the 1980s on uneven spatial development [...] should be conjoined with later institutionalist economic geography work on factors endogenous to local and regional economies [...]" (Dixon 2010, p. 198). Ray Hudson has also been systematically working on linking these different disciplinary developments, a summary of which is produced in his most recent book "Approaches to economic geography: towards a geographical political economy" (Hudson 2016b). Recent work by Brett Christophers also makes explicit linkages between geography and political economy using the empirical field of financialisation and the implications of the 2008 crisis to make this link (Christophers 2015).

Thus, contemporary new macroscopic theoretical analyses also strive for more empirical depth and detail, as well as seeking to make interdisciplinary links. The latter can practically be achieved through concrete studies. In the following section I will draw up a conceptual framework for my analysis using certain elements of the lines of thought outlined above (see Fig. $1^{2}$ ).

\footnotetext{
${ }^{2}$ Unless otherwise stated, all figures are produced by the author.
} 
Figure 1.

Drawing on critical traditions of economic geography and political economy for constructing my conceptual building blocks

\begin{tabular}{|c|c|c|}
\hline economic geography & critical political economy & shared ideas \\
\hline $\begin{array}{l}\text { uneven development } \\
\text { spatial fix, financial fix, } \\
\text { spatiality of capitalism in } \\
\text { different cycles } \\
\text { Hudson, Dunford-Liu, Peck }\end{array}$ & $\begin{array}{l}\text { variegated capitalism } \\
\text { plus VoC and comparative } \\
\text { capitalism research } \\
\text { Peck-Theodore, Jessop }\end{array}$ & $\begin{array}{l}\text { idea of one capitalist } \\
\text { system articulated in } \\
\text { a differentiated way } \\
\text { in different contexts }\end{array}$ \\
\hline $\begin{array}{l}\text { regions/ scales/ } \\
\text { internal fragmentation } \\
\text { Hadjimichalis, Hürtgen }\end{array}$ & $\begin{array}{l}\text { dependency theory, WST, } \\
\text { regulation school } \\
\text { Becker, Weissenbacher, } \\
\text { Gowan, Brenner, Arrighi }\end{array}$ & $\begin{array}{l}\text { idea of macro-scale } \\
\text { dependency and } \\
\text { how that affects } \\
\text { lower spatial scales }\end{array}$ \\
\hline $\begin{array}{l}\text { enterprises and space } \\
\text { GVC/ GPN, } \\
\text { financial chains } \\
\text { Coe, Werner, Sokol }\end{array}$ & $\begin{array}{l}\text { corporate governance } \\
\text { regulation } \\
\text { and its transformation } \\
\text { under financialisation } \\
\text { Vliegenthart-Overbeek }\end{array}$ & $\begin{array}{l}\text { concrete enterprises } \\
\text { linked to broader } \\
\text { economic processes } \\
\text { and to space }\end{array}$ \\
\hline
\end{tabular}

\section{Housing in political economy (chapter 1.2.1.)}

- role of housing in the investment of surplus capital

- and in how the crisis of 2008 manifests - capital is systematically withdrawn from the peripheries in crisis

- systematic approach to housing under financialisation

Authors: Aalbers, Bohle, Sokol

Methodological implications:

focusing on crisis + following the money

\section{Subnational unevenness}

in CEE (chapter 1.2.2.)

- multiscalar dependencies: internal fragmentation and external dependency

- core-periphery relations

- role of debt

Authors: Hürtgen, European dependency school in Vienna (Becker, Weissenbacher et al.)

Methodological implications: focusing on the debt relation + having a scalar approach

\section{A focus on enterprises}

(chapter 1.2.3.)

- firms as the conveyors of macro-scale processes

- understanding their role in transferring capital flows

- and how financialisation changes their functioning

- relational approach to firms

Authors: Dixon, Vliegenthart

Methodological implications:

focus on how firm strategy

relates to space 


\subsection{Conceptual building blocks}

In order to formulate the conceptual frame guiding my analysis, I will draw on various elements from the above-outlined broad disciplinary developments, approaching them all through the lens of uneven development. A central element in contemporary structuralist perspectives on capitalist development is that they avoid the debate of convergence or divergence altogether, by focusing on one capitalism that is inherently uneven and multiscalar in its articulation (Dixon 2010). This can be well aligned with the inherently interdependent, constantly pulsing dual logic of homogenisation and differentiation which is at the core of the notion of uneven development. This constant duality that is inherent to the logic of uneven development is what creates the infrastructure and institutional mechanisms making capital investment and extraction possible. The ebbs and flows of capital investment and extraction reproduce socio-spatial unevenness: they channel capital into social and spatial entities in a way that consequently opens channels for the extraction of resources (Hudson 2015).

This framework allows me to account for the simultaneous homogenisation on a systemic level (in the case of my concrete research: in terms of housing financialisation, for instance) and differentiation on lower scales (in terms of inequalities in access to credit or in house prices, for example). It also gives conceptual support to tracing cycles of capital spreading out and then retreating - and directs attention to the social and spatial consequences of this constant dynamic of uneven development. Housing markets are sensitive carriers of these dynamics.

Within this general framework of uneven development, I will develop three conceptual cornerstones that are important from the perspective of my inquiry. (1) First of all, I will mobilise the work of scholars tracing spatial patterns of capital investment, and, more specifically, who link housing to the way how contemporary capitalism develops. Scholarly work on the relevance of housing in political economy has rapidly expanded in the years following the crisis, directing attention to the role of housing in fixing surplus capital in concrete space under financial capitalism. (2) Second, I aim to highlight how capital flows (and, ultimately, capital extraction) are organised along patterns of core-periphery relations. This is true on diverse scales, with cores and peripheries being linked through relations of dependency. Macro-scale dependencies determine how the global and European economic space is hierarchically organised, while internal fragmentation on finer scales provides the basis of how the uneven spatial structure of capitalism is built up. These lower (subnational and local) scales of core-periphery relations are central to my argument. (3) Third, in order to understand the concrete institutional infrastructure that makes capital investment in housing possible, I build on literature focusing on enterprises as the actors translating capitalist processes.

\subsubsection{Housing in political economy and space}

\subsubsection{Housing as a crucial spatial fix under financial capitalism}

The financial crisis erupted on the housing market in 2007, and led to a wave of inquiry about the role of housing in contemporary capitalist processes. Linking financialisation and housing is important for research in political economy and economic geography because it allows to conceptually ground macroeconomic processes in very concrete space. In my analysis the housing market is the empirical material which allows to make claims about the spatial unevenness that financialisation produces. 
The recently increasing role of finance in the global economy has been highlighted by many scholars, and research on financialisation has exponentially increased after 2008 (Engelen 2012). Although the current cycle of financialisation has been going on since the 1970s, related underlying processes (and the political and social risks they entail) have been very explicitly brought to the surface by the most recent crisis. Some authors associate the idea of financialisation only with most recent development of the growing role of the financial sector, I however adhere to scholars who see the current process of financialisation in the perspective of long-term global economic developments. ${ }^{3}$ In this perspective, current financialisation originates in managing the crisis of overaccumulation in the US and the ensuing crisis of profitability in the productive sector from the 1970s onwards (Brenner 2004), along with managing the crisis of hegemony this went with (Arrighi 1994). In this frame, financialisation can be seen as a new regime of accumulation (see eg. Krippner 2005, Stockhammer 2004); as the dominant process in contemporary capitalism which translates the constant need to invest surplus capital. Furthermore, this new financialised regime of accumulation produces an exponentially growing supply of money waiting to be invested - also aptly called the "wall of money" (Aalbers 2016). This has various sources, an important one being that wealth and the stock of capital increase faster than income and production (Aalbers 2017, p. 4). The pressure of this growing stock of capital creates new spheres and spaces of investment, drawing more and more social sectors and geographies into the homogenising logic of financialisation. Thus, various phenomena defined as financialisation (related to the transformation of firms, of states, of households, of regions etc) can be seen as different manifestations of this search for profitable forms of investment.

Financialisation can be understood as a variegated process of surplus capital looking for a spatial fix (Sokol 2013). Some also call this global infrastructure that creates the conditions for the constant circulation of capital a 'financial fix' (Silver 2003, Aalbers 2017). In fact, both in how financialisation is sustained and in the effects it has, space and geography are central.

The inherently spatial nature of financialisation has lead an increasing number of geographers to engage with the topic (Sokol 2013, Engelen 2012), which has also supported the above-described shift of economic geography back to more macroscopic explanations. Although there are a few scholarly propositions that directly relate processes of financialisation to geography - such as Schwan's framework for analysing the financialisation of regions in the EU (Schwan 2017), understandings of the spatiality of financialisation are often tied to real estate. The terminology of FIRE (finance-insurance-real estate) economy is often used in relation to the structural transformations of contemporary capitalism (Aalbers 2017); highlighting the fact that in cycles of financialisation, when profitability drops in the productive sector, investment is systematically channeled towards real estate and towards other, nonproductive sectors of the economy - resulting in the increasing weight of these "FIRE" sectors. This results in a situation where the proportion of real estate in overall wealth has exponentially grown in the past two decades (Fernandez-Aalbers 2017).

In certain places of the global economy, housing became especially important in this process of asset-based wealth accumulation. The central role of housing was thrown into the light by the crisis of 2007-2008 - and provoked the multiplication of studies about housing with a political economy approach. On the other hand, there are also arguments for centering housing in more general political economy research - as a recognition of the role of this domain

\footnotetext{
${ }^{3}$ As stated erlier, I understand financialisation as a historically cyclically returning process, and do not limit my understanding of it to the developments of the past decades. For constraints of the scope of this dissertation, however, I will not adress the historical cyclicity inherent to processes of financialisation.
} 
in contemporary capitalist processes (Aalbers-Christophers 2014). However, the role of housing in financialisation cannot be understood detached from space and time, and must be embedded in a broader understanding of social relations (Fernandez-Aalbers 2017). This requires an investigation of the specific institutional mechanisms that channel capital into housing on various points of the global economy.

One of the most important channels for capital expansion in the past decades has been the credit-debt relation - which became one of the core elements of contemporary financialisation (Sokol 2013). Sokol argues that „credit and debt was at the epicenter of the crisis”, and as a further specificity of this period, this debt was increasingly borne by households (ibid). Mortgages are by far the most important element of this household debt. This means that in the early 2000s housing finance supporting a dominantly homeownership- and credit-based housing regime became an important pillar of a financialised regime of accumulation.

The credit-debt relation is especially important in the process of financialisation on the (semi)peripheries of the global economy - and in our case, specifically on the European peripheries (Sokol 2013, Becker et al. 2015, Raviv 2008). Becker et al. claim that financialisation can take two dominant forms: either that of fictitious capital (such as shares, securities - which we commonly encounter in Anglo-saxon economies and in studies based on them), or that of interest bearing capital, that is credit. The latter is more typical of the European periphery (Becker et. al. 2015). My claim is that if we understand financialisation as a regime of accumulation - that is, not just as a shift in corporate or household financial strategies, or as the increasing dominance of the financial sector - then it is not coincidental but necessary that financialisation is manifested in different ways in different places of the global economy. As all phases of global capitalism, this regime of accumulation is built up in a way to support capital being channeled towards the core of the global economy - which needs different institutional setups and vehicles in different contexts. This also supports the value of theorising financialisation from a CEE perspective, since it sheds light on this spatially differentiated articulation of a globally unfolding process.

\subsubsection{Households as the source of capital extraction under housing financialisation}

Investigating the financialisation of housing allows for grounding macroeconomic analysis in concrete space. The exact form it takes, however, varies from context to context, and, depending on institutional and historical circumstances, can take various forms from public housing stocks being bought up by financial market actors to the distribution of individual mortgages (Aalbers 2017). In Central and Eastern Europe, the changing role of banks is of crucial importance in the institutional infrastructure rolling housing financialisation out. In the past decades (in parallel with the increasing financialisation of large enterprises), banks have reoriented their business from companies to households (Gál 2014). One of the reasons for this is that large (transnational) companies now often finance themselves directly from financial markets, with a diminishing role of bank credit in their financial resources. On a European scale, with the liberalisation of financial markets and of the banking sector in the EU from the 1990s onwards, Western European banks could acquire subsidiaries and spread their activity to the peripheries of Europe (Gál 2014, Drahokoupil 2009). This became the main channel for the financialisation of European peripheries, and also become the dominant relationship of dependency tying together European cores and peripheries (Becker et al 2015). When banks enter a non-domestic market, household lending is much safer and more profitable than financing small and medium enterprises, leading to a general increase in the share of household lending compared to corporate lending (Bonin-Ábel 2000). (Until they could, banks would "cherry-pick" large companies to finance (Pósfai et al 2018) - however, this market gets quickly 
saturated, and large companies can also find their funding on better terms from international financial markets. Thus, this was not a market segment with good possibilities for expansion.) As we have elaborated in a previously published article:

"Typically, financial investment coming from the core does not go into long-term financing of productive activity on the periphery. Rather, it often goes into state or household debt, which offers less risky and more profitable forms of investment - due to high interest rates and the possibility to offer short-term loans (Gabor 2012). This financialization-based consumption model relying on short-term bank capital gradually replaced the FDI-based model in terms of external finance. Credit flows were reoriented towards households and had a limited role in corporate finance and economic development goals, which also shows that investors were never primarily oriented towards addressing the development needs of the host countries (Raviv 2008). In credit-based household consumption, housing-related costs became more and more important - with many consumption loans actually also being used for housing acquisition or renovation (Dancsik et al. 2015).” (Pósfai et al. 2018)

The shift of bank lending towards the household scale has severe social and economic consequences, because it means that households are individually integrated into a structure of financial extraction (Lapavitsas 2009). This process was of course also supported everywhere by public policies promoting individual credit-based homeownership. The financial sector thus plays a crucial role in tying together accumulation by dispossession ${ }^{4}$ and mechanisms of reproduction - Harvey highlights the role of the credit system as "a radical means of accumulation by dispossession" (Harvey 2007, p. 159). The instance of capital extraction through credit is also particularly important in semiperipheral economies or at moments of crisis (Vliegenthart-Overbeek 2007). This link is very clearly materialised in the sphere of housing - and was brought to the surface by how the financial crisis exploded on the housing market in 2007 (Lapavitsas 2009).

\subsubsection{Recent theoretical propositions about housing under financial capitalism}

Scholarly work elaborating on the link between financial markets, housing and crisis have flourished and taken various directions in recent years. In the following section I will situate myself in relation to three authors whose work is articulated at the crossroads of the geography and political economy of housing, and can also be related to the empirical field of Central and Eastern Europe.

\section{Aalbers - the variegated financialisation of housing}

Manuel Aalbers has been consistently writing about the role of housing in contemporary political economy and the intersecting points of housing, finance and state since the outbreak of the recent financial crisis. His current research agenda can be coined under the approach of variegated financialisation of housing, aiming to understand uneven and variegated trajectories of housing financialisation on various points of the globe as part of the same common trajectory (Aalbers 2017). Aalbers has contributed much in recent years both to building a theoretical framework for linking housing to contemporary dominant processes of capitalist transformation (most notably to that of financialisation), and also (with his research group) to producing empirically grounded research about this field. Coming from a geographical background, he has mobilised the work of critical geographers relating to the spatialisation and urbanisation of capital (Harvey 1978) in the post-crisis period.

\footnotetext{
${ }^{4}$ This theory is an extension of the original Marxist idea of primitive accummulation, and posits that capitalist accummulation constantly needs to integrate new external resources in order to exist. This extractive mechanism relies on often violent processes of dispossession (Harvey 2007).
} 
Fernandez and Aalbers claim that the debt-led financialised new accumulation regime has led to a situation where "housing is central to the variegated political economy of contemporary societies and therefore key to understanding actually existing capitalism and inequality." (Fernendez-Aalbers 2017, p.157). I build on the conceptual reference point put forward by Aalbers to see financialisation as the current dominant process shaping variegated trajectories of how housing develops (Aalbers 2017). In this perspective, financialisation is analysed as a set of processes pointing in the same direction within the contemporary regime of accumulation. Building on this framework I aim to understand the mechanisms of how housing financialisation is articulated in the context of the Hungarian housing market instead of "measuring" the extent to which housing in Hungary is financialised according to specific indicators (such as absolute debt levels or the share of the financial sector) which had been used to describe core contexts of the global economy.

In the following section (1.2.2.) I will introduce the element of dependency into the conceptual structure of variegated housing financialisation put forward by Aalbers. I aim to support the idea that the unevenness of different forms of housing finance and financialisation is hierarchical and systematic in its nature. For this I mobilise the notion of dependent financialisation proposed by authors from the Vienna University's Institute for International Economy and Development (Becker-Jager-Weissenbacher 2013, see also Pósfai-Gál-Nagy 2018).

\section{Bohle - varieties of residential capitalism}

Dorothee Bohle has published about the Hungarian housing market and its externally dependent structure of housing finance, along with the political and social consequences this structure has had (Bohle 2013, Bohle 2017). Her research can be situated in the disciplinary field of political science with an approach of transnational comparative capitalism research, with her work on housing relating to the varieties of residential capitalism approach (SchwartzSeabrooke 2009, Bohle 2017).

The way Bohle underlines the dependent nature of housing financialisation in Central and Eastern Europe (and specifically in Hungary) is a crucial point of reference for my analysis. In her most recent analysis (Bohle 2017) she develops how core-periphery relations and hierarchies on a European scale were made obvious by the most recent crisis. She also highlights how the dire consequences of the crisis were a result of pre-crisis uneven structures. This unevenness had resulted in unstable housing market processes, reflected by - for instance - house prices and debt-to-GDP ratios increasing much faster on the European peripheries than in the cores. In spite of these observations, however, Bohle claims that it is surprising that peripheries were hit stronger by the crisis (Bohle 2017), and takes over the typologies of varieties of residential capitalism proposed by Schwartz and Seabrooke in 2009. I propose to introduce the conceptual element of dependencies in order to understand why the harsher effects of crisis are in fact directly consequential of the way how these peripheral places were integrated in the European economic space in the years preceding the crisis (Smith-Swain 2010).

Bohle demonstrates how increasing global liquidity was - due to EU liberalisation policies - increasingly channeled into Eastern European mortgage markets through banks (Bohle 2017, p. 13). She thus demonstrates the institutional mechanisms which channeled the macroeconomic pressures behind the mortgage boom peripheral states experienced in the early 2000s. Elaborating on how private debt has grown to be larger than public debt, she argues that households actually carry the debt risk that economic growth is based on (especially in the context of very high rates of homeownership) - thus highlighting why housing should be considered as a particularly important segment of contemporary processes of financialisation. 
(This argument can also be related to the notion of privatised risk and privatised keynesianism put forward by Crouch 2009.) Thus, she argues that unevenness on a European scale can best be grasped through the issue of household debt, and it "seems misplaced" that both EU crisis management and critical scholarly analysis predominantly focus on the issue of public debt instead (Bohle 2017).

Bohle's analysis provides a crucial basis for understanding the institutional mechanisms translating global finance locally. However, I do not completely adhere to her comparative framework and would argue for a more systemically linked understanding of housing trajectories, that allows to better see the interconnected and hierarchical nature of the global system that local housing finance is integrated in and depends on. Instead of linking financialisation to crossing a "threshold" in certain indicators (such as debt-to-GDP), I would propose to understand the mechanisms of housing financialisation on the Hungarian housing market, and to inquire about the degree of vulnerability and about the historical trajectories specific modes of housing financialisation have. Furthermore, I would definitely argue with the statement according to which "the Hungarian policy response has successfully reversed the path of housing financialization." (Bohle 2017, p. 42). The concrete institutional forms in which housing financialisation was articulated in Hungary in the years preceding the crisis are currently being somewhat reorganised, but the fundamental logic is unchanged and new channels of housing financialisation are already being opened - it remains to be seen with exactly what effects.

\section{Sokol-financial chains}

Martin Sokol has been writing about the geographies of finance in Central and Eastern Europe for several years, and in his recent proposition for a research agenda he puts forward the lack of a coherent geographical theory of debt and its spatialities (Sokol 2017). He demonstrates how households are increasingly drawn into debt relations through mechanisms of exploitative financial inclusion. He claims that this mechanism of financial exploitation which is crucial to understanding how the extractive nature of financialisation works on various scales - has only been discussed in aspatial terms, while a geographical thinking about this process would be highly relevant (Sokol 2017, p. 682). This is an argument I strongly adhere to, and which is supported by my empirical results. Sokol highlights the need to develop tools that would help understand how financial relations between various agents shape uneven development, and how the debt-credit relationship is translated to spatial patterns (ibid). In my dissertation I will give an analysis of how actors of the housing market acting on "different scales (from micro to macro and back again) are inseparably 'chained' together" (Sokol 2017, p. 684). In institutional terms this translates to understanding how corporate strategies, access to finance, risk management, links to other actors of the sector determine uneven spatial patterns of how the Hungarian housing market develops.

While Sokol mobilises the metaphor of chains familiar to the GVC/ GPN approaches in economic geography (and which I find very helpful in understanding the corporate actors of this field and their relations to each other), I refer more to another tradition within the geographical discipline, situating my research within the conceptual frame of uneven development. However, these approaches are intrinsically linked, as "the importance of debtrelated 'financial chains' for uneven geographical development cannot be overstated" (ibid, p. 684). The research agenda put forward by Sokol is both conceptually and methodologically relevant for my research. I will build on the integrally scalar and relational approach proposed by the idea of financial chains - and will employ this approach to studying housing markets, highlighting the central role housing plays in tying financial flows to concrete space. 


\subsubsection{Proposing a frame of uneven development of housing - homogenisation and differentiation on various scales}

As Sokol highlights in his research agenda, there is very little empirical research and insufficient conceptual frames for understanding concretely how financialisation produces uneven development. Even less for contexts outside of the core areas of global capitalism and globally dominant academia. Therefore, such analysis is almost entirely lacking for Central and Eastern European countries. I aim to contribute to filling this conceptual and empirical gap with my research by analysing how financialisation produces uneven development through the housing market in Hungary.

If we employ the perspective of uneven development to housing, we can understand processes as an ebb and flow of homogenisation and differentiation (Hudson 2015) from two different perspectives. On the one hand in the sense of (1) how different housing systems develop in terms of their institutional structure, and on the other hand (2) in terms of spatial patterns of capital investment in housing.

In the first sense there is a common trajectory of increasingly financialising housing throughout Europe (and around the world), reflecting the growing importance of housing as a spatial fix for surplus capital. At the same time, this common trajectory is articulated through institutional structures and concrete mechanisms that are persistently different (or variegated) across different national and sub-national contexts (Fernandez-Aalbers 2017).

In the second sense, there is a constant pulsing of capital spatially spreading out and then being extracted, which at the same time uses and reproduces the uneven structure of the housing market. In boom periods there is a spread-out of investment into previously unexplored areas; spatially homogenising the housing market in the sense that mortgages (or other forms of financialised housing) become accessible in geographical areas and for social groups which were previously excluded (Lapavitsas 2009, Pósfai et al 2018). However, this spread-out becomes a mechanism of exploitative inclusion (Sokol 2013) (or financial overinclusion Aalbers 2012, or financial extraction - Lapavitsas 2009) in the mid term, since it includes the previously excluded (households or geographical spaces) in a fundamentally hierarchical economic relation. In the wake of a crisis this hierarchically opened channel allows the flow of resources from the peripheries to the cores and leads to increasing inequalities. Patterns of deepening differentiation thus reveal how capital accumulation in one place is inherently linked to capital extraction from another.

Geographical understandings of processes of financialisation are often spatially bounded. For instance, empirical studies about the spatial nature of financialisation are often about urban spaces, shedding light on how the financialisation of real estate happens through big urban real estate development projects (Savini-Aalbers 2016), or can also reflect on the financialisation of regions (Schwan 2017) or of companies which can be tied to specific spaces. The above outlined approach to understanding financialisation in the frame of uneven development allows for seeing financialisation as a constantly pulsing process of financial (over)inclusion and consequent exclusion, which draws new (also non-urban) spaces and households into a financialised regime of accumulation.

I will formulate my analysis of the Hungarian housing market in this dual frame of uneven development. Studies reflecting on the way housing is linked to broader processes of capitalism often have a bias towards cores on various scales: they are mostly about places at the centre of the global economy, and about urban areas. This bias inevitably develops if we focus on the most visible and quantitatively most important instances of capital being channeled into housing (since wealth accumulating in housing is not spread out evenly, but is concentrated in 
specific urban areas - Aalbers 2017). I propose to shift this focus, and claim that grasping the process of capital extraction and the channels and mechanisms of accumulation is actually key in understanding the development of housing markets under contemporary capitalism. In this approach, shedding light on relations of uneven development (or of core and periphery on various scales) are crucial. I thus propose to understand housing markets in the frame of uneven development; on multiple scales and in a relational way.

\subsubsection{External dependency built on internal fragmentation}

The framework of uneven development does not have a strong notion of cores and peripheries, and from my perspective its focus on how capital rewrites space does not sufficiently consider dependency and the systematic nature of unequal / exploitative spatial relations. In order to fill this conceptual gap, in the following section I strongly draw on theories of dependency - mainly on authors who have mobilised this line of thought for understanding dependent relations in contemporary Europe. Furthermore, I also draw on authors exploring notions of internal peripheries and internal fragmentation in relation to external dependencies.

In terms of terminology it is important to note that I do not use the notions of core and periphery in the strict macroscopic sense employed by world systems theory (where they apply to the function I particular place fills in the global economy). I employ these terms to other scales as well rather flexibly, and and instead of attributing them to very specific geographical spaces I think of them in a relative and functional way.

In this section I will federate conceptual elements contributing to the claim that integration in capital flows or economic systems (which in the case of my study will mean integration in systems of housing finance and housing-related investment) is not necessarily beneficiary from the point of view of a specific region or institution/ company. Integration can also become a channel of extraction depending on the structural position and the mode of integration a region or institution undergoes. Building up this argument from empirical grounds, it is a concern that comes from the realities of housing finance in Hungary. On a subnational scale the inclusion of ever wider segments of society in a debt-based housing finance model promoting homeownership has had serious consequences on social and spatial polarisation. This, in turn, is not independent from the macro scale of how the Hungarian financial sector is integrated in hierarchical transnational economic networks, which is determinant in how the housing finance system has developed on a national scale. Housing finance of the European peripheries is a field where European-scale surplus capital is systematically recycled, with conditions of accessibility that are much less favourable than in core European countries (Pósfai et al. 2018). This, in turn, also creates a subnationally fragmented housing system. As Costis Hadjimichalis put it: "...the fundamental spatial contradiction between the advantages of concentration $\mathrm{v}$. the necessity for territorial expansion worked out historically to produce a spatial hierarchy of cores and peripheries" (Hadjimichalis 1983, p. 128).

I will explore these scales of how unevenness is produced through dependent relations building on the work of scholars of dependency and world systems theory, particularly those who employ these approaches to contemporary Europe. I will highlight authors who take this macroscale analysis down to lower spatial scales and explain regional inequalities as a consequence of (and at the same time reproducing) the hierarchically organised global economic system. 


\subsubsection{External dependencies on the European periphery}

The political and economic consequences of the 2008 crisis have led to a growing number of inquiries about core-periphery relations in the European Union. Critical voices are strengthening that underline that the European project has, from the outset been built in a way to support the economic growth of core countries (Weissenbacher 2017), while systematically displacing crisis to the peripheries (Jessop 2014). These new critiques resonate with arguments of the so-called European dependency school, which had emerged in the wake of the crisis of the 1970s and the subsequently exploding indebtedness of the European periphery (Weissenbacher 2017). These authors built on the tradition of the Latin-American dependency school and world systems theory, but this line of research had later been swallowed in the neoliberal convergence euphoria of the late 1980s and 1990s.

In contemporary crisis- and debt-ridden Europe, the dependent nature of the integration of peripheral countries is again being affirmed by a growing number of scholars. On the one hand within the frame of the varieties of capitalism literature authors highlight the role of transnational corporations and banks in foreign ownership in the development of a "dependent market economy" (see for example: Nölke-Vliegenthart 2009, Drahokoupil 2009, BohleGreskovits 2012). Others establish the argument of dependency in a more structuralist way, beyond the practices of transnational corporations. Theories of dependency and world systems theory are currently being revisited and applied to new contexts. This body of literature - along with more "classical" authors of world systems theory who argue for defining Central and Eastern Europe as the European (semi)periphery (see for example Arrighi 1990, Gowan 2000) - provides the basis for my conceptualisation of core-periphery relations.

One such venture of reframing which is especially important from the perspective of my analysis is done by authors who explicitly employ notions of dependency to the European Union, and argue for the relevance of understanding these dependencies in terms of coreperiphery relations within this economic space (see for example Vliegenthart 2010, Becker et al 2015). According to their argument, economic growth and also crisis-management within the European Union are inherently based on the exploitation of unevenness between the European core and periphery (both southern and eastern). Based on their analysis I make the claim that cores and peripheries are mutually interdependent and that these positions are not incidental or interchangeable, and there is a systematic transfer of wealth happening from the periphery to the core (Arrighi 1990). Peter Gowan (2000) argues for understanding processes of peripheralisation in Central and Eastern Europe through the lens of world systems theory. Furthermore, he links his argument to uneven development in order to have a finer scalar analysis of core-periphery relations. He recognises the fact that world systems theory only highlights how core capitalism drives peripheralisation; but in uneven development we can also find arguments for how it is in the interest of the global core economies that non-core centres "catch up", and become more integrated in proceses of capital accummulation. This differentiated scalar understanding of core-periphery relations gives a meaningful framework for the analysis of the Hungarian housing market, and is also in line with the research agenda on peripheralisation proposed by the RegPol 2 research project, which highlights how certain regions are peripheralised in relation to national cores (see Lang et al. 2015). I strongly build on the idea of interdependent cores and peripheries, and understand the tension between them as the main driving force of uneven development. As Peter Gowan (2000, p. 70) states: "we need to bear in mind that core capitalism needs both peripheralisation and its opposite: new fields for dynamic capital accumulation." This dynamic tension will also guide my inquiry into the subnational socio-spatial inequalities of the Hungarian housing market. 
The claim that the crisis at the core of the European economy (which was, in turn, a displacement of the crisis at the heart of the global economy, in the US) was managed by displacing crisis to the European peripheries is a recurrent argument in the work of authors critically engaging with the political economy of Europe from various disciplinary positions. The whole process of the southern and eastern expansion of the EU can be understood as a process that "enabled the northern member states to moderate their own crises by deepening the regional division of labour within European economic space based on the promotion of peripheral Fordism and the extension of credit (Jessop 2014, p. 250), while Becker et al. demonstrate how contemporary, post-2008 crisis management is also done to the detriment of European peripheries - and specifically their middle classes (Becker et al. 2015).

Several authors highlight how credit and debt generally became central in how the transfer of wealth is happening from peripheries to cores in the past few decades (Sokol 2013). (Semi)peripheral countries are characterised by a systematic scarcity of capital and technology, which means they constantly need to attract foreign capital. In the early 2000 s, with increasing amounts of available liquid capital and the possibilities for foreign direct investment decreasing (after the slowdown of privatisation processes in the CEE region), there was a shift towards bank capital and credit as the dominant channel for this capital investment (Geröcs-Pinkasz 2018). On the other hand, credit poured into the European periphery in the 1990s and 2000s was an important vehicle for the economic core of Europe to displace its own crisis (Jessop 2014, Becker et al, 2015, Raviv 2008). As the financial crisis of 2008 showed, the most important problem was a stock of "mounting private debt, that had been unproductively invested in consumption and Ponzi finance of housing bubbles" (Jessop 2014, p. 254). Since external capital invested through the financial channel can also be rapidly withdrawn, the credit boom also made the periphery more vulnerable to crisis, with capital flows being very rapidly stopped when signs of crisis emerged in Europe (Vliegenthart 2010). The notion of dependent financialisation has also been developed, accounting for the fact that financialisation in CEE mainly happens through external relations of credit and debt (Becker - Jager - Weissenbacher 2013). Through this mechanism the capital surplus of the core fuels the financialisation of the periphery through real estate and consumption loans, also triggering the indebtedness of households (ibid, p.42; Pósfai et al 2018). Dependent financialisation is also characterised by external institutional control, transmitting unequal power relations between the core and periphery of the European economy (Gabor 2012, Gál-Schmidt 2017).

Now, if we come back to the claims made in the previous section about how housing has become a crucial field for investing surplus capital under financial capitalism, it can be seen how the housing issue is an important articulation of European-scale core-periphery relations. Since "capital flows that stimulated pseudo booms in the periphery which have not positively affected the 'tradable sector' but rather construction, real estate and the financial sector" (Weissenbacher 2017, p. 13). The way the CEE region has been integrated in the European economic space has led to increasing indebtedness and a stronger vulnerability to crisis in these countries (Myant-Drahokoupil 2012, Ban 2012, Becker 2016). The debt-led accumulation model that contemporary housing systems are built on is generally not a stable one - and this vulnerability is even more pronounced in peripheral economies. It is thus not incidental that the big housing market crashes following the crisis occurred all around the peripheries of Europe and not in the core. Similarly, the housing market booms these countries experienced in the years preceding the crisis had also been a consequence of integration through dependent structures of finance - dependent integration leads to impressive growth rates, and then to more vulnerability to crisis (Bohle 2016, p. 385, Vliegenthart 2010). This was also the case in Hungary: preceding the crisis a massive mortgage boom occurred mainly financed by capital channeled through the subsidiaries of Western European financial institutions. Following the 
crisis these lines of credit rapidly dried up, resulting in the near complete freeze of the Hungarian housing market (Raviv 2008).

This dependent financial integration and its reliance on housing can be highlighted along two dimensions: the foreign ownership of banks, and the spread of mortgage lending in foreign currencies. The extremely high share of foreign ownership of banks is the element of dependent development which is perhaps the most often underlined in the case of Central and Eastern Europe (see eg. Drahokoupil 2009, Bohle 2013). A dual structure developed in the banking sector as a result of financial liberalisation unfolding after 1997, with companies in foreign ownership dominating strategic positions (Gál 2014). This also results in a preference of these banks for household / consumption lending, since this is a segment that does not require a lot of local knowledge (as opposed to lending to SMEs, for instance), and generates high returns (Bonin-Ábel 2000). In peripheral countries, domestic interest rates are systematically higher (which is a part of the strategy these countries must employ for attracting foreign investment through various channels - Geröcs-Pinkasz 2018, Myant-Drahokoupil 2012). Thus, banks that have direct access to capital from international financial markets or from core mother banks can offer cheaper loans - even while pricing them much higher than they would in their home economies. This lead to the other flagrant aspect of dependent financialisation in CEE (and in Hungary specifically): mortgages and household consumption loans were a preferential product of banks in foreign ownership, while on the other side state policy made banks the sole institutions of housing finance and supported the rapid spread of mortgage lending. The combination of these factors made household mortgages a very convenient and profitable way to channel surplus capital into the European peripheries in the early 2000s (Raviv 2008, Pósfai et al. 2018). What is perhaps even more striking, is that contemporary strategies of crisis management are also organised along the same lines (Becker et al. 2015).

Generally, the dependent structure of peripheral finance is not something that developed in the $2000 \mathrm{~s}$ - the long-standing structure of external dependencies is characteristic of (semi)peripheral countries in the longue durée (Arrighi 1990, Brenner 2004, Gowan 2000 - for a contemporary Hungarian empirical study in this vein see: Geröcs-Pinkasz 2018). The dependent integration of Hungary in the European economic space also did not start at the point of political transition in 1989, but much earlier. This dependency takes different forms throughout historical cycles: in the productive cycle of the post-war years it mainly manifested as a lack of technology, and from the 1970s onwards increasingly took the form of debt. Already under state socialism, Hungary was (apart from Poland) the Central Eastern European country with the most important debt service towards Western European financial institutions (see Becker 2016, Éber 2014). This set the trajectory the country would follow in terms of aiming to acquire as much hard currency as possible from the early 1990s onwards (Becker 2016). This, along with significant pressure from international organisations, translated into concrete policies of privatisation of state-owned companies and support for foreign direct investment (Geröcs-Pinkasz 2018, Becker 2016). These processes of the 1980s and 1990s also strongly affected how the sphere of housing and housing policy developed during these decades in Hungary (Jelinek 2017). Thus, the dependent financialisation of housing which rolled out in the early 2000s can be understood as a new articulation of the same, indebtedness-based relation of dependency which has defined the trajectory of Hungarian economic development for decades. 


\subsubsection{Structural heterogeneity, internal fragmentation}

Understanding how external dependencies and hierarchical macroeconomic relations affect social and spatial structuring on the national or local scale is a central conceptual question for my analysis. One of the main gaps of scholarly work conceptualising Central and Eastern Europe as a semiperiphery is that they rarely go below the national scale in the analysis of coreperiphery relations. I adhere to authors claiming that internal fragmentation and socio-spatial disparities cannot be understood independently from external dependencies (Gowan 2000). Integrating the perspective of global positions in understanding intra-national spatial unevenness also became important in recent work in the field of economic geography (see Hudson 2016, Dunford-Liu 2017, Hürtgen 2015). This re-theorizing can be linked to the tendency I had described in the previous section, with a return to more macroscopic explanations within economic geography in the wake of the global financial crisis of 2008. Although the notion of uneven development has an inherently scalar approach, studies of the way how it unfolds on subnational scales often focus on the urban scale (Smith 1987), and rarely give a systematic understanding of subnational regional disparities, or more fine-grained urban-rural relations of capital extraction. Costis Hadjimichalis is one of the few authors who explicitly uses this terminology of critical geography for his analysis of regional inequalities arguing already in 1983 that "uneven regional development is the outcome of historical patterns of spatially differentiated accumulation processes" (Hadjimichalis 1983, p. 128.). In his more recent work, he underlines how cores and peripheries are dynamic categories embedded in a multiscalar way, which means that a certain place can have different positions in terms of peripherality or centrality depending on the scale we are looking at (Hadjimichalis-Hudson 2014).

Reconceptualisations of "old" (originating from the previous crisis cycle of the 1970s) critical theoretical approaches would also be highly relevant based on the work of the so-called European Periphery Group (Weissenbacher 2017). This was a relatively short-lived convergence of scholars belonging to the European dependency school (for which the institutional frame was the European Association of Development Institutes) in the early 1980s, who produced an edited volume entitled "The crises of the European regions" (Ostrom-Seers 1983). Inspired by the empirically observed, increasing regional inequalities in peripheral countries of Europe they claimed that "the periphery shows technological, economic and political dependency on the core of Europe" (Ostrom-Seers 1983, p. ix), and that hierarchical systems are produced within these economies as a result of their dependent position. Members of the European Periphery Group, such as Dudley Seers or Costis Hadjimichalis (see in Ostrom-Seers 1983) have a consistently multiscalar understanding of how dependent relations unfold - even though they do not use the terminology of scales. They understand increasing regional inequalities within peripheral European countries (of southern and northern Europe) as a consequence of the position these countries take up in a hierarchically organised economic space (ibid). This approach is precisely what is needed in contemporary Europe. Inquiries about increasing spatial unevenness within peripheral European countries will not have the necessary explanatory force without considering the broader logic of European integration they are embedded in. This broader logic is that of displacing the crisis of the European core to its (mainly southern and eastern) peripheries in subsequent waves (Becker et al 2015). Financial flows and debt are currently the main vehicle of how this happens, with the post-crisis austerity regime giving the institutional framework for the latest wave of this phenomenon (ibid). Scholars of the Institute for International Economy and Development at the Vienna Economics University have started to build on this body of work, aiming to conceptualise currently 
increasing regional inequalities in peripheral European countries in the context of their dependent integration in the European economic space (Weissenbacher 2017).

A further body of theoretical work calling to be brought back into contemporary discussions on spatial inequalities is the literature on internal peripheries and structural heterogeneity. The idea of structural heterogeneity had already emerged in the original literature of dependency theory (Pinto 1970). This notion also claims that external dependencies are linked to internal social and spatial structures - and the concrete outcomes of local economic and institutional development are produced by the interaction of these two. In dependency theory this idea also served as the starting point for a class-based analysis of dependent societies - scrutinising which social classes are in a position to exploit external economic dependencies to their advantage and which bear the cost of this dependency (Vliegenthart-Overbeek 2007). The revisited concept of structural heterogeneity applies theories of dependency and world systems theory to the context of contemporary financial capitalism and to the analysis of subnational, internal social and spatial inequalities (Hürtgen 2015). The basic claim put forward by Hürtgen is that national-scale indicators of economic growth and consumption do not indicate a general improvement of the situation of the population of the given country. On the contrary, the current economic growth model is based on social fragmentation; on internal unequal development (Hürtgen, 2015). She argues that the systematic transfer of resources from the periphery to the core happens not only on an international, but also on a subnational scale. Hürtgen claims that countries which are in a dependent position on the scale of the global economy will necessarily be more fragmented internally. Thus, she argues for the systematic and not incidental nature of socio-spatial unevenness (ibid).

The notion of inner periphery was also developed in the 1970s to account for subnational regional inequalities in a global framework. David Walls analyses the situation of the Appalachia in the US with this approach in a paper from 1978, arguing that going beyond a model of internal colonialism (which became a popular approach to studying internal inequalities following the success of the anti-colonial movements), the situation of systematically underdeveloped and dependent regions within the US should be understood in a model of peripheral regions within an advanced capitalist economy (Walls 1978). Several decades later Nolte mobilises the notion of internal peripheries, applying it to the European context in a historical investigation of regional inequalities in Europe (Nolte 1997). Central to his understanding of inner peripheries is its relational definition: peripheries are always defined in comparison to an area which is considered central and which benefits from the relations of dependency that tie the periphery to it. In the same volume on inner peripheries Nitz argues that - following Wallerstein's definition of peripheries on a global scale - the (semi-)periphery is first and foremost a functional spatial category (Nitz 1997). It should not be understood in terms of geographical distance or statistical data concerning the level of development of a bounded geographical region, but rather in terms of the function the peripheral area fulfils in its relation to the core (ibid.). This functional understanding of what a periphery is is something I strongly buily on in my analysis. Nitz also claims that it is very difficult for peripheries to change their role based on endogenous resources, or in a way that would benefit the entire population of the periphery - since the improving economic situation of the better-off part of the periphery's population usually goes together with the further impoverishment of the lower segments of the same society (ibid). This is also in line with Arrighi's understanding of the stability of positions certain countries take up in the global hierarchy of wealth (Arrighi 1990). 
Based on the line of thought sketched out above the argument I propose in the dissertation is that (1) internal spatial differentiation is inherently linked to external dependencies, and that (2) both on a transnational and on a subnational scale dependent core-periphery relations result in the systematic extraction of resources from the peripheries to the cores.

Housing has proven to be a crucial sector for investigating these questions. However, in order to understand how this concretely happens in terms of everyday economic reality, economic actors must be put center-stage. In the following section I will set the frames for my analysis of enterprises on the housing market.

\subsubsection{Reproducing uneven development through firm strategies}

In my analysis, I am interested in how firms of the housing market (such as banks, developers or real estate agents) are embedded in relations of uneven development, and on the other hand how they (re)produce socio-spatial patterns of unevenness. I aim to shed light on how corporate-level strategies are translated into uneven development, for "it is important to remember that [macro-level economic] processes are the result of decisions and actions taken by independent economic agents" (Dixon 2010, p. 201). Thus, when we talk about the "spatially uneven manifestation of capitalism" - what does that concretely mean on the scale of the actors "operating" this system? I am not interested in the internal mechanisms or institutional differences of these companies, rather I seek to understand the mechanisms by which they transfer structural constraints. The fact, for instance, that credit is more expensive in peripheral places (on a global or local scale) is completely common sense in the business and consultancy world, and is a logical response to managing risk in a capitalist, globally interdependent framework of doing business. The constant tension between the need for market expansion and the assumption of greater risk this entails is something that firms have to manage on an everyday basis. The balance they strike will depend on the strategy and "risk appetite" of the given firm, and also on the structural opportunities that open to them.

I will outline conceptual propositions that reflect on how global pressures influence the corporate structure and strategy of firms, and specifically how firms are at the same time the operators and subjects of dependent structures of capitalist development in Central and Eastern Europe. I adhere to conceptual approaches to the firm that shift their analytical starting point from the institutional scale and national regulatory framework to the broader scale of the capitalist economy, and aim to understand the integration of firms in this system (Hudson 2015). While taking capitalism and its systemic pressures as their starting point, these authors scrutinise concrete mechanisms of corporate governance and firm strategies (Werner 2016, Dixon 2010). This means that the organisational form or market decisions of a company are not understood as endogenous, company-scale decisions, but in their relationship to global processes. This approach results in a more relational and inherently multiscalar understanding of the firm, that focuses on the mechanisms at work in firm functioning instead of rigid institutional differences (Dixon 2010).

\subsubsection{The firm in economic geography}

In economic geography, there is a very large body of work that links the global economy to the firm and regional scale, which is coined under the global production networks (GPN) and global value chains (GVC) literature (Coe et al. 2004). The advantage of this literature (from the perspective of my analysis) is that it provides a very explicit link between corporate functioning and geography on a regional scale. Recently, geographers have argued for re- 
establishing the by now eroded critical edge of the global production networks perspective by combining it with uneven development (Werner 2016). This reformulation also gives valuable methodological tools to grasp capitalist processes on the scale of corporations and regions in a relational way. Werner (2016) gives several examples for these analytical tools, such as examining the stratification of the workforce along regional differences, or investigating patterns of constitutive exclusion, where excluded areas from global production network formations can be seen as sources for ongoing primitive accumulation (or of accumulation by dispossession, to use Harvey's term). At the same time, other geographical areas are drawn into global networks in an uneven way, with certain areas producing rapid economic growth as a result (ibid). These locally deeply interrelated processes of inclusion and exclusion can also be seen as analogies to the terms of financial exclusion and overinclusion used for example by Aalbers (2012), and which I also mobilise in later parts of my analysis.

Due to the historical context in which it emerged, the GVC / GPN literature mainly focuses on the productive sector, reflecting on how transnational firms navigate and produce the international division of labor (see eg. Coe et al 2004, Nagy 2005). Currently, with the continuously growing importance of finance, this conceptual toolkit needs to be shifted. Such a shift allows for a better understanding of how these global networks / chains function when channeling (growing amounts of) capital instead of products. Thus, although the fundamental logic is similar, it has different methodological (and conceptual) implications to "follow the money" and to follow the production strategies of transnational corporations. (Although it should be noted that even this earlier GPN literature has clear reflections on the fact that the type of financial capital available to firms is determinant for what territorial embededness they establish. This, in turn, significantly impacts their engagement with regional development (Coe et al 2004, p. 472).)

Recently, important advances have been made in the field of geographies of money and finance in developing conceptual (and methodological) tools for understanding the interconnectedness of firm-level strategies and global processes (see eg. Pike-Pollard 2010, for Hungary: Gál 2014), investigating the spatial patterns of financial institutions for instance (Gál 2014).

\subsubsection{The firm in political economy}

In the field of political science and institutional approaches to the firm, critical approaches aim to overcome the dichotomy of weighing convergence and divergence in corporate practices (which is predominant in studies coming from more microscopic or governance-oriented approaches investigating the functioning of firms). Rather, they highlight how these firm-level structures and strategies are being transformed in similar ways under systemic pressures (Apeldoorn et al. 2007). Apeldoorn et al. also give an overview of recently growing body of literature that relates the financialisation of the global economy to how corporate governance structures are being transformed (ibid. p. 17). It is important to come back to the varieties of capitalism literature at this point, because of its focus on the firm level. Although this approach usually understands corporate governance in relation to different national regulatory regimes, work relating to the dependent nature of corporate structures in Central and Eastern Europe gives an important point of reference for my analysis. Jan Drahokoupil (2009) proposes the terminology of "dependent market economies", Bohle and Greskovits (2012) analyse "capitalist diversity on Europe's periphery", providing a typology of different postsocialist capitalisms, and Vliegenthart and Overbeek (2007) give a proposition for an East Central European (ECE) variety of capitalism in corporate governance structures. In all three analyses, the high share of foreign ownership in the financial sector is a key element. Here, I will focus 
on the frame proposed by Vliegenthart and Overbeek, who argue that the process of "transformation" (that is, the political and economic changes at the end of the 1980s) in CEE were actually a process of accumulation by dispossession, and that the expansion of Western European firms into the region from the 1990s onwards served to resolve the long-term crisis of overaccumulation of capital in the core of Europe (ibid). They underline how there is a systematic dependence on external finance in CEE countries, and how the financial sector thus plays a central role articulating relations of dependency, and also in tying mechanisms of accumulation by dispossession to those of reproduction in economies in transition. This claim is strongly reflected in the field of housing, where housing credit becomes one of the dominant elements of extracting resources from households. A further important argument relates to the class base of different corporate structures. The dependent structure of these economies favours the emergence of a "comprador bourgeoisie" which can efficiently channel foreign capital to its advantage and can broker how transnational companies enter the country (ibid). The conditions of dependency described in the previous section are thus intrinsically inscribed in the way capitalist enterprises function in the CEE region. The lack of internal resources on (semi)peripheries leads to a situation where the structure of the firm facilitates capital being channeled back to the cores, thus becoming the concrete vehicles for capital extraction inherent to the logic of uneven development (Vliegenthart - Overbeek 2007).

Vliegnethart and Overbeek's conclusion actually goes beyond the frame of $\mathrm{VoC}$, giving a frame of common trajectories with persisting institutional specificities (also relating to local politics) in corporate governance. The proposition of Adam Dixon (2010) also falls along this line, who moves beyond $\mathrm{VoC}$ towards a variegated capitalism approach in doing research on the firm level. He proposes to empirically implement the approach of variegated capitalism through the study of the financial geographies of the firm, arguing that with the deepening of financialisation firms can no longer be understood merely in the national frame, but are also connected to multi-scalar processes of uneven development (Dixon 2010). To put it simply, in his approach the notion of variegated capitalism is a way to combine uneven development with firm-level agency and with regional differences. This frame allows to account for institutionally and historically determined differences (on various scales) and for general convergence as a result of capitalist integration at the same time. Building on the approach and tools of financial geography, he proposes a frame for the investigation of how firms operate differently in various places within the same global frame of financial capitalism. He proposes to set the "microfoundation for understanding broader macro-geographical transformations" (ibid, p. 201) through an analysis of how firms manage their finances, what strategies they employ and what corporate structures they build. Adaptation to financialised capitalism takes different forms in different political economies, or in different firms. He demonstrates on various examples how national traditions of corporate governance intersect with global pressures to produce specific strategies and trajectories. Which strategies, in the end, reproduce unevenness on various scales. Thus, it can be seen on the scale of corporate governance that in the context of increasing financialisation, the supposedly path-dependent trajectories of national corporate regulatory environments are undercut, and global pressures are manifested in homogenising corporate practices. This is something that can be observed in terms of the financialisation of housing as well: although the concrete institutions driving the financialisation of housing differ across various national economies, there are markedly similar tendencies. Dixon also argues for shifting scales of analysis from the national scale by demonstrating how there can be spatial variegation in how much corporate governance structures respond to pressures of global capital. Thus, the spatial pattern of investment by transnational firms (eg. investing in Central and Eastern Europe, or more specifically choosing certain urban agglomerations or certain regions on a subnational scale) will produce unevenness on other scales. 
In order to consider convergence and divergence as intrinsically linked elements of the same process, Dixon's proposition for doing a firm-level analysis with the approach of variegated capitalism is the following: "On the one hand, [...] recognize and show the importance of persistent nationally specific institutional difference. On the other hand, [..] reveal the need to take a multiscalar perspective to understand the relational dynamics between two different institutional environments and how economic actors can exploit aspects of one to solve for a constraint in the other" (Dixon 2010, p. 204). These are propositions I have recognised as helpful guidance in my investigation of firms of the Hungarian housing market.

In my analysis I will mobilise various conceptual elements from the lines of thought outlined above, shifting the focus given to one or another approach, while constantly remaining within the conceptual frame of uneven and dependent development. All of these conceptual cornerstones have methodological consequences as well, which I will outline in chapter 2.

\subsection{Existing research on housing and uneven development in Hungary}

Housing markets and spatial inequalities have both been quite extensively researched in Hungary, giving a rich body of studies I can build on even if their theoretical starting point often differs from mine. Many studies on housing in Hungary focus on the development of social housing and the privatisation of this stock (see for example Balogh 1999, Hegedüs 2013, Hegedüs 2006), on housing policy analysis and policy recommendations (see for example Hegedüs et al. 2009, Misetics 2013, Misetics 2017), or on housing finance relating to state policies and welfare regimes (see for example Hegedüs-Várhegyi 1999 or Hegedüs-Somogyi 2016). Studies introducing questions of space in relation to housing often focus on issues of segregation or gentrification on an urban scale; relating to urban regeneration projects and often having a strong bias towards Budapest (see for example Boros et al. 2016, Kovács-Szabó 2016, Keresztély-Scott 2012, Ladányi-Virág 2009, Lepeltier-Kutasi - Olt 2016), or rely on big sets of quantitative data for giving an analysis of spatial disparities of the housing market on a national scale (see for example Kovács et al. 2005, Buskó 2006).

These studies give rich empirical material and useful overviews of the development of housing in Hungary. However, they often neglect the broader political-economic context and interconnected scales of these changes. This leads to a situation where studies reporting about the state of affairs on the housing market or acknowledging the existence of socio-spatial inequalities in this domain can fail to give explanations for the reasons these inequalities are produced, or to analyse the actors behind these processes and the logic driving their decisions. I aim to contribute to this field of studies by explicitly linking the fields of housing and territorial inequalities in the frame of uneven development, and by giving an analysis of this field (and of the marge for manoeuvre of its agents) as embedded in global economic processes. In the following section I will overview important studies that address the issues of housing and spatial inequalities in Hungary, and will define the position of my research relating to these studies.

In recent studies Hegedüs (2011) and Hegedüs-Somogyi (2016) explicitly link developments of housing policy to the economic crisis of 2008. In their latest article they develop a periodisation of shifts in the Hungarian housing finance system since the 1980s onwards, giving a coherent analysis of the political economy of housing in Hungary (HegedüsSomogyi 2016). However, their analysis remains largely on the scale of the nation state and does not link these shifts in the housing finance regime to global economic processes. The 
periodisation they produce is, not surprisingly or coincidentally, very similar to that produced by Aalbers in his article from 2009 about cyclical shifts in American and "global" housing regimes (Aalbers 2015), even though they do not articulate their periodisation in terms of global economic cycles. The global connectedness of housing in Hungary is made explicit by Dorothee Bohle, focusing on how national public policies and institutions mitigate the effects of global economic shifts, on how public policy has contributed to the build-up of a crisisprone housing finance system, leading to shifting risk to individual households (Bohle 2013 and 2017, Bohle-Greskovits 2012). Analyses from the explicit perspective of the financialisation of housing are almost entirely lacking in the context of Hungary. A recent research project about mortgage lending took up the conceptual frame of the financialisation of everyday, linking it to an actor-based approach of researching agents of the Hungarian precrisis mortgage market (Pellandini-Simányi - Vargha 2016). My understanding differs from theirs in considering financialisation more as a regime of accumulation than as a transformative force in everyday practices and household decisions. I will build on these studies and aim to enrich the field of research on the financialisation of housing with further empirical inputs as well as an aim of "theorising from the periphery". As stated earlier, I believe that studies from CEE can have a theoretical contribution to this field of research, and that it is a relevant conceptual approach for understanding CEE housing finance systems and the role they play in the political economy of these countries.

There are a certain number of studies coming from the economics discipline which investigate the development of the housing market in relation to broader economic processes and with a long-term historical perspective. In his study from 1997 Zsoldos analyzes the change of house prices from 1980 onwards, demonstrating how levels of household savings and indebtedness, as well as available other options for investment influence households' investment in housing. He concludes that household investment in housing largely depends on interest rate levels and other macroeconomic factors such as the rate of inflation (Zsoldos 1997). In an article written ten years later Bethlendi draws on the study of Zsoldos and aims to extend the latter's long-term analysis of house prices (starting in 1970 and going up to 2006). He analyses four decades' data on the relation between household savings and housing-related investment, putting the role of available credit and the functioning of the credit market centre stage. He comes to the conclusion that household savings levels are generally very low in Hungary, and that investment related to consumption and housing is prevalent, and is very strongly linked to the availability of credit (Bethlendi 2007). These studies are especially valuable for my research because they adapt a long-term analysis of housing markets from the 1970s / 1980s onwards, and make explicit connections to broader economic processes (also reflecting on Hungary's structural position in the global economy), and understand housing in relation to the financial sector. Furthermore, the crucial role of household savings and household-scale investors in how the housing market develops has also been confirmed by my interview partners with regard to the contemporary Hungarian housing market.

The global financial crisis had very strong repercussions in Hungary through mortgages denominated in foreign currencies (forex mortgages). Consequently, in the aftermath of the crisis studies aiming to understand the phenomenon of forex mortgages emerged (PellandiniSimányi - Vargha 2016, Hegedüs - Somogyi 2016). A number of these studies are written within the discipline of economics (Schepp-Pitz 2012), or have a strongly quantitative approach (Tömöri - Süli-Zakar 2011); sometimes going into great technical detail, meticulously describing all policy measures related to handling the social and economic consequences of forex mortgages. They are important mainly for an empirical understanding of my field. The Hungarian National Bank has also produced a number of analysis about mortgage lending, and in 2016 they started a regular, semesterial publication about housing markets (MNB Housing 
market report). The Hungarian Statistical Office also has regular publications about the housing market. These are studies I will empirically build on. These publications are also interesting because often they contain elements relating to space and territorial inequalities of the housing market (see for example the MNB Occasional Papers Special Issue on non-performing mortgages - Dancsik et al. 2015).

In my research I also build on findings of financial geography, from which I gain a spatially sensitive understanding of capital flows and financial institutions in Hungary on various scales (Gál 2014, Kovács 2014).

There is an important tradition in Hungarian research - rooted in ethnography - of investigating spatial marginality and regional inequalities. These are often studies that focus on rural areas, investigating social relations based on in-depth qualitative research (eg. Vincze et al. 2015, Vigvári 2015). These studies provide very rich empirical material about peripheral spaces in Hungary, as well as about the coping strategies of agents situated in these spaces, and will be important in orienting my research. Although the subject of their study is often not specifically housing, this aspect emerges as a determinant factor of spatial inequality. However, they tend to consider marginality in an isolated way, sometimes failing to connect social phenomena in such places to core areas or to understand them as products of broader institutional and economic processes.

Research on housing - or on peripheralisation and socio-spatial marginality - has often been dominated by descriptive or endogenously explaining studies. While the role of the state is undoubtedly crucial, it tends to be overly dominant in existing studies, while the position the country takes up in a broader economic system has largely been disconsidered in Hungarian research on housing. According to a contribution to an edited volume on methodology in critical political economy, the accessibility of data that is sufficient enough in order to do what is deemed "rigorous" research will orient what people do research about (Phillips 2017, p115116) - in my view, the dominance of either policy analysis, statistical analysis or householdscale qualitative and narrative research about housing issues in Hungary can be partially explained by this factor.

A recently published study about processes of socio-spatial marginalisation in rural Hungary (Nagy et al. 2015), as well as a recent special issue in the Hungarian journal "Tér és Társadalom" (2016) explicitly situate these processes in the theoretical framework of uneven development. Nagy et al. empirically base their study on research conducted in areas identified as marginalised, which they consider to be isolated from core areas, and also from the general functioning of the system. While this is undoubtedly empirically true for many of the poorest areas in Hungary, in my research I will focus more on the relationality of cores and peripheries than on practices in peripheral spaces; focusing on mechanisms of dependency and capital extraction. In their analysis Nagy and co-researchers identify the housing market as an important aspect blocking mobility - highlighting the importance of housing in reproducing spatial inequalities and in transmitting uneven patterns of capital investment (Nagy et al. 2015).

\section{Uneven development of housing - linking space and housing}

There is a relatively small body of research on the uneven development of housing markets in Hungary, which is often related to possibilities of social mobility and access to employment. Already at the end of the 1960s Konrád and Szelényi wrote about the unequal patterns of distributing public housing (favoring higher social classes), which also revealed a clear spatial pattern advantaging larger cities (Konrád-Szelényi 1969). They show how the urban-rural differentiation in Hungary is actually not a divide of industrial and agricultural activity, but 
reflects a social stratification. This argument - that the hierarchy of settlements (in terms of size and status) also reflects a hierarchy of social class - is articulated by later studies as well, such as Koós-Virág 2010 or Timár 2007, or even by publication of the Central Statistical Office KSH 2015). These authors also agree that housing is a crucial element in this stratification.

There are a number of studies analysing the spatiality of the housing market in the years preceding the crisis. The two main strands of these studies are on the one hand national-scale studies mostly relying on quantitative methods, and local studies conducted primarily in urban areas, often in Budapest. Housing is an important although not central element of various studies about processes of urban change in Budapest, which often focus on processes of urban regeneration (eg. Kovács-Szirmai 2006, Ladányi-Virág 2009). Studies concerning the spatial unevenness of housing markets on a national scale are rarer, and often rely exclusively on quantitative data. Some examples include Kovács et al. (2005) or Buskó (2006).

Housing and uneven development is explicitly linked in Judit Timár and Mónika Váradi's article on suburbanisation in Hungary (Timár-Váradi 2001), as well as in various publications co-authored by Judit Timár and Erika Nagy (Timár-Nagy 2007, Nagy-Timár 2012). Contrasting to dominant narratives they argue that suburbanisation is not happening because of a personal taste or preference for single-family detached homes in Hungary, but as a consequence of broader economic processes. They also link spatial processes on the housing market to historical developments relating to privatisation of housing and reflect on the agency of actors involved in the production of housing (giving a picture of actors involved in real estate markets on the turn of the millennium). Their work is thus an important point of reference for me both in theoretical and empirical terms.

Building on the results of the studies briefly cited above, I aim to approach the analysis of the Hungarian housing market from a different perspective, hoping to contribute to the existing body of literature on housing studies and uneven development in Hungary. A further contribution my research seeks to make is the in-depth, qualitative understanding of strategies of companies engaged on the housing market. 


\section{CHAPTER 2}

\section{METHODOLOGY}

\subsection{Theoretical grounding - doing critical political economy}

I will largely rely on the framework proposed by Johnna Montgomerie in her recent edited volume entitled "Critical methods in cultural and political economy" (Montgomerie 2017) in setting up my methodology. In this volume, the authors give reflections on the methodological implications that research conducted with a critical political economy approach has. A cornerstone of research in critical theory is to acknowledge that methods are central in what kind of knowledge is produced, shaping "what is critical about a piece of research" (Montgomerie 2017, p2). In this approach, it would not make sense to use any method for its own sake, and the point of departure is always the identification of real-world issues that need further understanding. Constitutive elements of a sound methodology in critical research are reflections on (1) the positionality of the researcher and on other factors that influence his/ her understanding of the world (epistemology); (2) which will also determine how the object of empirical investigation is defined (ontology); and (3) on the theoretical perspective employed (ibid). In the following brief chapter I will situate my research according to these frames; giving account of my own positionality and engagement with this field of research, and outlining how my theoretical and conceptual considerations are translated to empirical analysis. Furthermore, reflecting on the empirical delimitation of my field of analysis, I will give an overview of what data collection methods and sources I used, as well as the temporal and spatial limits of this research project.

In their contribution to the Palgrave handbook of International Political Economy (Cafruny et al. 2016), Jager, Horn and Becker oppose methods of critical rationalism (which is identified as the mainstream approach in doing research about the economy in a way that splits economy, society and politics) to those of historical materialism and critical realism. The latter approaches, which the authors identify as methods of critical political economy drawing on Marx's method and dialectical approach (Jager et al. 2016), have been important in guiding my research. They highlight that in the dialectic approach of historical materialism, "emphasis [is put] on the understanding of processes, flows and relations over the analysis of elements, things and structures" (ibid, p.106). Furthermore, more weight is put on "the qualitative nature of social objects and relations on which causal mechanisms depend" (ibid, p.107). This approach also allows for the combined application of agency-oriented and structuralist perspectives. They cite Marx in saying that "men make their own history, but they do not make it as they please; they do not make it under self-selected circumstances, but under circumstances existing already, given and transmitted from the past" (Marx 1973 [1852], cited in Jager et al. 2016). Critical realism (which is identified by Jager et al. as the other main methodological framework for critical political economy research) has been perhaps most clearly formulated in Andrew Sayer's book entitled "Method in Social Science - A Realist Approach" (1992 [1984]). Critical realism can be understood as a halfway between interpretivist (constructionist) and more quantitative methodology-based descriptions of social reality; claiming that "the world exists independently of our knowledge of it" (ibid, p.5), but at the same time acknowledging the constructed nature of knowledge about the world. It rejects the approach to social sciences which tries to search for regularities and tests hypotheses akin to the methodology of natural 
sciences, but also rejects approaches that "reduce social science wholly to the interpretation of meaning" (ibid, p.4). Methodological approaches to research in critical political economy underline the importance of theory and conceptualisation in the methodology pursued throughout a research project, and link empirical investigation much more to conceptual cornerstones than to any particular method (such as statistics, surveys or a particular kind of interview). This framework has allowed me to adapt a flexible approach to my methodology, combining various methods - opening space, for instance, to study macroeconomic processes (such as mechanisms of capital investment on a European and national scale) through interpretive methods (that is interviews).

\subsection{About positionality and engagement}

Currently, a number of authors call for the need for more empirical studies in social sciences with a critical / structuralist theoretical approach. In the wake of the crisis, these approaches are again gaining more recognition within mainstream academia. Accordingly, there are research groups, new institutional positions and journals being established in this vein. We should, however, be conscious about how these research projects tend to reproduce a converging mainstream theoretical narrative and how they intrinsically produce knowledge in line with hierarchical relations within global academia. As part of such an international research project, my study can, in a way, be considered as a part of this broader wave of new structuralist explanations. While aware of this, I seek to remain consistent with my own semiperipheral position and with a grounded theoretical claim about dependencies and uneven development. This is also why I find it important to build on the tradition of dependency theories and on the work of authors from the Central and Eastern European region. I find this important to highlight because my experience is that from core academic positions, there is often a mistrust of arguments relating to global hierarchies.

Furthermore, I find it important to come back to one of the root positions of critical theory, which is to conduct research that has the capacity to affect change in real-world processes. I do not have any illusions concerning the fact that a $\mathrm{PhD}$ dissertation in itself could play this kind of role. However, this research has informed my knowledge about housing in Hungary in meaningful ways, which I will carry on in my further academic and - perhaps more importantly - non-academic endeavours relating to the field of housing. The starting point of this research project had also been a longer-term commitment with housing issues, and academic knowledge continuously intertwines with non-academic knowledge and practical engagement in my personal trajectory. In the research process, I was drawn towards segments of housing issues that were unfamiliar to me, leading me to inquire about how "big money" goes into housing, and to housing markets beyond those of Budapest. I am grateful for the possibility to access these hitherto unexplored fields of housing in Hungary.

\subsection{Conceptual notions building methodology}

Consequent with the above-outlined approaches to research in political economy, in the following sections I will reflect on some conceptual cornerstones that have guided my empirical research (which all originate from theoretical propositions I have put forward in the previous chapter). The notions I highlight below all have methodological implications, inherently carrying a certain way of seeing a set of empirical material. For an explicit 
connection to the theoretical building blocks of the dissertation, see the references to "methodological implications" in Figure 1.

\subsubsection{Crisis as point of analysis (Housing in political economy)}

Crisis is generally a crucial point of analysis in Marxist theoretical approaches, linked to a longue durée cyclical view of capitalism, where crisis inevitably develops at moments of decreasing profitability (Harvey 1982). "From Marx onwards, critical theorists have emphasised that capitalist development is inherently crisis prone and that uneven development is integral to it." (Hudson 2015). In this perspective, crisis is not exceptional, but is necessarily produced by capitalist development. Moments of crisis are important to study because they bring contradictions which are inherent to the functioning of the system to the surface, and because they often also result in a reorganisation of modes of production, of hegemonic power and of institutional structures (Ebenau et al. 2015).

Although this cyclical approach would imply a long-term analysis of how crisis manifests on the housing market (which would be very insightful to trace from the first wave of investment of global financial capital in the Budapest housing market at the turn of the $19^{\text {th }}$ $20^{\text {th }}$ centuries), in this dissertation I will restrict myself to a focus on the most recent, 2008 crisis - the period immediately preceding it, as well as its implications on the housing market. The crisis of 2008 threw the interdependence of financial markets and housing into very obvious light, and also provoked increased scholarly attention to the linkages of capital and housing. Furthermore, the way how the crisis rolled out and also the way how it was then managed showed the dependent, core-periphery relations on a European scale (HadjimichalisHudson 2014, Becker et al. 2015). Crisis management also resulted in important shifts in corporate strategies, which then gave rise to new patterns of unevenness.

Thus, in my analysis - both qualitative and quantitative - I will return to the turning point of the crisis again and again, as an important point of reference both in market restructuring, in the strategies of economic actors, and in grasping how uneven development unfolds. This perspective has had implications for my data collection as well, leading me to systematically question differences between the period before and after the crisis and to seek to disentangle the effects of crisis on the housing market.

\subsubsection{Scale - giving depth to uneven development (Subnational unevenness)}

A scalar approach will be central in guiding my analysis. The notion of scale has recently gained importance with an increasing interest in the geographies of capitalism (Christopherson 2011). Scales are at the same time geographical, institutional and cognitive hierarchical constructions. They can have quite concrete implications, linked to specific institutional structures, such as administrative units, for instance. However, I understand scales rather as processes and relations than particular places (ibid). In this I also draw on the work of feminist scholars of globalisation / international relations, who use the idea of scales to link global processes to everyday experiences (Werner 2016), and understand them as hierarchies of social power, advocating a relational approach to this notion (Nagar et al 2002). Scales are what give depth to the idea of uneven development in the sense that it is on various scales that concrete actors and institutions, as well as the relations between them can be investigated, and that the concrete processes of how capitalist development affects everyday life can be grasped. This feminist perspective - which builds on the line of thought established by Doreen Massey (1994) about linking local experiences to global processes - has also allowed for a rethinking 
of other conceptual and methodological notions in economic geography, specifically of global value chains and global production networks (Werner 2016). Such a relational and processoriented approach also implies that scales can be understood as analytical and conceptual devices and not as mutually exclusive, bounded spatial and institutional categories (MacLeodGoodwin 1999).

In my analysis of the Hungarian housing market, understanding uneven development on various scales has clarifying potential, shedding light on how the seemingly contradictory processes of homogenisation and differentiation are in fact happening in a mutually reinforcing way.

\subsubsection{Firms as conveyors of capitalist processes (A focus on enterprises)}

In my research I have focused on enterprises as the practical conveyors of capitalist processes. This focus is justified by an interest in uncovering the exact mechanisms through which capital is invested in housing. Centering firms in my analysis necessarily excludes a significant part of the Hungarian housing market - since the majority of housing transactions is effectuated between individual households, without the involvement of any corporate actor (not even a bank, since most transactions also do not involve a mortgage). About $50 \%$ of transactions involve a real estate agent, and according to estimations of market actors, currently around $30 \%$ of transactions involve credit taken from financial institutions (interviews 18, 21). Furthermore, the "moving" part of the Hungarian housing market is very small - this is a housing market that is traditionally dubbed very "immobile" (Hegedüs et al. 2009), which refers to the fact that only less than $4 \%$ of the housing stock changes owner per year - even though transaction numbers have been increasing since 2013 (MNB 2017). This is particularly striking in view of the fact that around $90 \%$ of housing is occupied by its owner - which means that household mobility is actually very difficult to achieve.

In spite of these conditions, why do I consider it to be relevant to focus merely on corporate actors of housing, excluding household-scale investigation? On the one hand, this is an unexplored territory in Hungarian housing-related research, with sorely lacking empirical material. On the other hand, from a more conceptual point of view, I think that focusing on the part of the housing market which is subject to the intervention of enterprises is revealing in spite of the fact that it is numerically smaller - especially because this is the channel for more significant capital investment. An entry point through the corporate actors of the field also allows to consolidate approaches of structure and agency in a pragmatic way: I focus on how firms navigate the housing market and through this the effects they have on socio-spatial unevenness. However, I put particular emphasis on understanding the structural constraints under which they operate and that determine their marge for manoeuvre.

At the same time, a focus on corporate actors necessarily introduces a polarising bias both socially and spatially. On the one hand, economically better off households and more expensive real estate will come under the focus of real estate agents, developers and banks to a higher extent. On the other hand, economic actors have a spatially quite particular presence especially since the economic crisis of 2008 -, focusing more narrowly on more prosperous areas. This bias can, however, also be exploited in an analytical way, exploring the unevenness uncovered by the presence and focus of these companies. Furthermore, a focus on firms sheds light on the part of the housing stock that moves and that opens possibilities for household mobility as well. Thus, it allows to grasp the instances of change and to understand how it happens. 


\subsubsection{Relationality - an approach to core and periphery}

The idea of relationality is important from the perspective of all of my "conceptual building blocks". On the one hand, my understanding of core and periphery is very much articulated in a relational way, principally through relations of dependency and by tracing flows of investment (and not, for instance by a statistical or other restrictive definition of what a periphery would be). I adhere to authors who claim that cores do not exist without peripheries, the development of the two being intrinsically dependent on each other (see eg. Lang et al. 2015).

This also has methodological implications, orienting attention towards macro-scale processes and towards instances of investment and disinvestment. Traditionally, the methodological/ empirical articulation of dependency theories and world systems theory was to investigate unequal relations of trade. Although this remains relevant in today's financial capitalism as well (since processes of financialisation in core economies can precisely result in the re-industrialisation of (semi)peripheries - see Geröcs-Pinkasz 2018), it is important to develop tools which help us grasp the dependent and hierarchical nature of the global economic system beyond the productive sector. Since dependent relations are increasingly articulated through the financial channel (Becker-Weissenbacher 2015), conceptual and methodological tools focusing on the centrality of debt as the main vehicle of dependency in contemporary financial capitalism are crucial. One of the concrete implication for my research is that I have given particular attention to understanding mechanisms of mortgage lending (and also, albeit to a lesser extent, to housing-construction-related firm-level loans) on various scales.

Scientific focus on relationality is strongly part of the economic geographical tradition, with an important body of literature on unequal relations of trade and global production networks, or the value chain approach. Within this perspective, Martin Sokol proposes the notion of financial chains, adapting the geographical approach of uneven development and value chains to the context of contemporary financialised capitalism (Sokol 2017), giving analytical support to tracing capital investment in spatially fixed forms (such as housing). In the geographical perspective, the investigation of firms is also explicitly relational and networked. Thus, this approach has supported one of my key entry points to the field which was to trace actors of the housing market through their relations on various scales, and not primarily through their "objective" position.

\subsection{Accounting for method and empirical field}

As highlighted in the volume on methodology in critical political economy research edited by Johnna Montgomerie (2017), critical research willingly and explicitly uses a diversity of sources, maintaining a "diverse diet of information as the basis for social science practice" (May 2017, p. 29). For shorthand, we can say that I employed a mixed methods research, iterating between quantitative and qualitative data sources, as well as between theory and empirics. My main data source were expert interviews conducted with representatives of various companies of the Hungarian housing market, which I complemented by statistical data analysis. I employed these methods (and conceptual reflections) in a constantly intertwined way. Perhaps the most flagrant example for this is that I acquired important statistical data sets through interviews on two occasions, or that I asked interview partners to reflect on findings based on quantitative data analysis. An iterative reflexive research strategy acknowledges the messiness of the research process, and allows "real world" phenomena and happenings to intervene in the imagined research process, as well as "being willing and able to recognise and 
take advantage of 'deliberative moments"' ((Montgomerie 2017, p. 100). The strongest case of such a "deliberative moment" in my research process was the annual conference of the real estate industry in Hungary - which presented the opportunity to personally approach key actors of the field,. This threw me into the interview process very quickly - which subsequently unfolded in a rather fruitful way.

\subsubsection{Expert interviews}

In the following I will give a more detailed account of the groups of economic actors I have included in my qualitative analysis. These groups are (1) companies active in new housing development, (2) real estate and credit agencies and (3) financial institutions (mainly banks active in mortgage lending). Furthermore, I also conducted one interview with a person responsible for housing policy in the Ministry of National Economy, with two representatives of the Hungarian National Bank, and with two professionals/ journalists of the real estate industry. My aim was not to understand the mode of functioning of particular companies on the housing market, but rather to understand the overarching institutional logic of how the housing market functions. (See list of interviews in the Annex.)

Property developers are the most obvious actors in terms of housing market activity, however, the social and spatial bias is extremely high in their case. On the one hand, new housing only represents a fraction of all housing transactions (about 7\%), which is by far more expensive than the average (Pósfai-Nagy 2017). Furthermore, large property developers are only present in the very core housing markets in a very concentrated way. This spatial scope could be broadened by integrating a higher number of smaller-scale construction companies in the research, but they were the actors who were practically the most difficult to access. This was mainly because they are typically small, often family-run businesses with no free capacities - and also little interest in the kind of non-practical discussion an interview conducted by me could offer. Also, since I was conducting my interviews during the period when the new family-based housing subsidy $(C S O K)$ was being rolled out, smaller construction companies often involved in the construction of these subsidised housing units were typically overburdened with work.

Real estate and credit agents proved to be my most valuable interlocutors, especially in contexts outside of the dominant / core housing markets. Often, they were actors with long term experience about a given local housing market and with a diversity of experience from different segments of the housing market, between which they play a connecting role. Among my interview partners they also provided the broadest overview of the housing market both socially and spatially - since they engage in the transactions of used housing units (and often also in the sale of properties burdened with mortgages), are approached by households of lower economic status as well, and due to their mobility often also cover geographical areas which are not visible / accessible to larger institutions. The strong bias introduced in this aspect of my research was that most often I passed through the networks of larger agencies, asking them (usually representatives in the headquarters) to connect me with agents in their network from other cities. In some cases I contacted smaller, only locally operating offices based on internet research, but the majority of my interlocutors were members of national-scale agencies. I did, however, strive for diversity in the kind of networks I entered, balancing more top-down, hierarchically organised franchise agencies and more loosely connected, network-type agencies.

Financial institutions were obviously crucial for my research, given my focus on capital flows and investment in housing. Because of the dominance of individual ownership, this 
mainly meant a focus on banks involved in household mortgages. However, I also gave attention to uncovering potential other channels of housing finance (see in chapter 3). Understanding patterns of mortgage lending gives the broadest possible overview of how capital is invested in housing. A further important source of capital to trace would be individual investment by households (either for their own housing purposes or for investment/ rental purposes). This, however, is empirically very difficult and exceeded the scope of the present research project.

In my interview process, I got access to a few gatekeepers through the professional event mentioned above. Then, I proceeded to find my interview partners predominantly with a snowballing method, although I payed attention to maintaining a balance; some kind of subjective or intuitive representativity. This meant that I sought to have actors from the three dominant segments of the housing industry which I have identified (property development, agents and financing), as well as having interlocutors from various positions in company hierarchies and a variety of characteristic geographical locations. Although I did not delimit any specific geographical case study area, my research did have a strong spatial focus. This was manifest on the one hand through explicitly questioning my interlocutors about various spatial dimensions of their work, and also by following the networks and relations of these actors to a variety of locations in the country.

One of the important biases in my geographical scope is that passing through the networks of nationally present actors (and already the fact of focusing on the segment of the housing market economic actors engage with) oriented me towards more prosperous housing markets. I have somewhat balanced this bias by deliberately approaching individual local actors (see below), but the picture I have received remains to be quite fragmented in this sense. Local branches of financial institutions (or financial institutions other than banks) and smaller construction companies proved to be the most difficult to access.

Concerning the methodology of interviewing itself, I conducted expert interviews, which can best be called semi-structured interviews, but more akin to what Ian Bruff described as interviewing according to a "topic guide" with example questions, but not sticking to any order or concrete questions (Bruff 2017, in Montgomerie 2017). Additionally, as the process of interviewing advanced and I gained more knowledge about the field, the addressed topics also started to change. This makes it difficult to "compare" my interviews, or to analyse the transcripts according to answers given to the same questions, but they give a wealth of iterating information. Such a more flexible approach also allowed me to bring in comments made in earlier interviews and build what Bruff calls "an inter-subjective narrative that took into account the evolving journey of the interview process and its key themes" (Bruff, p127 - in Montgomerie). On occasions, I allowed the interviews to drift into forms more akin to discussion. This was partially due to the fact that I felt I had to navigate a line between seeming professional enough to be taken seriously (which was made more difficult by age and gender bias compared to my predominantly middle-aged men interlocutors) and not overly orienting my interview partners with statements based on my perception of the topic.

Apart from the interviews I once organised a quasi focus group with local representatives of the housing market (two local financial institutions - one of which was the member of a large national bank, the other a local savings cooperative, a real estate agent and a credit agent) in one of the more peripheral county seat cities. This did not work well because I failed to recognise beforehand that conflicting business interests would block open communication. However, valuable information still emerged about points that were more descriptive and consensual concerning the housing market dynamics of the city. 
In the analysis of my interviews I focused on the topics that were conceptually central to my research; putting emphasis on understanding the mechanisms of capital investment in housing within these companies, and on how their corporate practices reproduce spatial unevenness. Thus, I did not seek to give descriptions of concrete companies or of concrete geographical localities. The former would not have been possible for ethical reasons either, since the majority of my interview partners only agreed to respond under conditions of anonymity. Thus, the concrete companies I discuss are not recognizable in the dissertation, and company names are only mentioned when the information does not come from the interviews and is an element of explaining context. Similarly, when geographical locations are mentioned in relation to company strategies, they are anonymised, while in some contextual analysis I will mention concrete geographical localities.

\subsubsection{Statistical data}

My other main data source was statistical data. Accessing and analysing this data had been a long and iterative process; almost omnipresent throughout the years of the research project. There is a wealth of statistical data on housing available through the Central Statistical Office (CSO). The most important data for my research concerned house prices and transactions (although it was already a long process to come to this conclusion after going through endless excels of housing-related statistics). Data for transactions is available in a quite coherent way, statistics about house prices, however, were not collected before 2000 by the CSO, and only for cities between 2000 and 2008. The cartographical and descriptive statistical analysis of this data is mainly included in an article published as a partial output for the RegPol ${ }^{2}$ research project (Pósfai-Nagy 2017).

Another pool of data I was very keen to gain access to from the very beginning of my research came out of my conceptual focus on tracing capital flows into housing. After having identified that the main channel for investing capital in housing in Hungary was through mortgages, I sought to acquire spatially differentiated data on mortgage lending. To this end I had consulted with researchers at the Hungarian National Bank on various occasions, had done official data requests and had also met with the representatives of the company responsible for collecting data about non-performing mortgages (BISZ Zrt). All these attempts proved to be in vain, this data not being accessible for research purposes in any way (except if one is employed by the Hungarian National Bank as a researcher - which I also tried, via a scholarship application, but was refused). Finally, I had managed to receive spatially differentiated longterm mortgage lending data from one of the high-ranking bank representatives I had interviewed - but this only concerns mortgages issued by this particular bank, and is only relative and not nominal data; comparing the regional share of mortgages disbursed by this bank every year. Concerning European-scale mortgage lending, I had used a data set from the European Mortgage Federation - where I could contact the researcher responsible for this data set also through one of the interviews I had conducted with a representative of a Hungarian bank. The analysis of European-scale mortgage lending data is mainly included in a book chapter on dependent financialisation published this year (Pósfai-Gál-Nagy 2018), while the national-scale data is analysed in chapter 3.3 ("Uneven landscapes of housing credit") of this dissertation.

\subsection{Temporal and spatial delimitation}


In terms of temporality, I situate the beginning of my research in the last years of the 1990s - in 2000, the former marking the legislative changes allowing for contemporary housing market actors to emerge, and the latter marking the introduction of a law and state subsidy provoking the massive spread of mortgage lending in Hungary. For the conceptual reasons described above, I pay particular attention to the crisis of 2008 and to the consequences this had on the circle of actors present on the Hungarian housing market. The latest important chronological turning point is around 2014/2015, which marks the beginning of a new upswing of housing market activity, which is currently (early 2018) still ongoing. Although my analysis only covers the past two decades, it is important that my understanding of processes on the housing market is embedded in a long-term, cyclical view of capital investment in housing under capitalism. Thus, I do not see contemporary developments on the housing market as independent from previous cycles.

Because of the difficulties of data accessibility outlined above, and also because of more emphasis put on qualitative data sources, my account is strongly biased towards the contemporary, post-crisis period. In order to have a deeper account of previous periods, a much more consistent research would be needed with actors who are not active on the housing market anymore (or whose role has changed); as well as a more in-depth historical document analysis. The majority of my interlocutors are currently active on the housing market (although many of them have also been so before the crisis), which took the focus towards the current upswing and optimistic outlook. However, it is important to see that the current (as of early 2018) situation of expanding mortgage lending, increasing construction and transaction numbers, with generally favourable conditions for most corporate actors is characteristic of a particular period, where economic conjecture and government incentives interact. These particular conditions are not likely to last very long (on which a number of my interlocutors had reflected), and the general volatility of the Hungarian housing market can easily reshuffle the situation within a relatively short timespan. For this reason, I have always aimed to broaden the temporal and spatial scope of the narratives received through the interview process nevertheless, the bias of the present, favourable moment undeniably exists.

In spatial terms, although I empirically limit myself to the Hungarian housing market, I think about this field in an inherently multiscalar way. That is, I have explicitly connected observations made on the national scale to European and global processes, and have also followed the fragmented spatial presence of the enterprises I have investigated to subnational scales. There remains, however, important scope for empirical research on these other spatial scales. On the one hand, I could go beyond the present spatial delimitation by breaking the urban (and predominantly Budapest-centred) bias that is conveyed by the representatives of housing market firms, and investigate the housing markets of non-urban areas more in depth, or focus on the interface between firms and households. On the other hand, with a perspective of upscaling, I could prolong my macroeconomic-interpretive research methodology to the transnational scale by conducting interviews with international actors linked to the Hungarian housing market.

As already stated, I did not identify specific spatial foci in a concrete geographical sense, rather followed the networks and relations of actors I was investigating. I focused on understanding the mechanisms through which internal firm strategies are translated to spatial unevenness. This focus did, however, (in spite of the lack of strictly "geographical" case studies) draw out a certain spatial pattern of the housing market within the country. 


\title{
CHAPTER 3
}

\section{A FRAMEWORK OF UNEVEN DEVELOPMENT ON VARIOUS SCALES OF THE HOUSING MARKET}

\begin{abstract}
Previously, I had demonstrated on a theoretical basis that housing plays an important role in current processes of financialisation, and is a crucial articulation of the inherently spatial nature of this process. Thus, as I have claimed, we can use the analysis of housing markets as a way of understanding the spatiality of contemporary, financialised capitalism. I have proposed a conceptual frame of uneven development on various scales to guide this endeavour. In this process I will focus on the issue of housing finance, which I have identified as the central node allowing me to grasp the idea of financialised housing as a spatial fix for capital. I am interested in understanding how this process unfolds in the concrete case of Hungary, recognising that national institutional and historical contexts largely influence how the concrete local variegations of a common trajectory of financialised housing develop (Aalbers 2017).
\end{abstract}

\subsection{A brief chronology of channelling capital into housing in Hungary since the late 1990s}

In this section I will give an overview of the historical and institutional specificities (and their evolution over the past two decades) that determine how capital accumulating on financial markets is channelled into the Hungarian housing market, and also of how the financial resources behind investment in housing have shifted. Since the dominant institutions for channelling money into the housing market in Hungary are banks, my analysis will be focused on them, and, more particularly, on institutions and sources for housing credit (although other mechanisms of housing finance will also be discussed to some extent). The dominance of banks in housing finance has its roots in structural characteristics of the Hungarian economy. Due to the semiperipheral position of the country, there is a strong financial reliance on the banking channel (that is, dominantly on credit) as opposed to reliance on money-markets (which is more characteristic of core, especially of Anglo-Saxon economies) (Becker et al 2015). This general importance of the banking channel and of credit in semiperipheral financialisation is supplemented by the dominance of individual homeownership on the Hungarian housing market (up to $90 \%$ - although currently this share is decreasing - of housing is occupied by its owner). This tenure structure, coupled with the fact that many households do not have the financial means to acquire housing merely with their savings, means that the main instrument of housing finance is household mortgage. This lack of other options available to households for housing themselves meets a general shift in the weight of banks' crediting activity from enterprises to households (Bonin-Ábel 2000). Households have generally become more important in bank lending, but especially so in contexts with a high share of foreign ownership of banks (I will elaborate more on how a bank's ownership structure influences their lending strategy in chapter 4.3). These factors add up to the very clear dominance of banks in Hungarian housing finance, and vice versa, to the importance of household lending in banks' performance and investment strategies. 
Mortgages are only the dominant form of housing finance if we consider institutional forms of finance, since the majority of housing transactions in Hungary are realised directly between households, without any involvement from the part of firms (banks or agencies). Currently, about $30 \%$ of transactions involve a mortgage (based on evidence from interviews, since data on the number of newly issued mortgage contracts is not published), and there are currently about 150.000 transactions in a year (the stock of total housing is about 4 million, so this means a turnover rate of less than 4\%), 10.000 of which concern newly built housing (KSH 2017). Thus, the Hungarian housing market is generally quite immobile, and direct household involvement (through intergenerational transfers, savings or inheritance) in providing housing is very significant. Nevertheless, focusing on mortgage lending is relevant because this is the most important institutional channel for investment in housing, and because it also very plastically grasps the connection between local housing markets and international finance. The currently outstanding stock of mortgages in Hungary is about 13 billion euros, and more than $20 \%$ of Hungarian households holds a mortgage (MNB 2017). This is just the tip of the iceberg of household indebtedness in Hungary, with more than 4,5 million ongoing household loan contracts (of various types) in a country of less than ten million inhabitants (ibid). In 2014, 140.000 of these mortgage debtors (that is, about $25 \%$ of the whole mortgage portfolio at that time) were meeting persistent difficulties of payment (Dancsik et al. 2015). (This figure has decreased this year, but this is mainly due to a massive sale of non-performing mortgages to claims management companies. The difficulties of payment were, for the majority of these households, not resolved.) Currently, there is a yearly 30-50\% increase in new mortgage contracts, and house prices and transaction numbers are also on the rise - but all of these dynamics show strong inequalities within the country (Fellner et al. 2016). As a result of increasing investment in housing, house prices have steeply increased in Hungary in past years (by over 14\% from 2015 to 2016, and by $27 \%$ from 2013 to 2016). This is well over price increses in other countries of the region, and is among the highest in Europe (ibid).

A comprehensive discussion of the ways in which financial markets and broader capitalist development link to housing in Hungary would require a historical analysis which unfortunately goes beyond the scope of the present dissertation. Thus, I will only focus on the latest period of housing finance, which has unrolled since the turn of the millennium and is characterised by a strong push towards a model of indebtedness-based individual homeownership. During this period, there have been a few important turning points in how finance and housing interlink. I will give a chronological overview of the main institutional shifts relating to housing finance, and will also reflect on what financial resources were channelled into housing during these various periods. ${ }^{5}$

\subsubsection{Establishing the new institutions of housing finance (late 1990s)}

The fundamental elements of the contemporary Hungarian housing market were laid down at the end of the 1990s. An important turning point was the piece of legislation introducing mortgages in 1997; along with the establishment of the first mortgage bank of Hungary, the Land Credit and Mortgage Bank (FHB). Regulating mortgages meant that financial institutions could enter this market, their capacity to reclaim real estate as collateral having been secured (Pellandini-Simányi - Vargha 2016). This opened the possibility for wider segments of society to access housing finance. Previously, throughout the 1990s, instruments of housing finance

\footnotetext{
${ }^{5}$ When I speak about resources behind mortgage lending, this is not understood in a direct way, since the asset and liability sides of a bank's financial management are not connected in a way that would earmark certain resources for particular purposes.
} 
were limited to the spin-off of regulated housing credit issued prior to 1989 under the state socialist regime, and to collective savings-based building associations, which were very limited in their scope and were only accessible to the middle class (Hegedüs 2006). With the process of massive privatisation of the stock of public housing — which had kept the housing market somewhat mobile in the 1990s - drastically slowing down, pressure to open channels of household mobility increased on the government.

Among the turbulent political and economic deals of the 1990s, there was also a political debate relating to the institutional and financial structure housing finance should take in Hungary. As one of my interlocutors who had followed these debates closely in the 1990s explained (interview 35), consultants of the World Bank and politicians of the liberal and socialist parties were in favour of a structure resembling the American model of housing finance. The idea was to establish a two-tier mortgage system, with a few mortgage refinancing institutions (jelzálogbank) covering the bundled mortgages of a number of commercial banks - very similar to how the financial institutions nicknamed Freddie Mac and Fannie Mae work(ed) in the US. This model builds primarily on tapping capital into the housing market from global financial markets. Opposing this stood a proposal building on the German, savingsbased model of housing finance, which primarily saw domestic household savings as the source for housing finance. This position was pushed for by German enterprises entering Hungary already in the late 1980s and early 1990s, and was supported politically by centre-right political fractions. The institutional framework for this model are so-called home savings and loan associations (lakástakarékpénztár). In the end, a specific mix was implemented, with the law "on Home Savings and Loan Associations" Institutions and Covered Bonds"7 in 1997. FHB was established as the main institution of the mortgage-type housing finance model, however it was never involved in US-type securitisation, and started issuing covered bonds (and not securities) for refinancing mortgages. This is a differentiation that has implications for how "disconnected" the housing finance mechanism can become from the real economy; covered bonds generally being considered safer than the mechanism of securitisation - but the former is nevertheless also an instrument for creating secondary mortgage markets and selling repackaged mortgages on financial markets. In spite of the support of international institutions for a mortgage- and money-market based housing finance mechanism, it seems that the creation of FHB was rather the result of expert lobbying from within the Hungarian National Bank (interview 12), and less from the part of Western consultants. Some characteristics of the bank show this "non-American" preference - such as opting for covered bonds instead of securities, or the fact that it was founded as a state-owned bank, and was, in its initial years exclusively focused on agricultural land-backed mortgages, financing the buy-up of agricultural re-privatisation bonds by Hungarian entrepreneurs (interview 12). The reason for this was that the mechanism for privatising agricultural land in Hungary (through privatisation bonds) opened a market that investors were eager to tap into. FHB provided credit lines for these investments. It was only somewhat later, during the credit boom of the 2000s that FHB became active in refinancing the real estate-backed bonds of retail banks (and only after 2008 and following a change of ownership that it shifted towards retail banking and household mortgages as well).

Although the savings-based model was introduced with an institutional structure very similar to the German one and with very generous state subsidies included in the model (which prevails until today), it did not have much practical significance until about 2009. The reason

\footnotetext{
${ }^{6}$ 1996. évi CXIII. törvény a lakástakarékpénztárakról; accessible at: https://net.jogtar.hu/jr/gen/hjegy_doc.cgi?docid=99600113.tv

7 1997. évi XXX. törvény a jelzálog-hitelintézetről és a jelzáloglevélről; accessible at: https://net.jogtar.hu/jr/gen/hjegy_doc.cgi?docid=99700030.TV
} 
for this is that these savings institutions need time to accumulate funds before they can start crediting - and savings levels in Hungary were generally low. Furthermore, by the time enough capital could have been accumulated, the combined effect of state subsidised mortgages introduced in 2000, and of the huge wave of cheap credit that swept across Europe in the early 2000 s eroded the legitimacy (or interest) of savings associations. In the meantime, the legislation introduced about mortgages in 1997 and EU-level processes of financial liberalisation allowed for the rapid expansion of Western European banks in Central and Eastern European countries, and for the boom of household mortgage lending that unfolded after 2000 .

The apparent "victory" of the model of savings associations in the political debates of the 1990s was, according to my interview partner, primarily due to the presence of economic actors that were willing to introduce it as a working model, and to the political decision of not selling the major Hungarian bank, OTP to an American investor, but rather to privatise it on the stock exchange - which resulted in a somewhat more diffuse and domestically anchored ownership structure. However, the de facto victory of the mortgage-based model of housing finance was pushed through by broader market processes originating on the European scale. The exact process of how these negotiations and political decisions relating to housing finance unfolded would deserve more in-depth research in itself.

By the end of the 1990s, the institutional and legal framework opening the possibility to channel international capital into the Hungarian housing market was established. The entry of FHB on the Luxembourg stock exchange with covered bonds was one of the first instruments of this channel (interview 12). Then, the transnational opening of housing finance accelerated in the early 2000s, when financial markets were liberalised in the run-up to EU accession.

\subsubsection{Riding the tiger: pre-crisis dependent housing financialisation (2000-2008)}

The short decade preceding the financial crisis is referred to by all actors of the Hungarian housing market as the "golden period". Many also highlight (not surprisingly, taking into consideration the important political and social consequences that have since then erupted) the risks involved in this period of escalating housing market activity. An interview partner from one of the important (foreign owned) commercial banks, who had been in a number of different influential positions relating to housing finance since the 1990 s very plastically captured this Zeitgeist of thrill and risk by the expression of riding a tiger (interview 20). He described how various elements of the housing market reinforced and further pushed each other: state subsidised mortgage interest rates, the introduction of cheap mortgages denominated in foreign currencies by banks, generally abundant liquidity in the banking sector, the mushrooming networks of real estate and credit agents, expanding new housing construction with many new international actors - all contributed to a quickly escalating housing market.

\subsubsection{Early 2000s: state subsidised mortgages and the liberalisation of the banking sector}

The fuel to this engine was expanding mortgage lending. Widespread mortgage lending was kickstarted in 2001 with a decree introducing various forms of state support to access to homeownership; most importantly a subsidy for reducing interest rates on mortgages. ${ }^{8}$ The target groups of this program were continuously broadened to include more and more

\footnotetext{
${ }^{8}$ 12/2001. (I. 31.) Korm. rendelet a lakáscélú állami támogatásokról; accessible at: https://net.jogtar.hu/jr/gen/hjegy_doc.cgi?docid=A0100012.KOR
} 
households, but underwriting criteria (concerning income levels and loan-to-value ratios, for instance) were still relatively strict. Thus, although mortgage lending was very rapidly expanding, it was mostly concentrated in urban areas and on better-off social groups.

In the meantime, the liberalisation of financial markets on a European scale and the process of adhesion to the EU opened the door throughout Central and Eastern Europe for investment from Western European financial institutions, which actively started entering the market of individual mortgages in the region (Bohle 2013, Bohle 2017). Western European financial institutions started entering the Hungarian market either through the acquisition of privatised national banks or through greenfield operations already in the 1990s (with Hungary experiencing the highest share of foreign bank entry in the world during this decade) but this process accelerated in the early 2000s (Bonin-Ábel 2000). Acquiring branches in Hungary was mainly motivated by the possibilities of expansion into hitherto untapped markets (Raviv 2008, interview 10), and can be understood as a response to pressures of capital investment and the search for new spatial fixes; resulting in an increase of foreign capital coming into the country through the banking sector (Hardy 2014, Smith and Swain 2010). In these markets, since locally issued mortgages were very expensive, foreign banks which had access to cheaper capital from their mother banks could have a significant market advantage compared to domestic banks, and could rapidly expand their client base (interview 12). This market expansion was supported by the systematically higher interest rates that could be realised in these countries than in core economies (Pósfai et al 2018), and by policy initiatives in the region particularly oriented towards increasing attractiveness for foreign investors (VliegenthartOverbeek 2007). The banks (especially Austrian, Italian and Belgian) entering these "emerging" peripheral European markets were typically not the dominant actors in their home economies and were seeking to overcome the competitive disadvantages they faced there (Vliegenthart-Overbeek 2007). This meant that the CEE markets could become even more important within their company structure, and the banks entering CEE markets in this period made a significant part of their revenues in these markets (proportionately much more than what their institutional involvement would imply - Pósfai et al. 2018).

These factors led to escalating foreign ownership in the Hungarian banking sector: by 2000, already about two-thirds of all banking assets were in foreign ownership (Bonin-Ábel 2000 ) and this ratio climbed to over $80 \%$ by 2006 (EBRD Transition Report 2006). Thus, by the time the state subsidised mortgage program was stopped for budgetary reasons in 2004 (Hegedüs-Somogyi 2016), the liberalisation of the financial sector was sufficiently advanced to allow for a smooth shift to purely market-based mortgages.

\subsubsection{From 2004: forex mortgages}

2004 marks the beginning of the disbursal of credit denominated in foreign currencies (forex loans), which became dominant from 2004 to 2008, drastically increasing mortgage penetration in Hungary. In retrospect, many actors say this was an "over-credited" situation, where households were bearing disproportionately high risks (interviews 20, 10,36, 7, etc). Effectively, the level of indebtedness of Hungarian households jumped from $5 \%$ to $31 \%$ of GDP between 2000 and 2008 (MNB 2016a - referenced in Pósfai-Nagy 2017). Apart from the very fast growth of outstanding mortgage debt (which in itself carries risk), the issue was the structure of this debt.

These mortgages were cheaper than the previous state subsidised ones because of cheap capital available to new international retail banks through their mother banks in various Western European countries (interview 38, Raviv 2008). Furthermore, by denominating the 
mortgages in foreign currencies, the risk of changes in the exchange rate between the Swiss franc (the currency most forex mortgages were denominated in) or the Euro and the Hungarian forint were pushed on households. A further element of risk inherent to the structure of mortgages disbursed in this period was a variable interest rate (which allowed for banks to try to cover their losses in the first shock of the crisis by increasing interest rates - beyond the increase that the depreciation of the forint already caused), as well as continuously relaxed lending criteria, gradually including households with less and less stable economic conditions in this debt driven model of homeownership (Dancsik et al. 2015, interview 29). In the last years before the crisis there are stories of mortgages given out without any demonstrated income whatsoever (interview 15), of mortgages covering up to or over $100 \%$ of the value of collateral (interviews 13, 19), and of a growing proportion of consumer loans, which were issued when there was no way a household could be eligible for a mortgage. Consumer loans typically have higher interest rates and shorter durations than a mortgage, and were overrepresented in economically worse off regions (interview 25). The magnitude of these combined risks was not fully considered by any of the actors involved until the devastating consequences of the crisis made it impossible to ignore.

In spite of the risks involved, using mortgages for leveraging housing market activity as much as possible was the interest of all actors involved: banks could invest surplus capital, developers did not need significant amounts of own capital (which allowed smaller/ new actors to enter the market as well), households could access ownership who under other circumstances would not have had this possibility, and the government could reap the political benefits of this housing market expansion without having to institutionally or financially engage (interview $20,12)$.

\subsubsection{Sources of housing finance}

During this period loan-to-deposit ratios of local bank branches were very low, and the main financial resource for banks were interbank transfers from their mother banks, or - in the case of domestic banks - other forms of acquiring capital from international financial markets (such as entering stock markets with covered bonds ${ }^{9}$ ). For the local subsidiaries this meant access to cheap resources, with which they could respond to a quickly expanding demand and market possibilities in terms of mortgage lending (interview 12). From the perspective of international financial institutions, this provided a response to the market pressure of abundant liquidity available on a European scale, waiting for investment.

Predominant explanations of the pre-crisis housing market boom in Hungary tend to emphasise endogenous factors such as a "delayed response to housing needs" and policy instruments such as subsidised mortgages. While these aspects are undeniably important and are played out in interaction with external factors, I claim that the position Hungary takes up within the global and European economic space must be considered in terms of housing finance institutions that develop. The mortgage boom of the early 2000 s also needs to be understood in the broader context of an upswing of mortgage lending on a European scale, which became an important channel for investing the growing amount of surplus capital on European financial markets (Hardy 2014). For many of the foreign banks entering Central and Eastern European

\footnotetext{
${ }^{9}$ Although the majority of mortgages were never backed by covered bonds (jelzáloglevél), this instrument was also more important in the years preceding the crisis than it currently is (interviews 10, 20,21). The main reasons for this were that early on state subsidies on mortgages were only accessible in certain cases if the mortgage was backed by a covered bond, and that two of the three banks entitled to issue covered bonds in this period were domestically owned (OTP and FHB) and thus also needed this instrument to access international financial markets.
} 
markets in this period, possibilities of fast and high profits opened due to untapped market potential and generally higher interest rates (Raviv 2008). Several of my interlocutors were very clear about how the short decade before 2008 was characterised by fast and easy money on the housing market - which many international actors could tap into (e.g. interviews 8, 10).

During these early years of the commercialised housing market ${ }^{10}$, foreign presence was important beyond banks and mortgage lending as well: the lure of high returns on Central European real estate markets drew in a number of (especially Irish and Spanish) real estate developers (interview 2,11) and individual investor-buyers (many Irish, German and Israeli) (interviews 2, 6, 20). The latter mainly invested in downtown Budapest - where flats were cheap and run-down at that point (interviews 4,6). A number of agents also specialised in facilitating this investment process - the most successful of which is today the leading real estate franchise agency of the market. Large foreign real estate consultancies also entered the market of commercial and office real estate, bringing with them a group of international managers who introduced real estate business as a new profession (interview 6). Yet again, disentangling the actors and interests driving the Hungarian housing market in this turbulent period could be a further potential body of empirical research in its own right.

\subsubsection{Dependent housing financialisation}

The forex mortgage boom was a very clear articulation of the dependent nature of housing financialisation in Central and Eastern Europe - and even within the region it was most important in Hungary (Pósfai et al. 2018). One of the very banal manifestations of this dependent relation is the systematic difference in interest rate levels (see Fig.2.): even though forex mortgages could be acquired at very low interest rates compared to the options available on the Hungarian market (which is why they could spread so quickly), these were always systematically higher than interest rates on Western European markets and allowed for a significant profit margin even after adding costs related to interbank capital transfers and "emerging market risks" (interview 35, EMF 2015). Thus, banks investing in CEE subsidiaries made a significant (if not dominant) part of their profits here (for instance, the pre-tax profit of Erste and Raiffeissen Bank generated in CEE exceeded 64\% and 78\% respectively on June 30, 2008 - Pósfai et al. 2018). During this period, it was worthwhile for a bank to enter the Hungarian market as a "stand-alone" mortgage lending actor (that is, without a diverse portfolio of products), because margins on mortgage lending were around 5-8\% - which is very high compared to current levels (interview 20).

The exploding stock of household mortgages became a channel for capital extraction (thus, for uneven development) on a European scale through the ownership structure of the banking sector and the nature of forex mortgages. The dominance of foreign retail banks and the nearexclusivity of forex mortgages meant that household savings and monthly payments were tapped into European-scale financial markets in a very direct way, exposing households to the risks of these macroeconomic shifts.

Apart from rapidly increasing household indebtedness, public debt also increased during this period (both on the scale of the national and local governments), in a similarly dependent structure. This is another important aspect of semiperipheral finacialisation, I will, however, not address this issue in the dissertation.

\footnotetext{
${ }^{10}$ It is important to note that I do not see the period before 1989 as one entirely lacking a housing market. I think a housing market did exist in this period, however, a generally commercialised / commodified one developed in the period of housing privatisations in the 1990s, and professional commercial actors of the housing market only emerged in the late 1990s, early 2000s.
} 


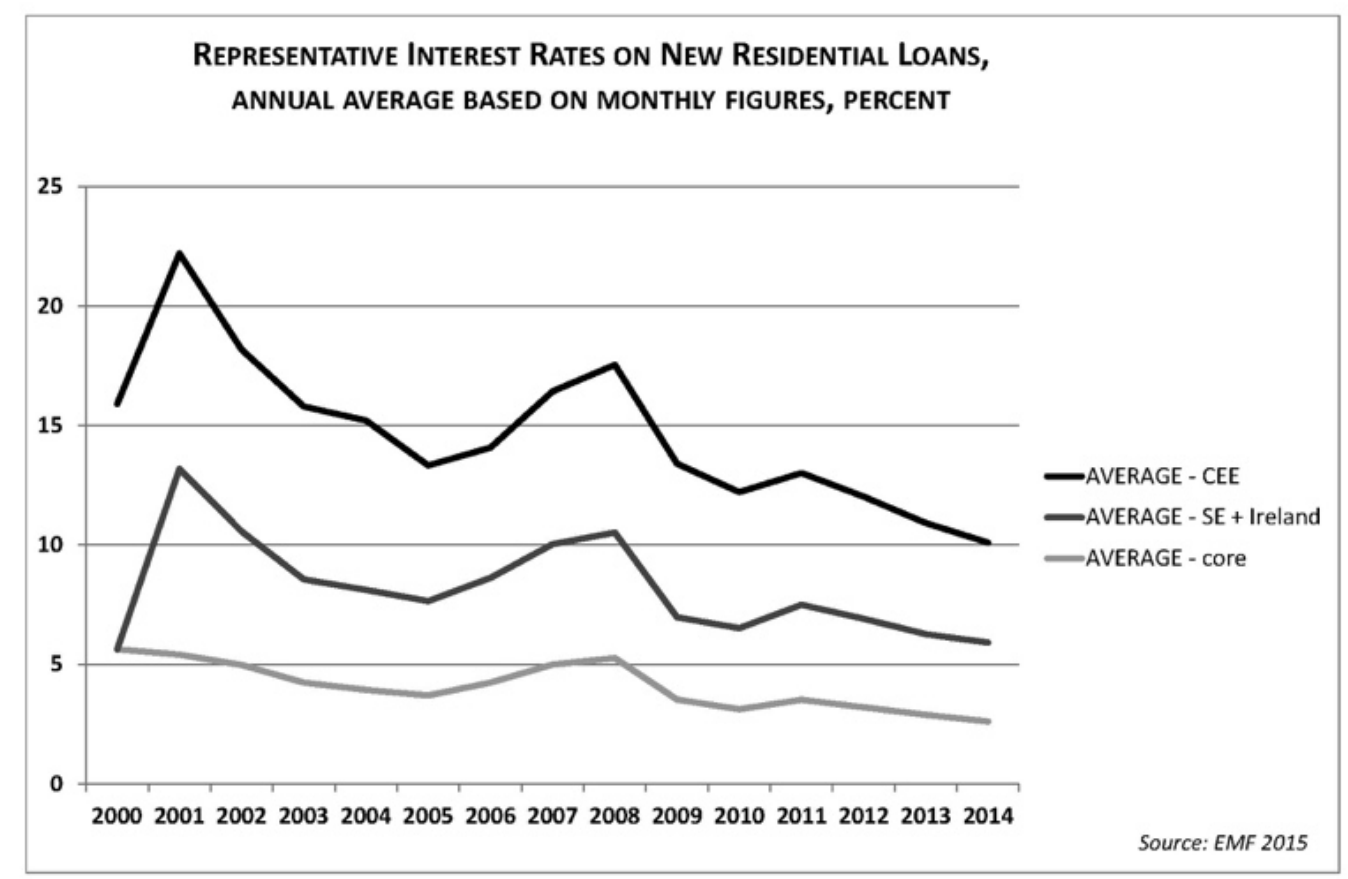

Figure 2. Differences in average interest rate levels on new residential loans by country groups $^{11}$

\subsubsection{Crash and freeze ( 2008 and the following years)}

In the autumn of 2008, mortgage lending abruptly froze as the financial crisis reached European markets and the banks present in Hungary were confronted by the dual pressure of blocked capital flows on an international scale and increasing problems of payment reported by their local subsidiaries (interview 10). The crisis clearly exposed the hierarchical nature of peripheral financialisation as capital flows were practically blocked, and mortgage lending came to a swift halt (Bohle 2017, interview 12), generally stopping capital investment in housing on the European peripheries (see Figure 3). In many banks in foreign ownership, decisions were taken almost overnight in headquarters in Vienna or Milan to stop issuing mortgages in the more risky Eastern European markets (interview 10, 12).

\footnotetext{
${ }^{11}$ The countries with available data are grouped in the following way: 'core': Austria, Belgium, Denmark, Finland, France, Germany, Italy, Luxembourg, Netherlands, Sweden, United Kingdom; 'Southern Europe and Ireland': Cyprus, Greece, Ireland, Malta, Portugal, Spain; 'Central and Eastern Europe': Bulgaria, Croatia, Czech Republic, Estonia, Hungary, Latvia, Lithuania, Poland, Romania, Slovakia, Slovenia I base this categorisation primarily on Arrighi's notion of the semiperiphery (Arrighi 1990), modifed by the type of housing regime these countries have (Fernandez and Aalbers 2016).
} 


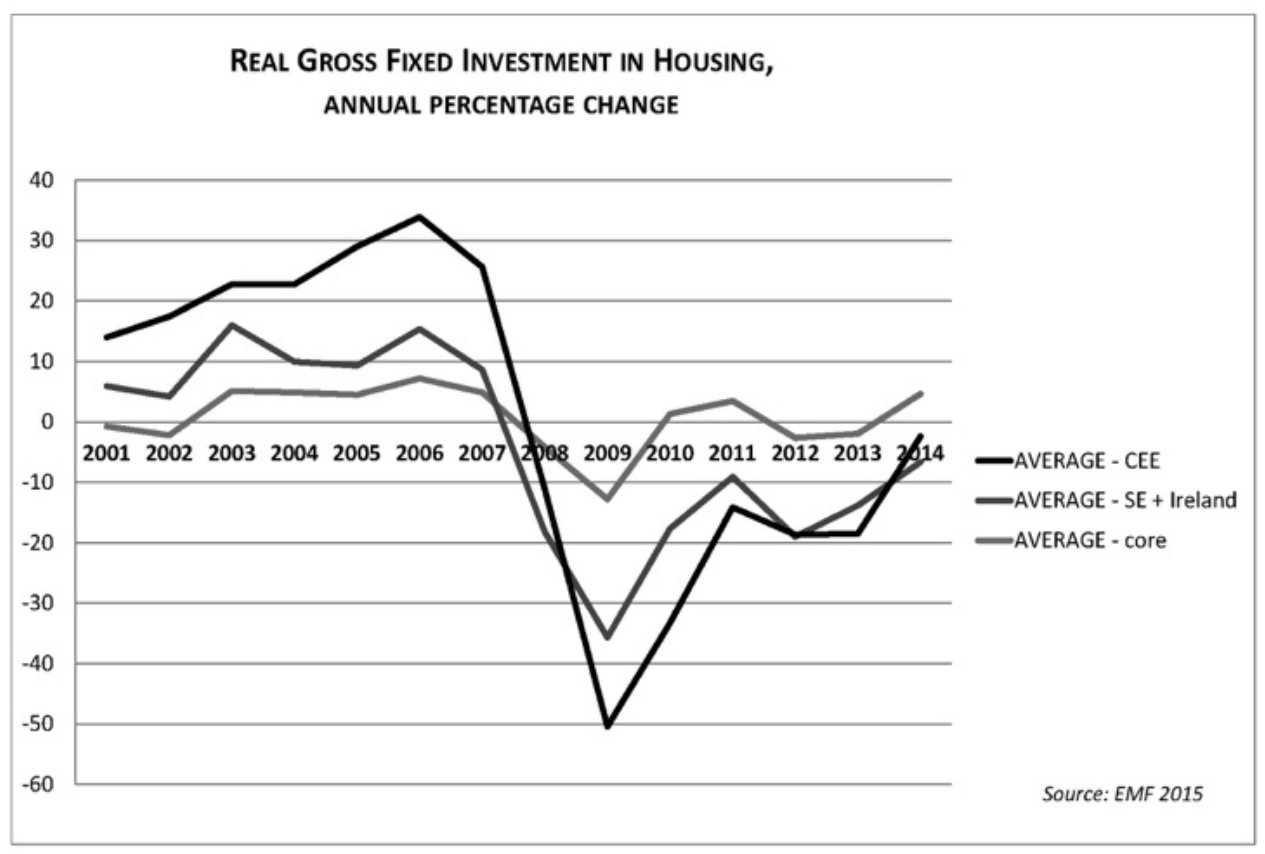

Figure 3. The volatility of capital investment in housing on the European peripheries ${ }^{12}$

With an abrupt halt of bank finance both to households and to developers, projects were sharply stopped and many developers who had been eager to benefit from the boom quickly left the country, leaving unfinished real estate projects across Hungarian cities (interviews 2, 6). During this period, capital flows were reoriented towards core European economies: Germany became the only European country where house prices increased during the postcrisis years (EMF 2015), and new forms of housing financialisation developed in countries where the housing market was deemed sufficiently safe by investors (eg. Calbet Elias 2017).

Shifting targets of capital investment also happened beyond the European, on a global scale: one of my interlocutors gave account of financial investors who had been present in Hungary in the years preceding the crisis and now, with Central and Eastern Europe becoming less interesting, invest in South America and Southeast Asia (interview 28).

From the perspective of households the crisis resulted in the drastic increase of their debt burden. With the depreciation of the forint and banks translating their increasing losses to hiking interest rates, forex mortgage debtors' monthly instalments increased by $75 \%$ on average between 2009 and 2013 (Schepp-Pitz 2012, Bohle 2013). As a consequence, (further amplified by growing unemployment) the number of nonperforming mortgages rapidly increased, and a political and economic ,mortgage crisis" developed, with many households falling into a debt spiral (Pósfai et al. 2018).

Banks in foreign ownership could not exit as easily as other international actors of the housing market because they had significant outstanding liabilities. The government could thus push them to assume part of the costs of the policy measures they started to introduce from 2010 onwards in order to tackle the "forex mortgage crisis". (For an overview of relating governmental measures see: Gagyi-Jelinek 2017, Bohle 2017, Hegedüs-Somogyi 2016.) As a result of these measures, there are currently practically no more mortgages denominated in foreign currencies in Hungary, but a significant part of the population nevertheless still carries

${ }^{12}$ Country groups are constructed in the same way as for Figure 2. 
an unmanageable debt burden. State involvement in the housing market could have initiated new processes and new institutions beyond the usual model of debt-based homeownership at this point, but this was clearly not a political priority (interview 6). Thus, housing policy in these years was mainly restricted to attempts to manage the consequences of forex mortgage lending.

\subsubsection{Channelling domestic savings into housing finance (since 2015)}

In the years following the crisis the combination of several factors resulted in a significant reorganisation of the sources of housing finance in Hungary. Most visibly, there was a political rhetoric from the part of the right-wing Fidesz government to reduce the external dependency of housing finance (which was framed in political rhetoric as a freedom-fight against western banks). The main tools for implementing this were legislative restrictions on forex mortgages (making it technically impossible to issue these kind of loans), and the "nationalisation" of the banking sector (both directly, with state acquisitions, and through supporting the market expansion of domestic banks) (interview 21). The latter shift was, of course important in terms of more general economic policy, beyond the question of housing (Voszka 2013, interview 35). As a result, $55 \%$ of the banking sector was in domestic ownership by $2015^{13}$ (Király 2016) showing a fast shift in ownership compared to 2005-2006, when $85 \%$ of the banking sector was in foreign ownership. Another important aspect of decreasing foreign dependency relates to the sources of housing finance: while loan-to-deposit ratios were around $140 \%$ in 2008 (as a result of mortgages being financed from external resources), currently this figure is well under $100 \%$.

\subsubsection{Macroeconomic context: increasing savings, low interest rates}

The significantly increasing stocks of savings in Hungarian banks provide an important basis for current housing finance mechanisms, and currently mortgages are predominantly financed by these savings (in an indirect way). This phenomenon can be related to the mistrust in investing on the market following the crash of 2008, and is also a result of economic policy under the Fidesz government, which economically strengthened a new domestic middle class (who now have savings to accumulate). Additionally, the internal policies of European banking groups also shifted, and the intra-group bank transfers that were halted at the outbreak of the crisis were not reopened in the same way. Locally operating subsidiaries of international banks are now also usually expected to collect deposits to cover their loan issuing (interview 10). Meeting this expectancy is currently not a problem because of the important increase in the stock of savings that had accumulated in Hungarian banks in the meantime.

After 2013, in the context of historically low interest rates and a stabilising economy these accumulating deposits started to flow out of the accounts of financial institutions into real estate and particularly into housing. This global tendency was given a further push in Hungary by a few very mediatised "broker scandals" in 2015 (interviews 19, 25). With the bankruptcy and then mediatised cheating and Ponzi schemes of a few brokerage companies, there was a frantic move (from the part of those who didn't lose their money) to move all of their savings into something stable; initiating a new wave of investment in housing. Beyond small-scale investors appearing in growing numbers, low interest rates are also orienting financial investors

\footnotetext{
${ }^{13}$ A summary of the largest finance- and real estate-related professional online portal: https://www.portfolio.hu/finanszirozas/bankok/bankok-magyar-kezben-ket-lepesben-teljesult-orbanalma.220294.html
} 
or medium-sized companies of other economic sectors towards the housing market (interviews $15,19,25)$.

\subsubsection{An old-new housing policy package}

Catching up (or in tandem) with the market upswing (positions vary as to which was the driving process - interviews $2,5,21$ ), massive government communication and policy-making rolled out from the end of 2015 / beginning of 2016 relating to investment in housing. Housing is being used as a central tool for political gains and for economically favouring certain social classes and economic groups. "The national-conservative government in Hungary has used its two-thirds majority to redesign central elements of the Hungarian housing finance system in the context of a deep economic and social crisis" (Bohle 2017, p. 28). Thus, there is a mutually reinforcing process at work between market pressures and economic interests on the one hand and a conservative, neoliberal political ideology of homeownership on the other. This combination has proven to be quite efficient: the Hungarian housing market is currently living a new small "golden age", with house prices and transaction numbers quickly increasing. The new housing policy instruments that had been rolled out since 2015 / early 2016 can actually be seen as a revival and rebranding of those introduced in the early 2000 s. Their two main pillars are - as perviously - expanding access to individual mortgages and providing state subsidies to certain households (mainly based on the number of children they have). Along with these "demand-side" incentives, there are also a number of "supply-side" support mechanisms, the most important of which is the reduction of VAT on new housing construction from $27 \%$ to $5 \%$ (for a limited period of time, until the end of 2019). Thus, we are currently witnessing a new wave of policy supporting indebtedness-based homeownership on the one hand and the construction industry on the other - which is well in line with the general direction of housing financialisation and neoliberalisation throughout Europe (Fernandez-Aalbers 2016).

Thus, the new housing finance regime is, in its essence, unchanged: it is aimed at individual households, who should acquire private property with the help of a mortgage. However, the financial resources behind these mortgages are now the deposits accumulated in banks, which are, in turn, now in majority domestically owned. Thus, the current housing finance system is, in the end, built on the savings of Hungarian households, but passes through commercial banks which are reorganised in a way to benefit the economic and financial elite preferred by the government. This money is then redistributed along the political preferences determined by mortgage regulations and state subsidies which favour the (preferably childbearing) middle class. This pattern of capital extraction through housing finance works well for the time being, but has its limits in terms of available household savings. These savings could accumulate (on the accounts of a given social class) under the specific conditions of the post-crisis years and recent measures of economic policy, but cannot be seen as a stable resource in the long term in the broader context of a dependent economy (interview 38) and increasingly unequal society.

A further aspect of currently seemingly decreasing international dependency of housing finance is the increasing role of home savings associations - which by definition of their institutional regulation cannot use external resources, and have a stable structure for issuing mortgages based on collected savings. Their position was strengthened in post-crisis years when commercial retail banks fell out of competition, and their more expensive but more stable credit structure became a viable option for households (interview 35). Home savings associations are estimated to currently provide well over $20 \%$ of all mortgages in Hungary (interview 21), and their share is expected to increase. This could potentially become a 
stabilising force in the Hungarian housing finance system - while nevertheless remaining in the framework of a credit- and ownership-based regime.

There is a generally prevailing narrative among housing market actors that there is abundant liquidity that needs to be invested (interviews 8, 20,35). This new pressure for capital investment can also be seen on a European scale, where there is renewed interest to invest capital in the housing markets of the European periphery. This leads to new instances of housing financialisation such as transnational investment funds buying up defaulting mortgage debtors' houses in Spain to create a new rental sector (Fields-Uffer 2016). My interlocutors tended to agree that the issue is currently not one of available resources, rather of finding appropriate channels to invest these resources. Put differently, the issue is how considerations of risk management and market expansion can be balanced.

\subsection{Characteristics of semiperipheral housing finance}

I have previously argued that Hungarian housing finance is fundamentally dependent in its nature. ${ }^{14}$ On the other hand, there are also clear indications that in the years following the crisis there have been attempts to reduce this external dependency and housing finance now relies more on internal (domestic) resources. I do not see these latter developments as contradicting the argument of a broader dependent integration in the global economy, and I argue that this dependent integration also has consequences for how housing finance is generally organised in Hungary. This is true even if for certain, historically specific periods the indications of this are not as clear as they were during the few years of the forex mortgage lending period. In this section, I propose two arguments about what I consider to be fundamental characteristics of semiperipheral housing finance.

\subsubsection{A systematic lack of long-term financial resources ${ }^{15}$}

As described in the previous section, the development of the institutions of the contemporary, credit-based Hungarian housing finance system in the early 2000s was strongly influenced by external pressures and processes of liberalisation on the European scale. The axis of mortgage debt became an important carrier of European-scale dependencies in the period preceding the financial crisis; with much of the surplus of core European economies (specifically of Germany) going into bank lending on the European peripheries (Pósfai et al 2018). One of the most important characteristics of this dependent housing finance model is its volatility, with an impossibility of being able to count on long-term, stable financial resources for housing. The lack of long-term resources can best be grasped through the practice of financial institutions. On the scale of these institutions, the question is usually related to the duration of loans (received and disbursed) and the management of risks relating to differences in the structure of duration on the two sides of managing assets and liabilities. A mortgage loan is by definition long-term (given out to a customer for 15-20 years), which a financial

\footnotetext{
${ }^{14}$ For a more in-depth elaboration of the arguments relating to dependent housing financialisation see: Pósfai, Zs., Gál, Z., Nagy, E. (2018): Financialization and Inequalities: The Uneven Development of the Housing Market on the Eastern Periphery of Europe, in: Inequality and Uneven Development in the Post-Crisis World; eds.: Fadda, S., Tridico, P.; Routledge, pp 167-190.

${ }^{15}$ I will discuss the risk-related aspects of this issue in chapter 5.3.
} 
institution will ideally seek to balance with long-term resources on the assets side. However, in the context of a (semi)peripheral economy such long-term resources are much more difficult to acquire, since investors and other transnational financial actors will be more risk averse, expecting repayment in a much shorter period of time. Furthermore, higher interest rates and higher expectations of profitability also make interest rates systematically higher in (semi)peripheral locations. Various authors have demonstrated that a dependent, semiperipheral position in the global economy leads to the predominance of short-term, impatient finance (Gabor 2012). This cannot be counterbalanced merely by household savings, because income levels usually do not allow for large-scale savings, and domestic financial savings schemes are also often not considered a safe options by those actors that have the capacity to accumulate capital (partly due to the higher volatility of semiperipheral economies more generally).

This context has important consequences for housing finance. Long-term financial resources in housing finance usually come from institutional investors with an interest in longterm, stable, and in exchange less profitable forms of investment (pension funds are a typical example for this). However, since investors are usually expecting higher and faster returns in semiperipheral markets, institutional investors investing in the long term have never been very present in Hungarian housing finance. There is a general recognition among actors of this field that the lack of long-term financial assets is a key obstacle to the development of a less volatile and more affordable system of housing finance in Hungary (interviews 10, 21, 29, 35). This lack of long-term resources was clearly recognised by my interlocutors to be a consequence of the position Hungary takes up in the global economy, and the ensuing greater volatility of domestic financial markets (interview 21). The lack of such resources means that banks refinance long-term lending (mortgages) by constantly revolving short-term resources. Although the linkage between the resource and lending side is not entirely explicit, since assets and liabilities are managed by different institutional divisions within a bank ${ }^{16}$, the constant pressure of refinancing presents a cost and a risk, which financial institutions will systematically transfer to households. In practical terms this results in more expensive and variable interest rate mortgages (as opposed to cheap, fix interest rate mortgages available to western European households).

A further consequence of the broader semiperipheral position is the weak savings capacity of most households. In most countries, the indirect basis for long-term stable sources for housing finance are household savings, through their deposits in banks or through dedicated institutional investors such as pension funds and insurance companies (interviews 37, 21). At the moment, the circle of domestic institutional investors also appears to be broadening in Hungary, and they are, in effect, the main investors in covered bonds and real estate investment trusts (interview 20) - which are both instruments of investment in the housing market recently being supported by the Hungarian National Bank. However, the currently increased savings capacity of a newly emerging Hungarian middle class can by no means by considered stable and calculable in the long term, and is very dependent on the current political and economic environment.

\footnotetext{
16 The exact conditions mortgages will be offered with, as well as sales target numbers are the result of internal negotiations between various divisions in a bank (responsible for risk management, management of assets, strategy and sale, etc) (interviews 21,36). Altogether, it is a highly regulated iteration where individual actors only see specific phases of the process (interview 21).
} 


\subsubsection{Bond-based vs deposit-based forms of housing credit}

In the following I propose an analysis of how various elements of the new housing finance regime unfolding since 2015 in Hungary mutually support each other, in order to illustrate an argument about how the volatility of housing finance in a semiperipheral context is managed by the state and by corporate actors. For this I will draw on a conceptual frame proposed by Blackwell and Kohl in a recent article. In their long-term historical analysis of housing finance systems across Europe, Blackwell and Kohl (2017) identify four different typologies of housing finance, which they attribute to different countries building on the typological analysis of the varieties of (residential) capitalism approach and on corporate finance literature. They identify four typologies of housing finance: direct finance and state finance (outside the banking system), and deposit-based and bond-based mortgage systems (within the banking system), stemming in modes of housing finance developed in the $19^{\text {th }}$ century.

Although I argue with the typological approach, I find this analysis helpful in order to understand various housing finance instruments related to mortgage in a more global and historical perspective. (It is important to note here that the role of mortgages in housing finance could also be questioned - but in a context where this is the absolutely predominant form of housing finance, it is relevant to scrutinise its specificities.) Rather than attributing these housing finance modes to national typologies, I would highlight the argument that these different modes of housing finance are actually present in an intertwined and simultaneous way within a given national housing finance system.

The contemporary Hungarian housing finance system - which is experiencing a drastic increase of activity - relies on a simultaneous push in all segments (or "typologies") identified by Blackwell and Kohl. The current radical increase in mortgage lending is primarily due to the pressure of increased deposits in the accounts of banks, combined with low interest rates. However, this predominantly deposit-based mortgage lending could not function without state subsidies allowing for households to have the necessary downpayment for a mortgage, or without the mobilisation of intra-family resources for the same purpose. As previously argued, the current high level of savings in Hungarian banks is most likely not sustainable in the long term. This brings us back to the initial question of lacking long term financial resources behind Hungarian housing finance.

One of the responses put forward to this issue by the government is recent legislation that is, a central bank decree ${ }^{17}$ - introducing an obligation for financial institutions to cover at least 15\% (and, from November 2018 onwards 20\%) of all issued mortgages with bonds (Grécs 2017). This legislation pushes banks to increase the share of bond-based mortgages in their portfolio and makes them rely more on financial markets. This does not seem necessary at the moment: although mortgage lending is increasing, it is not nearly sufficient as a channel of investment, since the stock of savings in Hungarian financial institutions currently accounts for nearly 20 billion euros, while annual mortgage issuance is only 1.4 billion euros. The new covered bond regulation can thus be seen as a regulatory effort for establishing the channel of Hungarian housing finance to international financial markets for the future.

I see the current coordinated effort of various policy interventions and market pressures as a way of channelling suddenly available abundant capital into the housing market. I argue that rather than historically persistent, nationally based typologies of housing finance, in Hungary (and I would risk to say more generally in semiperipheral economies, but this remains to be

\footnotetext{
17 20/2015. (VI. 29.) MNB rendelet a hitelintézetek forint lejárati összhangjának szabályozásáról; accessible at: https://net.jogtar.hu/jr/gen/hjegy_doc.cgi?docid=A1500020.MNB\&txtreferer=00000003.TXT
} 
investigated) we see consequent, rather volatile cycles of housing finance, in which these different channels of housing finance are mobilised in a combined way. In order to understand how and when these cycles of shifting housing finance emerge, the aspect of macro-scale dependencies, resulting in a lack of long-term resources, needs to be added to the equation.

At a first glance, the currently emerging "domesticated" housing finance system (see previous section) could result in less volatility and external exposure of the Hungarian housing market (or at least will result in the Hungarian National Bank keeping more control over processes of housing finance). However, I see the general possibilities of what instruments and mechanisms of housing finance can develop largely determined by the structural constraints described above. Furthermore, there are two important issues to further investigate. One is the class politics and broader economic interests underlying such a reorganisation of actors of the field of housing finance. It is not incidental that massive reorganisations of beneficiary groups have occurred in recent years in Hungary in sectors of the economy which are spatially fixed such as real estate (Voszka 2013, Király 2016). This new housing finance system clearly benefits a new middle class on the household scale and a circle of actors tied into clientalist networks of the government on the corporate scale (both of these arguments will be developed in the following chapters). Thus, we are witnessing the strengthening of a new economic elite in the financial and real estate sectors through the issue of housing, strongly supported by state intervention.

The other question relates to the sustainability of this system, which largely depends on the "end-resources" it can mobilise. As developed above, currently high levels of savings are not necessarily based on long-term stable sources of capital. Furthermore, with the new minimum requirements on covered bonds and the legislative-financial support the central bank is giving to real estate investment trusts, new investment channels supporting housing financialisation are also developing. If we take the claim seriously that housing finance is increasingly connected to global financial markets (Fernandez-Aalbers 2016), it seems reasonable to search for this linkage in the new, nationalised regime of housing finance as well. To uncover these linkages would mean that we have to understand the current shift towards domestic financial sources in a broader perspective, investigating further layers behind the apparent break with international dependency in housing finance. This question draws up further research avenues relating to, for instance, how domestic banks and institutional investors are capitalised from financial markets.

It is interesting to disentangle how the specific juncture of global relations of dependency and national institutional structures also determines which actors can enter the Hungarian housing market. The combination of capital available through conditions of impatient finance (with high interest rates and short durations), invested by international actors in a volatile way; of the questionable sustainability of domestic savings; and of a lack of political will to engage in or support institutions that would manage housing in a durable way leads to a situation where the Hungarian housing market is necessarily volatile, and the only form of housing that can structurally easily emerge is that of individual homeownership (interviews 6, 21, 37). This context also determines that banks become central actors of the housing market, acting as principal intermediators towards both households and economic actors wishing to enter the housing market. 


\subsection{Uneven patterns of mortgage lending on the national scale ${ }^{18}$}

If we investigate processes of housing financialisation through the conceptual lens of uneven development, the key instance to look for is that of capital extraction from the peripheries to the cores on various scales. Previously, I have demonstrated how the dependent nature of housing finance creates the mechanisms for capital extraction on a transnational scale, now I will consider this process on a national and subnational scale. After giving a spatial analysis of mortgage lending (as the dominant instrument of housing finance) and the processes of uneven development it carries, I will propose an analysis of how mortgages and the familybased housing subsidy for access to homeownership complement and reinforce each other.

\subsubsection{Overinclusion and exclusion through individual mortgages}

The patterns of uneven development of the housing market on a national scale can best be grasped through the patterns of homogenisation and differentiation in mortgage lending. In relation to mortgages, in the literature of financial geography this dual pattern is mostly described with the terms of financial (over)inclusion and exclusion. Both notions refer to dialectical processes where first there is a social and spatial homogenisation or diffusion of capital investment, which however opens channels for capital extraction, and often results in further differentiation - or new social and spatial exclusions. I will describe how this process practically unfolds in the case of mortgages in Hungary.

As already stated, mortgages are only used in a relatively small proportion of all housing transactions. Exact data about the ratio of mortgage penetration is difficult to access, but based on narrative evidence from the expert interviews I have conducted, it is currently around $30 \%$, with important spatial differences (interviews 13, 21). The typical spatial pattern that emerges is that in areas that are economically less well-off, mortgages will be used to a higher extent. For example, in one of the most expensive new housing developments in Budapest, only about $20 \%$ of the buyers use a mortgage (interview 28), while this ratio is around $60-70 \%$ in the eastern suburbs of the capital or in a peripheral / non-industrial county seat in the east of the country (interviews 16,34). The ratio of mortgage penetration will be even lower if we consider the totality of housing transactions (agents currently cover around $50 \%$ of all housing transactions), because clients of real estate agents will be more likely to use a mortgage since the reason for seeking the services of an agent is often to help orientation in the increasingly bureaucratic and complex system of acquiring a mortgage loan. On the other hand, contracting mortgages is typically the more profitable business branch for a real estate agent, they will thus encourage their clients to use this service as well. (Furthermore, this service is technically free of charge for the client, since fees for the agent after the contracted mortgage will be payed by the bank.)

Real estate and credit agents reported accompanying around 35\% of their housing transactions with mortgages at the peak of the credit boom before the crisis (which decreased to nearly zero during the crisis). Currently we are already approaching this figure, but the

\footnotetext{
${ }^{18}$ For more statistical analysis and a different elaboration of some of the arguments presented in this subchapter see the following two articles:

Pósfai, Zs, Nagy, G (2017): Crisis and the reproduction of core-periphery relations on the Hungarian housing market; European Spatial Research and Policy, 24(2), pp. 19-40.

Pósfai, Zs, Jelinek, Cs (2018): Reproducing socio-spatial unevenness through the institutional logic of dual housing policies in Hungary. In: Lang, T., Görmar, F. (eds.): Local and Regional Development in Times of Polarisation: Re-thinking spatial policies in Europe. Palgrave, series: New Geographies of Europe; forthcoming.
} 
momentum of all actors involved in pushing for more mortgages does not seem to be slowing down. Thus, the current situation will probably lead to more mortgage penetration than was the case before the crisis (which would make sense considering lower interest rates, more domestic savings and more generous state subsidies as well).

In spite of the fact that mortgages are being used only in the minority of housing transactions, and a significant part of acquisitions is conducted without the involvement of corporate actors (agents or banks) in the process, I argue that investigating spatial patterns of mortgage lending is nevertheless highly relevant to understanding uneven development on the Hungarian housing market. It is the dominant channel of institutionalised housing finance, and one that - unlike transfers within families and individual savings - can be linked to enterprises operating in the field. Furthermore, mortgage lending captures the extractive mechanisms at play in the infrastructure of housing finance: from peripheries to cores, from households to international financial actors. Since the majority of mortgages is issued by financial institutions operating on an international (but minimum national) scale, there is always a pattern of extracting capital from the peripheries to the cores on various scales. The weight and nature of this capital extraction is technically translated to the conditions a mortgage is issued with - and it is here that systematically higher interest rates and shorter loan durations on the periphery become important. We have seen how the inequalities of the conditions of mortgage lending and the institutional and ownership structure of financial institutions has led to a dependent model of housing financialisation on a European scale. Very similar patterns play out on a subnational scale as well. This unevenness displays clear spatial patterns, both in terms of the penetration and of the structure of mortgages issued in various places across the country.

\subsubsection{The ebb and flow of overinclusion-exclusion running up to the crisis}

Mortgage lending since 2000 in Hungary is characterised by subsequent waves of financial overinclusion and exclusion. We have previously identified these processes in the following way (Pósfai-Jelinek 2018): "The former is a pattern of including social and geographical entities which were previously excluded from financial services. However, in the mid-and long term, this inclusion also creates the vehicle which allows for the extraction of resources from these more peripheral/ marginal spaces and social groups. Consequently, a new wave of spatial (known as redlining) and social exclusion follows, as a strategy of risk management for the stakeholders involved in the process. The geography of overinclusion and redlining largely overlap (Aalbers 2008)."

In the history of mortgage lending in Hungary, this dual pattern can clearly be traced. In the years of the mortgage boom between 2000 and 2008, the social and geographical scope of households included in mortgage lending was continuously broadened. This meant that economically more and more unstable households and geographical areas could also be included in the regime of mortgages (and thus could access homeownership). This homogenisation (in the terminology linked to uneven development) of credit lending practices thus lead to patterns of social and geographical overinclusion, which accelerated after 2004 (interview 7).

As an indication of the accelerating process of social overinclusion; according to an analysis recently produced by the Hungarian National Bank, households acquiring mortgages in the forex-mortgage period (2004-2008) generally had lower income and education levels than debtors of previous years. Furthermore, the disbursed loans also had riskier structures (such as over 90\% loan-to-value ratios), and there was an increasing share of consumer loans as opposed to mortgage loans (Dancsik et al. 2015). Consumer loans, which are always issued 
with more relaxed criteria and at higher interest rates (being more profitable and more risky for financial institutions), were particularly prone to default after the crisis - showing how a stretched mortgage lending regime contributes to the production of new inequalities in the midterm (Pósfai-Nagy 2017). As a result of these patterns of expanding household lending, $40 \%$ of the loans which were still problematic in 2017 were issued in the course of 2007-2008 (interview 29). Real estate and credit agents clearly recall how it got easier and easier in the years running up to the crisis to acquire a mortgage (interviews $7,17,24,32$ ), how a "worse" household portfolio was gradually included, especially through the expansion of consumer loans (interviews 18,24), and also have first-hand experiences of how these situations then often led to default in a few years' time (interviews 7,25).

Beyond social overinclusion, I claim that processes on the Hungarian housing market before the crisis also reflected a pattern of spatial overinclusion (Aalbers 2011, Dymski 2009). This means that in their search for new spatial fixes (similarly to what happened on a European scale with the opening of Central European markets), financial institutions broadened their geographical reach to perviously unserved areas. Banks were opening a growing number of branch offices across the country, and mortgages were distributed to smaller settlements as well. An analysis of statistical data provided by a dominant bank in mortgage lending (which has the widest spatial scope among large commercial banks) about the distribution of their yearly new mortgage issuance shows this spatial deconcentration in the years preceding the crisis (see Figure 4). This is especially true if we analyse the data on a regional scale: by 2007 the total value of allocated mortgages was almost the same among the five big geographical regions defined by the bank. Investigating along a different spatial division, according to settlement categories, this spread-out is less even but nevertheless clearly present. In Fig.4. I show the spatial concentration of new mortgages in a given year, along three different spatial divisions. The regions and settlement categories correspond to those used by the bank in question; the five regions are large geographical units covering the whole country, while settlement categories are three hierarchical units according to settlement size (with the first category covering county seats and main cities, and the third category meaning smaller settlements).

One of the interesting points is that in 2002, when the state-subsidised mortgage program (in which this bank was particularly heavily involved) gained momentum, the concentration among settlement categories sharply increased. This was due to the fact that in these early years, mortgage lending was strongly concentrated in larger cities. 2004 - the introduction of forex mortgages - brought the turning point when spatial concentration among settlement categories decreased. That is, this structure of mortgage lending, which was known for becoming more and more inclusive (or risky) in social terms was also broader in its spatial scope. After 2008, together with a drastic drop in the volume of mortgages, spatial concentration also increased. Capital was concentrated to core housing markets, draining capital available for housing purposes on the peripheries. (This spatial concentration was also a social concentration, with very few households having - or wanting, for that matter - access to a mortgage.) The fact that this spatial concentration could happen so fast demonstrates how peripheries were more prone to crisis also on a subnational scale. This vulnerability is also apparent in important drops in house prices and transaction numbers in more peripheral spaces (understood in an embedded and functional, and not in a categorical sense - see eg. Nitz 1997). While core housing markets (Budapest and other prosperous cities) experienced less important drops in house prices, in more peripheral areas (understood in a broad sense; also including larger cities in worse economic positions) house prices dropped by around 50\% between 2008 and 2013 (Pósfai-Nagy 2017). Since 2012, we see a relative stabilisation in the overall spatial concentration of issued mortgage loans. 


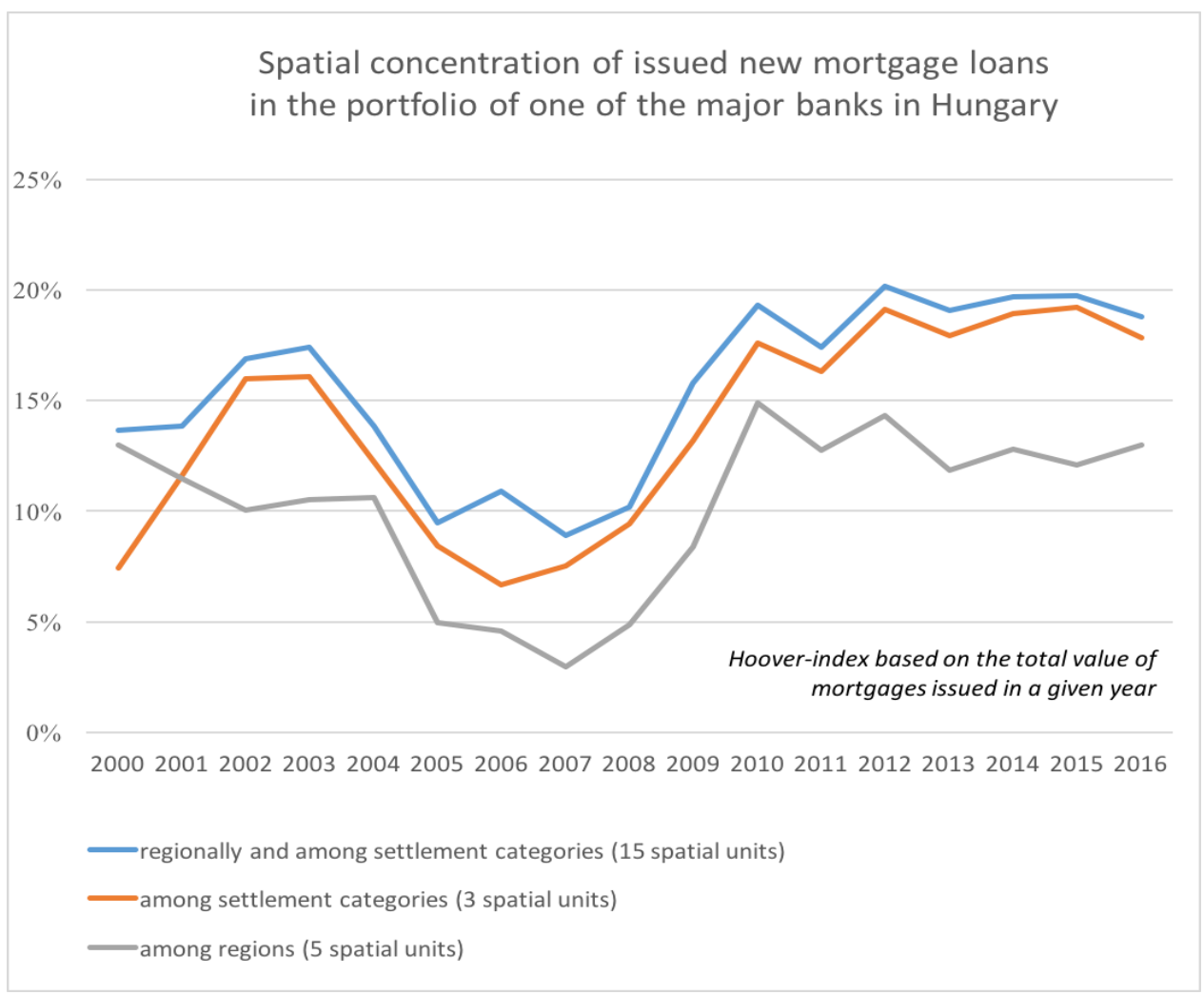

Figure 4. Spatial concentration of issued new mortgage loans $2000-2016^{19}$. Source: data of one of the major banks.

Looking into the geographical patterns of mortgage lending, we can observe a growing share of mortgages disbursed in secondary cities throughout the country in the years preceding the crisis (see Figure 5). The share of smaller settlements (third settlement category) in new mortgages was also somewhat increasing in these years; although this phenomenon was most pronounced in the Southern Transdanubian region, where this was most likely a result of a boom of new purchases of secondary homes and real estate for investment purposes on the southern shores of the lake Balaton. The investment boom in this area triggered rapid price increases, which also affected small settlements a bit further from the shore - this would give a further explanation for the increasing stock of mortgages.

However, the tendency of spatially broadening mortgage lending before the crisis can be observed beyond the very obvious case of the Southern Transdanubian region as well. This is particularly true if we consider the number of new mortgage contracts (and not the volume of money being lent): although large cities are always dominant in terms of total capital invested in mortgages due to larger average loan values, small settlements actually received a relatively higher share of all disbursed mortgages in the years preceding the crisis compared to their demographic weight. Thus, although in terms of the amount of capital invested, smaller settlements are not significant, there is still a clear spatial expansion in the number of households included in a mortgage lending regime.

\footnotetext{
${ }^{19}$ The Hooover index describes spatial disparities of any given indicator. The value of the index shows how much of the given indicator (in this case, the stock of issued new mortgages per year) should be regrouped among the investigated spatial units to create a spatially even distribution.
} 
Share of yearly mortgage allocations [FT - volume] 2000

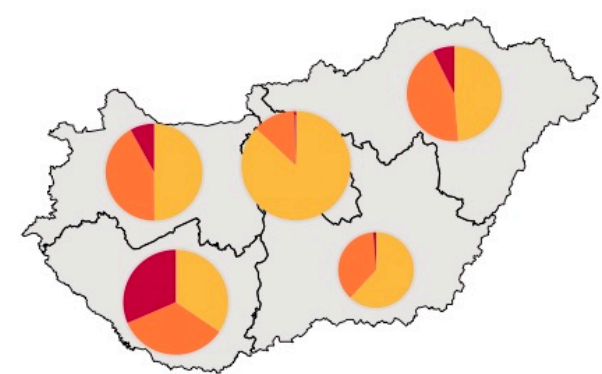

Share of yearly mortgage allocations [FT - volume] 2008

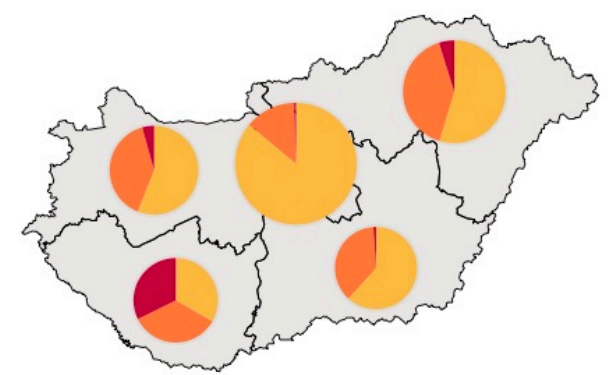

Share of yearly mortgage allocations [FT - volume] 2013

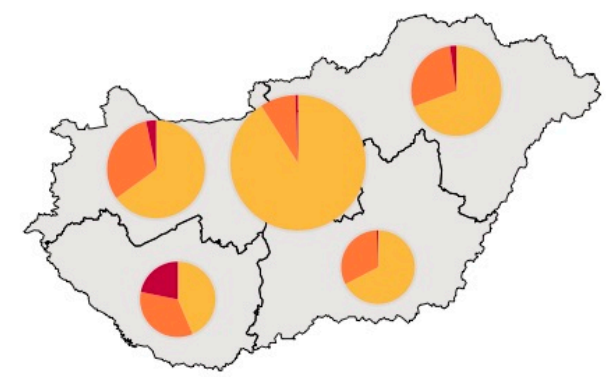

Share of mortgage allocations [FT - volume] - 2016

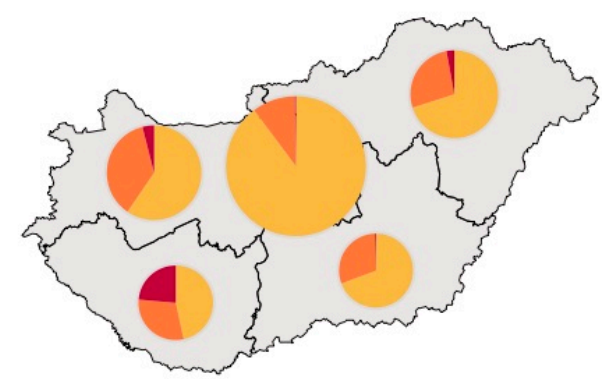

Share of yearly mortgage allocations [nr of contracts] 2000

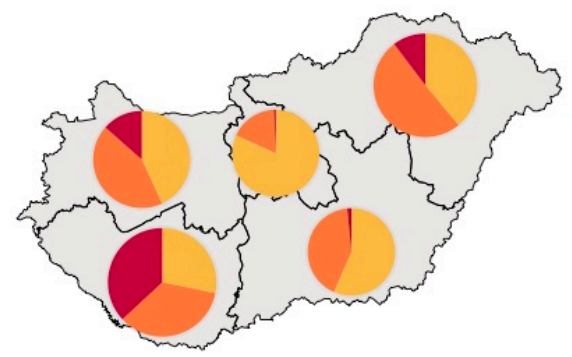

Large city

City

Distribution of yearly mortgage issuance $10,00 \%$ \begin{tabular}{|r|}
\hline \\
$\mid 30,00 \%$ \\
\hline $40,00 \%$ \\
\hline
\end{tabular} $50,00 \%$ Share of yearly mortgage allocations [nr of contracts] 2008

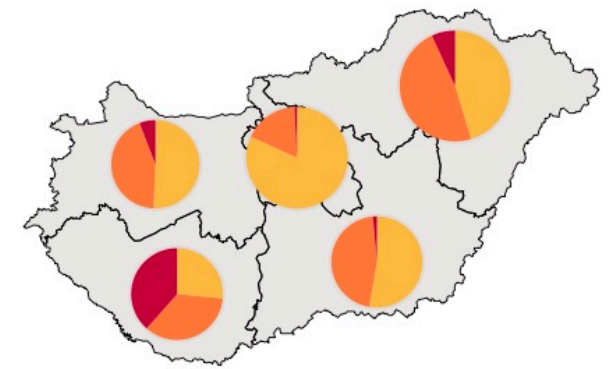

Share of yearly mortgage allocations [nr of contracts] 2013

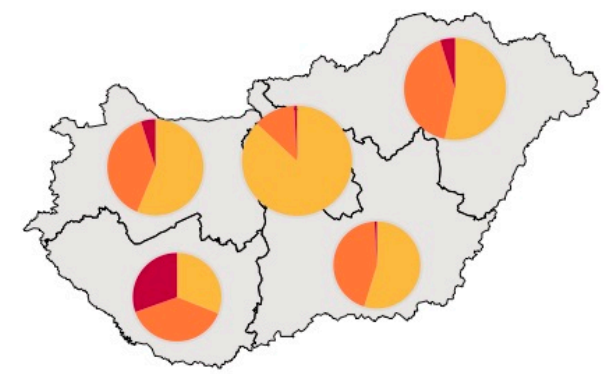

Share of mortgage allocations [nr of contracts] - 2016

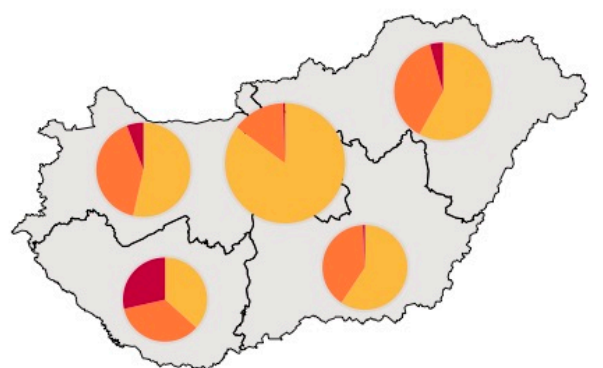

Figure 5. The spatial distribution of new mortgages in a given year (in terms of capital and number of contracts ${ }^{20}$ ); Source: data of one of the major banks.

${ }^{20}$ The data used is only relative data, representing the spatial distribution of new mortgages in a given year. The maps do not in any way represent the totel number of new contracts or the absolute volume of mortgages. 
While the share of new mortgages disbursed in the different regions is rather evenly distributed (which could also be due to internal corporate strategies and pressures), there are systematic differences in the average value of loans according to settlement size. This can be explained by differences in house prices and by lending policies discussed above, which lead to lower loan-to-value ratios in smaller settlements.

It is important to note that this analysis excludes consumer loans, which were often used for housing purposes and were more prevalent in smaller settlements, where banks do not necessarily accept real estate as collateral (interview 32). Thus, the spatial diffusion of household credit was in reality even wider than what this dataset shows.

Broadening social and spatial inclusion in such a regime of debt and dependent housing financialisation became problematic when the crisis hit. In Hungary, a crisis of indebtedness and new geographies of exclusion rapidly emerged on the housing market after 2008. Households started to meet severe difficulties in repaying their mortgages (for reasons detailed in the previous section), and the indebtedness of Hungarian households is a significant issue until today. The new geographies of exclusion were characterised by significantly dropping house prices and inactive housing markets, leaving indebted households with negative equity and unsellable property - demonstrating how peripheries are more vulnerable to crisis on a subnational scale as well (Pósfai-Nagy 2017).

I argue that the spaces of financial overinclusion and exclusion overlap, and that this sheds light on how mechanisms of capital extraction function within the uneven structure of the housing market. The areas that experienced the most important and fastest inflow of mortgages, and consequently rapidly rising house prices in the years before the crisis were the ones that were most severely affected when the crisis hit (interviews 12,36). Typically, these were not the most prosperous housing markets (which typically had higher house prices in a stable way, independently from the availability of mortgages), and also received relatively less mortgages compared to the number of housing transactions. Rapid increases in house prices are characteristic of areas which had relatively lower prices and then experienced a significant influx of mortgages (or other forms of investment in housing, but before the crisis this typically meant a mortgage), which quickly drove prices up. In contrast, the places that experienced the quickest booms before the crisis then also faced the most severe busts (Pósfai-Nagy 2017): in places where the majority of properties were financed with a mortgage, there was no more demand for housing when credit lines dried up in 2008. However, there was an increasing stock of housing up for sale, as those mortgage debtors who were meeting difficulties to continue their payments were trying to sell their properties. This lead to frozen housing markets and swiftly dropping prices in these areas "intoxicated by forex mortgages" (interview 17) - which were typically agglomeration areas I worse-off geographical regions. This led to increasing unevenness on the housing market, which was further deepened in the period of relaunched mortgage lending.

\subsubsection{A new selectivity socially and spatially following the crisis}

Currently, there is a new upswing of housing market activity and the number of disbursed mortgages is constantly on the rise. This is apparent from statistics published by the central bank, is reported by market actors and is also pushed for in government communication. The current market pressure - which is called "finding a spatial fix for surplus capital" on a theoretical level and "abundant liquidity in the financial sector" on the level of managers - is articulated as increasing target numbers for mortgage sales on the scale of the front-desk 
operators of this system; that is, bank and credit agents (interview 18,34). These agents are put under pressure by their managers to meet increasing target numbers - while also having to consider legislative and corporate regulations about stricter credit scoring and real estate valuation. Driven by concerns to avoid the overinclusive crediting of the pre-crisis years (and held to this "concern" both by legislation and by internal rules of corporate risk management), financial institutions are now being much more selective both socially and spatially with the mortgages they issue (interviews 10,13,34). The result is an increasing amount of mortgages being injected in the market in a socially and spatially selective way. These two kinds of selectivity are translated to firm-level practices by the two main mechanisms of evaluation in the process of deciding about a mortgage loan: client scoring and real estate / collateral valuation. The bank's decision about the conditions of the issued mortgage (and whether they issue it at all) will be based on a combination of these evaluations.

Social selectivity is articulated under practices of client scoring systems of financial institutions (interview 36). A potential client is evaluated based on completely personal characteristics (such as age and family status), and also in terms of income and employment status, as well as previous mortgage history. Concerning the latter, inclusion on the list of mortgage debtors (which is a database compiled as a combined effort of the most important retail banks, and individuals who have a currently active loan are included in it) with a nonperforming loan results in automatic exclusion. The combination of stricter regulation concerning maximum loan-to-value ratios of issued mortgages (currently usually around 70\%) and rising house prices also means that households now need to have quite significant savings in order to make the necessary downpayment. All of these factors contribute to a quite diminished pool of potential "good" mortgage debtors, for whom banks are in competition (interview 10). Those, however, who meet the criteria can now receive mortgages under very favourable conditions. For many banks this is seen as a possibility to improve the quality of their clientele: through a series of government-initiated measures and the recently accelerated packaged sale of remaining non-performing mortgages, banks now have the possibility to clear their accounts and reopen their mortgage lending focusing on financially more stable clients. Several of my interlocutors formulated how this new wave of mortgage lending is predominantly for the (waged) middle class (interviews 10, 17, 31, 34).

The other main aspect in the decision about a mortgage loan relates to the real estate serving as collateral. It is an open secret that all financial institutions have "settlement rating lists" - that is, lists where they categorise every settlement in the country according to their riskiness / desirability in terms of mortgage lending (interviews 13,36). This practice is called redlining in the theoretical literature (Aalbers 2008), and has become much stricter in Hungary following the crisis. Before the crisis, banks were financing "whatever and everything"; now there is a lot of caution taken and local housing markets as well as the quality of the real estate are always assessed (interview 36). The settlement rating categories are generally constructed based on statistics about housing transactions and prices, as well as mortgage requests coming from the given settlement (in order to assess potential market activity), or data on employment, infrastructure and demographics. Economic activity and anticipated changes in this (such as branch openings of manufacturing companies) are often taken into consideration with particular weight. The rating will vary among financial institutions according to the spatial policies they employ, their target groups and "appetite for risk" (interview 10), and will sometimes be spatially quite nuanced, with particular neighbourhoods within given cities, or adjacent agglomeration towns receiving mortgages at different loan-to-value ratios (interviews $16,32)$. Settlements that fall into riskier categories will either receive mortgages with worse conditions (typically lower loan-to-value ratios and higher interest rates), or will not receive a mortgage at all (interviews 10, 32, 34). Small settlements with low numbers of housing 
transactions, as well as agglomeration areas which are legislatively not residential (zártkert which are very often spaces of displacement from inner-city areas), or farms which are typical of the Great Plains area (tanya) are typically redlined areas (interviews 24, 25). This mechanism is a crucial element of uneven development on the housing market, because it means that economically better-off areas will be leveraged with abundant cheap credit, while in economically more difficult places this leverage will be inaccessible or much more expensive. Yet again, this is the same mechanism of uneven development which we have observed on an international scale - translated subnationally.

A map edited based on such a "settlement rating list" of one of the stricter banks (different than the one previous data referred to) shows that the majority of Hungarian settlements are actually redlined (although this represents a smaller share in terms of population) (Figure 6). Redlining has generally become much stricter since the crisis (interview 6). As a result, mortgage lending is very concentrated in spatial terms.

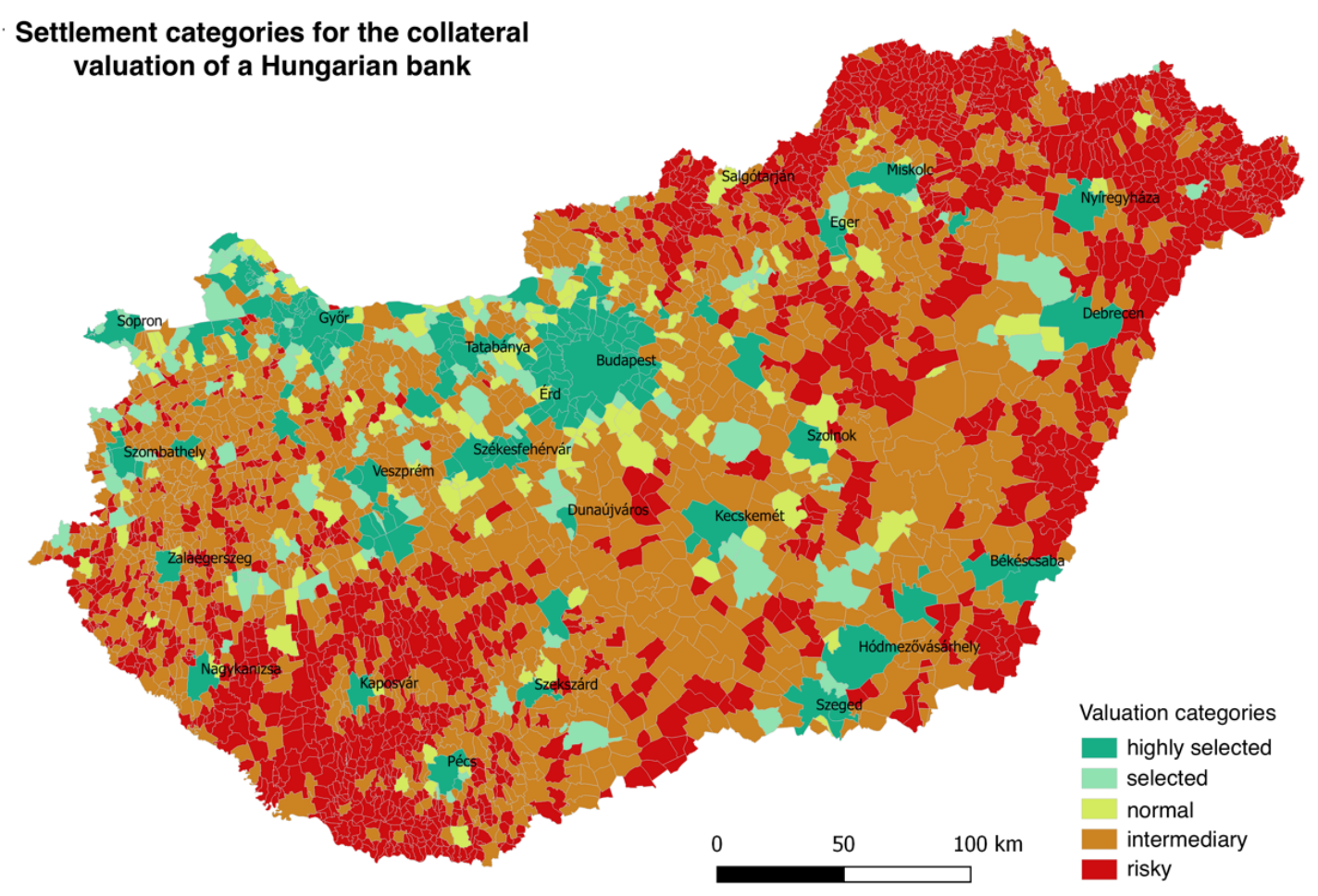

Figure 6. Settlement categories for collateral valuation. Source: one of the major banks.

When comparing the two main pillars of evaluation a financial institution employs when deciding about issuing a mortgage - that is, client scoring and collateral evaluation - the current tendency is to give more importance to client scoring (interview 36). This is due to post-crisis experiences of the difficulties (and legislative constraints) to sell real estate serving as collateral for a non-performing loan. Furthermore, banks do not wish to manage real estate that they could potentially be stuck with - thus, testing the capacity of payment of the client and ensuring a stable cash-flow from monthly instalments has become the priority (interview 12). In this sense, the new exclusions from housing finance can, perhaps, be better grasped in social than in spatial terms - but the effects of the two strengthen each other. Stricter client scoring criteria and stricter redlining policies mean that currently mortgage lending is only accessible to a more restricted circle of clients. This coincides with the political ambition of the 
government to avoid a similar crisis as forex mortgages had resulted in. However, since other channels of access to housing remain very precarious, this means many households are technically excluded from access to housing.

Coming back to the previous dataset (see Figure 5), this concentration of post-crisis mortgage lending is also apparent in the way Budapest has gained absolute dominance in the share of new mortgages after the crisis (even within the portfolio of a bank that has a broad spatial approach). In 2016, nearly $40 \%$ of all capital disbursed through mortgages of this bank was invested in Budapest, which is more than twice of what the city's demographic weight would imply. This is mainly due to very high house prices in the capital (the difference in house prices between the capital city and other cities has increased in recent years - cf. Pósfai-Nagy 2017) — and, in the self-reinforcing logic of capital investment, the overrepresentation in terms of new mortgages will contribute to further increasing house prices. Rapid house price increases were driven by investor-buyers in the first years following the crisis. They had appeared on the market before mortgages became widely available again, and started buying in a spatially very selective way (see chapter 3.4 - "Specific localities of investment"), driving prices up in these locations (interview 12). Since 2015/ 2016 (with mortgages becoming widely available again), house price increases are reported much more in cities in eastern regions of the country (interview 19) - demonstrating how less prosperous housing markets are more reliant on credit.

In terms of the number of new issued contracts (which shows the number of new households being included in a financialised housing regime), it is rather the county seats which are overrepresented compared to their population size in the post-crisis years, while smaller settlements receive proportionally fewer contracts (see Figure 5). To sum up, we can currently observe a concentration of mortgage lending to Budapest on the national scale, and to local urban centres on the regional scale - with many financial institutions actually not giving mortgages in towns smaller than county seats (interview 17). This spatial selectivity drives house prices up in specific areas, while not contributing to a generally better access to housing. The stronger selectivity would not be an issue in itself - however, combined with the fact that other means of housing finance available to households are very limited (limitations of the family-based subsidy CSOK will be discussed later on), exclusion from mortgages also means increasing inequalities on the Hungarian housing market.

\subsubsection{Mortgage penetration and housing needs}

As we have argued elsewhere (Pósfai-Jelinek 2018): “A credit-based housing finance system necessarily benefits more to households that have a higher wealth and income status. In their case a mortgage can act as an effective leverage in a process of individual wealth accumulation. This becomes particularly important in the context of a society where inheritance and inter-generational transfers play a crucial role in access to housing. Credit lending policies of financial institutions are constructed in a way to favor clients of more reliable economic indicators, thus better off households will receive credit with much better underwriting criteria. Policy instruments focusing on subsidizing the cost of credit are thus disproportionally channeled to middle class households (Hegedüs 2006) and to economically more prosperous geographical areas."

There is an inherent contradiction in the way mortgage lending can facilitate access to housing. The emerging pattern is that it is predominantly households without other means of accessing housing that take mortgages. The use of mortgages as a leverage for investment is 
quite rare (some examples were reported in interviews 24, 34): those who acquire for investment purposes typically use their own capital, and households that can manage to acquire housing without a loan will systematically do so (interview 13). This means that a lot of accumulated household savings are being directly channeled into housing (interview 15, 18). As a result, the majority of housing transactions are still done without a mortgage, and mortgage penetration shows significant differences spatially and in terms of the target groups of different economic actors.

Accounts of actors of the field shed light on how there is a balance to be navigated between areas preferred by financial institutions for mortgage lending and those that are financially accessible to households who would actually need the mortgages. From the perspective of households the main aspects to consider are those of housing affordability and access to employment, while developers and financial institutions will consider profitability and risk management. As a result, the highest ratio of mortgage penetration (among all transactions they manage) was reported by my interlocutors in the suburban area of Budapest - which is considered to be safe by banks, is profitable enough for developers and relatively accessible for households (interview 12, 16). Secondary cities also have a high usage of mortgages, relatively higher than in Budapest (interview 13). The lowest mortgage penetration among clients was reported by a high-end developer building in one of the prime locations of Budapest. The majority of his customers are rather those, who are looking for a safer investment for their capital (interview 28). Households taking mortgages are typically those who acquire property for solving their own housing needs (interview 14). The common pattern on the contemporary Hungarian mortgage market is that households with less economic means will represent the most important demand for mortgages (and with the highest loan-to-value ratios) (interview 32). For instance, households typically use mortgages for their transactions to a larger extent in cities of the eastern regions of the country than in the western part of the country. This can be directly related to more savings and more investment-oriented acquisitions in the latter.

The inherent contradiction in this pattern is that households in a relatively worse economic situation and living in a location with relatively weaker economic performance will only have access to mortgages with worse conditions. That is, in the end, they will pay a higher price and carry more risk when taking a mortgage - and these households will proportionately take mortgages more frequently than their economically better-off counterparts. Another relating tension lies between the interests of financial institutions on the one hand, which are facing the contradiction of being under pressure of abundant liquidity to disburse more mortgages, but to do so only to a more carefully selected (and thus narrower) circle of clients; and household needs for a mortgage on the other hand. Although most financial institutions claim that they serve all clients who come to them for a mortgage (although not under the same terms interview 21,39), credit agents underline their role in managing to find the adequate financial institution willing to give a mortgage to a more "problematic" client (interviews 25, 34).

\section{The complementarity of mortgages and the family-based housing subsidy}

The polarising spatial effects of mortgage lending are reinforced by the family-based housing subsidy allocated according to the number of children in a family (previously called "szociálpolitikai kedvezmény" or szocpol (meaning "social policy benefit"), now called "családok otthonteremtési kedvezménye", or CSOK for short (meaning "home-establishing benefit to families")). This subsidy is currently the most significant housing-related element in the Hungarian state budget. It is a non-refundable subsidy that households can acquire for the construction of new housing or purchasing existing housing. There is a non-linear scale 
strongly benefiting those who buy / construct new housing, and who have at least three children. (In the latter case a subsidised mortgage is also available in addition to the subsidy.) CSOK is practically a continuation of the very similar previous policy instrument (szocpol) which had been in effect since the 1990s (with a brief interruption after 2009). However, in its current, revised form it does not carry any "social" (needs-based) criteria as the previous one did. At the same time, however, it does contain minimum requirements concerning income level and employment, as well as minimum infrastructural conditions of the property to be bought. Practically, this means that low-income households are systematically excluded from this subsidy (interviews 31, 34; Pósfai-Jelinek 2018). Analysing responses from my interlocutors (especially real estate and credit agents operating in secondary cities) about the proportion of their customers using CSOK and mortgages, the codependency of these different instruments of housing finance clearly emerges (Pósfai-Jelinek 2018).

Potential mortgage clients who struggle to meet criteria relating to necessary downpayment will very often use the family-based housing subsidy (CSOK) for this purpose. This has been made possible by changes in bank policies in the course of 2017, realising that for many of their potential clients this was the only way they could acquire a mortgage (interview 25), For some banks, there is even an internal policy to not accept requests for filing CSOK without a mortgage. Banks are charged to act as the front-desk operators of this state subsidy - which is obviously only worthwhile for them in business terms if they can also sell a mortgage together with it (interview 31). Since CSOK also gives the possibility to promise future children and thus elevate the amount of the subsidy one can receive, many families that are struggling to have enough money for the downpayment will engage themselves to have three children within the 10 years deadline in order to receive the maximum amount of the subsidy. This is, however, a serious risk (in the case of not "accomplishing" the promised children the subsidy must by payed back with interests), that certain actors estimate will become a significant problem in the future (interview 16). Nevertheless, there are of course some cases of banks issuing the subsidy without a mortgage to go with it. Currently, about $80 \%$ of households acquiring $C S O K$ also take a mortgage (interview 26). However, the subsidy is very rarely sufficient in itself to be able to buy housing. It can only be used in this way in the most peripheral places with extremely low house prices. Otherwise, households either have to have savings, or be able to take a mortgage (or preferably both). In economically less well-off cities, there is a systematically higher proportion of housing acquisitions happening with the use of CSOK and with a mortgage as well - in one of the northeastern county seats in a relatively difficult economic situation for instance, $80 \%$ of the customers of a credit agent were using this subsidy (interview 32), while in one of the western, more prosperous county seats this proportion was only around $10 \%$ (interview 24 ).

Data from the large bank already analysed above also shows how patterns of distributing the family-based housing subsidy and mortgages correlate (see Figure 7). On the figures below we can see how the number of new mortgage contracts and the number of new CSOK allocations in 2016 in a given geographical area are very similar - although CSOK allocations are more important in smaller settlements, showing how these are the places where this subsidy can be used without a mortgage. If we compare the volume of mortgages and the volume of CSOK allocations in the same year, smaller settlements have a more important weight in the latter, due to larger average loans in bigger cities. The number of allocated mortgages and family-based housing subsidies moves together throughout the period between 2000 and 2016 (for the whole dataset I had access to). However, in the years before the crisis, there was a tendency that less prosperous regions - dominantly the northeastern region, and to some extent, the southwestern region - stood out by receiving a higher share of the family-based housing subsidy (szocpol) than of mortgages. Thus, during this period there was a significant 
part of households who could acquire housing without a mortgage, only with the help of szocpol. Furthermore, in these regions there was a systematically higher share of the smallest settlements receiving the family based housing subsidy than elsewhere. The weight of the northeastern region in szocpol allocations was generally much higher than that of other regions. This correlates with lower housing prices in this region and with accounts of how a particular "business branch" developed of building houses for or selling flats to low-income families who could acquire szocpol but had no other savings (interview 31 ). These often meant low-quality or segregated housing.

Szocpol was stopped in 2009 (further reinforcing the general housing market freeze resulting from the crisis), and until 2015 there were only smaller public policy instruments relating to subsidising mortgages for quite specific target groups, (such as young couples with a certain socio-economic status) (interview 21). This is reflected by a drastic shift in housing-related public subsidies issued by the bank in question: from 2010 to 2015 there was a massive concentration to Budapest and to a few larger cities. In 2015 the reformulated/ rebranded version of szocpol, called CSOK was introduced. The spatial pattern of CSOK distrubution shows a strong correlation with mortgage distribution, with secondary cities receiving a relatively higher share.
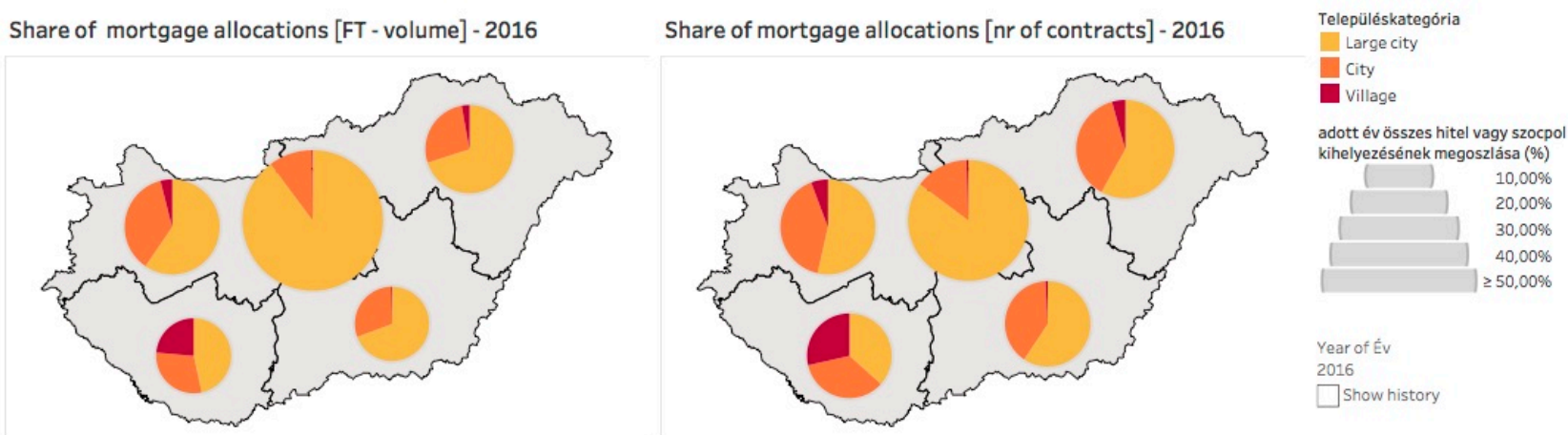

Share of szocpol / CSOK allocations [FT] - 2016

Share of szocpol / CSOK allocations [nr of househ.] - 2016
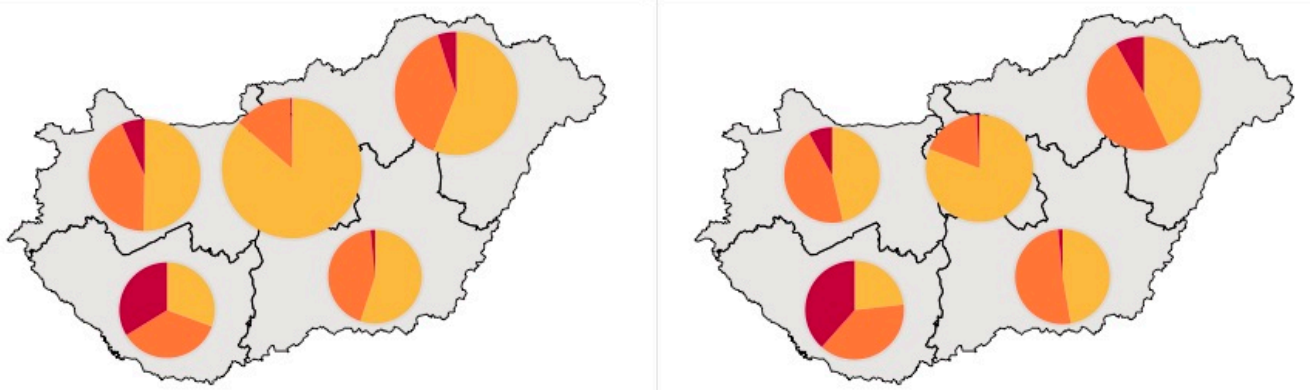

Figure 7. Spatial correspondence of mortgage lending and the family-based housing subsidy (Share of distributed new mortgages and new subsidies in a given year).

Source: data from one of the major banks.

The combined effects of mortgage lending and state subsidies are reflected in specific spatialities on a finer scale as well. These locally articulated mechanisms of uneven development through the combination of state subsidies and mortgages will be discussed in the following section. 


\subsection{Localities of investment and disinvestment}

In this section I will reflect on spatialities of housing-related investment (beyond that of mortgage lending), which articulate uneven development on the housing market on a local scale. Although I will not analyse shifts in the economic situation of various cities, I would nevertheless like to highlight that many of my interlocutors underlined the fact that spatial characteristics of the housing market are often very localised, and are very dependent on the development of the local economy (interviews 12, 13, 15, 25). In the following, I will first of all outline a rough spatial structure of cores and peripheries which emerges from the analysis presented in the previous section, then I will reflect on the effects project loans and individual investment (which are two important channels of investment in housing beyond mortgage loans) have on particular housing markets.

\subsubsection{Embedded cores and peripheries}

I identify "core" housing markets as those which are the preferred spaces of investment for economic actors; where house prices are systematically the highest, where the majority of new constructions take place, and which are the target areas of those who acquire housing for investment purposes. Geographically speaking, these areas are mainly the inner-city neighbourhoods of Budapest and some of the other larger cities that either have significant industry (such as Győr and Kecskemét, which have car manufacturing industries) or larger universities (such as Szeged or Debrecen). In these areas, investment in housing happens rather independently from state intervention, although the latter can definitely give a further push. Since these housing markets are characterised by the dominance of acquisitions for investment purposes of individuals seeking to channel their savings in more profitable fixed forms, the penetration of mortgages is lower (interviews 18,28), and the family-based housing subsidy also has a quite insignificant role (since house prices are high compared to the amount of the subsidy). These are the only housing markets that are really considered to be "stable" by representatives of the industry (interview 6).

"Peripheral" housing markets can be understood on various scales. In a more absolute sense, we can think of smaller settlements in geographically remote and/ or economically disadvantaged areas. These places typically do not appear on the housing "market", since transaction levels are very low and transactions or new constructions are typically conducted by households themselves, without the involvement of economic actors. Such settlements can be affected by particular housing-related interventions, such as the family-based housing subsidy (during the period when there was no criteria relating to income level and households could acquire very cheap housing by these means); or by the most expansive phase of mortgage lending in the last years before the crisis (interview 31). However, access to housing in these places is often driven by displacement from elsewhere, by the rigidity of intergenerational family trajectories (inheriting unsellable property, for example), or by the lack of financial means to have other options. After the crisis, these peripheral places were increasingly affected by a geography of redlining by financial institutions. In terms of concrete geographies we can imagine small settlements in economically struggling regions such as more remote areas of northeastern or southeastern Hungary (the redlining map of Figure 6 can give some orientation regarding these areas). 
Beyond these rather obvious spaces of exclusion there is also a more relational and functional dimension to how I understand peripheral housing markets (Nitz 1997). On a national scale, there are systematic inequalities between the housing markets of cities in eastern and western regions, and between cities of different economic trajectories (Pósfai-Nagy 2017). In this sense, the postindustrial cities of the northeastern region, or the difficult-to-access, traditionally agricultural cities of the southeast can be seen as peripheral compared to the capital city or to northwestern prosperous cities. The axis / contrasted comparison between Békéscsaba (a southeastern county seat with low housing market activity) and Györ (a booming city of the car industry close to the Austrian border) was actually drawn up in several of my interviews when questioned about inequalities of the housing market on a national scale (interview 13, 39).

This relational and functional approach brings me to the third broad spatial category which I call "intermediary" housing markets. These spaces are the ones that play some kind of intermediary, translating and transitioning role in the relations of core and periphery on the Hungarian housing market (somewhat similar to the idea of the semiperiphery on a global scale). These spaces are the most important from the perspective of my analysis. These are the areas that respond the most sensitively to changes in the availability of mortgages and housingrelated state subsidies, this is where the largest number of housing transactions related to housing needs (and not investment) takes place. The combination of state subsidies and mortgages (taken with the help of the former) moves these markets the most (interview 7, 36). In terms of demographic mobility, this is also where the movement of households can best be grasped. In geographical terms these can be more peripheral / intermediary neighbourhoods in Budapest (outer districts of the city), the agglomeration area of Budapest (currently mainly the eastern suburbs) or secondary cities and their suburbs (interview 36). In some cases, the relations and processes characteristic of "intermediary" markets can be grasped in the centres of these cities, in other cases it is their respective agglomeration areas. This is of course a very diverse and shifting geography - which is precisely why I stress that they should be understood through the role they fill on the Hungarian housing market.

To give some examples for this role: in two different county seats of northeastern Hungary, my interlocutors could name a few specific towns of the agglomeration area, where the majority of new housing construction in the pre-crisis forex mortgage period was concentrated. In the case of the more prosperous of the two (Debrecen), they described a current shift from these pre-crisis booming agglomeration areas to the centre of the city, where families are buying newly constructed flats with the help of the new family-based housing subsidy (interview 19). In the other, less well-off county seat, where households have less savings (Miskolc), the current new wave of mortgage lending continued to fuel construction in the agglomeration area, but in a different town than a decade earlier (interview 32). In part, this might be explained by the fact that the previous wave of mortgage lending left many defaulting debtors, which means that the towns most affected by this wave of lending now have bad mortgage ratings, and are - at least partially - excluded from new mortgages (interviews 31, 32). Our previous statistical analysis has shown that the three settlements showing the most volatility in house prices comparing the periods before and after the crisis (Sajószentpéter, Mórahalom and Pécsvárad) are all towns in the agglomeration areas of county seat cities (Pósfai-Nagy 2017).

These agglomeration areas are the ones where the housing market does not move without the push of more forceful mortgage lending and / or state subsidies. However, when these conditions come together, they experience fast expanding localised housing booms. The most emblematic case of this strong responsiveness to the introduction of housing finance - and the ensuing strong volatility - that I have encountered is the eastern agglomeration area of 
Budapest. Here, the majority (around 60\%) of transactions are done with the help of the familybased housing subsidy, and practically everyone takes a mortgage (interview 16). Furthermore, the consequences of pre-crisis mortgage lending can also be strongly felt: about $90 \%$ of the transactions of existing housing units involve property serving as collateral for a previous mortgage. Another interlocutor called these agglomeration areas of the capital as those that are "strongly polluted with forex mortgages" (interview 17). This area is an important transitory zone between core and peripheral housing markets: many households moving here have been pushed out of Budapest through their inability to pay their mortgage, while many others had settled here to be able to benefit from the proximity of the capital, but not being able to afford living in the city (interviews 7, 16). Before the crisis many people moved here from other parts of the country, while currently the dominant flow of people are the ones moving out from innercity areas (mainly due to financial constraints). Financial institutions also confirm that currently the largest number of new mortgages are issued in the agglomeration areas of Budapest (interview 10). This is the specific spatiality of the current mortgage-related housing boom that emerges at the intersection of state subsidies, risk management of market actors and considerations of affordability and livelihood from the part of households.

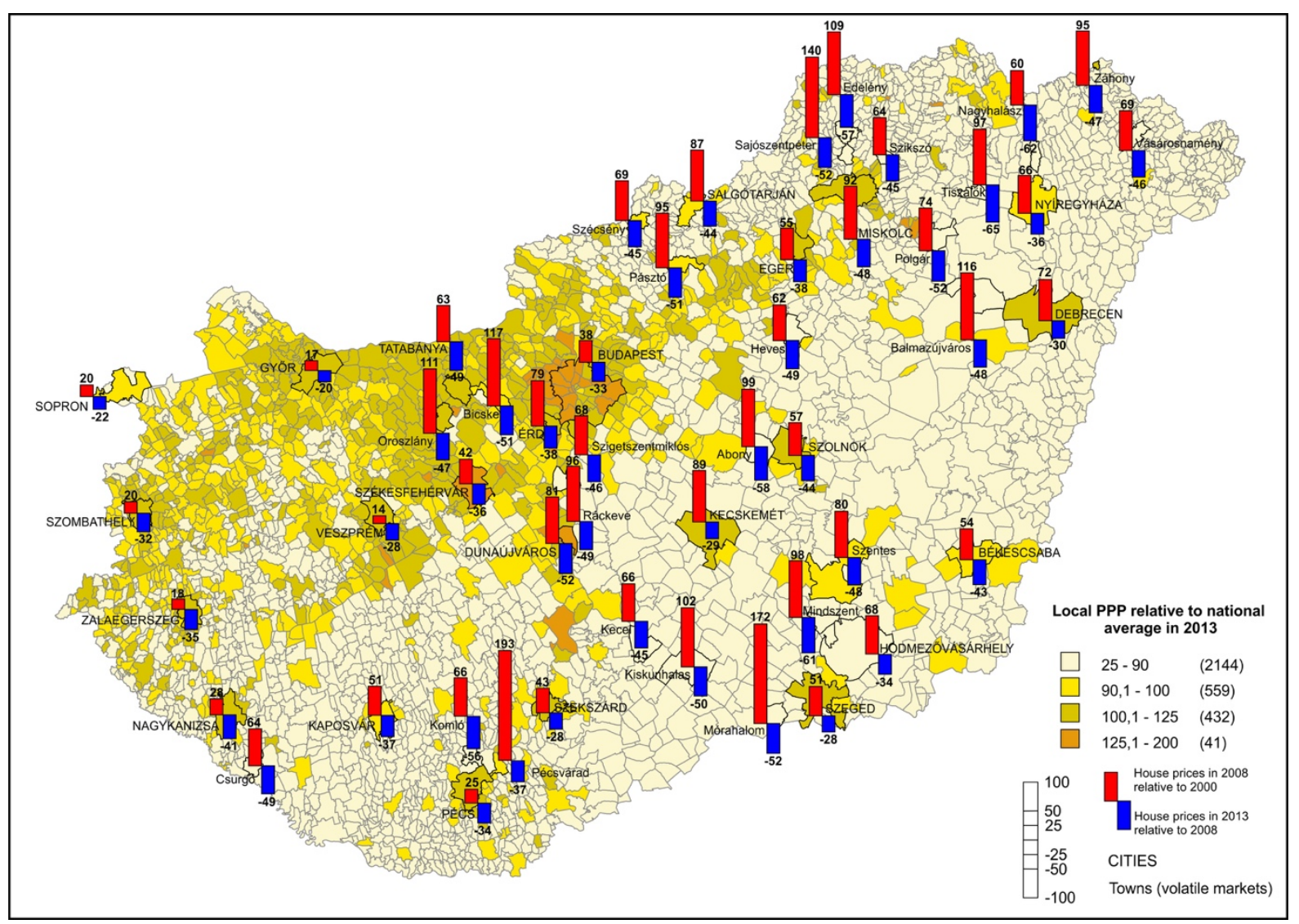

Figure 8 . Volatility of house prices in selected locations as a result of the crisis ${ }^{21}$ Source: Pósfai-Nagy 2017

\footnotetext{
${ }^{21} \mathrm{PPP}=$ purchasing power parity. The broad lowest category $(25-90 \%)$ is used on the map in order to highlight the areas which have average or above average PPP levels; since our assumption is that this will strongly influence housing market activity. All numbers on the legend are to be understood in percentage. The red and blue bars show the relative change in average house prices per square meter in the given settlement (based on real transactions) from 2000 to 2008 (red), and from 2008 to 2013 (blue).
} 


\subsubsection{Locally particular unevenness of project loans}

The conditions with which a developer can get a project loan mainly depends on the company's track record and does not carry an explicit spatiality. However, in practice this does imply a specific spatiality, because larger, more trusted developers are typically the ones that can acquire land in prime locations and tend to focus only on these most profitable areas, while smaller developers will be present in more marginal locations. This pattern is reinforced through the logic of project loans, which are issued with more favourable criteria to larger actors. Thus, the same kind of self-reinforcing logic of unevenness is at play as we saw in the case of individual mortgages. The crisis brought a shift to much stricter lending criteria concerning project loans as well. Developers now have to demonstrate around $30 \%$ or higher ratio of pre-sales (which is a guarantee for the bank that the developer will be able to sell and repay the mortgage over a short duration of time) and have to provide $30 \%$ downpayment (interview 8). These criteria are often difficult to meet for smaller developers (interview 12). Another constraint to new development lies in restricted capacities: many developers went bankrupt (or, in the case of foreign companies, exited the country) during the crisis. The ones that lived through the crisis cannot rebuild their capacities so rapidly (also due to a lack of labour force), and newly emerging companies have difficulties in entering the market due to more restricted access to financing. As a result, the awaited relaunch of new housing construction is happening slower than what many (political and corporate) actors would have liked to see.

Many financial institutions will not finance new housing projects outside of Budapest and the few main, economically prosperous cities (such as Györ, Debrecen, Kecskemét). Even in smaller/ less well off county seats (e.g. Békéscsaba), developers often rely on a direct investor, because they would access a bank loan with too unfavourable conditions (interview 39). Even within core housing markets, the market-leading developers concentrate on specific localities, where profitability can be the best, and there are available large-scale plots for construction. Thus, some claim that $80 \%$ of all new housing construction in the country between 2016-2017 was concentrated to 5 districts of Budapest (interview 8). Although this claim seems to be biased from the perspective of a financial institution focusing on core markets, this tendency is also reflected by the advertisements for newly constructed housing on the largest real estate portal (ingatlan.com).

A particular spatiality of new housing construction also develops out of the way the familybased housing subsidy is allocated. Developers can calculate the amount of the subsidy a family can get, and choose their areas of investment very particularly, based on the outcome of a calculation involving: the cost of the plot / the possibility of attracting families eligible for the subsidy / the profit margin to be realised. This calculation has led to booming housing construction in very particular (often brownfield) neighbourhoods of Budapest, for instance (interview 2).

\subsubsection{Locally particular unevenness of individual investment}

In recent years, the role of small-scale investors has significantly increased on the Hungarian housing market, with individuals buying a few flats to rent them out (Hulse and Reynolds (2017) call them "household investor purchases", here I will just call them investor- 
buyers). This tendency is principally due to low returns on other forms of financial savings: according to a representative of one of the important financial institutions, their private banking division gives clear indications that when interest rates on savings drop below $3 \%$ (compared to which the $5-6-7 \%$ to be earned with rental housing makes a significant difference), money starts flowing out of the accounts and towards real estate (interview 20). This has been a very important tendency since about 2014 / 2015, targeting higher value real estate in "prime" locations that will be sure to keep their market value. Other main aspects for investment decisions by these investor-buyers are the "rentability" of the given unit, or intra-family considerations of buying a flat in a different city to secure the future housing of children in this way.

Concerning the background of these investors and the capital mobilised for this purpose, several of my interlocutors pointed to the fact that there is an increased amount of capital and an emerging new upper middle class in the Hungarian economy (partly due to economic policies of the government, and also fuelled by EU transfers), which increases the amount of surplus capital looking for its way into real estate. This came as a somewhat surprising turn several of my interlocutors voiced opinions such as "you wouldn't think so many people in Hungary have that money" (interview 25), or "the presumably non-existent Hungarian middle class - well it seems that it actually does exist" (interview 10), or concerning one of the prime locations for new construction: "I don't understand where all these people come from who are willing to pay over 3000 euros for a square meter" (interview 24).

These investments are very specific in their spatiality. They display unevenness on a national scale, with acquisitions for investment mainly happening in Budapest and a few secondary cities which either have a university or significant industry (the usual suspects of Kecskemét, Győr, Debrecen), or in cities that are highly valued for other - eg. political reasons (such as Balatonfüred). There is a systematic overrepresentation of investor-buyers in economically more prosperous regions and cities (interviews 12, 19, 23, 27). A further aspect of national-scale unevenness is that while foreign actors only purchase in the downtown districts of Budapest (before the crisis Irish and Israeli investors were the most typical, while now there is a growing importance of Chinese and Russian investors), secondary cities have a predominance of local investors (often local businessmen or members of the local upper middle class) and completely lack foreign actors (interview 19). In prime locations (of downtown Budapest) new construction projects' customers are these small-scale investors for up to $50 \%$ of the flats in the project (interviews 11, 28). Some of these companies also offer specific services to their investors, managing the flats they buy: from furbishing to renting out and managing. Thus, investors only receive the returns for their investment, without having to manage the practicalities real estate investment usually goes with (interview 11). Other large developers (sometimes through private businesses of the owners) are considering to open smaller branches of construction-for-rental, in order to also benefit from this expanding market (interviews 2, 28).

In secondary cities with booming housing markets, investor-buyers are usually locally or regionally based entrepreneurs or members of the local upper middle class, who buy up to a maximum of five flats. The share of investors in these places is relatively lower, around 25-30, sometimes $40 \%$ (interviews 25,27 ). In less well-off secondary cities / county seats, where the local housing market is not profitable enough, potential investors will consider buying in other, more "dynamic" cities or in Budapest (interview 34) - channelling this wealth from more peripheral regions to the capital. Beyond these broad patterns on the national scale, investmentrelated acquisitions reflect a more nuanced geography as well, since these investors not only go to specific cities, but also to specific parts of these cities, where they believe renting at the expected rate of profitability will be easy to manage. Thus, the main targets for investment are 
inner-city flats in Budapest or in prosperous/ university secondary cities (preferably close to universities or other points of interest), which have a good built quality as well.

Beyond these core housing markets, investment-related purchases are mainly related to defaulting mortgage loans of the pre-crisis mortgage lending period. These investments also have a particular spatiality, which overlaps with that of overinclusive mortgage lending, and can also be linked to creating new exploitative forms of substandard rental housing. Most often, investors will not keep these properties, but after some renovation resell them at a higher price (interview 24). In some cases, however, the previous owner would remain in the flat as a tenant (interview 25). I will elaborate on these tendencies in chapters 5.1. and 5.2., where I will discuss the current institutional and spatial consequences of pre-crisis mortgage lending.

After the housing market freeze of the crisis, investors were the first ones to start transactions, before any of the government measures taken to relaunch the housing market were introduced in 2016 (interview 12). Money flowing out of bank accounts and into the housing market started to increase investment-motivated transaction numbers in selected locations already starting in 2013-2014 - first in Budapest, then in some secondary cities (interviews 19, 20). In 2016, with the introduction of CSOK and the re-opening of mortgage lending, households buying for their own housing needs also started to re-enter the market (interview 7), and new construction boosted by the reduction of VAT then also started to push for more housing market activity. Since investor-buyers typically buy without a mortgage, they cause a disjuncture of real estate market activity and mortgage market activity (interview 20). One of their aims is to "store" their money in a more profitable way, thus investor-buyers are less sensitive to price levels, willing to pay (or not caring much about) higher prices (interviews 6, 10). This of course further drives house prices - and, as a consequence - rent levels up in those selected spaces of investment (interview 36). Furthermore, since investor-buyers do not take much risk (they buy in cash and are not looking for something to respond to their own housing needs) they can be a lot quicker and easier clients in the eyes of the seller - who is often also an individual or family (since institutional owners practically do not exist). Thus, investorbuyers are gradually driving households buying for their own housing needs out of core housing markets. This tendency is reflected in the data cited above concerning the important differences in the spatial patterns of purchase-for-investment.

Altogether, the combined effects of (1) decreasing house prices after the crisis (making it a cheap investment to buy housing), (2) the consequences of non-performing mortgages and the increasing difficulties for many households to acquire private ownership (providing an increasing supply of housing for sale and a developing new demand for rental housing) and (3) very low interest rates payed on savings led to an increasing investment-motivated interest in core housing markets. This has resulted in a somewhat increasing private rental sector however in a way does not give any security, and that tends to increase inequalities by driving prices and rents up in core housing markets. 
In this chapter, I gave an overview of the structure of uneven development of the Hungarian housing market on various scales, focusing on the sources and channels of capital being invested in housing. I have highlighted various instances of this system that result in capital being channeled from peripheries towards cores. ó

If we consider how housing transactions are financed, it is interesting to note that maximum about $20-30 \%$ of transactions involve a mortgage. That is, the majority of housing is acquired with household savings - since institutional actors buying housing in Hungary are completely marginal. These savings can serve the housing needs of families - this is the case for households that cannot acquire a mortgage -, or investment purposes. These different sources of financing transactions also reflect a particular spatial pattern: investor-buyers are concentrated in core areas (where it is safe to invest in housing for rental purposes), while households who cannot acquire a mortgage will typically buy in more peripheral housing markets. This also explains the high prevalence of mortgage lending in particular housing markets which I have identified as intermediary.

Currently, banks dispose of abundant financial resources - the problem is rather how they can invest this money in a way that sufficiently manages risks (interview 35). The fundamental contradiction lies between the high amounts of capital waiting to be invested and the narrow channels through which it can be invested on the housing market. These channels are narrow because there are not enough "good" debtors (many households do not have enough income or savings, or are indebted), because new housing construction can not expand quickly enough due to various constraints, and a large part of the existing housing stock is burdened with previous mortgages. Recently introduced government measures can be understood as mechanisms aiming to widen these channels of potential capital investment in housing. 


\title{
CHAPTER 4
}

\section{MAPPING FIRMS OF THE HOUSING MARKET AND HOW CRISIS RESHUFFLES THEM}

\begin{abstract}
Although around half of all housing transactions is managed by households themselves without the involvement of any corporate actor (real estate / credit agent or financial institution), the role of the latter is increasing in housing provision. With the increasing role of credit in housing provision the role of financial institutions is growing. With increasing levels of financial literacy needed to acquire housing (interview 40), and a constantly increasing complexity of the process of acquiring a mortgage, the role of financial intermediaries and agents can be seen as more important (interviews 21, 25, 32). This is further accentuated by agents themselves, who also see households managing their own transactions as their "main competitors", or the main scope for market expansion (interview 9). Recent regulatory changes have also pushed for a professionalisation of the construction industry (interview 16).
\end{abstract}

The legal and institutional framework of the contemporary Hungarian housing market is very young, having been determined by the regulatory changes of the 1990s. Even during this short existence, important fluctuations have completely changed market possibilities and reorganised the circle of actors. First, between 2000 and 2008 there was a very rapid expansion phase with a very high intensity of housing market activity and many new entering actors. The significant players were typically international ones in in all segments of the housing market (interview 6). Banks were in foreign ownership up to $85 \%$ of the banking sector; opening the channels for the rapid expansion of mortgage lending in foreign currencies. Real estate and credit agents were a very diverse group: international agencies also had their branch offices in Hungary during these years, while other agencies specialised specifically in organising property acquisitions for international investors. The rapidly increasing number of housing market actors is often described with reference to the anecdotical manicurist-became-real estate developer: to emphasise how during the early 2000s it became a business where everyone hoped to make fast money. Property developers were also "parachuting in" from Spain and Ireland (these two nationalities are often mentioned as emblematic of the pre-crisis housing bubbles), constructing quickly with cheap capital - and then leaving the country when the crisis hit, sometimes leaving unfinished projects behind. Altogether, the Hungarian housing market was strongly internationalised and diversified in the years before the crisis. This was followed by the shock of the economic crisis in 2008, wiping the arena of housing market actors rather clear.

Currently, with the new market upswing happening since 2014 / 2015, a new wave of housing-related government policies and newly entering companies, there seems to be a concentration and a general "Hungarianisation" going on in the real estate - and particularly in the housing - sector. Following the crisis, there was an important reorganisation in all segments of the housing market, due to a combination of market pressures and regulatory changes relating to the financial and housing sector. These transformations in the corporate landscape relating to housing have a strong link to shifting class relations within the country (Vliegenthart 2007), with the rise of a new, national bourgeoisie in recent years. This shift in internal class relations needs to be understood in relation to broader relations of dependency: the economic elite of the pre-crisis years, and the corporate network benefiting most from 
housing market activity as well, was strongly linked to international capital flows, mainly linked to the accelerating integration of Hungary in the European economic space during this period. The way how different actors could respond to the years of the crisis also sets out the current patterns of concentration and reorganisation in various segments of the housing market. The most visible aspect of the reorganisation is a strong "Hungarianisation" of actors of the housing market. This also goes together with a concentration of actors in almost all housingrelated fields, which might loosen in the future if housing market activity continues to expand similarly to how it has since 2015 .

The geographically uneven structure of the housing market is reflected in and reproduced by the hierarchy of the actors present in this field. In all segments of the housing market we can differentiate various categories of actors according to their size and geographical scope. Largest companies, which have a national relevance and are often also present on the regional scale of Central and Eastern Europe, mostly focus on Budapest. On the other end of the spectrum, the smallest actors are individual households - who are still the most numerous actors of the housing market. In between the two, there are a number of smaller scale and intermediary actors, who are the most important - and most difficult! - to investigate for grasping the shifts and changes on the housing market. In the following chapter I will explore how companies respond to and navigate the unevenness of the housing market in terms of their corporate structure and strategy, according to the main actor groups I have identified: property developers, agents, and financial institutions. In general, there is a connection between the institutional and ownership structure of a firm and the market strategies they will employ. Which, in turn, affect the position they can take up in the market, as well as the way they influence existing inequalities of housing. Intra-firm hierarchies and decision-making mechanisms are also intrinsically linked to the position a company takes up in external hierarchies and core-periphery relations. I will give an overview of these different hierarchies in the case of the three main actors groups of the housing market, and will also reflect on the effects the recent crisis had on the circle of active firms or on their corporate strategies.

\subsection{Property developers}

The most evident group of actors to start with are real estate developers. New housing construction is much more polarised than the whole of the market, and is strongly concentrated to Budapest and a few larger cities (Pósfai-Nagy 2017). Large developers are practically only present in the capital city (interview 6), and will sooner expand their activity internationally than to the rest of the country (interview 11). This is mainly a question of economies of scale and profitability: on smaller housing markets (which, in this case also applies to the second largest city in Hungary) the number of transactions is not high enough to make a large-scale investment of several hundred flats safe to build. However, the largest companies do not engage in smaller projects (interview 11). The costs of construction are similar everywhere (the only major difference being the cost of land), while sales prices show very significant and increasing differences (Pósfai-Nagy 2017, interview 12,13) to the benefit of the capital city.

Beyond these core housing markets (already in outer districts of Budapest), smaller construction companies are predominant, which often function as family-based enterprises, and build smaller apartment blocks or individual family houses. Often (also because these smaller developers receive credit under less favourable conditions) these construction companies will require more pre-payments from future buyers, and finance the construction process by gradually raising money from future residents in this way. Since these companies are not fullscale property developers, they will often team up with real estate agents in order to manage 
the whole chain of housing construction, marketing and sales and to support them in accessing finances, as well as to be able to respond to market needs identified by agents (interviews 5 , $16,22)$.

Generally speaking, there is a tendency of combining different services related to housing market transactions - which manifests itself in different ways on different points of the institutional hierarchy. Market-leading housing developers are typically integrated in broader real estate corporate groups or holdings, where a diversity of commercial real estate, housing and finance-related services can be provided (interviews 11, 28). One of the largest banking group, for instance, also has a real estate developer company, which is among the five biggest in the country. They constitute a whole "ecosystem" of real estate developer, retail bank, home savings and loan association, mortgage bank and real estate agency. The bank finances both the developers and the customers of new housing projects, while the agency orients potential customers towards mortgage products and also has a role in managing and selling real estate behind non-performing mortgages (interview 5). Although large real estate developers usually see it as beneficial to have separate companies for the different real estate branches (because of different professional skills necessary for either), operating in one group allows them to benefit from increased institutional capacities and financing possibilities. Recently (in 20162017), the question of concrete construction capacities is a big issue, since there is a lack of labour force in the construction industry. Being a member of a larger corporate group gives these companies a competitive advantage in this respect as well (interview 11,28). (Typically, they will work in subcontracting mechanisms with smaller construction companies, who now have a marge for manoeuvre in choosing who to work for.)

Concerning the ownership structure of property developers, there is a claimed difference between shareholder-owned, publicly listed "Western-type" developers and those with more "family business type" ownership structure (interview 11). According to my interlocutor from the top management of one of Hungary's leading housing developers, which is in majority owned by a duo of father and son, their ownership structure leads to more selectivity in the projects they undertake and to a model of less volume but higher profitability compared to a publicly listed company, where the management is interested in the production of the maximum volume possible (interview 11). In comparison with "Western companies constructing with cheap money coming from money markets" he claims that basing their business on the capital of the owners results in a more prudent functioning. (Although considering the volume of housing units produced by this company - in 2017, 25\% of all new housing units in Budapest were built by them -, this rheotirc of lower volumes can be questioned.) Nevertheless, it is interesting to make the comparison between listed and privately owned companies in terms of their attachment to the local economy. Although in the case of market leading companies their ties to international financial markets are quite straightforward, they still have more knowledge about local tendencies of housing markets and policy shifts than an international developer recently entering the country (interview 6). In this sense, there is also a difference between housing and commercial real estate, the latter being much easier to access for international investors and developers alike. The market of commercial real estate is in a sense completely detached from the local economy, since these properties are financed by international banking groups or with money raised on international financial markets, are often constructed and managed by international companies, and are rented by multinationals who locate their offices here for reasons of cost-efficiency (interview 6).

Another important difference between commercial and residential real estate is the "factory-like" nature of the latter. Several of my interlocutors referred to housing as a "boxed product", which can be produced in a factory-like way (interview 11,21). That is, its advantage is its simplicity and replicability. This fragmented approach is partially due to the fragmented 
ownership structure of housing in Hungary, which also results in the lack of institutional investors - which are only directly present in commercial real estate in Hungary. In a situation where the overwhelming majority of housing is owned by individual households, there is no possibility (or product) for larger investors to enter — or this would require management capacities they do not wish to assume. This is confirmed by one of the main housing developers, according to whom larger investors are only present on the Polish and Romanian housing markets within the CEE region (interview 11). These countries adopted a system of privatisation after 1989 that left whole buildings (that is, larger stocks of housing) in one hand. This creates a situation where larger scale acquisitions for investment purposes are possible. The lack of (international) institutional investors is regretted by large property developers, because these actors would mean a possibility for faster and more secure sales of new housing units (interview 5, 11, 28), without having to deal with individual households.

\section{Effects of crisis: narrowing financial channels and corporate concentration}

The segment of new housing construction is extremely sensitive to crisis cycles and to government intervention because of its capital intensity. Thus, when the crisis hit and credit lines as well as state subsidies were abruptly stopped, new housing construction also almost completely stopped (again shedding light on how directly macroecoomic pressures influence the functioning of firms - Dixon 2010). Many property developers went bankrupt and the majority of international actors who were very typical of the pre-crisis market left the country. The larger property developers did not withdraw and kept up a minimal functioning, but selling newly built expensive housing units was almost impossible for years. (As a result, some minor innovative practices also emerged - for instance, some large property developers managed unsold units as rental housing during this period. - interview 11, 14)

The construction industry typically has quite strong lobby power, because of its strong impact on the economy and employment generally, and because it is an important channel for the government to influence investment that is "fixed" and cannot leave the country. Financial institutions also prefer to finance new housing construction for the reasons outlined above. Thus, a concerted push for relaunching new housing construction was in the interest of various actors. It is not surprising that the two government measures which (1) reduced VAT on new housing construction by $22 \%$ (to $5 \%$ ), and (2) launched the new family-based housing subsidy, which orients households towards new construction were introduced around the same time at the end of 2015 / beginning of 2016. While the reduction of VAT was a huge support to the whole sector of housing developers, the introduction of the new family-based housing subsidy $(C S O K)$ was probably most important from the perspective of smaller developers: the exponentially higher subsidy that can be received with three children when buying a newly constructed house orients many households to the market of new construction. In certain areas this leads to a mushrooming of new "CSOK-suburbs" (interviews 16, 32). This market is complicated, slow and not profitable enough for actors at the top of the housing market, but for many smaller local developers this has created a new market since 2016.

The property developers that survived the crisis now have the advantage of having very good references with financial institutions and getting project loans on preferential terms. Furthermore, they are also in an advantageous position when it comes to hiring construction companies - which is a scarce asset on the contemporary Hungarian real estate market. Many actors also speak of a "clearing" market of developers, since the "unprofessionals" disappeared during the crisis. However, now that new construction is again becoming a very lucrative business, the larger, more established actors are again lamenting the entry of smeller new actors. 
Generally speaking, those actors that managed to keep the majority of their corporate infrastructure during the crisis years are now in an easier position to keep and advance their market positions. It is a particular difficulty of volatile, semiperipheral housing markets that available capital flows can abruptly stop, leaving many companies without a sustained channel of credit. In the construction industry, where projects are financed by a constant rollover of project loans, it can lead to bankruptcy quite quickly if credit lines dry up in this way. However, when there is a market upswing, it also happens rather rapidly - as it currently is -, resulting in institutional capacities struggling to catch up. Thus, those who did not significantly reduce their capacities, who have managed to maintain a loyal circle of subcontractors, or who have strong political and/ or economic connections to be able to expand rapidly are in more advantageous positions.

\subsection{Real estate and credit agents}

Real estate and credit agencies are two different circle of actors, although they overlap to some extent. Real estate agents are crucial actors moving (and understanding) the contemporary Hungarian housing market. They have the broadest view of all households involved in transactions, because they do not only cover new transactions or transactions with a mortgage involved. Thus, they have access to market processes that both developers and financial institutions bypass. Furthermore, they are the most localised in their scope and often have long-standing local engagements. This made them very valuable interlocutors in my research.

Credit agents need to be certified by the central bank (which has become increasingly difficult in recent years), and are in contractual relations with banks to sell a number of their financial products, not only mortgages. This system of agencies has been simplified by legislative means in recent years, and is now limited to the three steps of bank, "main agent" and "agent"; the main agents being umbrella-type companies that have licences to work with banks and to subcontract individual smaller agents; while individual agents are only allowed to be contracted with one single such umbrella organisation (interviews 17, 18). Their interface with banks is crucial in how credit is practically distributed to households and will be discussed in the next section. Credit agents will seek clients through various channels, one of them being through real estate agencies. This is an important channel, since the most important financial service households typically use is a mortgage (interview 18). Some real estate agencies (such as the market-leading DunaHouse) have their own dedicated credit agencies, who will (not exclusively, but dominantly) only deal with clients of the real estate agency (interview 19). Real estate agents, on the other hand, approach the housing market through the lens of concrete real estate. They are almost always in close cooperation with a credit agent, but will typically "pass the client on" to the credit agent they work together with once the client has expressed their interest to take a mortgage linked to their search for a property (interviews 7, 13, 25).

Both kind of agencies are also diversified according to their presence on a national or more regional/ local scale. There are very few real estate and credit agencies that have national networks. In both segments there are two-three companies which are the clear market leaders and provide their services nationally, and a few smaller, regionally based agency networks (interview 17). There has been a strong centralisation of agencies due to legislative changes and to market difficulties after the crisis (interview 34). Since March 2016, the fees of credit agents are legislatively maximised at $2 \%$ of the value of the issued loan. For many agents, this meant an important challenge to their business model, and has significantly reduced the appeal of this sector for new entrepreneurs. This is especially true in light of the increasingly strict 
and complicated process of applying for a loan, meaning that the number of clients successfully acquiring a mortgage has also been reduced. One of the related consequences is that many agents have diversified the portfolio of financial products they sell (interview 15).

In the following I will focus on real estate agencies, and on their differences of internal structure according to their market strategies. The two market leading real estate agencies are similar in the sense that they have franchise networks structured in a rather hierarchical, topdown way and that they also have their own dedicated credit agencies. They both grew during the pre-crisis lending boom, and operate a professionalized and rather unified national network, with profit-oriented expansion strategies resulting in a high number of offices nationally.

The majority of other real estate agencies currently present on the market were started after the crisis (with most previously existing agencies going bankrupt during the crisis), based on a geographically more narrow focus. Two of the agencies following the market leaders in the inter-company hierarchy are comparable from several perspectives. One of these newer agencies was started in 2009 and was initially only present in Budapest, while another one of similar scale started in one of the secondary cities of western Hungary and expanded from this regional basis, being much more present in secondary cities up until today (although they recently also managing to open offices in Budapest - interview 3). Apart from their geographical focus, these two agencies can also be compared in their internal structure. While one of them manages its offices "internally" within the same company structure, the other combines franchise and "own" offices. The latter are seen as a possibility for experimenting and then spreading certain modes of functioning (interview 3). Both of these organisational structures are rather experimental, and were developed as a response to market pressures. They differ from the company structure employed by the market leading agencies (which are both more traditional franchise companies). At the other end of the spectrum, a loose federation of locally operating real estate agents only aims to share certain costs (of advertisement or trainings, for example), but do not pursue a common business strategy. This loose federation has many members from smaller settlements as well. Typically, many local agencies joined this network who have been operating independently for a long time, but saw the benefit of joining a network in the low years of the crisis (interview 14).

In terms of ownership, the two largest agencies are owned by Budapest-based, internationally oriented businessmen, and one of the two companies was also recently listed on the Budapest stock exchange and started an expansion to other CEE countries. In contrast, two of the important "second-tier" agencies are owned by young Hungarian entrepreneurs from smaller cities. They represent an ethos of a new kind of "self-made man", coming from outside of Budapest and from outside of the economic elite. They also have a narrative of supporting the housing needs of "everyday families" and a strategy of also serving secondary (or even smaller) cities, with a concern to help housing mobility between cities and to build a business model that would work in cities that are considered too small / not profitable enough for other, larger agent networks (interview 14). This narrative is somewhat contradicted by the fact that for reasons of profitability both companies are currently focusing on Budapest and on the market of new constructions (and, consequently, focusing on higher value transactions for higher status customers; reproducing the unevenness they claim to go against). A third "secondtier" agency is also owned by a Hungarian entrepreneur with long-standing experience in real estate intermediation. The business model of this agency is to have a narrow focus on more profitable market segments and geographical areas, having higher expectations of profitability form their individual offices (interview 15). In the case of franchise companies, a wide presence and visibility is more important, which also allows for keeping less profitable offices in certain cases (which is also a logical decision because of the franchise fees they pay). 
It is also relevant to understand the perspective of local agents that choose not to enter any network or federation of agencies. They are typically run by individuals who have been active on a given local housing market for a long time (in several cases working as real estate appraisers before), and who have a particular business model developed for this context; often in cooperation with local construction companies (interviews 16, 23). For them, participation in a national network would not bring any benefits, since they have a sufficient client base (passing clients on between offices and between cities being one of the main benefits of participation in a broader network), and see it as a disadvantage to share their information and revenues with others (interview 16), as well as considering franchise fees and other related costs to be too high (interview 23).

\section{Effects of crisis}

Real estate agents were probably the actors who could best discover and use the niches of the remainders of the housing market after the crisis of 2008; many of them engaging in the sale of properties becoming available following the mortgage crash. Credit agents were more severely affected, since mortgage lending drastically decreased and transactions were realised without taking a loan. The ones that could survive the crisis years did so by becoming real estate agents, or by diversifying their portfolio to sell other financial products.

Several independent real estate agents entered larger franchise networks in the low market years following the crisis. Agents who remained outside of larger networks are typically the ones that have a complex business model in which they manage local networks that federate all aspects necessary on the local housing market from finances to construction. This kind of independence is easier to achieve for real estate agents (especially if they are linked to local construction companies), however, regulatory changes concerning financial intermediation have made it very difficult for credit agents to function independently. Thus, in the field of financial intermediation there has been an important process of centralisation and the number of credit agents is now significantly lower than before the crisis.

The crisis also made it more difficult to economically survive as an independent agent, and those who entered larger networks during these years now often find it convenient to stay (interviews 7, 19). On the other hand, involvement in national networks also sheds light on inequalities of this market on a national scale. Some agents expressed frustration about how their colleagues in the same network from more prosperous parts of the country earn much better due to higher real estate prices and more transactions (interview 34 ).

Generally speaking, there has been a reduction in the number of agencies and real estate and credit agents compared to the pre-crisis years, and it is now a somewhat less lucrative business than it used to be. The shift from international to domestic actors in the wake of the crisis can be observed in this segment of the housing market as well. Before the crisis there was a huge diversity of agents; the sector was very loosely regulated, and it was easy to start "doing credit" or "doing real estate"; attracting a huge number of new individual entrepreneurs. International franchise companies also spread to the country. However, the crisis brought the crash of many (international) real estate agencies, and opened the space for new, domestically based actors to emerge. These companies all used the post-crisis years to strengthen their position, and in terms of organisation-building capacities benefited from the high number of agents on the market who were now more open to joining franchise networks. Currently, many agents see their possibilities for market expansion through diversifying the services they provide - expanding from managing transactions to all kinds of related services. A further scope for expansion is to draw an increasing number of households into a business relation with an 
agency. Due to considerations of profitability, the main focus of most agents is on new construction and on mortgage issuance - the interfaces on which this happens will be discussed in a later section (4.5. - "Critical points of interface").

Real estate agents have a very interesting approach in perceiving their role as supporting households in the complicated and often stressful process of acquiring or selling property - and highlight how this role is becoming increasingly important in the context of more and more regulations and more complex bureaucratic processes relating to state subsidies and financial services (interviews 24, 25). This increasing complexity is also perceived as their possibility for market expansion. Such a "supporting" role is also welcomed by banks, who willingly rely on agents in navigating clients through the heavy administration that goes with increased consumer protection rules which developed as one of the legislative responses to the mortgage crisis (interviews 13,21). Through this mechanism, real estate and credit agents also have a role in spatially expanding the housing market and spreading housing finance instruments potentially becoming the concrete carriers of tendencies of financial overinclusion outlined in the previous section. This was apparently a more important phenomenon before the crisis; currently the majority of agents focus on urban centres and do not actively search for clients from more peripheral markets (often also limiting their radius of activity to around 30 kilometres from the larger city they are based in). However, this might change in the coming period with increasing pressure to find new markets.

\subsection{Financial institutions}

The three main categories of financial institutions active in housing finance are retail banks (and among them, domestic and international banks), home savings and loan associations, and savings cooperatives. Their respective weight and presence in housing finance is currently strongly shifting. One of the possible entry points for investigating the spatial unevenness of housing finance institutions is through the inequalities of infrastructural presence of financial institutions (the geography of their branch offices), which already implies patterns of spatial exclusion (Kovács 2014). However, my main focus here will not be their infrastructural presence, rather how the corporate structure and business strategies of financial institutions affect spatial unevenness on the housing market. First, I will give an analysis of how the internal hierarchies of a financial instiution determine their decision-making process relating to housing finance, then I will give a sketch of how the role mortgage lending has in the portfolio of a financial institution is related to its market position / weight. Then I will discuss how ownership structure is related to the market strategies they pursue. Strategic choices in crediting policy, such as whether banks focus on a selected client base or a broad one, are technically translated to policies of credit scoring and redlining (which I have discussed in the previous chapter), as well as to internal mechanisms of decision making. Ownership structure, corporate strategies, identified target groups thus all have implications for the spatial presence of financial actors, as well as for the ways they reproduce unevenness on the housing market.

\subsubsection{Decision-making hierarchies}

Following the crisis almost all banks centralised their decision-making process about mortgage issuance. The only exception is the largest, market-leading bank in the field of mortgages, where local decision-making remains in all branch offices. This has the advantage of being able to offer faster decisions (which can be crucial in the process of buying a house) and allows for a more personalised assessment of the loan request. However, it has the 
disadvantage from the perspective of the bank of having to ensure the same assessment capacities in all offices (even where there are only very few loan requests) - which means more engagement in terms of training and human resources, and is also more expensive than an automated credit scoring system. Thus, the bank is faced with the dilemma of cost efficiency and the market advantage they have because of their localised decision-making (interview 21). From the perspective of the manager of a local office of the same bank, this personal aspect of a loan decision is very important; since it allows to "look into the person's eye" and see how they communicate about their financial situation - which, she claims, can be a more important source of information than the documents and numbers used in an automated credit scoring process (interview 39). This dilemma, and the recent shift in banks' consumer loan and mortgage lending practices 'from 'soft', 'relational' methods towards 'hard', statisticallydriven techniques" (Lapavitsas 2009: p.138-139), often through the tool of credit scoring, is a general phenomenon under financialised housing regimes.

There is also a certain degree of differentiation in the scale of decision making on a caseby-case basis. As a general rule, loan decisions are made at higher institutional levels in the case of any "atypical" or negotiated loan request (typically ones that involve larger sums). This can mean upscaling the decision from a local branch office to the regional or national centre (interview 21,31), or, in the case of project loans and above a certain threshold, can also mean transferring the decision from the Hungarian subsidiary to the headquarters of the banking group abroad (interview 8). When the crisis hit, this centralised decision-making process was clearly indicated by the foreign risk management officials many Western European mother banks sent from their headquarters (interview 2, 12).

From a research perspective it was quite clear that financial institutions are the most hierarchically structured institutions of the housing market: while in the case of real estate or credit agents it was relatively easy to access local actors, in the case of financial institutions this was practically impossible, and in most cases only bank representatives at the center of the institutional hierarchy were entitled to respond to me. Thus, apart from three cases, all of my interviews with representatives of financial institutions were conducted at the headquarters.

Another aspect of hierarchical processes within banks relates to sales target numbers. While all banks (and probably the majority of agencies as well) apparently have internal target numbers in terms of mortgage loans to be disbursed, it varies whether these are determined according to individual offices or on a regional scale (interview 36). This question also comes back to the issue of where decisions are made: if target numbers are determined on the scale of local offices, there are now legislative restrictions in place not allowing loan decisions to be made at the same scale (interview 36). This is one of the many regulative repercussions of the pre-crisis overstretched mortgage lending, aiming to block a similar kind of escalation. Such concerns may not be exaggerated since several credit agents reported having the impression that internal target numbers for contracted new mortgages are on the rise within most banks (interview 18). These target numbers show the growing, but spatially uneven role mortgage lending again starts to have in the financial sector. The important regional differences in mortgage target numbers within the network of a bank are a very plausible, technical translation of how spatial patterns of the housing market are produced by inter-firm practices (interview 36).

Altogether, the spatial scope of a financial institution in terms of the branch offices it has and the number of agents it employs is tightly connected to whether its lending policy is based on higher selectivity or a broader client base. This, in turn, will also determine the price range of the loans. Those banks that currently opt for a more risk-averse strategy will be much more selective both in social and spatial terms (interviews 10,36). In return, they will be able to offer 
relatively favourably priced mortgages, because their risk of default will be minimised. However, this strategy has its limits in terms of the volume of mortgage lending they can achieve. On the other hand, the few banks that are willing to issue mortgages with more relaxed criteria have a much wider social and spatial scope. They balance this risk with high volumes of issued mortgages, and with relatively high interest rates and fees (interviews 21, 36). Consequently, these financial institutions also need a broader presence throughout the country.

\subsubsection{The role of mortgage lending within the bank}

Fundamentally, mortgage lending is considered by some banks as a profitable product / branch of activity, while for others it is a hook- or anchor-product, which is important because it attracts and then ties customers to the given financial institution in the long term. Since a mortgage is crucial in the financial life of a household, the experience of banks is that they are willing to adapt their other financial services to the institution they have taken a mortgage with (interviews 10,21). Furthermore, since a mortgage is usually 15-20 years long, it means a longterm stream of revenue, and additionally, plenty of opportunities to sell other products to the client as well (interviews 12,18). With favourable conditions selected / high-profile clients can be attracted who will use other, more complex financial services as well (interview 10). The question of what role mortgages play in the business model of a given financial institution is a question of strategy, and is also reflected in the market share a given actor achieves. For the bank with the broadest spatial scope, mortgages are a product of profitability, and they strive to be market leaders in this product (and keep this position in a very stable way). The representative of another financial institution claims that under current market conditions it is not worth it anymore to build a financial institution primarily around mortgages. This was the case before the crisis, when mortgages could be issued at high interest rates (at the time, 5-7\% profit margins on mortgages were common, whereas today they are at 1-2\%). Under current circumstances, he sees mortgages as an obligatory element of a range of financial services, but other, more profitable business branches need to be developed (interview 20). In the case of this particular financial institution this more lucrative business branch appears to be that of consumer loans. Beside the very concrete advantage of higher interest rate levels for consumer loans, this shift in strategy is also explained by the fact that the bank aims to to have a more evenly distributed presence among different market segments, to avoid being so dependent on mortgages. For other financial institutions, mortgages can be the central element they strategically build around.

Banks have recently also relaunched (most of them had stopped this branch following the crisis) their business branches for financing project loans for new housing construction. This branch provides faster returns and higher volumes than individual mortgages, and is currently strongly pushed by government subsidies for new construction. Those banks which can benefit from the current upswing in mortgage lending to a lesser extent have also put more emphasis on developing other business branches such as consumer loans or loans to entrepreneurs. In some cases, these were branches they had developed in the years of the crisis, when possibilities for housing finance were very limited.

\subsubsection{Ownership structure and market strategy}

The issue of foreign ownership of banks in Central and Eastern Europe is often raised as the main manifestation of the dependency of these economies. The notion of dependent market economies, introduced by varieties of capitalism scholars, builds its argument mainly on this phenomenon (Myant-Drahokoupil 2012, Vliegenthart-Overbeek 2007). However, a process of 
centralisation and nationalisation has been going on in the banking sector in Hungary since 2010; the key element of which has been the shifting ownership structure from a dominance of foreign owned to a dominance of domestically, or even state owned banks (Király 2016). As a result, foreign ownership radically declined in the Hungarian banking sector from around 85\% before the crisis to about $45 \%$ by 2015 . This could be seen to override claims about dependency, however, I argue that this issue needs to be considered in a broader context than the mere issue of bank ownership. Understood in the broader context of long term macroeconomic trajectories and the broader economic integration of the country (GeröcsPinkasz 2018, interview 35), the current reorganisation of financial institutions can be seen as an institutional restructuring serving the strengthening of a national capitalist class. This, however, does not build economic capacities that would contribute to a "more independent" development in the long term. In the case of housing finance this can be seen as well, since the resources it relies on are not necessarily stable in the long term.

Here, I propose a reflection about what the ownership structure of financial institutions has meant in how mortgage lending developed in Hungary from the late 1990s onwards. The dominance of foreign ownership of the banking sector in Hungary (reaching more than $80 \%$ of the banking sector by 2006 - EBRD Transition Report 2006), which prevailed until the 2008 crisis, had direct consequences on the financial channels available to housing finance in the country. Financial services were predominantly provided by institutions that did not have immediate stakes in, or in-depth knowledge about the country's economy. In the meantime, they had to respond to high profit-expectations of their shareholders - this pressure being especially important since they entered the CEE market precisely in order to alleviate the constraints of diminishing returns in saturated Western European markets (Raviv 2008).

Household lending gained a very important weight in the portfolio of foreign banks entering Central and Eastern European markets. This can be explained by various factors: for international financial actors entering an unknown market, household lending is a much safer and more accessible option, than lending to enterprises. Large transnational companies often raise their own resources on financial markets (through the process of the increasing financialisation of these companies), and small and medium enterprises are often deemed costly and complicated to finance for international banks lacking local experience. Furthermore, household lending is generally more lucrative, and is also a market that can be easily expanded (especially in the context of "under-credited" households in Central and Eastern Europe).

Thus, as a consequence of corporate interests stemming from the ownership structure of banks, lending activity in Hungary was primarily focused on households and consumer loans, which are the easiest and most profitable forms of credit lending (Bonin-Ábel 2000). No specific knowledge of the local economy is required, and mortgages or consumer loans can be distributed in a quasi-automated, homogenised way. This is what the industry jargon calls a "boxed product" (interviews 11, 21) - akin to instant food that can be heated up and replicated without too much complication. This intra-firm motivation is important to understand relating to the rapid expansion of household lending in pre-crisis years in Hungary. It also gives an explanation to the way how in the last years of the credit boom (2007-2008) consumer loans became predominant as opposed to mortgages: these loans have even more lax lending criteria (allowing them to be spread to a wider circle of clients) and higher interest rates than mortgages (Dancsik et al. 2015). These consumer loans were often taken by households that did not have access to credit with more favourable conditions, and are at the origin of many of the nonperforming loans that cause problems until today - 40\% of currently still non-performing loans were disbursed in 2007-2008 (interview 29). 
As a result of the nationalisation process going on in the banking sector since 2010, the market share of the subsidiaries of international banks in mortgage lending and project loans relating to housing construction radically decreased: the international banks that dominated the pre-crisis forex mortgage market now only account for around one fourth of the market. In the meantime, domestically owned banks are strengthened in this sector: the primacy of OTP, the largest Hungarian bank has always been unquestioned in mortgage lending. Additionally, two new actors are currently strongly emerging in the field of housing finance that merit attention: the first mortgage bank of Hungary, FHB, has stepped into a federation with the savings cooperatives which were traditionally the "banks of the countryside" (Király 2016). This conglomerate of various financial institutions will allow for the emergence of a new strong domestic bank with all the elements of a housing finance ecosystem (from a refinancing mortgage bank to a retail bank, a real estate investment trust and spatially very accessible, locally embedded financial institutions); combining the advantages of having a very broad social and spatial outreach and of accessing international financial markets as the largest covered bond issuer of the country. At the moment, the role of savings cooperatives in housing finance is negligible, because their products are usually more expensive than those of commercial retail banks. However, because of a broad social and spatial scope, they are already starting to give housing credit to households that have been rejected by other financial institutions (interview 39), and in places where other financial institutions are not present. There is a declared intention from the part of savings cooperatives to start actively engaging with mortgage lending (interviews 17, 18). With their recent reorganisation in a national federation, and with a capital-intensive mortgage bank behind them, they will probably soon be able to issue mortgages on better terms (interview 12).

A further interesting development is the post-crisis strengthening of home savings and loan associations. These institutions combine a deposit-based and a mortgage-based housing finance system and generally have a more slowly-building financial model and more stable mortgage construction. The largest such association, currently has the second highest market share in mortgage lending. This is a financial institution with no offices, only a very mobile network of agents and very efficient sales strategy (interview 21). However, in a way home savings associations could also be a much more stable, anti-cyclical kind of housing finance mechanism, pairing household savings with a generous state subsidy and a mortgage with a fixed interest rate. According to a representative of the largest home savings association, the guarantee for this kind of stability lies primarily in their ownership structure. This company is $75 \%$ owned by three other home savings associations (two Germans and one Austrian) which means that the owners are very well aware of the importance of long-term stability in housing finance, and are themselves following strategies of slower returns and more regulated lending policies, where sustainability is a primary concern (interview 38). According to the representative of this company, this is an important difference compared to the other home savings associations of the Hungarian market, which are all members of larger banking or insurance groups; meaning that they have to align to the broader strategies of these groups. This institution also has a very broad (probably the broadest) spatial scope, and currently covers over one fifth of the mortgage market. Other home savings and loan associations are also gaining market share, and the sale of their products is also an expanding business branch for many real estate and credit agents. What we see in the current institutional structure of Hungarian housing finance is that a wide spatial presence is probably needed in order to make mortgages the core profit base of a bank. On the one hand, core housing markets have a predominance of investment-oriented acquisitions, while it is clear from the accounts of real estate and credit agents that investor-buyers usually do not use mortgages. Furthermore, the family-based housing allocation, which is currently boosting mortgage lending, is not high enough to play a significant role on core housing markets. This results in the rather narrow 
geography of mortgage lending plus $C S O K$ that I have described at the end of the previous chapter. However, this spatiality will have to be expanded if financial institutions want to continue broadening their lending activity. Currently, most agents working outside of Budapest report that the majority (in smaller locations the very dominant majority) of the mortgages they manage are issued by the biggest bank, which has the broadest lending policy. Other financial institutions present in more peripheral areas are the largest home savings and loan association (which covers $22 \%$ of all mortgage lending!), and savings cooperatives. The latter are also supported by government initiatives in restructuring the banking sector (which I will return to in the following chapter). Furthermore, both the market-leading bank (OTP) and the bank which is the largest actor in the newly-emerging federation of cooperative banks (FHB) have traditionally always been very active in distributing housing-related state subsidies (fulfilling the role of front-desk operators of housing policy). Thus, the state is actively intervening in the frontline of mortgage lending, to broaden the geogrpahies which can be included by financial institutions.

The spatial-institutional structure that emerges from this is one where financial institutions for which mortgage lending is a core activity will have to have a wide spatial and social base, and will also have to be strongly implicated in managing government subsidies to housing. There seems to be an increasing diversity in the institutional character of these institutions, with the dominant actor of this market somewhat losing its weight to the detriment of new types of actors of housing finance: a federation of savings cooperatives backed by a big mortgage bank (issuing covered bonds to institutional investors), and a home savings and loan association based on individual household savings.

In the meantime, international retail banks which had been heavily dominant in the precrisis mortgage boom seem to be caught in the shrinking space between stricter risk management and the pressure of investing surplus capital. The most important international retail banks currently only cover 15 and $7 \%$ of the mortgage market, with other international banks falling even more behind (interview 21). The possible outcome of this situation could be that these banks reorient their activity towards other segments of the real estate market towards commercial real estate, for instance, or project loans for housing development. Other options would be that they turn towards consumer loans, or towards the more complicated business of financing enterprises.

\subsection{Critical points of interface}

On the graph below, I have outlined how the main actor groups of the Hungarian housing market relate to each other (Figure 9). The points of interface between them are the practical channels through which uneven development is mediated. I will highlight some of them, which appear as most important in shifting the housing market (these are indicated with black lines; the strength of the relation is indicated by the width of the lines). 


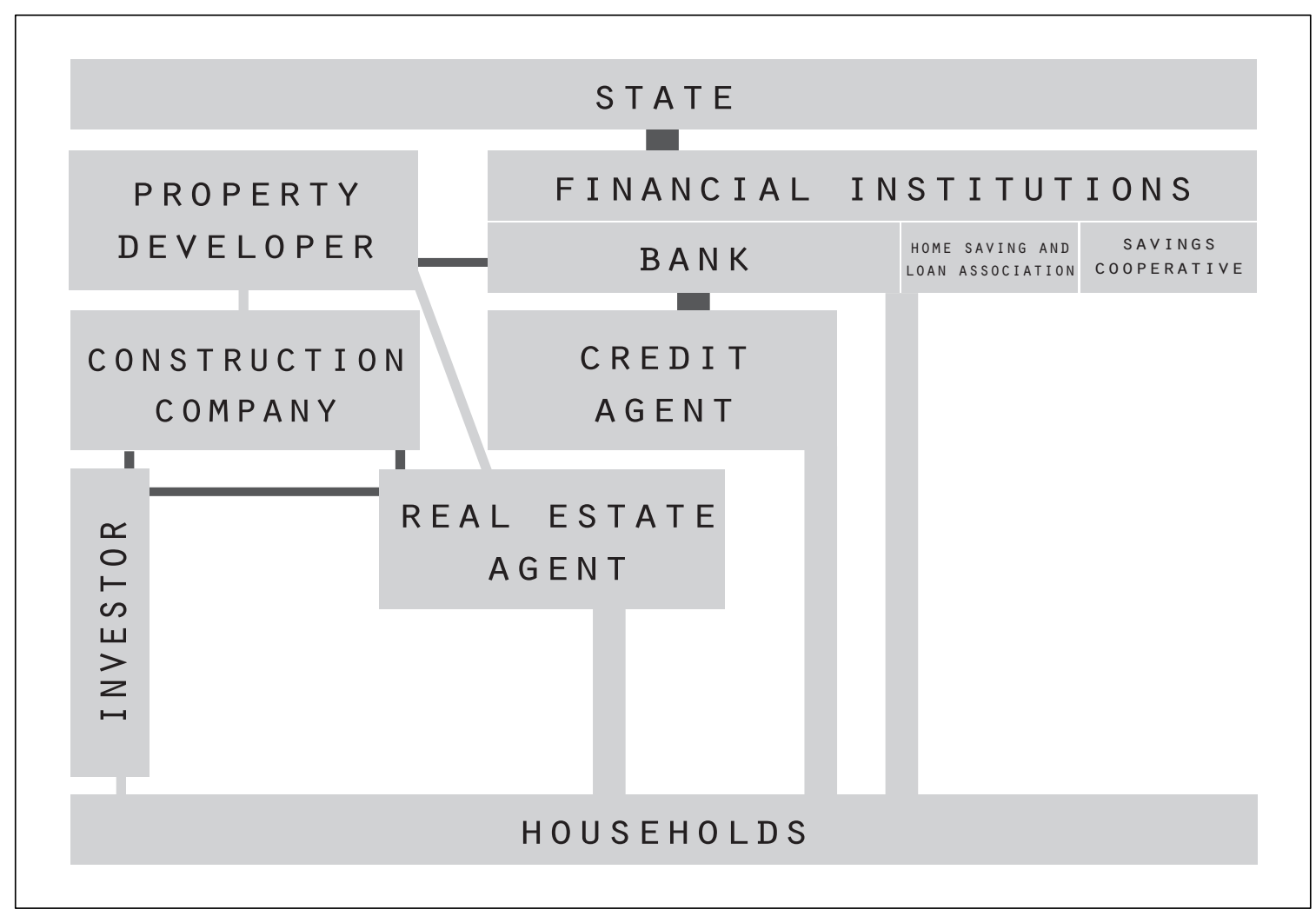

Figure 9. Mapping economic actors of the housing market and their relations.

Source: own compilation.

\subsubsection{Credit agent - bank}

The interface between credit agents and banks is crucial in channeling capital into the housing market. This channel predominantly concerns individual mortgages issued to households. The accepted estimation across the sector is that credit agents bring between 40$60 \%$ of new mortgage clients in all major retail banks (interview 21). This relationship is one of strong codependencies: banks heavily rely on agents for broadening their client base, and recently also in responding to stricter requirements of consumer protection. Credit agents, on the other hand, are completely dependent on the banking sector for maintaining their business. Recently, they are increasing their marge for manoeuvre in this respect by giving more weight to home savings and loan associations in their activity, and will soon probably also be able to enter the market of savings cooperatives (at the time of research, the latter was only under negotiation in several credit agencies).

In the years of the pre-crisis credit boom, the number of new credit agencies and individual agents rapidly grew. It was a very lucrative business, and the market was big enough to make space for everyone. During this period, credit agencies could freely negotiate their fees with the banks they approached. Naturally, larger networks could get better deals from financial institutions: mainly in terms of the percentage offered as an intermediation fee, but also concerning other benefits / particular advantages. Agencies would thus make banks compete in their offers, and would orient clients towards specific banks according to the benefits to be reaped (interview 17). When the mortgage crisis hit, credit agents were pushed to the fore in the blame-game that followed. Several banks vowed not to work with agents again (interview 25 ), and much stricter regulation was introduced concerning the activity of financial intermediaries in 2010 and then in 2016. The latter meant an especially strong blow to the 
sector, as it maximised the fee for intermediation at $2 \%$ of the contracted mortgage value. This was sometimes half of what credit agents would normally work for - but also meant a market advantage for those who already had lower fees before the regulation; who were typically agents active in more peripheral locations or in smaller companies ${ }^{22}$. However, several of my interlocutors highlight that the maximum $2 \%$ intermediation fee also meant that agents in less prosperous housing markets - thus, who manage a lower number of transactions and smaller mortgages - cannot make enough money under these conditions (interviews 17, 34). Coupled with stricter criteria for obtaining a licence, this has led to a reduction in the number of financial intermediaries compared to the pre-crisis years.

One of the strategies for coping with declining profitability in the market of mortgages is to diversify their portfolio with a number of other financial products. Banks are willing to give them permission to sell an increasing variety of their products, because this is also a way of keeping the intermediaries engaged. The importance of personal contacts and of having a smooth and dynamic interaction between the bank professionals and financial intermediaries is also highlighted. Often, intermediaries continue to work with the same banking professionals even if they change office (or even company - which makes banks interested in keeping their employees who have extensive agent-contacts). Some banks will also designate specific offices dedicated to working with credit agents. These dedicated offices only exist in Budapest reinforcing many other dimensions of better access to finances in core areas (interview 13).

Since mortgage lending started to expand since 2013, banks have again become more dependent on financial intermediaries because they are meeting difficulties to increase their internal capacities in terms of human resources at a sufficient pace. Furthermore, since most banks reduced their number of offices during the crisis, they currently also need agents as a direct interface with customers. Also, in light of stricter customer protection regulation ("fair banking rules" 23 , which translates to stricter and more complex credit scoring systems, as well as the complicated process of being able to use state subsidies, the role financial intermediaries can play in "navigating" clients through a mortgage request becomes more important (interviews 18, 25, 32). As a representative of one of the major banks put it, agents have an important role in handling the "bureaucratic anxiety" involved in the process of obtaining a mortgage (interview 21). Furthermore, working with external agents instead of employees is also cheaper for banks, since it does not increase their overhead costs - which would be higher than the now fixed $2 \%$ fee they pay to externals. Thus, in the context of increasing competition on the mortgage market, banks are currently increasing their share of new mortgage contracts through credit agents. Other actors of the financial market - most notably the savings cooperatives - are also establishing collaboration with them. This recently articulated interest from the part of savings cooperatives falls in line with their strategy to become more important actors in the market of mortgage lending: through financial intermediaries they hope to have access to higher status clients. As the manager of one of the savings cooperatives in a peripheral county seat put it, for the time being, households approaching them with mortgage requests are usually those "who had already been sent away by three commercial banks" (interview 39).

It is in the interest of both sides (of financial institutions and of credit agencies) to broaden this interface. This is, however, in contradiction with the reduced profitability of this segment of housing market activity, which makes it less attractive for potential agents. This is reflected by the fact that when questioned about the challenges they meet in their business development,

\footnotetext{
${ }^{22}$ https://www.portfolio.hu/finanszirozas/hitel/most-aztan-jol-megnezhetik-magukat-ahitelkozvetitok.222430.html

${ }^{23} 2014$. évi LXXVIII. törvény a fogyasztónak nyújtott hitelről szóló 2009. évi CLXII. törvény és egyes kapcsolódó törvények módosításáról; accessible here: https://www.mnb.hu/letoltes/2014-evi-lxxviii-torvenymodosito-torveny-1.pdf
} 
many agencies highlighted the lack of adequate workforce - both in numbers and in experience and qualification (eg. interviews 18, 19).

In terms of the effect this interface has on the unevenness of the housing market, somewhat contradicting tendencies are at work. On the one hand, in order to attract financial intermediaries, banks will propose more favourable conditions (in terms of initial fees / speed of getting the mortgage decision through / possibility of early repayment etc.) to clients brought by the agents (interview 10). This can mean that households can get a mortgage on somewhat better terms if they pass through an agent. Furthermore, credit agents also have a role in expanding the pool of households who can be included in the dominant, mortgage-based housing finance regimes: through their overview of different banks' offers they can sometimes arrange a mortgage for a household who might not have managed to receive one on its own (interviews 25, 32). However, due to considerations of profitability, credit agents will necessarily focus on clients with a higher status and better financial possibilities - since these clients will buy more expensive housing, take a higher mortgage and thus generate more revenue -, and on more profitable housing segments - which means new construction and core urban markets. Thus, they will actively contribute to channeling more money to the "top end" of the housing market, and will also be financially interested in rising house prices.

Generally speaking, financial intermediaries will balance "quality" and "quantity" of their pool of clients. While the former process increases inequalities through making capital more accessible at the top of the social and geographical spectrum, the latter raises the question of whether a new wave of financial overinclusion is on the rise. This question is also debated by professionals of the field (formulated as a fear of new housing bubbles), but they usually claim (in a self-reassuring way) that current more prudent lending policies guarantee that this is not (yet) the case (interviews 2, 9).

\subsubsection{State - financial institutions}

The interface between the state and financial institutions is of crucial importance on the Hungarian housing market. Since the state aims to minimise its institutional capacities and involvement in the implementation of housing policies (interview 26), banks become the front desk operators of the overwhelming majority of state subsidies allocated to housing purposes (Pósfai-Jelinek 2018). Practically, the dominant channel for the state to intervene in the housing market is currently through financial institutions. Beyond the general lack of political and institutional engagement in the domain of housing from the part of the government (there is no clearly defined responsible for the issue of housing within the government, for instance), this approach of "passing through the banks" also falls in line with the strong political preference for individual homeownership as the only supported form of housing.

This channel also opens possibilities for the state to shift the field of financial institutions. This is done in some cases through acquisitions or legislative changes, but also through more subtle means, such as disseminating information. When important new policy instruments are introduced, banks can gain or lose important market shares according to how quickly they can adapt their services. When the new family-based housing subsidy was introduced in early 2016 , it was very clear that the two main domestic banks already had the infrastructure for advertising and managing this subsidy set up and ready to go (interviews 12, 25).

Because of the role banks play in implementing housing-related subsidies (now $C S O K$, or previously subsidised mortgages), they also appear to be the most important consulting partners of the government in decisions about housing policy (interviews 20,29, 40). The main official forum for this is through the Banking Association, but there are some consultancy forums 
operated by the central bank (interview 29), and more informal channels for consulting also exist between professionals and bureaucrats involved in housing issues for a longer period of time (interviews 20,26).

\subsubsection{Property developer - bank - household}

The locally articulated spatial unevenness that is produced by the logic of project loans has been outlined in the previous chapter. Here I will sketch the way how the triangular interface between banks, property developers and households acquiring housing in new development projects plays out. It is very common for banks to have specific deals with property developers to secure the financing of the project from both the project development side and the customer side (interviews $2,11,12$ ). When a project loan is granted, the bank will often also develop a specific offer for households taking a mortgage to acquire property in the given project. This is advantageous for all parties, because the developer can be sure that their customers will receive the necessary credit, households can get the mortgage faster and often with better conditions, and the bank can be sure that they will be the main mortgagee (interview 12). However, the end result is that banks are financing the same flats two times: once from the project construction side and once from the customer side; earning interests and securing their risks through both channels. Furthermore, this is supported by important state subsidies on both channels: the almost simultaneous introduction of a drastic reduction of VAT on new construction (giving important subsidies to developers) and the new family-based housing subsidy (leveraging the buying potential of households) in early 2016 is thus quite directly financing the benefits of financial institutions on new housing development projects.

\subsubsection{Investor - construction company - real estate agent}

Another triangular interface emerges among financial investors becoming interested in the housing market, smaller scale construction companies and real estate agents. Because of low interest rates on savings and other forms of financial investment, and the profitability of new housing construction with low VAT, a number of investors who had previously not been involved in real estate are currently showing interest in the housing market. However, since they lack experience in this domain, often they team up with real estate agencies to realise their projects. These investors can also be ideal partners for smaller construction companies who fall outside of the narrow circle of the biggest property developers preferred by banks, and thus cannot acquire bank loans on good terms (interview 12). The investors in question are typically domestic entrepreneurs from other sectors of the economy. For example, in the case of one of the agents involved in making these kind of connections in Budapest, the main investors involved are a domestic cosmetics company, workforce renting agencies (which have become important in Hungary in the recent wave of re-industrialization; providing rather precarious labour force for the expanding car industry), as well as a real estate investment fund from one of the secondary cities (interview 15). Compared to large financial investors or the largest property developers, these companies typically have more mixed profiles and are involved in projects outside of the "prime" core locations - but in places that are still safe investments (eg. in outer districts of Budapest or more prosperous secondary cities).

Many real estate agents have recently developed a specific branch of activities focusing on new construction (interviews 14, 15, 22), bringing their expertise about the housing market (often already advising an investor on where to buy land) and managing bureaucratic and sales issues; connecting different actors. This focus is a consequence of higher returns in the segment of new housing than what can be earned by engaging in transactions on the market of existing 
housing units. However, since large property developers usually have their own internal marketing and sales divisions, this branch of services is interesting for the "second-tier" construction companies described above (interview 24). Another type of - less active involvement from the part of real estate agencies in this market segment is to approach developers once the project is underway and to engage for the management of sales activities and of mortgage requests for the future clients (interviews 14, 19).

\subsubsection{The inherent logic of business: concentrating on the top}

Generally speaking, economic actors tend to focus on households of higher economic status. This is true for real estate agents and financial intermediaries, who are interested in deals involving more expensive housing units and higher value mortgages. This focus also orients them towards giving priority to new housing development projects (interview 22). The bias towards new construction is present in all segments of the housing market because of its higher rates of profitability, whereas new housing still - in spite of the construction boom - only represents less than $15 \%$ of all transactions. Real estate agents also tend to focus on investorbuyers (if they are active in markets where they have the possibility to do so), who can return and become customers several times, and are also "less complicated" than households buying for their own housing purposes (interview 15). Thus, although real estate agents often present a narrative of supporting average families in their access to housing, in reality their business considerations will not always coincide with this ethos (interview 14). The logic inherent to the business decisions of firms (based on considerations of profitability) channels more money towards economically better off social groups and geographical areas- while also securing better conditions and easier access to this money. This process can be seen as an example of how the everyday functioning of firms is transformed under the pressures of financialisation (Dixon 2010).

I think it is important to also direct attention to lower scales of the hierarchy of firms on the housing market. Beyond the "top" and "core" (which is visible in real estate-related press and conferences), there is an often overlooked diversity and messiness of housing market actors, intertwined with each other on a local scale. For instance, I believe the currently broadening field of smaller scale investors is very relevant to investigate. There are reasons to assume that some of these actors are currently emerging as new actors managing rental housing of various forms, stepping into a niche of lacking "real estate professionals" in the domain of housing. (Although in many cases, it is only an issue of providing financial means for smaller projects of housing construction for sale.) These individuals and companies appear to be important actors in shifting housing markets that lay beyond the most central and most profitable. An in-depth investigation of their investment strategies would be a valuable further avenue for research.

If we shift perspective in terms of uneven development, looking from the peripheries we find a quite different view of housing market developments than what the dominant narrative conveys about a new boom period. In relatively peripheral cities, bank administrators struggle to meet target numbers for allocating mortgages, since many households are not eligible for a mortgage - because of an ongoing, previous debt or because of insufficient income levels / employment status (interview 30, 39). This means that many households also do not have access to housing - since savings are not enough and house prices are starting to rise in less prosperous cities as well (interview 39). In these cities, construction capacities are also lacking, because it is more profitable for companies of the local construction industry to work on projects elsewhere, with higher prices and higher returns (interview 39). Corporate actors of the housing market adapt to these market conditions in the business model they employ. 
Generally speaking, the lower a firm is situated in the hierarchy of company size or locality, the more diverse and flexible it will have to be in its business model. As a result, hybrid real estate companies emerge in smaller, local housing markets, combining their financial resources and their services related to housing (and real estate more broadly) in a creative way in order to make a livelihood. 


\section{CHAPTER 5}

\section{KEY MECHANISMS OF REPRODUCING UNEVEN DEVELOPMENT ON THE HOUSING MARKET}

In this final chapter I will highlight a few key mechanisms through which unevenness is reproduced on the Hungarian housing market. I am interested both in mechanisms that restructure and reproduce hierarchies among the actors of the field, and in socio-spatial inequalities that are produced in terms of access to housing. I am particularly interested in grasping mechanisms through which firm-level decisions and corporate strategies (which often relate to market competition or to risk management) are translated into uneven spatial development. I will approach this issue from various perspectives in the following chapter.

\subsection{Layered consequences of overinclusive mortgage lending}

Due to its scale and rapidity, the pre-crisis mortgage boom had a huge impact on the Hungarian housing market, and determines its dynamics in many ways until today. These layered consequences of the period between 2000 and 2008 can be seen in various aspects of how the housing market functions today; from the prevailing high level of indebtedness of Hungarian households, through the actors that have managed to strengthen their market positions, to spatial inequalities of house prices and transaction numbers. Previously I have argued that the dual dynamic characteristic of uneven spatial development; that is, processes of homogenisation and differentiation can best be grasped on the housing market through mortgage lending. Within the literature of financial geography the dual spatial dynamic of mortgage lending is often described with the notions of financial overinclusion and exclusion. Approaching the housing market through this duality expresses the idea of how inclusion in an extractive system inherently carries the production of further unevenness (Lapavitsas 2009). In the case of housing, this extractive mechanism channels resources from households towards corporate actors, and within the hierarchy of corporate actors towards the top of the hierarchy. When looking to housing markets that lie beyond the narrow "core" segments, the effects of previous mortgage lending become apparent.

The deep social and political crisis induced by the crash of forex mortgages after 2008 has provoked a number of political responses. A number of social movements emerged in response to this issue, framing a critique of capitalist housing markets from a strongly nationalist perspective, targeted against western banks (Gagyi-Jelinek 2017). The government has introduced a series of measures with the end result of practically cancelling all forex loans, but not being able to handle the broader problem of huge household debt (Bohle 2017, HegedüsSomogyi 2016). Here, I will focus on the implications of this process in terms of spatial dynamics and of firms present on the housing market; highlighting how the pre-crisis mortgage boom determines many dynamics of the housing market today.

\subsubsection{Spatial consequences}




\subsubsection{Spaces of exclusion}

Many people fall out of the current new mortgage-based housing boom which is rolling out since 2015/2016 because of their inclusion in the previous wave. The most straightforward aspect of this new exclusion is that there are still over 140.000 (this is around the number of total housing transactions in a year) non-performing mortgage loans, which automatically excludes these households from acquiring a new mortgage, since they are registered on a list of non-performing debtors, who cannot take a new loan from a financial institution. (This list also includes debtors failing to pay other loans, not only mortgages. Altogether, there are 1.6 million non-performing loans registered on $i^{24}-$ which is a huge number in a country of 10 million people.) Beyond the sheer fact of non-payment, the housing market immobility this implies is also important. The majority (over $80 \%$ ) of these debtors owe more money than what they had originally borrowed, and the total value of outstanding debt accounted for $140 \%$ of the pledged collateral (which means the value of real estate behind these loans) in 2015 (Dancsik et. al 2015). That is, as we have written elsewhere (Pósfai et al 2018): "a high share of debtors are in negative equity - partially because of increasing values of debt (due to changes in exchange rates and interest rates and accumulating fees throughout the years of nonpayment) and partially because of declining house values (especially in disadvantaged regions). This means that even if debtors were to sell their real estate, they would not be able to conclude their debt - which in turn leads to social and geographical immobility."

Since debt cancellation is only accessible in very restricted cases, households in negative equity have no way to move out of their situation: if they would sell their property in order to repay the debt, they would still have the remainder of the loan (above the value of the house) to repay and would not be able to "start clean". They would not have the money to buy new housing and are not eligible for a mortgage. Thus, the most common option is to go into rental housing - with their reduced income while paying off the remainder of their debt. Often, rental housing is not affordable for these households (rent levels in urban areas have been steeply increasing in recent years) and thus they find informal / substandard housing conditions, or move to peripheral areas. Several housing market tendencies emerge from this process which is articulated on the household scale.

On the one hand, given the above circumstances, one of the very logical decisions often taken by households is not to move at all: in this way they continue to accumulate debt, but at least have a place to live. This strategy was possible until early 2016 , since for the majority of the time between 2009 and early 2016, there was a legislative ban in place on evictions due to a defaulted mortgage. This moratorium did not concern other evictions and also did not protect against various forms of pressure put on households by debt collectors, but still meant that banks needed to find other ways to recover their money. This contributed to the low level of housing transactions throughout these years. Currently, there is a new wave of auctions and evictions, making the exclusionary consequences of overinclusive mortgage lending yet again more visible.

Another important consequence is that this process has created a new demand on rental housing, which is being recognised by a number of new housing market entrepreneurs. The pressure on rental housing is constantly on the rise, since an increasing number of people cannot receive mortgages under current stricter credit scoring policies and since house prices are steadily increasing.

\footnotetext{
24 https:/www.portfolio.hu/finanszirozas/hitel/hitelkatasztrofa-magyarorszagon-47-ezer-elbukott-lakas-milliostomeg-a-bar-listan.278173.html
} 
In terms of spatial processes, I claim that the previous spatiality of financial overinclusion and the current spatiality of exclusion overlap. In order to better understand how this concretely happens, it is useful to go into more empirical detail about the spatiality of non-performing mortgages. As argued in the third chapter, in the last, most expansionary years of the mortgage boom (2006-2008), forex mortgages spread out in geographical terms as well; to areas that can thus be seen as most heavily affected by overinclusive mortgage lending (interview 29). After the crisis many mortgages in these areas started defaulting: non-performing mortgages are thus over-represented in smaller settlements and in economically less well-off regions (Dancsik et al. 2015). As a result, the number of houses for sale increased (with owners who were quite desperate to sell) and house prices dropped, while there were no interested customers and noone that would have had the financial means to buy. When these properties got to an auction, they would sell at even lower prices; often to emerging entrepreneurs who specialised in this kind of business (while the mortgage debtor was still stuck with an important debt). Even if there weren't many auctions in a given area, the depreciation of house prices and the low level of transactions involved in this process meant that settlements which were previously heavily involved in overinclusive mortgage lending practices now typically get very bad ratings from financial institutions. House prices and transaction numbers are important components of any bank's redlining policy, because their possibilities for selling a property serving as collateral for a mortgage will depend on this (interview 12).

The lack of available mortgages creates a further block on the housing market. As previously argued, households acquiring property for their own housing purposes (especially in less prosperous areas) use mortgages more often, while investor-buyers hardly ever take a mortgage. Thus, in new redlined housing markets where mortgages are hard to get, the role of household savings in acquiring housing will increase. In the agglomeration area of a northeastern postindustrial city, several settlements are struggling in the trap of being eligible for bank credit only on very restricted terms. Even in larger settlements of this area, properties only get financed up to $50 \%$ of their estimated value. This means that households wanting to sell their property have difficulties to find customers (interview 32). A different agent from the same city explains how these patterns of previous overinclusion and current exclusion overlap even in one of the urban (close to the city centre), but lower-status housing estates: many people moved here with the help of the previous family-based housing subsidy and forex mortgages. As a result (if they met difficulties of payment), they are currently penalised and can not have access to either channel of housing finance (interview 31). He also highlights how there were clearly more forex loans in this city than in other, more prosperous cities of the region. In one of the agglomeration towns of this northeastern city, a real estate agent running a small local office describes the spiral of financial exclusion many households in the area encounter under the contemporary housing finance regime: households typically do not have any savings, and if they are not eligible for $C S O K$ (because of the lack of a long enough work contract, for example), then it is impossible for them to make the necessary downpayment for a loan. Especially since in these settlements they will typically receive bank financing only for a smaller part of the whole price of the house (interview 30).

The spatial consequences of overinclusive mortgage lending can also be traced through the activity of the National Asset Manager (NET), which is a state-owned company buying up properties of defaulting mortgage debtors at reduced prices. Comparing the acquisitions of NET and general housing transaction statistics, the emerging pattern is that in peripheral areas this agency became the dominant actor of the housing market in the years following the crisis (Pósfai et al 2018).

Beyond these most marginalised spaces, in areas that were heavily involved in the precrisis mortgage lending, but are not in the trap of negative equity (and households are thus 
willing to sell in order to free themselves of debt), often the majority of housing transactions (of not newly built housing units) involves a property burdened with debt. In some parts of the eastern agglomeration of Budapest this can reach up to $90 \%$ of all transactions (interview 16).

\subsubsection{Spaces of displacement}

The consequences of overinclusive (homogenising) patterns of pre-crisis mortgage lending are not only situations of blockage and immobility, but also of mobility and displacement. Mortgage debtors living in places where housing market activity gained momentum in the past few years and house prices started to rise were put under much more pressure to give up their properties, and also had better chances to sell than in peripheral areas. This resulted in a wave of displacement of mortgage debtors of the pre-crisis period towards the peripheries of core housing markets. Accounts from Budapest and from one of the most prosperous secondary cities (one of the car-industry cities) clearly outline this process. A real estate agent working in one of the outer districts of Budapest and adjacent agglomeration towns describes how in the years after the crisis, up to $40 \%$ of her clients were mortgage debtors selling their flats in the city and moving out with what little money they had left after repaying the bank (interview 7). Households who could not pay their debt were faced with the choice of either selling their house themselves (hopefully at a higher price) or waiting for the bank to reclaim / auction it. Since there was a moratorium on evictions in place, households could theoretically hold out however, in more prosperous / mobile housing markets, banks and debt collectors are usually more interested in realising their mortgage rights, than in peripheral, stagnating housing markets. Thus, debtors living in major cities were usually put under more pressure to sell. Households moving out of the city in this way typically bought low quality housing in the more peripheral parts of the agglomeration area (interview 7). Currently ongoing research conducted in this area by a colleague also suggests that displacement as a result of mortgage lending happens in subsequent waves, with the more vulnerable households later being pushed further on from the nearby agglomeration ring to more peripheral areas (Vigvári forthcoming).

In the county seat of Kecskemét, the opening of a big car manufacturing plant (decided in 2008 and starting production in 2012) had a very strong impact on the local housing market. In this city as well, my interlocutors affirmed that over $50 \%$ of the transactions (of not newly built units) they manage concerns real estate serving as collateral for a non-performing mortgage. They say that the majority of these debtors are content if they can sell the house for the amount they owe - and are mostly left without any capital. Thus, they also look for rental housing, which, however, has become very expensive in this city due to the local housing boom. As a result, defaulting mortgage debtors are typically pushed out towards nearby more peripheral towns and cities (interview 25).

\subsubsection{Consequences from the perspective of firms}

Since the number of non-performing mortgage loans (NPL) was so high compared to the overall number of housing transactions in recent years, they had a significant effect on housing market processes and also opened a space for new economic actors of the field. Generally speaking, the share of properties with a debt burden is very high on the market of not newly built housing. In certain areas it can reach up to $90 \%$ (interview 16), but in most places it appears to be the majority of transactions that real estate agents manage. This means that real estate agents have had to develop new services in order to facilitate the often complicated process of managing a transaction where one debt has to be cancelled and another usually has to be obtained (on the side of the purchaser). Examples for this include the development of a 
form that is easy for clients to fill out, which is a request towards the bank in case there is a seriously interested buyer, or developing specific legal support services (interview 15). This process also has a rather tight temporality, which agents step into by managing it in an efficient way (interviews 24, 25). Making the necessary connections and supporting these processes in an "innovative" way was often what allowed real estate agents to survive the years of the crisis (interview 19). In general, these kind of agreements are in the interest of all parties involved (or, in the case of the debtor is the "least worst" option), because in these cases usually a higher price is agreed on than if the property would be put to auction.

One of the real estate agencies has also engaged in negotiating with banks to support the development of a protocol for partial debt clearance of clients, which would cancel negative equity and allow debtors to "walk away" (interview 15). The owner of the agency is trying to negotiate this model with banks with the perspective that such an agreement would unblock an important part of the housing market. This appears to work better in locations outside of the most core housing markets: in Budapest, banks are less willing to cancel the debt which remains above the selling price of the house (interview 15), while in cities with less active housing markets, such agreements can be more easily reached (interview 32 ).

From the perspective of financial institutions non-performing mortgages meant an important weight on their financial performance for several years after the crisis (by 2014, nonperforming mortgages accounted for one quarter of the total mortgage portfolio - Dancsik et al. 2015). I will briefly outline the main options a bank has in handling a significant portfolio of nonperforming loans (NPL).

The first option is to agree on a restructuring of the loan and to receive instalments of payment from the debtor for as long as possible. This way the bank can ensure a cash flow albeit lower than previously expected, but still better than complete non-payment in a context where satisfying mortgage claims through foreclosure was difficult (interviews 10, 12), partially because of legislative constraints and also because of market dynamics. During this period, particularly in economically less well-off regions, it was very difficult to sell property, thus, many banks in Hungary were dominantly following the strategy of restructuring for quite a long time. This, however, is an expensive process in the sense that it requires human resources for potentially long-stretching negotiations. In the post-crisis years, when many banks were closing offices and reducing employee numbers, this was not an option. In many cases this blocked situation led to NPLs stalling for many years, with the amount of debt silently exponentially growing. The consequences of this somewhat postponed bomb are manifesting today. Now that mortgage markets are again expanding and banks meet an increased pressure to clear their accounts (the central bank also circulated a recommendation on this topic to all concerned banks in March 2016), the 140.000 debtors who still have non-performing mortgages are currently faced with quicker processes.

The second common strategy to deal with NPL has been to sell the property and repay the whole or partial amount of outstanding debt (interview 21). One version of this process was to reach an agreement with the debtor who would sell the property themselves or through a real estate agent. The largest Hungarian bank created an own real estate agency to deal with these cases (interview 31), and others contracted external real estate agencies (interview 32). In these situations property could be sold on average for around $60 \%$ of the estimated value of the real estate (interview 21). The second option was to go through the legal procedures of enforcement and selling at an auction. This is a much more costly process for the bank, and (up until 2016) properties sold at auctions were bought under $50 \%$ of their value - thus, this meant a lower ratio of recovered capital. Selling independently or through a real estate agent is usually an 
option in the case of properties that have better market value, while allowing it to go on auction will usually happen with less valuable real estate in more peripheral locations (interview 31 ).

A third option from the perspective of the bank is to engage in a large debt sale, and to sell NPL in packages to institutional investors (interviews 8,20 ). This was not a common strategy before 2016, however it became interesting when the possibility for foreclosures was reopened, and when new mortgage lending restarted. This led to a very important debt sale in the Hungarian banking sector in the last quarter of 2016, amounting for over $6 \%$ of the total outstanding stock of credit to households (MNB 2017). A single financial actor (a bank previously strongly involved in forex mortgage lending) sold over 200 million euros worth of NPL to one institutional investor, reducing the share of NPL in its household loan portfolio from $25 \%$ to $9 \%$ (interview 20). Such a large-scale debt sale is unprecedented on the Hungarian housing market and its consequences remain to be seen. The main investors are international claims management companies who had previously been active in the market of unpaid utility bills. The major investor in the sell-off of NPLs at the end of 2016 was a Swedish company active in over 20 European countries (interview 10). When the property behind an NPL is sold at an auction or as part of a packaged debt sale, the households at the end of the mortgage debt will typically have significant material losses. Their property will be sold well below the market value, which will leave them with a very significant portion of the debt still unpaid - in addition to most likely also losing their home.

A fourth option open to banks and households is for the property to be taken over by the National Asset Manager (NET). This is a state agency founded in 2012 to take over the properties of non-performing mortgage debtors based on social criteria. It was a measure targeted at debtors in difficult socio-economic situations, who then stay in their house and become tenants of NET. This was an acceptable solution for banks, since they could regain around $50 \%$ of the value of collateral, and was, on the other hand, a quite significant socially oriented public intervention in the housing market. This agency could have been a possibility for rebuilding a public housing stock, and was a solution for the cc. 30.000 households who could enter the program. However, the program has currently reached its limits and there appears do be no political initiative to make a long-term instrument out of it.

A last option for banks would be to keep the real estate portfolio behind non-performing mortgage loans and manage it. In the case of fragmented, single housing units with a defaulting individual mortgage loan, there is no management strategy that would be financially viable from the perspective of a bank. Additionally, the NPL remaining in banks' portfolio by 2015/ 2016 were typically the ones that cover real estate in worse housing market locations and economically weakest debtors. The series of government measures which had been introduced since 2009 in order to "manage the forex mortgage crisis" typically offered exit options for households in better economic positions (Gagyi-Jelinek 2017). Thus, those who were left represented the weakest segments of NPL. It is clearly not an option for banks to open operations of real estate management for the sake of this portfolio. Assuming management of a housing portfolio behind defaulting loans could be an option in the case of larger housing projects with many housing units. For instance, if a housing construction project defaults before being sold to individual customers, it could theoretically be kept and managed as rental housing by the bank, or later be sold by the bank to other investors. This is a strategy which is more often pursued in the US, for instance, but is not common in Hungary (interview 8); mainly due to the fact that there is no market and no corporate practice for these cases, along with a lack of institutional ownership of larger stocks of housing. Consequently, a potential investor in either packaged mortgages or a larger (defaulted) housing project would face extremely scarce exit options - which is not a wise decision in the logic of corporate governance. For this reason, banks in Hungary will typically prefer to manage NPL by restructuring loans, and when 
repayment by the household is clearly not an option anymore, they will prefer fast solutions for getting rid of the real estate serving as collateral. The latter, however, has proven to be difficult in many cases.

Altogether, pre-crisis mortgage lending clearly has a strong influence on how contemporary processes can unfold on the housing market - both from a spatial perspective, and also if we consider the market options available to economic actors. It would of course be possible to "dig into" further chronological layers and uncover how the particular way mortgage lending rolled out in the early 2000s was, in turn, a consequence of previously existing patterns on the housing market. This, however, would extend the scope of the present dissertation.

\subsection{Emerging new institutions of housing financialisation}

Many of the new forms of housing financialisation on the contemporary Hungarian housing market grow out of how dependent financialisation was articulated through overinclusive mortgage lending in the years preceding the crisis. The way how various actors react to the developed situation of a very important stock of non-performing household loans opens space for and triggers new processes. The dominant channel of housing financialisation continues to be that of individual mortgage lending - the new exclusionary patterns of which I have analysed in previous chapters. However, current tendencies also allow for new actors and new mechanisms of housing financialisation to emerge. It is interesting to understand these emerging mechanisms of investing capital in housing within the conceptual framework of financialisation because they shed light on how this globally unfolding process of housing becoming increasingly important as a form of fixing surplus capital is concretely articulated in the institutional and economic context of a Central and Eastern European country. With the analysis in this section I contribute to a field of expanding knowledge about how housing is intrinsically linked to global capital markets in variegated ways, shedding light on how new forms of housing financialisation in Hungary are also embedded in hierarchical, dependent relations of capitalist development.

\subsubsection{Institutional developments for a new wave of mortgage lending}

\subsubsection{Selling packaged NPL}

The process of selling packaged non-performing loans (NPL) described at the end of the previous section is important because on the one hand, it is a last step in the process of "handling" (in the sense of displacing this problem to other segments of the economy and of politics) the devastating effects of the pre-crisis mortgage boom. On the other hand, it is a necessary step for being able to roll out a new wave of mortgage lending - which dominates current housing market processes. The large debt sale at the end of 2016 was in part made possible by a recommendation issued by the central bank in March 2016 pushing banks to consolidate their NPL portfolios (interview 29).

Selling packaged mortgage debt can be seen as a kind of "inverse" subprime lending: good and bad collateral are packaged together (although clearly there is a strong dominance of nonperforming loans in these packages - MNB 2017 -, even among the non-performing there 
are more or less hopeless cases) and sold on secondary markets, but instead of being sold at higher prices than the aggregated value of real estate behind these loans, they are sold at much lower prices. In the case of the very large debt sale at the end of 2016, the selling value was $65 \%$ of the total gross value of the debt according to central bank statistics (MNB 2017), but in the case of particular financial institutions this value is reported to sometimes be around $25 \%$ (interview 10). This process can be seen as both an "upscaling" and "downscaling" in terms of the actors involved: on the one hand, claims are sold to international institutional investors, but on the other hand, these companies have the infrastructure to do the "on the field" work of debt collection; having the human resources for the negotiation process that banks often do not have. In the case of Hungary, the largest investor was a claims management company that has been present in Hungary since 1993, thus already had an existing corporate structure. Furthermore, since it has been involved in the field of collecting debts in utility payments, it has already had some engagement with the Hungarian housing market. Nevertheless, the current question is what these investors will do with the stock of non-performing mortgages they have bought. Even though legislative restrictions to satisfying mortgage claims have been raised, evictions still remain politically unpopular, and, as demonstrated earlier, "bad" mortgages are disproportionately backed by collateral in more peripheral and thus less liquid housing markets. Furthermore, these companies are not specialised in real estate management, and will most likely approach the management of this portfolio rather according to the capacity of the household to repay its debt than according to the possibilities to sell the property. In either case, this will most likely lead to a new kind of polarisation on the housing market: households that are considered capable of payment, or have mortgages backed by real estate that is considered more liquid on the market will be pushed harder by debt collectors. More pressure will be put on households where there is a chance of repayment, and "discount deals" of agreeing to repaying only a part of the outstanding debt will not be made available in locations where property is easier to sell. On the other hand, debtors in more depreciated housing markets may have better chances to cancel a part of their debt (interview 15). In this particular form of financialised housing, in an upside down logic households that are in the worst situation (among the "worst" circle of long-term non-performing debtors) may have better chances to keep their housing. Which, however, will not give any solution to their socially and spatially blocked situation.

\subsubsection{Mortgages backed by covered bonds}

One element in the attempts to make the Hungarian housing finance system less volatile and less externally dependent is the recent introduction of a minimum requirement for banks to back at least $15 \%$, and from November 2018 onwards $20 \%$ of their mortgages by covered bonds. The declared aim of this regulation is to increase the share of long-term resources behind mortgages and to channel new financial resources into housing finance. While the latter objective seems superfluous in the context of abundant liquidity in the financial sector, the former objective would be crucial in stabilising the Hungarian housing finance system. The idea is that this legislation will allow banks to attract more long-term reources and thus manage the risks associated with the different termination periods of their financial assets and liabilities - that is, to be able to put long term resources behind issued mortgages (Grécs 2017). However, the adequacy of this new legislation for handling the problem of lacking long-term resources is questionable since it determines the minimum duration of issued covered bonds in merely two years.

New resources are not drawn into the housing finance system through this channel because Hungarian financial institutions are actually mainly just recycling their own capital among each 
other through buying covered bonds; without any external capital entering (Grécs 2017). Although the central bank has set a maximum barrier to the extent of this practice, covered bonds have actually become a convenient way for Hungarian financial institutions to invest their surplus capital, while allowing mortgage banks to formally comply with the new regulation (interview 20). Nevertheless, this mechanism could potentially introduce some stability in the system by attracting capital from institutional investors with interest in longterm investments (such as pension funds or insurance companies). However, the fact that bonds can be issued on merely two-year terms seems to be a serious constraint to this aim of stability.

Although representatives of mortgage banks underline the differences between covered bonds and securitisation (interviews 8,12 ), the underlying logic of both mechanisms is to attract capital from financial markets for covering mortgage issuance, through instruments of financial investment which are somehow tied to real estate (interview 35). Furthermore, the institutional logic of mortgage banks as refinancers is also very similar to that of the US mortgage system before the crisis. Covered bonds are thus interesting to follow when tracing how global capital is invested in local housing markets. This segment of Hungarian housing finance will expand in the coming period, and will most likely be a crucial element of how stable the current wave of mortgage lending can be, and will also shed light on the global linkages of domestic processes of housing financialisation.

An interesting aspect of the minimum requirement for covered bonds is that this market is now clearly dominated by domestic institutional investors (according to one market actor, this is simply because international investors do not invest in Forint (the Hungarian currency) interview 20). Thus, it reinforces the role of these actors, and even if the financial resources channeled through this mechanism are in reality neither new external resources, nor long-term - they still fill the role of positioning a group of domestic institutional investors and a handful of refinancing mortgage banks as inescapable actors in the new Hungarian housing finance system.

\subsubsection{New investor-buyers - housing as investment}

Following the crisis the share of investor-buyers on the housing market was quite high, since mortgages were not available and thus housing transactions were technically restricted to those who had money to spare. Currently, the number of investor-buyers is growing because returns on savings are very low, and there is also an increasing demand (and thus business opportunity) for rental housing. I see this phenomenon as an important part of the new forms of housing financialisation, because it is a very direct case of considering housing as a store of value and as an alternative form of investment measured against others. Furthermore, since institutional owners are extremely rare on the Hungarian housing market, these individuals and small-scale entrepreneurs buying up individual housing units can be seen as crucial actors of a new expanding segment of the housing market beyond the dominant form of acquiring homeownership through inheritance, savings or an individual mortgage.

In chapter 3.4. I have discussed the specific spatial patterns of acquisitions-for-investment. Here, I will focus on how this practice emerges as a new form of housing financialisation and the actors it mobilises. There are a number of factors which have contributed to the expansion of this group of actors. First of all, very low interest rates payed on deposits and a few scandals and bankruptcies of brokerage agencies in 2015 have made capital flee from savings accounts and from other forms of financial investment in recent years (interviews 12, 19). Second, as a result of the economic policies introduced by the conservative government in power since 
2010, there is a strengthening upper middle class with increased savings and investment capacities. These people could benefit from decreasing house prices in the years after the crisis, and also saw housing as a safe way to invest their savings. Third, the stock of cheap housing (which could be targeted by investment-purpose acquisitions) was also boosted in certain locations by the sale of properties to repay nonperforming mortgage loans. Fourth, buying as an investment also started to be more lucrative in terms of the rents it can generate - because the demand for rental housing is strongly increasing as individual privateownership becomes more difficult to access for an increasing number of people.

The combination of these factors has led to an expanding but very fragmented private rental sector. The two dominant spatialities of acquisition-for-investment which I have identified are the "best" core housing markets on the one hand, and spaces of previous overinclusive mortgage lending on the other. The circle of actors stepping into these two spaces are very different. Housing markets of inner-city Budapest are dominated by foregin investorbuyers (before, Irish and Israeli investors were the most typical, while now there is a growing importance of Chinese and Russian investors), while "good" locations of secondary cities are dominated by domestic entrepreneurs. Entrepreneurs that buy properties of defaulting mortgage debtors are a different circle of actors - empirical research about them would be very valuable to produce (although accessing these actors is surely very difficult). Currently, the market of non-performing mortgages is no longer very interesting, because the minimum selling price at an auction was recently regulated at minimum $90 \%$ of the value of the property (which means investors will be less likely to buy), and the above-mentioned large scale institutional debt sales will probably become more typical solutions for clearing banks' portfolios of non-performing loans.

As a further form of investment in housing, an increasing number of entrepreneurs realise the market potential in the most precarious housing situations, as a result of which we see a boom of private workers' hostels, "tenant-houses", private student residencies and of various forms of exploitative, usury rental. Property developers are also starting to see the potential of a new rental segment, and although very carefully, they are also starting to step into this market. Some of the large developers are currently keeping a small portion of the flats they build and start managing them rental units (interview 2, 28).

\subsubsection{Transforming institutional structures under housing financialisation}

Tendencies of financialisation can be observed in the strategies of various agents of the housing market (Dixon 2010). For instance, the largest real estate agency has recently gone public on the stock exchange, aiming to attract capital this way from small domestic investors, and has also founded the first only residential real estate-backed real estate investment fund in Hungary, where they also hope to attract international investors (interview 4). Financial investors have started to establish real estate companies and to directly enter the real estate market more and more (interview 6), while existing real estate companies have also, in some cases, been taken over by financial investors (interviews 2, 28). These tendencies mark instances of how real estate and financial sectors become intertwined under financialisation. REITs (real estate investment trusts) are also on the rise with active support for their development from the central bank.

Altogether, pre-crisis expansive mortgage lending, the consequences this had at the moment of the crisis, and the responses to the crisis are now creating new spaces for the financialisation of housing and for emerging forms of institutional ownership. 
Individual investors buying at foreclosures, claims management companies buying distressed assets in packages, or the National Asset Management Agency are all actors that could become new institutional actors of an emerging rental market. However, for the moment it seems that they all refrain from really stepping up as such — in spite of the increasing market pressure / demand for rental housing. This is partially due to a lack of regulatory and budgetary engagement from the state which would facilitate this process, and also to the fact that much faster returns are still accessible when engaging in housing sales and new construction. Especially since government policies also strongly channel capital towards the latter. A further possible reason for this lack of institutional engagement in a new rental sector is the lack of experience and capacities in this kind of activity, and with the "scary" example of public housing being something none of the actors wish to engage with.

The concrete forms housing financialisation takes largely depends on the ownership structure and regulatory / institutional context in a given country. Thus, the concrete channels and spatial patterns of housing financialisation are very much rooted in domestic class politics. Nevertheless, there are structural similarities in how housing financialisation unfolds on the (semi)peripheries - mainly linked to the sources of finance available on the housing market. As argued in the third chapter, since impatient finance invested with a volatile temporality and expectations of high returns characterises semiperipheral housing finance, this also favours tenure structures of individual homeownership and thus mortgages as the dominant channel of housing financilisation. Currently, with possibilities for accessing homeownership getting narrower, the dominance of this tenure structure is shifting on the peripheries of Europe. New space is opened where new forms of rental housing develop, which often become the new channels for housing financialisation (Fields-Uffer 2016). These are most often forms of rental housing which merely create new channels for capital extraction from households, and are often even more precarious than private property acquired with debt. The question is whether the wavering of the model of indebtedness-based homeownership could be used to create more stable and accessible forms of housing.

\subsection{Bearing the risks of financing housing}

When investigating the housing market from the perspective of corporate actors, the notion of risk management is central. This is what determines how these actors will step into processes on the housing market, and ultimately, it is practices of risk management that are translated to uneven development. In this brief section I will borrow the lens of risk management and apply it beyond the circle of economic actors of the field - to investigate how the risks and costs of housing provision are assumed (in a dependent, semiperipheral structure of housing finance). I will demonstrate how, in the end, households are the actors who do not have the capacity to push huge risks and costs involved in the acquisition of private property on any other actor and thus have to assume it themselves.

The Hungarian government has introduced a number of measures for consumer protection as a result of the mortgage crisis; strictly regulating lending criteria, aiming to limit the risks borne by individual households (such as maximising loan-to-value ratios and payment-toincome ratios, or banning forex mortgages unless the debtor has revenue in the given foreign currency). However, the limits of this mitigation are very obvious: as my interlocutor from Hungary's main commercial bank (which issues one third of all mortgages) put it: in an economy that lacks long-term financial resources, mortgage lending will always (understood on a historical scale) mean significant risks for one actor or another, and someone will always end up getting burned. In this context, the question is who the risk-bearing actor will be and to 
what extent. He claimed that the main obstacle to a stable system of housing finance is this lack of long term resources; along with the strong volatility of the regulatory environment which leads to a constantly shifting and more difficultly manageable landscape of risk. This, in turn, also makes the products (mortgages) more costly for end consumers (interview 21). This latter point is true of course because banks aim to transfer as much of their risk as possible to the households who are their end consumers - and risk always translates to cost in a capitalist logic.

In the dominant approach to housing policy of promoting individual homeownership through credit, it can be argued that the state privatises the risk of housing provision in two directions: to households and to corporate actors. Although, through financing their access to private property, risk is ultimately borne by households. In a context where housing provision is entirely pushed on market actors (financially and infrastructurally as well), the market actors that have better negotiating capacities will usually succeed in pushing this risk off of themselves. On the one hand, they will negotiate conditions with government actors that allow for significantly reduced risks on their side (interview 26) - waiting for the lobbying efforts related to the decrease of VAT on new construction before starting new housing development projects was a typical example for this. On the other hand, they will use market mechanisms such as subcontracting or engaging buyers with significant pre-payments to secure against their risks. Another such mechanism is how a new housing development project involves the same bank as lender for the developer (issuing short-term project loans) and lender for the households (mortgages, often supplemented by state subsidies). This is a way for the bank to benefit financially, and also to secure risks. The state subsidies that households can mobilise are also an important securing mechanism against the risks to be taken by financial institutions.

Thus, the risk of housing provision is ultimately borne by households, who will be paying off the housing-related loans. Furthermore, since a significant part of new construction (of single family homes) is still managed by households themselves, often the risks and costs associated to materially-infrastructurally providing housing are also taken on by individual households. Smaller economic actors with less institutional and financial capacity are also prone to more risk than the large actors of this market - although they will also strive to transfer as much of this risk as possible on the households that are the end consumers.

It was widely acknowledged among my interlocutors that the current predominance of variable interest rate mortgages is making households run a similar (albeit somewhat lower) risk as with the forex mortgages of the pre-crisis period (eg. interviews 10, 21, 24, 25). None of them expect the central bank interest rates to stay as low as they currently are in the long term. One of the risk-management strategies employed by Hungarian households is to have a preference for fixed interest rate mortgages (since one of the clear lessons of the crisis is how interest rate levels can change drastically and rapidly). These products are, however issued by financial institutions at a very high price: precisely because a fixed interest rate means that the risks associated with volatile interest rates have to be assumed by the financial actors (interview 21). This often proves to be too expensive for households, who thus opt for a variable interest rate mortgage, which is a guarantee for the financial institution that they will be able to realise the high yields expected by their shareholders even if the cost of money on financial markets increases. Thus, financially weaker households only have access to riskier mortgages.

The state plays an important role in making this process of risk management possible: with the coordinated introduction of developer-side financial support (through the 5\% VAT) and the subsidies given to the consumer-side (with the family-based subsidy), the relative risk of housing-related crediting for financial institutions was significantly decreased since the beginning of 2016. This situation can be evaluated as an important supportive push to the 
banking sector, which is the most important negotiating partner for government institutions in their process of elaborating housing policies (interviews 20,26,40). It can seem ironic that this support was given during a period of historically low interest rates and a general market pressure to increase lending activity (this can be seen as a result of structural pressures to open channels of investment wide when fluctuating sources of capital are available, and can also be seen as a result of lobbying efforts of financial institutions). The interface of negotiations and the motivation for certain policy decisions would definitely need further investigation, without which I can not make claims in the frames of the current dissertation.

Financial institutions are interested in providing long-term, stable (and cheap) housing loans only if the host economy is considered stable enough, and if they have a way to push the costs of changing interest rate levels (which will inevitably change over a longer period of time) on another actor. Managing risk between the banks and households is translated in technical terms of housing finance to the question of how the yield curve is laid out; that is, what yields a bank expects from the issued mortgages over what period of time. The higher the expected yields are, and the faster the bank wants to achieve these yields, means that mortgages will be more expensive for households (that is, will have higher interest rates and will be issued for a shorter duration of time). This is where decisions of corporate governance, or the structure of certain financial products can be linked back to macro-scale dependencies. Expected yields are systematically higher in (semi)peripheral countries of the global economy. Hungary actually has the steepest yield curve of "all countries that count" (interview 21), which means that yield expectations of economic actors are very high. In the meantime, the volatility of the economy (linked to its position in the global economy) means that all actors aim to secure these expected yields under the shortest possible period of time, in order to reduce their exposure to volatility. This context is largely unfavourable to the development of a stable and accessible model of housing finance, and means that some actors of the chain of housing finance will have to assume significant risks (interview 21). The question of which actor ends up managing the risk of this dependent, semiperipheral mode of housing finance can, in my opinion, be seen as a political question.

\subsection{Effects of state policy ${ }^{25}$}

State involvement on the housing market is clearly very important even compared to other real estate sectors. Tracing the cycles of the Hungarian housing market in the past few decades, it is quite apparent that public intervention is usually necessary for bigger upswings of the housing market, and economic actors of the field often claim that state involvement is necessary in order to have housing market activity. However, the relation of market pressures and policy intervention on the housing market merits more scrutiny. We can see a pattern of procyclical intervention from the part of the Hungarian government: that is, policy initiatives related to the housing market usually give a further push to processes already underway (interview 6). The most recent example was the introduction of the new family-based housing subsidy at a moment when mortgage lending was already increasing due to low interest rates and high savings levels.

\footnotetext{
${ }^{25}$ For a more in-depth elaboration of some of the arguments put forward in this section see: Pósfai, Zs, Jelinek, Cs (2018): Reproducing socio-spatial unevenness through the institutional logic of dual housing policies in Hungary. In: Lang, T., Görmar, F. (eds.): Local and Regional Development in Times of Polarisation: Rethinking spatial policies in Europe. Palgrave, series: New Geographies of Europe; forthcoming.
} 
The field of housing is most often studied from the perspective of policy interventions and their effects. Systematic work exists with this approach, which I strongly build on in my understanding of the Hungarian housing market (Hegedüs-Somogyi 2016, Misetics 2017). However, my dissertation deliberately took its entry point through the perspective of corporate actors of the field. I have touched on various aspects of state intervention in the previous chapters, and here I will only draw out a few strands - without any intention of an exhaustive analysis - that seem central in the way how the Hungarian state intervenes in housing market processes.

Since the 1980s, the spine of Hungarian housing policy has quite systematically been to support access to homeownership, with a preference for new construction. According to a highranking official in public administration, "the definition of Hungarian housing policy is actually just different forms of subsidies to homeownership" (interview 26; cited in PósfaiJelinek 2018). The main instruments at the service of this goal were first the large-scale privatisation of public housing in the 1990 s, then, since 2000 a shifting combination of nonrefundable state subsidies based on the number of children a family has, and supporting / subsidising access to mortgages (Pósfai-Jelinek 2018). Throughout the different periods of these two-legged policies since 2000, there have been various levels of accessibility in social and spatial terms. The new version of the "mortgage lending plus family-based housing subsidy" scheme clearly orients capital disproportionately towards households of higher economic status and favours better-positioned housing markets. Thus, state intervention in housing currently tends to reinforce selective market tendencies already at play in the unfolding new expansion of housing-related investment. As the same real estate professional put it, "while there is a right-wing government in power, it is clear that they will put all money into helping their own middle class access private property" (interview 6).

The result of the current concerted policy push for new construction and new mortgages is to increase house prices (particularly in the locations where the combination of CSOK and mortgages can best be used - interview 12, and see section 3.3.), and to increase the profits of the construction and banking sectors - which will ultimately be payed by households. In terms of urban form, two dominant types of new construction emerge: on the one hand, larger housing projects in core housing markets, constructed by property developers. Some of these projects are specifically calculated in a way to allow for the housing mobility of households who have a previous property to sell (eg. a lower-quality flat), can access the family-based subsidy and are also eligible for a mortgage (interviews 2, 12). Another typical urban form where the two branches of housing policy can best be used are the detached family housing units in the agglomeration areas of the capital and other more dynamic cities. The majority of households using the maximum level of the family-based housing subsidy typically build a house in these kinds of locations (interviews 12, 16, 22).

Another characteristic of Hungarian housing policy is the systematic lack of institutional involvement form the part of the state. On the one hand, there is no clear place of responsibility for housing issues within the government. On the other hand, the government quite deliberately seeks to avoid to have to maintain any kind of institution managing housing issues. Thus, all policies are conceived in a way - in line with the dominant neoliberal ethos - that they are practically implemented by corporate actors. A very clear example of this is how banks are charged with distributing the family-based housing subsidy. This also obviously leads to an even stronger connection between mortgage lending and the family-based housing subsidy, some banks making it a clear policy not to give out subsidies without the client taking a mortgage with it (interview 31). Furthermore, the government is likely to introduce new housing policy measures only if there are corporate actors who engage in implementing it (interview 38). This approach allows the government to successfully use measures relating to 
housing policy at the service of economic policy and political popularity, while not having to assume the costs of implementation. Accordingly, the most important platform for consultation with economic actors involved in the housing market is the Hungarian Banking Association. This is the platform through which officials of the government and of the central bank regularly consult the banking sector concerning new housing policy measures (interviews 29, 40), and they appear to have a quite important role in initiating policy shifts as well. Other than consultations with the Banking Association, consultations with industry representatives appear to be rather ad hoc (interview 20,26).

State policies obviously also have an impact on which economic actors are strengthened in various waves of housing market activity. I have outlined various dimensions of the shifts in the hierarchy among the economic actors of the field in the fourth chapter. The most apparent impact is perhaps the nationalisation of the banking sector in the "freedom fight" waged against Western capital, with forceful legislative interventions and acquisitions in the banking sector. Beyond a strong shift towards domestic capital, this has also led to the strengthening of new institutions in housing finance. Recent policy interventions have also created an incentive for a number of actors to enter the market of new housing construction. The state has also supported the strengthening of a circle of domestic real estate developers (through state real estate projects, legislative exceptions or easier access to finances), who now dominate the market, taking over from foreign property developers dominant before the crisis. With legislative restrictions and requirements concerning financial intermediation, the state has also strongly influenced the market of credit agencies in recent years. This has led to increasing concentration in this field (as well).

The current post-crisis policy regime relating to housing recreates new channels for the financialisation of housing, but with an important reorganisation of the economic actors channeling capital into housing. This is related to broader attempts to reduce external dependencies - and relies on the deepening of internal socio-spatial unevenness. Contemporary Hungarian housing policies show a particular class and spatial politics, favouring better-off social groups and geographical locations. Thus, the growth of the housing market and related economic sectors (such as the construction industry and the banking sector) is happening at the price of increasing internal fragmentation. 


\section{CONCLUSIONS}

In my analysis I have focused on how uneven development is reproduced on the Hungarian housing market through the intervention of corporate actors in this field. Firms are actually involved only in a smaller part of all housing market activity - which can be understood principally as the number of housing transactions - since the majority of this activity happens directly between households (and the part of housing units changing owner in a given year is also quite small compared to the total housing stock). This could lead to questioning the relevance of this focus in relation to broader patterns of uneven development on the Hungarian housing market. However, the points where economic actors of the housing market intervene are the points of change and of shifting dynamics, which are important to grasp if we are interested in 1) how capital is channelled into housing, and 2) what the conditions for access to housing are.

In the end, it is not surprising that in a capitalist housing regime, where the production and financing of housing is almost entirely left to enterprises functioning according to a market logic and to individual household initiative; unevenness will be reproduced. Nevertheless, it is worthwhile to uncover the concrete mechanisms through which this happens, as well as to assess the scope and socio-economic consequences of this uneven development. Furthermore, it is relevant to trace how the state intervenes in this process in a way that further supports the expansion of a financialised housing regime. This can be flagrantly illustrated by the fact that currently the dominant form of public investment in housing is through a family-based housing subsidy supporting acquisition, which is taken with a mortgage in $80 \%$ of the cases. Although the percentage of households who hold a mortgage is not as high as in many Western European countries, the structure of these mortgages is systematically more risky and makes households more exposed to the fluctuations of financial markets (see Pósfai et al. 2018). Furthermore, there is a general severe indebtedness of households in Hungary (affecting around one fourth of the population), mainly composed of various elements relating to housing costs; dominantly debt in utility payment arrears (Misetics 2017). Thus, housing-related indebtedness affects a large part of Hungarian households and puts the question of mortgage penetration as well in a different light.

As a summary of the arguments I have presented in previous chapters, I will return to the three main conceptual cornerstones I have started the dissertation with (chapter 1.2); highlighting how this research has empirically contributed to enriching these inquiries.

\section{Housing in political economy and space}

The general conceptual claim here is that in cycles of financialisation capital is channelled into housing globally, and that currently we are witnessing such an upswing of investment in housing, which produces various patterns of unevenness. I have outlined the mechanisms of how this happens in the context of Hungary. On the one hand, we can see that the dependent integration of the Hungarian economy in the European and global economic space is determinant to what kind of resources are available to housing finance. Before the crisis, this rolled out a very clearly dependent form of housing financialisation, with an exponentially growing stock of individual mortgages being financed through the local subsidiaries of European banks, denominated in foreign currencies. This led to an important economic and social crisis in the aftermath of the crisis. Currently, housing finance is much less dependent 
internationally, but new forms of - partially more 'domestic' - housing financialisation unfold. The tendency of channelling surplus capital into housing is very clear and strong on various scales: on the one hand, there is an increasing push for a new roll-out of mortgage lending based on the deposits that have accumulated on banks' accounts since the crisis. At the same time, low interest rates push individual investors towards direct investment in the housing market, buying up properties in cash. Furthermore, new institutions and channels for investing capital in housing are developing (such as a new regime of mortgage lending backed by covered bonds; institutional investors entering the market of non-performing loans, or non-bank financial institutions' increasing role in housing finance). Thus, the financialisation of housing has definitely not decreased (on the contrary!), but is merely unfolding in new forms. Due to the ongoing, currently shifting nature of these processes, it is, for the moment, difficult to see where exactly these new forms of housing financialisation will lead. What is sure, however, is that they further deepen existing patterns of unevenness on the Hungarian housing market both in social and in spatial terms. Mortgage lending remains to be the dominant form of housing finance in Hungary; thus, the essence of how housing financialisation happens is unchanged compared to the pre-crisis period, but both the class base and the institutions channelling this new wave of mortgage lending have significantly shifted. In terms of social class, there is now a higher selectivity in who can access mortgages, while in terms of institutions there is a shift towards a dominance of domestic financial institutions.

This structure reveals certain tensions that will be interesting to follow in the coming period. On the one hand, the pressure of surplus capital on the accounts of financial institutions will likely push mortgage lending beyond the current safe markets, and potentially again start including increasing social and spatial segments in the mortgage-based debt relation. Another important question is whether these new forms of housing financialisation will be as globally/ internationally dependent in their nature as the pre-crisis housing regime was. I believe the current Hungarian housing finance regime is less dependent in a direct / immediate way (in the way forex mortgages were). However, the global position of Hungary fundamentally determines what forms of finance are available to housing (I refer here mainly to the fact that long-term, stable financial resources - which is often called patient finance - is not available in (semi)peripheral locations of the global economy), which, in turn, determines what kind of housing (at what costs, accessible to whom) can be produced. This is something that is also very clearly seen by corporate actors of the field, who interpret this situation as having to manage higher risks - which will be translated to higher costs in a capitalist logic. In order to intervene in this logic of housing production, most likely a non-market / non-capitalist source of finance, and a completely different mechanism of risk management would be needed.

It can be seen as the characteristic of semiperipheral housing finance that there are no housing finance mechanisms available that would be accessible for a broad number of households, and at the same time would be stable in the long term. This leads to a situation where individual ownership and household mortgages dominate the housing market. A housing regime built around the individual debt-relation inherently increases inequalities, and the dominant tendency in the activities of economic actors (not only of banks, but also of real estate and credit agents or developers) is to include an increasing number of households in this relation. As long as housing finance is limited to individual mortgages, access to housing will remain difficult for those who cannot access a mortgage and do not have enough savings to acquire property themselves. This increasing part of the population will typically solve its housing situation through mobilising resources on the scale of the household (through intergenerational transfers, for example), or will resort to some kind of informal or precarious housing solution. A potential answer to this situation would be the development of a wider, less precarious rental housing sector. For this, new institutional capacities would have to be 
developed. However, there are currently no actors present on the Hungarian housing market which would be interested in, or have the institutional capacities and experience to engage with owning and managing housing. One of the reasons for this lack of institutional engagement is that owning housing only becomes profitable in the long term. On the short term, many other forms of investment are more profitable and require less management capacities. This kind of investment can be worthwhile in the long term, in a more stable economic context - however, as one of my interlocutors put it, "in Hungary people are afraid to plan for the long term" (interview 14).

\section{External dependency built on internal fragmentation}

The broader framework of external dependency and impatient housing finance builds on and also reinforces internal fragmentation in the domain of housing in Hungary. The way how this happens can be grasped both in the period when housing finance was explicitly externally dependent (pre-crisis forex mortgage lending), and when housing finance serves to recycle domestically accumulated capital in a socially and spatially selective way (current wave of mortgage lending). The internally fragmenting effects of purely market-based housing finance are very clear if we examine the social and spatial patterns of mortgage lending. The sociospatial effects of different periods of mortgage lending are layered on each other: previous overinclusion determines current patterns of exclusion, and also produces typical geographical spaces (such as in-between zones where both mortgage lending and related state policies play an especially important role).

The mechanism of internal fragmentation in the context of external dependencies can be understood by the way how economic actors intervene in the housing market: the dependent position of a country is translated to corporate terms as higher risk; and with the experience of the financial crisis and how it had affected the peripheries of Europe much stronger than the cores, economic actors are currently more risk averse in these places. This means that they will systematically concentrate their activity on more profitable market segments and on economically better-off social groups, and will seek to invest their money on shorter duration. This increases inequalities within the country's housing market and also narrows the circle of households who can have access to homeownership through credit. In the meantime, however, there is a tension between an increasing amount of capital on domestic and international financial markets looking for a profitable form of investment and the more narrow channels for investment in housing determined by risk aversion and by regulatory constraints on mortgage lending. This results in a situation where places and households that can access a mortgage will be able to do so on very good terms - leading to even more resources being channelled into these selective locations.

The flipside of this phenomenon is that the economic actors which have a broader spatial and social presence and thus open access to housing markets for households who would otherwise be excluded (this was the case, for example, of widely expanding international banks in the pre-crisis period or large domestic banks and home savings and loan associations in the current period) are also more expensive. In this way, the result is often that they accentuate inequalities and channel resources from the peripheries towards the core.

It is interesting to investigate the minimum 70 percent of housing transactions that take place without institutional finances - that is, to uncover the pattern of housing-related investment in cases when individuals, households or companies acquire housing without a mortgage. This also shows a strong spatial segmentation, since the two dominant types of acquisitions without a mortgage are, on the one hand those purchasing for investment purposes, 
and on the other hand those who are not eligible for a mortgage. The former typically invest in the "most core" housing markets, where flats can easily be rented out and the value of real estate is sure to be stable. These are typically the inner-city areas of Budapest and a few larger university or industry cities. The other typical spatiality of investor-buyers are areas heavily affected by non-performing pre-crisis mortgage loans. Those who buy for their own housing purposes but without a mortgage (only with their savings or family transfers) will typically purchase lower value real estate in more peripheral areas. Between the two, the typical spaces of households eligible for mortgages and also for the family-based housing subsidy develop. In these areas the share of households taking mortgages is usually very high. Of course, these are not mutually exclusive, clear-cut spatial categories, and neither are the "profiles" of those buying properties. This overview does, however, provide insight into how the particular patterns of access to housing finance, as well as the ways how acquiring housing turns into a logic of investment under a financialised housing regime can lead to increasing social and spatial segmentation on the housing market.

A further example of the interdependence of internal fragmentation and external dependency is that prosperous housing markets outside of the prime Budapest areas are typically secondary cities that have branches of different large transnational corporations. An increased demand for housing and the strong presence of investor-buyers on these local markets (resulting in house prices increasing much more rapidly than in other areas) is always linked to the presence of these TNCs - which, in turn, is dependent on broader patterns of hierarchical integration in the European economic space.

\section{Reproducing uneven development through firm strategies}

Beyond the general framework of how more risk aversion in (semi)peripheral places translates to a higher concentration of capital invested in core locations, there are a number of mechanisms on the firm level that reproduce unevenness on the housing market. There is, for instance, a rhythm of ebb and flow inherent to the functioning of firms on the housing market, which results from the balancing of the two ever-competing drivers of profit realisation and risk management within a firm. This means that in shorter term cycles of economic expansion (understood here on the scale of the Hungarian national economy - and more specifically of the housing market - and not as long-term cycles of the global economy), when profit realisation becomes more important, there is a spatial spread-out of their activity, while in crisis cycles, when the internal logic of risk management dominates, there is a withdrawal and spatial concentration. Following the crisis the logic of concentration affected not only the spatial presence of economic actors but also their internal structure, with a number of companies becoming more hierarchical and centralised in their decision-making structures.

Considering how various actors of the Hungarian housing market manage the lack of long term resources for housing finance, there is an overarching tendency to realise yields as fast as possible (and as high as possible), with a lack of actors interested in long-term investment. This can also be related to the overarching characteristics of impatient finance. If we consider property developers and construction companies: they build their business model on acquiring short-term project loans, which they repay within a 2-3 year cycle by rapidly selling new housing units. For this, they also need a customer base who will be able to buy new housing units - which can, for instance, be secured by simultaneous policy interventions on the demand and supply side of new housing construction (which happened in Hungary in early 2016). Banks financing both developers and consumers are not interested in giving long-term stable mortgages to households, because this would mean that they are the ones assuming the risks of a fluctuating economy. This, however, means that risks and costs will be pushed on households 
(to the extent made possible by regulatory intervention). The current source of mortgage lending is increased domestic savings, which, however, also does not have a stable base, since the long-term savings capacities of the majority of Hungarian households have not improved. Thus, it seems that the current upswing of the housing market is mainly a short-term possibility for reorganising the circle of institutions channelling capital into housing (strengthening a circle of domestic enterprises), that builds on the current situation of domestic capital available for this purpose. This is done in a way that benefits economically better-off households and geographical areas.

The position a given enterprise takes up in core-periphery relations (on various scales) also determines the kind of risk management strategies they employ. These different strategies can be observed in the current period of the post-crisis upswing. Those who concentrate on core markets and have access to capital even under more restrictive conditions usually choose to focus on small, safe and profitable market segments (such as high-end housing construction or a carefully selected client base). Smaller local actors (such as local real estate agencies) usually tend to diversify their scope of activities. National actors can choose to mitigate risk by big numbers, continuing to have a wide spatial and social base and balancing for defaults in this way (which is the strategy of the largest domestic bank). These different strategies will of course affect their spatial presence and the way they channel capital in the uneven structure of the housing market.

The above described corporate-level strategies are in constant tension with household strategies for survival and housing provision. This produces a constantly moving frontline between the logic of housing as investment and that of housing as the sphere of social reproduction. This frontline can be grasped in spatial terms as well, and is also where the state intervenes through housing policy measures.

It may, be claimed that it is not surprising that firms function according to a capitalist logic and thus produce uneven social and spatial patterns along the logic of profit maximisation and risk avoidance. This, of course, is true, and also highlights the need for not profit-oriented, not market-based interventions in the domain of housing. At the same time, there is also a characteristic of the housing market actors in Hungary that was highlighted by several of my interlocutors, and which could be an interesting conceptual experiment in how we think about their intervention in the field of housing. This relates to the fact that there is generally a lack of large, institutional actors on the Hungarian housing market apart from financial institutions and a few big property developers. The majority of actors are smaller-scale companies, usually not listed on the stock exchange and in many cases not as detached from concrete local housing markets as would be the case if the Hungarian housing market would be accessible to large institutional owners and investors. This could potentially open up avenues for more reflected, needs-based investment - if the money for this kind of investment would be available.

The coming years will surely bring interesting developments on the Hungarian housing market, with the pressure of channelling more capital into housing on the peripheries of Europe again strongly present. In the meantime, the social and political stakes involved in housing have also been constantly surfacing since the outbreak of the crisis, pushing for a different, more egalitarian logic in relation to the production of housing. Neither of these two pressures are likely to subside in the coming years. The spaces where these tensions meet will continue to be the arenas of rapid transformations of the housing market, of housing-related exclusions and potentially also of housing struggles. 


\section{Acknowledgements}

Finishing a PhD is a very sentimental thing, and standing on the verge of this point I am sure that writing acknowledgements are the favourite part of most $\mathrm{PhD}$ candidates. First of all, I would like to highlight the productive tension between the way how a $\mathrm{PhD}$ is at the same time a very individual and an entirely collective process. I have experienced both elements as liberating: while it gave me the possibility to pursue my research according to my own interests and rhythm, this would not have been possible without a strong base of collective endeavours. Among these collective frames I would like to highlight the Critical Urban Studies Collective and the Public Sociology Working Group Helyzet. Without the knowledge produced in these groups in a collective way over several years, my $\mathrm{PhD}$ research would have lacked serious points of orientation, and would have generally not been imaginable.

The liberty and resourcefulness of this $\mathrm{PhD}$ process was possible because I was part of the "RegPol ${ }^{2}$ - Socio-economic and Political Responses to Regional Polarisation in Central and Eastern Europe" Marie Curie ITN project. I am well aware of the privileges this meant, and am very grateful for them. Beyond giving an institutional framework that was extremely beneficial, it gave access to an enriching, inspirational network of researchers, and also made a six-month stay in Leipzig possible. During the research project I was employed at the Békéscsaba group of the Institute for Regional Studies, Centre for Economic and Regional Studies of the Hungarian Academy of Sciences. I am very grateful for this possibility to be involved in one of the most critically minded research groups in this field in Hungary - for all aspects involved. Living in Békéscsaba part-time was in itself an important experience, and the supportive environment provided by the research group was extremely valuable. I am particularly indebted to my supervisor Erika Nagy and to Judit Timár for their unwavering professional and personal support throughout the three years. Along this line, I am also very grateful to Thilo Lang, the coordinator of the RegPol${ }^{2}$ project from the IfL in Leipzig for his sharp insights and timely support. I would also like to recognise the supportive environment of the Department of Economic and Social Geography at the University of Szeged, and the supervision of dr. Zoltán Kovács.

I am grateful to Csaba Jelinek for his support at various points of decision (of all scales and kinds) throughout this $\mathrm{PhD}$ process, to Ágnes Gagyi for her conceptually guiding questions. To Márton Czirfusz for being the best pedagogue ever, and for giving prompt and life-saving help at crucial moments, as well as for all his conceptual and practical support with data analysis and cartography. I am also indebted to Gábor Nagy at the Institute for Regional Studies for his support in statistical analysis and cartography, as well as to Eszter Turai, Márta Zöld, József Vámos and Eszter Szedlacsek for their help in typing my interview transcripts. I am grateful to Attila Juhász and Orsi Pósfai for their presence and support in the past months, as well as to the people and time at the ecodharma centre in late 2017 - they helped prevent me from freaking out in the last intense period of writing, making it an enjoyable process in the end. I am also grateful to my living community for having endured and lived together with the hectic rhythm that my involvement in this research project had meant in the past three years.

I am particularly grateful to all of my interview partners, who made the core of this research possible, and many of whom showed a real commitment to and passion with the issue of housing in Hungary. Our exchanges were a true source of inspiration and I trust that our professional paths will cross again, and that we will have further possibilities to exchange. 


\section{REFERENCES}

Aalbers, M. B. (2008): The financialization of home and the mortgage market crisis, Competition \& Change, 12, pp. 148-166.

Aalbers, M. B. (2011): Place, Exclusion and Mortgage Markets, Wiley-Blackwell.

Aalbers, M. B. (2012): Subprime Cities: The Political Economy of Mortgage Markets, WileyBlackwell.

Aalbers, M. B. (2017): The Variegated Financialization of Housing. International Journal of Urban and Regional Research, 41, pp. 542-554.

Aalbers, M.B. (2015): The Great Moderation, the Great Excess and the global housing crisis. International Journal of Housing Policy, 15 (1), pp. 43-60.

Aalbers, M.B., Christophers B. (2014): Centering housing in political economy. Housing, Theory and Society, 31 (4), pp. 373-394.

Arinci, L. S., Pessina, N., Ebenau, M. (2015): All Varieties Are Equal... Contributions from Dependency Approaches to Critical Comparative Capitalisms Research. In: Ebenau et al. (eds.): New Directions in Comparative Capitalisms Research, Palgrave Macmillan UK, pp. 189-206.

Arrighi, G. (1990): The Developmentalist Illusion: A Reconceptualization of the Semiperiphery, in: Martin, W.G. (ed.) Semiperipheral States in the World-Economy. Greenwood Press, Westport CT, pp. 11-42.

Arrighi, G. (1994) The Long Twentieth Century: Money, Power and the Origins of Our Times, Verso, London-New York.

Balogh, K. (1999): Hol tart a budapesti önkormányzati lakások privatizációja? Területi Statisztika, 2 (4), pp. 363-367.

Ban, C. (2012): Sovereign Debt, Austerity, and Regime Change: The Case of Nicolae Ceausescu's Romania. East European Politics and Societies 26, pp. 743-776.

Becker, J; Weissenbacker, R. (2015): Changing Development Models: Dependency School Meets Regulation Theory. Conference paper for: Colloque International Recherche et Régulation 2015: "Changing Development Models: Dependency School Meets Regulation Theory”, 10-12 June 2015, Paris.

Becker, J. (2014).:Finanzialisierung und globale Peripherie. In Politische Ökonomie der Finanzialisierung. Springer, Wiesbaden, pp. 181-196.

Becker, J. (2016): Europe's Other Periphery. New Left Review 99, pp. 39-64.

Becker, J., Jager, J., Weissenbacher, R. (2013): Abhängige Finanzialisierung und ungleiche Entwicklung: Zentrum und Peripherie im europäischen Integrationsprozess. Journal für Entwicklungspolitik XXIX (3), pp. 34-54.

Becker, J., Jager, J., Weissenbacher, R. (2015): Uneven and dependent development in Europe - the crisis and its implications. In: Jager, J, Springler, E. (eds.): Assymmetric crisis in Europe and possible futures, Routledge.

Bethlendi, A. (2007): A hitelpiac szerepe a hazai háztartások fogyasztási és megtakarítási döntéseiben. Közgazdasági Szemle LIV, pp. 1041-1065. 
Blackwell, T., \& Kohl, S. (2017). The origins of national housing finance systems: a comparative investigation into historical variations in mortgage finance regimes. Review of International Political Economy, pp. 1-26.

Bohle, D. (2013): Post-socialist housing meets transnational finance: Foreign banks, mortgage lending, and the privatization of welfare in Hungary and Estonia, Review of International Political Economy 21 (4), pp. 913-948.

Bohle, D. (2016): East Central Europe in the European Union. In: Cafruny, A. W., Talani, L. S., \& Martin, G. P. (eds.): The Palgrave Handbook of critical international political economy. Palgrave Macmillan, London pp. 369-390.

Bohle, D. (2017): Mortgaging Europe's Periphery. LSE 'Europe in Question' Discussion Paper Series: LEQS Paper No. 124/2017.

Bohle, D., \& Greskovits, B. (2012). Capitalist diversity on Europe's periphery. Cornell University Press.

Bonin, J.P., Ábel, I. (2000): Retail Banking in Hungary: A Foreign Affair? Paper prepared for thw Workd Bank, nr. 27829.

Boros, L., Fabula, Sz., Horváth, D., Kovács, Z (2016): Urban diversity and the production of public space in Budapest. Hungarian Geographical Bulletin 65 (3), pp. 209-224.

Brenner, N. (2011): Critical Sociospatial Theory and the Geographies of Uneven Spatail Development. In: Leyshon, A., Lee, R., McDowell, L., Sunley, P. (eds.): The SAGE Handbook of Economic Geography. SAGE Publications, pp. 135-148.

Brenner, R. (2004): New boom or new bubble? The trajectory of the US economy. New Left Review, 25, pp. 57-100.

Bruff, I. (2017): Qualitative research practices and critical political economy. In:

Montgomerie, J. (ed.): Critical methods in political and cultural economy. Routledge, pp. $125-128$.

Büdenbender, M.A. (2017): New spaces of capital: the real estate/ financial complex in Russia and Poland. Dissertation presented in partial fulfilment of the requirements for the degree of Doctor of Science (PhD): Geography. KU Leuven.

Buskó, T.L. (2006): A lakáspolitika területi hatásai Magyarországon az ezredfordulót követően. Szakmai Fórum, pp. 109-119.

Cafruny, A. W., Talani, L. S., \& Martin, G. P. (2016): The Palgrave Handbook of critical international political economy. Palgrave Macmillan, London.

Calbet Elias, L. (2017): Financialised Rent Gaps and the Public Interest in Berlin's Housing Crisis: Reflections on N. Smith's ,Generalised Gentrification'. In: Albet, A., Benach, N. (eds.): Gentrification as a Global Strategy: Neil Smith and Beyond. Routledge; New York, London; pp. 165-176.

Christophers, B. (2015): The Limits to Financialization. Dialogues in Human Geography 5(2), pp.183-200.

Christopherson, S. (2011): The Geographies of Capitalism. In: Leyshon, A., Lee, R., McDowell, L., Sunley, P. (eds.): The SAGE Handbook of Economic Geography. SAGE Publications, pp. 163-174.

Coates, D. (2015): Varieties of Capitalism and "the Great Moderation." In New Directions in Comparative Capitalisms Research. London: Palgrave Macmillan UK, pp. 11-27. 
Coe, N. (2011): Unpacking Globalization: Changing Geographies of the Global Economy. In: Leyshon, A., Lee, R., McDowell, L., Sunley, P. (eds.): The SAGE Handbook of Economic Geography. SAGE Publications, pp. 89-101.

Coe, N. M., Yeung, H. W.-C. (2015): Global production networks: theorizing economic development in an interconnected world. Oxford: Oxford University Press.

Coe, N.M., Hess, M., Yeung, H.W-C., Dicken, P., Henderson, J. (2004): 'Globalizing' regional development: a global production networks perspective. Transactions of the Institute of British Geographers. 29 (4), pp. 468-484.

Coe, N.M., Kelly, P.F., Yeung, H.W-C. (2007): Economic Geography: A Contemporary Introduction. Blackwell Publishing, Oxford.

Crouch, C (2009) Privatised Keynesianism: An Unacknowledged Policy Regime, The British Journal of Politics and International Relations, (11), pp. 382-399.

Dancsik B. et al. (2015) Comprehensive analysis of the nonperforming household mortgage portfolio using micro-level data. MNB Occasional Papers Special Issue.

Dixon, A.D. (2010): Variegated capitalism and the geography of finance: Towards a common agenda. Progress in Human Geography 35(2), pp. 193-210.

Drahokoupil, J. (2009): After transition: Varieties of political-economic development in Eastern Europe and the Former Soviet Union. Comparative European Politics, 7(2), pp. 279-298.

Dunford, M., Liu W. (2017): Uneven and combined development. Regional Studies 51(1), pp 69-85.

Dymski, G. (2009): The Global Financial Customer and the Spatiality of Exclusion After the End of Geography. Cambridge Journal of Regions, Economy and Society, 2, pp. 267-85.

Ebenau, M. (2015): Directions and Debates in the Globalization of Comparative Capitalisms Research. In New Directions in Comparative Capitalisms Research. London: Palgrave Macmillan UK, pp. 45-61.

Ebenau, M., Bruff, I., \& May, C. (Eds.). (2015). New Directions in Comparative Capitalisms Research - Critical and Global Perspectives. Palgrave Macmillan.

Éber, M.Á. (2014): A centrum hitele: A magyar állam külső eladósodásának történetéről. Fordulat, 2014 (1), pp. 64-86.

EBRD Transition Report (2006): Transition report 2006 : Finance in transition. EBRD. Retrieved from: http:/www.ebrd.com/downloads/research/transition/TR06.pdf

Engelen, E. (2012): Crisis in Space: Ruminations on the Unevenness of Financialization and its Geographical Implications. In: Barnes, T.J., Peck, J., Sheppard, E. (eds.): The WileyBlackwell Companion to Economic Geography, Blackwell Publishing Ltd, pp. 242-257.

European Mortgage Federation (2015): Hypostat 2015, A review of Europe's mortgage and housing markets.

Fellner, Z., Kovalszky, Zs., Winkler, S. (2016): Lakáspiaci jelentés - 2016 október. Magyar Nemzeti Bank.

Fernandez, R. and Aalbers, M.B. (2017): Housing and capital in the $21^{\text {st }}$ century: realigning housing studies and political economy. Housing, Theory and Society 34 (2), pp. 151-158. 
Fernandez, R., Aalbers, M.B. (2016): Financialization and Housing: Between Globalization and Varieties of Capitalism. Competition and Change, 20(2), pp. $71-88$.

Fields, D., Uffer, S. (2016): The financialisation of rental housing: A comparative analysis of New York City and Berlin, Urban Studies, 53(7), pp. 1486-1502.

Frank, AG: (1967): Capitalism and Underdevelopment in Latin America. Monthly Review Press.

Gabor, D. (2012): The road to financialization in Central and Eastern Europe: Revisiting the early policies and politics of stabilizing transition. Review of Political Economy, 24 (2). pp. 227-249.

Gagyi, Á., Jelinek, Cs. (2017): Bringing Back Uneven Development to the Urbanization of Politics: Understanding Right Wing Reactions to the Forex Mortgage Crisis in Hungary. Conference paper for or the 17th session entitled "The Urbanization of Politics in Eurasia" of the Annual RC21 Conference 2017.

Gál, Z. (2014): Role of financial sector FDI in regional imbalances in Central and Eastern Europe, in: Gostyńska A., Tokarski P. (eds.): Eurozone enlargement: challenges for the V4 countries. Warsaw: The Polish Institute of International Affairs, pp. 19-30.

Gál, Z., Schmidt, A. (2017): Geoeconomics in Central and Eastern Europe: Implications on FDI; in: Mark Munoz (ed.) Advances in Geoeconomics; Routledge, pp. 76-93.

Gereffi, G., Evans, P. (1981): Transnational Corporations, Dependent Development, and State Policy in the Semiperiphery: A Comparison of Brazil and Mexico. Latin American Research Review, 16(3), pp. 31-64.

Gerőcs, T., Pinkasz, A. (2018): Debt-ridden development on Europe's Eastern Periphery, in: Boatcă M., Komlosy A. and Nolte H-H. (eds.): Political Economy of the World-System Annuals: Global Inequalities in World-Systems Perspective. Paradigm

Gille, Zsuzsa (2010): Is there a Global Postsocialist Condition? In Global Society, Vol. 24, No. 1, pp. 9-30.

Gowan, P. (2000): Peripheralisation of Central and Eastern Europe in the 1990s, Labour Focus on Eastern Europe, 65.

Grécs, Á. (2017): A jelzáloghitel-finanszírozás megfelelési mutate bevezetése elött és utánavagy jelzálog-hitelintézetek és jelzáloglevél-piac Magyarországon. Thesis submitted at the Corvinus University Budapest.

Hadjimichalis, C. (1983): Regional Crisis: the State and Regional Social Movements in Southern Europe. In: Ostrom, K., Seers, D. (eds.): The Crises of the European Regions. Palgrave Macmillan, pp. 127-147.

Hadjimichalis, C., Hudson, R. (2014): Contemporary Crisis Across Europe and the Crisis of Regional Development Theories. Regional Studies, 48:1, pp. 208-218.

Hall, P., Soskice, D. (2001). Varieties of Capitalism: The Institutional Foundations of Comparative Advantage. Oxford University Press.

Hann, C.M. (2002): Postsocialism -- Ideals, ideologies and practices in Eurasia. Routledge, London.

Hardy, J. (2014): Transformation and crisis in Central and Eastern Europe: A combined and uneven development perspective, Capital \& Class, 38(1), pp. 143-155. 
Harvey, D. (1978): The urban process under capitalism: a framework for analysis. International Journal of Urban and Regional Research 2.1-4, pp. 101-131.

Harvey, D. (1982): The Limits to Capital. London: Verso.

Harvey, D. (2007): A Brief History of Neoliberalism. Oxford: Oxford University Press.

Hegedüs József (2013): Housing privatization and restitution in post-socialist countries, In: Hegedüs-Lux-Teller (eds.): Social Housing in Transition Countries, Routledge, pp. 3349.

Hegedüs, J. (2006): Lakáspolitika és a lakáspiac - a közpolitika korlátai. Esély 5, pp. 65-100.

Hegedüs, J., Eszenyi, O., Somogyi, E., Teller, N. (2009): Lakhatási szükségletek Magyarországon. Városkutatás Kft. report for Habitat for Humanity Hungary.

Hegedüs, J., Somogyi, E. (2016): "Moving from an Authoritarian State System to an Authoritarian Market System: Housing Finance Milestones in Hungary between 1979 and 2014," in: Jens Lunde:, Christine Whitehead (eds.): Milestones in European Housing Finance: Wiley, pp. 201-218.

Hegedüs, J., Várhegyi, É. (1999): A lakásfinanszírozás válsága a kilencvenes években. Közgazdasági Szemle, XLVI., pp. 101-120.

Heires, M., Nölke, A. (2014): Politische Ökonomie der Finanzialisierung. Springer, Wiesbaden.

Hudson, R. (2015): Uneven Development, Socio-Spatial Polarization and Political Responses. In: Lang et al. (2015): Understanding geographies of polarization and peripheralization - Perspectives from Central and Eastern Europe and Beyond. Palgrave Macmillan, pp. 25-39.

Hudson, R. (2016a), 'Rising powers and the drivers of uneven global development', Area Development and Policy, pp. 279-294.

Hudson, R. (2016b): Approaches to economic geography: towards a geographical political economy. Routledge.

Hulse, K., Reynolds, M. (2017): Investification: Financialisation of housing markets and persistence of suburban socio-economic disadvantage. Urban Studies, pp. 1-17. DOI: $0.1177 / 0042098017734995$.

Hürtgen, S. (2015): Das Konzept der strukturellen Heterogenität und die Analyse fragmentierter Wachstumsgesellschaften in Europa. Working Paper der DFGKollegforscherInnengruppe Postwachstumsgesellschaften, Nr. 2/2015, Jena.

Jäger, J., Horn, L., and Becker, J. (2016): Critical International Political Economy and Method. In: Cafruny, A. W., Talani, L. S., \& Martin, G. P. (eds.): The Palgrave Handbook of critical international political economy. Palgrave Macmillan, London, pp. 101-118

Jelinek, Cs. (2017): Uneven development, urban policy making and brokerage: urban rehabilitation policies in Hungary since the 1970s. PhD dissertation, Central European University.

Jessop, B. (2014): Variegated Capitalism, das Modell Deutschland, and the Eurozone Crisis, Journal of Contemporary European Studies, 22:3, pp. 248-260.

Jessop, B. (2015): Comparative Capitalisms and/or Variegated Capitalism. In New Directions in Comparative Capitalisms Research. London: Palgrave Macmillan UK, pp. 65-82. 
Jones, M. (2011): The Local in the Global, In: Leyshon, A., Lee, R., McDowell, L., Sunley, P. (eds.): The SAGE Handbook of Economic Geography. SAGE Publications, pp. 121-134.

Keresztély, K., Scott, J.W. (2012): Urban Regeneration in the Post- Socialist Context: Budapest and the Search for a Social Dimension. European Planning Studies, 20(7), pp. 1111-1134.

Király, J. (2016): A magyar bankrendszer tulajdonosi struktúrájának átalakulása. Közgazdasági szemle, LXIII, pp. 725-761.

Konrád, Gy., Szelényi, I. (1969): Az új lakótelepek szociológiai problémái. Akadémiai Kiadó, Budapest.

Koós, B., Virág, T. (2010): Nyertesek és vesztesek -- A magyar településhálózat polarizálódása. In: Barta, Gy., Beluszky, P., Földi, Zs., Kovács, K. (eds.): A területi kutatások csomópontjai. Pécs: MTA Regionális Kutatások Központja, pp. 32-54.

Kovács, S. Zs. (2014): Elérhetőség és kirekesztés Magyarországon a pénzügyi szolgáltatások aspektusából. Területfejlesztés és Innováció, 8(3), pp. 28-35.

Kovács, Z. (2008): A városi táj átalakulása Magyarországon a rendszerváltás után. In: Orosz, Z., Fazekas, I. (eds.): Települési környezet. Confrence paper for the conference "Települési Környezet" at the University of Debrecen, 8-10. November a 2007.

Kovács, Z., Szabó, B. (2016): Urban restructuring and changing patterns of socio-economic segregation in Budapest. In: Tammaru, T., Marcińczak, S., Ham, M. van, Musterd, S. (eds.): Socio-Economic Segregation in European Capital Cities: East meets West. London; New York: Routledge, pp. 238-260.

Kovács, Z., Szabó, B., Székely, G. (2005): A lakáspiaci dinamizmus néhány jellemzője Magyarországon. Statisztikai Szemle, 83(5), pp. 461-479.

Kovács, Z., Szirmai, V. (2006): Városrehabilitációs beavatkozások és a térbeli társadalmi kirekesztés: A társadalmilag fenntartható városfejlődés budapesti lehetőségei. Tér és Társadalom, 20, pp. 1-19.

Krippner, G. R. (2005) The financialization of the American economy, Socio-Economic Review, 3, pp. 173-208.

Ladányi, J., Virág, T. (2009): A szociális és etnikai alapú lakóhelyi szegregáció változó formái Magyarországon a piacgazdaság átmeneti időszakában. Kritika 7-8, pp. 2-8.

Lang, Th., Henn, S., Sgibnev, W., Ehrlich, K. (2015): Understanding geographies of polarization and peripheralization - Perspectives from Central and Eastern Europe and Beyond. Palgrave Macmillan.

Lapavitsas, C. (2009): Financialised capitalism: crisis and financial expropriation, Historical Materialism, 17, pp. 114-148.

Lepeltier-Kutasi, L., Olt, G. (2016): Demander réparation(s). À Budapest, les mobilisations collectives à l'épreuve de leur visibilité. Cultures \& Conflits 101, pp. 81-98.

Lewicki, M. (2013): Financialization through the Mortgage Credit in Poland. Paper for the SASE Annual Meeting, "States in Crisis”, Milan, 27-29.06.2013.

Leyshon, A., Lee, R., McDowell, L., Sunley, P. (2011): The SAGE Handbook of Economic Geography. SAGE Publications.

MacLeod, G., Goodwin, M. (1999): Space, scale and state strategy: rethinking urban and regional governance, Progress in Human Geography, 23 (4), pp. 503-527. 
Massey, D. (1994): Space, Place, and Gender. Minneapolis: University of Minnesota Press.

May, C. (2017): Norms, political economy and serendipity: thinking pragmatically about IPE. In: Montgomerie, J. (ed.): Critical methods in political and cultural economy. Routledge, pp. 28-32.

May, C., Ebenau, M., \& Bruff, I. (2015): Conclusion: Towards a Critical, Global Comparative Political Economy. In New Directions in Comparative Capitalisms Research. London: Palgrave Macmillan UK, pp. 224-232.

Misetics, B. (2013). Javaslatok egy egalitariánus lakáspolitikai reform fó irányaira: politikai és szakpolitikai vázlat. Esély, (1), pp. 39-73.

Misetics, B. (2017). Lakáspolitika és hajléktalanság. In Zs. Ferge (Ed.), Társadalom- és Szociálpolitika Magyarország 1990-2015. Budapest: Osiris, pp. 338-363.

MNB Housing market report: all accessible at https://www.mnb.hu/kiadvanyok/jelentesek/lakaspiaci-jelentes

Montgomerie, J. (2017): Critical methods in political and cultural economy. Routledge.

Myant, M., Drahokoupil, J. (2012): International Integration, Varieties of Capitalism and Resilience to Crisis in Transition Economies. Europe-Asia Studies, 64(1), pp. 1-33.

Nagar, R., Lawson, V., McDowell, L. and Hanson, S. (2002): Locating globalization: feminist (re)readings of the subjects and spaces of globalization. Economic Geography 78, pp. 257-284.

Nagy, E. (2005): Adaptation and differentiation: the corporate strategies of international investors in the emerging retail market of Hungary. In: Foreign Investments and Regional Development in East Central Europe. (ed. D. Turnock), Ashgate: London pp. 267-291.

Nagy, E., Timár, J. (2012): Urban restructuring in the grip of capital and politics: Gentrification in East-Central Europe. In: Csapó, T., Balogh, A. (eds.): Development of the Settlement Network in the Central European Countries: Past, Present, and Future. Berlin; Heidelberg: Springer Verlag, pp. 121-135.

Nagy, E., Timár, J., Nagy, G. and Velkey, G. (2015): The Everyday Practices of the Reproduction of Peripherality and Marginality in Hungary. In Lang, T., Henn, S., Ehrlich, K. and Sgibnev, W. (eds.) Understanding Geographies of Polarization and Peripheralization. London: Palgrave Macmillan, pp. 135-155.

Nitz, H-J. (1997): Der Beitrag der historischen Geographie zur Erforschung von Peripherien. In: In: Nolte, H-H. (ed.): Europäische Innere Peripherien im 20. Jahrhundert. Franz Steiner Verlag Stuttgart, pp. 17-36.

Nölke, A., Vliegenthart, A. (2009): Enlarging the Varieties of Capitalism: The Emergence of Dependent Market Economies in East Central Europe. World Politics, 61(4), pp. 670702.

Nolte, H-H. (1997): Europäische Innere Peripherien - Ähnlichkeiten, Unterschiede, Einwände zum Konzept. In: Nolte, H-H. (ed.): Europäische Innere Peripherien im 20. Jahrhundert. Franz Steiner Verlag Stuttgart, pp. 7-16.

Ostrom, K., Seers, D. (1983): The Crises of the European Regions. Palgrave Macmillan.

Overbeek, H., Apeldoorn, B. van, \& Nölke, A. (eds.) (2007): The Transnational Politics of Coporate Governance Regulation. Routledge. 
Peck, J. (2016): Macroeconomic geographies, Area Development and Policy, DOI: $10.1080 / 23792949.2016 .1237263$.

Peck, J., Theodore, N. (2007): Variegated capitalism, Progress in Human Geography, 31(6), pp. 731-772.

Pellandini-Simányi L., Vargha Z. (2016): Why market-making interactions between states and firms fail despite aligned interests and ideas: Organizing the Hungarian mortgage market as a socio-technical process. Conference paper for the SASE $28^{\text {th }}$ annual meeting, R\&R at Organization Studies.

Phillips, N. (2017): Doing research in the shadows of the global political economy. In: Montgomerie, J. (ed.): Critical methods in political and cultural economy. Routledge, pp. 115-120.

Pike, A., Pollard, J. (2010) Economic geographies of financialization, Economic Geography, 86, pp. 29-51.

Pinto, A. (1970): Naturaleza e implicaciones de la "Heterogeneidad Estructural" de la América Latina. El Trimestre Économico, 37(145), pp. 83-100.

PoSCoPP: Research Group Production of Space in the Context of Polarization and Peripheralization (2015): Understanding New Geographies of Central and Eastern Europe. In: Lang et al. (2015): Understanding geographies of polarization and peripheralization - Perspectives from Central and Eastern Europe and Beyond. Palgrave Macmillan, pp. 1-24.

Pósfai, Zs., Gál, Z., Nagy, E. (2018): Financialization and Inequalities: The Uneven Development of the Housing Market on the Eastern Periphery of Europe. In: Fadda, S., Tridico, P. (eds.): Inequality and Uneven Development in the Post-Crisis World; Routledge, pp. 167-190.

Pósfai, Zs., Jelinek, Cs. (2018): Reproducing socio-spatial unevenness through the institutional logic of dual housing policies in Hungary. In: Lang, T., Görmar, F. (eds.): Local and Regional Development in Times of Polarisation: Re-thinking spatial policies in Europe. Palgrave, series: New Geographies of Europe; forthcoming.

Pósfai, Zs., Nagy, G. (2017): Crisis and the reproduction of core-periphery relations on the Hungarian housing market. European Spatial Research and Policy, 24(2), pp. 19-40.

Raviv, O. (2008): Chasing the dragon east: exploring the frontiers of Western European finance. Contemporary Politics, 14 (3), pp. 297-314.

Savini-Aalbers (2016): The de-contextualisation of land use planning through financialisation: Urban redevelopment in Milan. European Urban and Regional Studies, 23(4), pp. 878894.

Sayer, A. (1992 [1984]): Method in Social Science: A Realist Approach. Routledge.

Schepp Z., Pitz M. (2012): Lakossági devizahitelezés Magyarországon: problémafelmérés és a frankhitelek banki árazásának empirikus vizsgálata. Mühelytanulmányok 2012/3. Pécsi Tudományegyetem Közgazdaságtudományi Kar Közgazdasági és Regionális Tudományok Intézete.

Schwan, M. (2017): Which roads lead to Wall Street? The financialization of regions in the European Union. Comparative European Politics 15 (4), pp. 661-683. 
Schwartz, H., Seabrooke, L. (2009): Varieties of Residential Capitalism in the International Political Economy: Old Welfare States and the New Politics of Housing. Comparative European Politics, 6, pp. 237-261.

Sheppard, E. (2013): Rethinking Capitalism from a Geographical Perspective. Annals of the Association of Economic Geographers, 59 (4), pp. 394-418.

Silver, B.J., Arrighi, G. (2003): Polanyi's 'Double Movement': The Belle Époques of U.S. and British World Hegemony Compared. Politics and Society, 31 (2), pp. 325-355.

Smith, A., Swain, A. (2010) The global economic crisis, Eastern Europe, and the Former Soviet Union: models of development and the contradictions of internationalization. Eurasian Geography and Economics, 51: 1-34.

Smith, N (1987): Gentrification and the Rent Gap. Annals of the Association of American Geographers, 77(3), pp. 462-465.

Smith, N. (1984): Uneven Development: Nature, Capital, and the Production of Space. The University of Georgia Press, Athens, Georgia.

Smith, N. (2011): Uneven Development Redux. New Political Economy, 16(2), pp. 261-265.

Sokol, M. (2013) Towards a 'newer' economic geography? Injecting finance and financialisation into economic geographies. Cambridge Journal of Regions, Economy and Society, 6, 501515.

Sokol, M. (2017): Financialisation, financial chains and uneven geographical development: Towards a research agenda. Research in International Business and Finance, 39, pp. $678-685$.

Space and Society [Tér és Társadalom] special issue (2016): "Horizontális mühely", various authors. Vol. 30 (3). Accessible at: http://tet.rkk.hu/index.php/TeT/issue/view/429

Stockhammer, E. (2004) Financialisation and the slowdown of accumulation, Cambridge Journal of Economics, 28 (5), pp. 719-741.

Timár J, Váradi, M.M. (2001): The uneven development of suburbanization during transition in Hungary. European Urban and Regional Studies, 8(4), pp. 349-360.

Timár, J. (2007): Different Scales of Uneven Development - in a (No Longer) Post-socialist Hungary. Treballs de La Societat Catalana de Geografia, 64, pp. 103-128.

Timár, J., Nagy, E. (2007): A középvárosi dzsentrifikáció társadalmi hatásai a posztszocialista Magyarországon. In: Enyedi, Gy. (ed.): A történelmi városközpontok átalakulásának társadalmi hatásai. MTA Társadalomkutató központ, Budapest: pp. 293-319.

Tömöri, M., Süli-Zakar, I. (2011): The state of the Hungarian residential market in the time of the global economic crisis. Belgeo [online], 3-4. Retrieved at: $\mathrm{http}: / /$ belgeo.revues.org/6289.

Vigvári András (2015) Vissza a tanyákra - egy cigány család újrakezdési esélyei a szabolcsi pusztai világban. In Virág Tünde (ed.): Törésvonalak. Szegénység és etnicitás vidéki terekben. Argumentum, Budapest, pp. 211-227.

Vincze, E., Bartha, A., \& Virág, T. (2015): Theoretical potential of addressing production of marginality at the crossroads of spatial exclusion and development. Intersections. East European Journal of Society and Politics, 1(4), pp. 4-13. 
Vliegenthart, A. (2010): Bringing Dependency Back In: The Economic Crisis in Post-socialist Europe and the Continued Relevance of Dependent Development. Historical Social Research / Historische Sozialforschung, Vol. 35, No. 2 (132), pp. 242-265

Vliegernthart, A., Overbeek, H. (2007): Corporate governance regulation in East Central Europe: the role of transnational forces. In: Overbeek et al. (eds.): The Transnational Politics of Coporate Governance Regulation. Routledge, pp. 177-198.

Voszka, É. (2013): Államosítás, privatizáció, államosítás. Közgazdasági szemle, lX., pp. 12891317.

Wallerstein, I. (1976): Semi-Peripheral Countries and the Contemporary World Crisis. Theory and Society, 3 (4), pp. 461-483.

Walls, D. (1978): Internal Colony or Internal Periphery? A Critique of Current Models and an Alternative Formulation. In: Lewis et al (eds.): Colonialism in Modern America; The Appalachian Case, Boone, NC: Appalachian Consortium Press, pp. 319-349.

Wehr, I. (2015): Entangled Modernity and the Study of Variegated Capitalism: Some Suggestions for a Postcolonial Research Agenda. In New Directions in Comparative Capitalisms Research. London: Palgrave Macmillan UK, pp. 134-151.

Weissenbacher, R. (2017): Peripheral integration and disintegration in Europe: the 'European dependency school' revisited. Journal of Contemporary European Studies [online]: http://dx.doi.org/10.1080/14782804.2017.1302875.

Werner, M. (2016): Global production networks and uneven development: Exploring geographies of devaluation, disinvestment, and exclusion. Geography Compass, 10(11), pp. 457-469.

Werner, M., Bair, J. (2011): Losing our Chains:Rethinking Commodities through Disarticulations. Environment and Planning A 43 (5), pp. 998-1015.

Yeşin, P. (2013): Foreign Currency Loans and Systemic Risk in Europe, Federal Reserve Bank of St Louis Review, 95(3), pp. 219-235.

Zsoldos, I. (1997): A lakosság megtakarítási és portfolio döntései Magyarországon 1980 1996 között. MNB Füzetek 1997/4. - publication of the Hungarian National Bank. 


\section{STATISTICAL DATA SOURCES}

European Mortgage Federation (EMF) (2015): statistics compiled by the EMF on mortgages, interest rates and house prices on a European scale. Received via email from the EMF on 25.11.2015.

Központi Statisztikai Hivatal (KSH - Central Statistical Office) (2015): Lakásstatisztikai Évkönyv (Yearbook of housing statistics). Downloaded from internal website on 06.12.2016.

Központi Statisztikai Hivatal (KSH - Central Statistical Office) (2016): statistics on housing construction, transactions and house prices compiled on individual request. Recieved via email from $\mathrm{KSH}$ on 16.06.2016.

Magyar Nemzeti Bank (MNB - Hungarian National Bank) (2016): statistics on household mortgages. Accessible at: http://www.mnb.hu/statisztika/statisztikai-adatokinformaciok/adatok-idosorok/x-monetaris-es-egyeb-merlegstatisztikak. Downloaded on 19.02.2015.

Magyar Nemzeti Bank (MNB - Hungarian National Bank) (2017) : statistics for the MNB Housing market report. Accessible at:

https://www.mnb.hu/kiadvanyok/jelentesek/lakaspiaci-jelentes/lakaspiaci-jelentes-2017november. Downloaded on 15.12.2017.

Anonymised data sources from two banks concerning spatial patterns of mortgage lending and a settlement list for real estate valuation. 
LIST OF INTERVIEWS

\begin{tabular}{|c|c|c|c|}
\hline $\begin{array}{l}\text { NR OF } \\
\text { INTERVIEW }\end{array}$ & DATE & TYPE OF ACTOR & $\begin{array}{l}\text { POSITION OF } \\
\text { INTERLOCUTOR }\end{array}$ \\
\hline 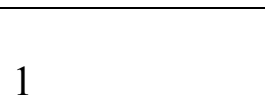 & 2015.09 .11 & $\begin{array}{l}\text { bank (Hungarian, also mortgage } \\
\text { bank) }\end{array}$ & $\begin{array}{l}\text { department director, } \\
\text { responsible for research }\end{array}$ \\
\hline 2 & 2016.11 .29 & $\begin{array}{l}\text { property developer (among the } \\
\text { largest, active in Budapest) }\end{array}$ & managing director \\
\hline 3 & 2016.12 .01 & $\begin{array}{l}\text { real estate agency (franchise, } \\
\text { started in a secondary city, HQ) }\end{array}$ & franchise director \\
\hline 4 & 2016.12 .08 & $\begin{array}{l}\text { real estate agency (market leader, } \\
\text { top-down franchise, HQ) }\end{array}$ & owner \\
\hline 5 & 2016.12 .09 & $\begin{array}{l}\text { property developer (member of a } \\
\text { banking group, among the largest) }\end{array}$ & general manager \\
\hline 6 & 2016.12 .14 & $\begin{array}{l}\text { real estate industry: online portal } \\
\text { and event organization }\end{array}$ & $\begin{array}{l}\text { real estate analysts (two } \\
\text { people) }\end{array}$ \\
\hline 7 & 2016.12 .15 & $\begin{array}{l}\text { real estate agent in the outskirts } \\
\text { of Budapest (bottom-up franchise) }\end{array}$ & $\begin{array}{l}\text { local office manager/ } \\
\text { owner }\end{array}$ \\
\hline 8 & 2017.01 .05 & $\begin{array}{l}\text { bank (foreign banking group, also } \\
\text { mortgage bank) }\end{array}$ & $\begin{array}{l}\text { department director for } \\
\text { real estate finances }\end{array}$ \\
\hline 9 & 2017.01 .30 & $\begin{array}{l}\text { real estate agency (top-down } \\
\text { franchise, HQ) }\end{array}$ & lead analyst \\
\hline 10 & 2017.01 .31 & $\begin{array}{l}\text { bank (foreign banking group, also } \\
\text { mortgage bank) }\end{array}$ & $\begin{array}{l}\text { retail banking } \\
\text { administrator, } \\
\text { responsible for mortgage } \\
\text { lending }\end{array}$ \\
\hline 11 & 2017.02 .22 & $\begin{array}{l}\text { property developer (market leader } \\
\text { in housing development) }\end{array}$ & general manager \\
\hline 12 & 2017.02 .28 & $\begin{array}{l}\text { bank (Hungarian, also mortgage } \\
\text { bank) }\end{array}$ & press referent \\
\hline 13 & 2017.03 .07 & credit agency (national scale, HQ) & director \\
\hline 14 & 2017.03 .08 & $\begin{array}{l}\text { real estate agency (national scale } \\
\text { bottom-up franchise, } \mathrm{HQ} \text { ) }\end{array}$ & $\begin{array}{l}\text { owner, managing } \\
\text { director }\end{array}$ \\
\hline 15 & 2017.03 .08 & $\begin{array}{l}\text { real estate agency (national scale, } \\
\text { HQ) }\end{array}$ & $\begin{array}{l}\text { owner, managing } \\
\text { director }\end{array}$ \\
\hline 16 & 2017.03 .13 & $\begin{array}{l}\text { real estate agency (local office, } \\
\text { outskirts of Budapest, not part of } \\
\text { network) and local construction } \\
\text { company }\end{array}$ & $\begin{array}{l}\text { owners and managers of } \\
\text { both companies (two } \\
\text { people) }\end{array}$ \\
\hline 17 & 2017.03 .17 & credit agency (national scale, HQ) & $\begin{array}{l}\text { director for branch of } \\
\text { household credit }\end{array}$ \\
\hline 18 & 2017.03 .22 & credit agency (national scale, HQ) & director \\
\hline 19 & 2017.03 .23 & $\begin{array}{l}\text { linked real estate and credit } \\
\text { agency (large secondary city in } \\
\text { the east), member of franchise }\end{array}$ & $\begin{array}{l}\text { managers of both } \\
\text { agencies (two people) }\end{array}$ \\
\hline 20 & 2017.03 .27 & $\begin{array}{l}\text { bank (foreign banking group, } \\
\text { recently started mortgage bank) }\end{array}$ & $\begin{array}{l}\text { deputy managing } \\
\text { director }\end{array}$ \\
\hline 21 & 2017.03 .28 & $\begin{array}{l}\text { bank (Hungarian, also mortgage } \\
\text { bank) }\end{array}$ & $\begin{array}{l}\text { household credit branch } \\
\text { director }\end{array}$ \\
\hline
\end{tabular}




\begin{tabular}{|c|c|c|c|}
\hline 22 & 2017.03 .30 & $\begin{array}{l}\text { real estate agency and } \\
\text { construction company (secondary } \\
\text { city in the west, not member of } \\
\text { franchise) }\end{array}$ & owner, manager \\
\hline 23 & 2017.03 .30 & $\begin{array}{l}\text { credit agency (secondary city in } \\
\text { the west, member of franchise) }\end{array}$ & credit administrator \\
\hline 24 & 2017.04 .03 & $\begin{array}{l}\text { real estate agency (secondary city } \\
\text { in the center-west, member of } \\
\text { franchise) }\end{array}$ & owner, manager \\
\hline 25 & 2017.04 .04 & $\begin{array}{l}\text { linked real estate and credit } \\
\text { agency (large secondary city in } \\
\text { the center-east), member of } \\
\text { franchise }\end{array}$ & $\begin{array}{l}\text { office manager and } \\
\text { credit administrator (two } \\
\text { people) }\end{array}$ \\
\hline 26 & 2017.04 .06 & Ministry for National Economy & $\begin{array}{l}\text { department director for } \\
\text { "home establishment" }\end{array}$ \\
\hline 27 & 2017.04 .10 & $\begin{array}{l}\text { real estate agency (secondary city } \\
\text { in the west, member of franchise) }\end{array}$ & office manager \\
\hline 28 & 2017.04 .11 & $\begin{array}{l}\text { property developer (among the } \\
\text { largest, active in Budapest) }\end{array}$ & $\begin{array}{l}\text { director for housing } \\
\text { sales }\end{array}$ \\
\hline 29 & 2017.04 .12 & Hungarian National Bank & researchers (two people) \\
\hline 30 & 2017.04 .18 & $\begin{array}{l}\text { real estate agency (suburban city } \\
\text { of a secondary city in the east, } \\
\text { local office, not member of } \\
\text { franchise) }\end{array}$ & office manager \\
\hline 31 & 2017.04 .18 & $\begin{array}{l}\text { real estate agency (secondary city } \\
\text { in the east, member of franchise) }\end{array}$ & office manager \\
\hline 32 & 2017.04 .18 & $\begin{array}{l}\text { credit agency (secondary city in } \\
\text { the east, member of franchise) }\end{array}$ & regional manager \\
\hline 33 & 2017.04 .19 & $\begin{array}{l}\text { credit agency (secondary city in } \\
\text { the east, member of franchise) }\end{array}$ & office manager \\
\hline 34 & 2017.05 .04 & $\begin{array}{l}\text { credit agency (secondary city in } \\
\text { the east, member of franchise) }\end{array}$ & credit administrator \\
\hline 35 & 2017.05 .05 & home savings and loan association & $\begin{array}{l}\text { director for strategy and } \\
\text { regulation }\end{array}$ \\
\hline 36 & 2017.05 .08 & $\begin{array}{l}\text { bank (foreign banking group, } \\
\text { Budapest inner-city offices) }\end{array}$ & $\begin{array}{l}\text { office manager for all } \\
\text { inner-city offices }\end{array}$ \\
\hline 37 & 2017.05 .10 & $\begin{array}{l}\text { bank (Hungarian, also mortgage } \\
\text { bank, secondary city in the east) }\end{array}$ & $\begin{array}{l}\text { former local branch } \\
\text { director }\end{array}$ \\
\hline 38 & 2017.05 .12 & home savings and loan association & $\begin{array}{l}\text { director for strategy and } \\
\text { regulation }\end{array}$ \\
\hline 39 & 2017.05 .15 & $\begin{array}{l}\text { local focus group, secondary city } \\
\text { in the east }\end{array}$ & $\begin{array}{l}\text { local office of a large } \\
\text { national bank, local } \\
\text { savings cooperative, } \\
\text { credit agency, real estate } \\
\text { agency (four people) }\end{array}$ \\
\hline 40 & 2017.05 .17 & Hungarian Banking Association & secretary general \\
\hline
\end{tabular}


LIST OF FIGURES

\begin{tabular}{|c|c|c|}
\hline NUMBER & TITLE & PAGE \\
\hline Figure 1. & $\begin{array}{l}\text { Drawing on critical traditions of economic geography and } \\
\text { political economy for constructing my conceptual building } \\
\text { blocks }\end{array}$ & 17 \\
\hline Figure 2. & $\begin{array}{l}\text { Differences in average interest rate levels on new residential } \\
\text { loans by country groups }\end{array}$ & 54 \\
\hline Figure 3. & $\begin{array}{l}\text { The volatility of capital investment in housing on the } \\
\text { European peripheries }\end{array}$ & 55 \\
\hline Figure 4. & $\begin{array}{l}\text { Spatial concentration of issued new mortgage loans } 2000 \text { - } \\
2016\end{array}$ & 65 \\
\hline Figure 5. & $\begin{array}{l}\text { The spatial distribution of new mortgages in a given year (in } \\
\text { terms of capital and number of contracts) }\end{array}$ & 66 \\
\hline Figure 6. & Settlement categories for collateral valuation & 69 \\
\hline Figure 7. & $\begin{array}{l}\text { Spatial correspondence of mortgage lending and the family- } \\
\text { based housing subsidy }\end{array}$ & 73 \\
\hline Figure 8. & $\begin{array}{l}\text { Volatility of house prices in selected locations as a result of } \\
\text { the crisis }\end{array}$ & 76 \\
\hline Figure 9. & $\begin{array}{l}\text { Mapping economic actors of the housing market and their } \\
\text { relations }\end{array}$ & 94 \\
\hline
\end{tabular}




\section{ENGLISH LANGUAGE SUMMARY}

In the dissertation I have investigated the uneven socio-spatial development of the Hungarian housing market since the end of the 1990s. The focus of my investigation was the logic of investment in the housing market, and the strategies employed by firms active in this field. I have payed particular attention to the effects of the recent crisis of 2008 on the housing market and its institutions. My main research question has concerned how the corporate, institutional strategies of firms are translated to reproducing uneven development on the housing market. I conceptually position my research in relation to the notion of uneven development, and thus approach my study through the lens of understanding patterns of homogenisation and differentiation. This approach supports a relational understanding of cores and peripheries, as well as a focus on the mechanisms underlying the production of socio-spatial unevenness in housing, rather than merely giving an empirical observation of the existence of these inequalities.

I have conducted the research leading up to this $\mathrm{PhD}$ dissertation in the framework of a Marie Curie Initial Training Network, as part of a research project entitled "RegPol ${ }^{2}$ - Socioeconomic and Political Responses to Regional Polarisation in Central and Eastern Europe". This has determined some of the main guiding elements of my research, most notably the focus on the mechanisms how subnational socio-spatial inequalities are reproduced in Central and Eastern Europe. I argue that these patterns of internal fragmentation cannot be understood without taking into consideration the integration of a given country in broader hierarchical and dependent economic relations. Thus, I see the dynamic tension between cores and peripheries as the main driving force of uneven development.

The economic crisis of 2008 brought the inherent links of global capitalism and housing to the surface, and also brought the strengthening of more structuralist theoretical approaches. Following this turning point, a number of studies critically engaging with the political economy of housing emerged in various contexts around the globe (see eg. Aalbers 2017). However, the majority of these analyses build their theoretical claims based on empirical material from the core of the global economy and often see the financialisation of housing as a consequence of the economic shifts happening since the 1970s. Thus, although I strongly build on these studies of the new "critical mainstream" in political economy and economic geography, I also aim to go beyond them in at least two respects. Firstly, I integrate the perspective of macroeconomic relations of dependency and the position in which Hungary is integrated in the hierarchically structured European and global economy (Becker et al. 2015). Furthermore, I do not see financialisation as merely the development of the past few decades, rather as a cyclically recurring phase in the longue durée perspective of capitalist development, when increasing amounts of surplus capital are systematically channelled into infrastructural and geographical fixes (Arrighi 1990).

Conceptually, I position myself in relation to research traditions of critical political economy and economic geography, drawing especially on studies that have emerged following the 2008 crisis and represent critical / more macroscopic approaches to understanding contemporary capitalist development. Within these disciplinary approaches I mobilise notions that can be related to the development of the housing market. This directs my attention to scholarly work that focuses on the ways how capital is invested in housing. Thus, I draw on the literature relating to the variegated financialisation of housing (linked to new developments in financial geography), and on studies of residential varieties of capitalism (in political science and political economy). I claim that households are included in the extractive logic of financial capitalism primarily through household credit - especially in the context of housing regimes 
extremely dominated by individual homeownership (which is the case of Hungary). I believe that financial mechanisms available to the development of housing fundamentally determine what type of actors will be present on the housing market, and also to whom and under what conditions housing is accessible. Furthermore, in line with the tradition of critical political economy, I see crisis as an instance that reveals underlying mechanisms of channelling capital from the peripheries to the cores - thus, I continuously come back to the analysis of the turning point of the recent economic and financial crisis. In my view, the development of the Hungarian housing market in recent decades cannot be understood independently from broader relations of dependent integration in the European and global economic space. Thus, I strongly draw on scholars of dependency theories, particularly those who have employed this frame of thought to contemporary Europe.

I also understand the issue of subnational socio-spatial disparities in relation to these external dependencies, and argue that internal fragmentation within Hungarian society, economy, or in the spatial structure of the housing market can be linked to the semiperipheral position Hungary takes up in the global economy. I believe that inquiries about increasing spatial unevenness within peripheral European countries, and about the increasing marginalisation of certain local spaces will not have the necessary explanatory force without considering the broader logic of European integration they are embedded in. I propose a research agenda for such a multiscalar understanding of uneven and dependent development. The housing market is a very apt empirical field for understanding how these extractive mechanisms play out on various scales.

In my analysis, I focus on corporate actors as the concrete conveyors of capitalist processes on the housing market. I am interested in how firms themselves are embedded in core-periphery relations, and on the other hand how they (re)produce socio-spatial patterns of unevenness. I aim to shed light on how corporate-level strategies are translated into uneven development. In this, I build on conceptual approaches that link corporate governance strategies to macroeconomic processes.

Beyond the resurging theoretical interest in the spatial unevenness of capitalist development, the research agenda proposed by the $\mathrm{RegPol}^{2}$ research project was fundamentally one responding to a pressuring social and spatial phenomenon: the increasing inequalities within Central and Eastern European countries. Within this research agenda the focus on the issue of housing seemed particularly appropriate on the one hand because of its very direct implications for social and spatial equality, and the way how households are directly affected by this concrete aspect of uneven development; and on the other hand because it is a field where the interlinked effects that economic pressures and public policy interventions have on spatial patterns of unevenness can be well assessed.

In the dissertation, I argue that capital is being systematically transferred from the peripheries to cores on various scales through housing. This can be observed on a European, national and local scale, and can be grasped in the concrete strategies of various types of actors of housing (such as financial institutions, developers or agents). Examples for this process include how Western European financial institutions entered Central and Eastern European (CEE) markets before the crisis and channelled capital towards cores on a European scale; or how individual mortgages and project-financing credit are allocated with much more favourable conditions in core areas on a national scale; or through the fact that investor- buyers from all over the country prefer to invest in prime real estate locations in the capital city. The capital-intensive and investment-oriented segment of the housing market - where economic actors prefer to intervene - is thus increasingly concentrated in core areas (which often produces inequalities and displacement locally), while in peripheral areas the provision of housing is left to the 
responsibility of individual households (relying on their own resources or on credit to secure housing).

In my research I have empirically focused on corporate actors of the housing market; understanding their logic of intervention and the socio-spatial effects this has. Households and state institutions have only indirectly been included in the research, and my point of entry has deliberately been from the perspective of firms. Understanding firm strategies has been a way to grasp how finance and sptial unevenness are linked through housing.

In terms of housing finance there has been an important shift following the crisis from international to domestic sources of housing finance in Hungary. It remains to be seen whether this new structure can create future avenues for more stable and long-term forms of housing finance. What is already clear from the current reorganisation of housing finance is that the institutional hierarchy of actors involved in the housing market has shifted, benefiting an emergent new national capitalist class.

The availability of capital, the internal firm strategies balancing profit seeking and risk management, as well as instances of public intervention interact to produce cycles of ebbs and flows of investment and disinvestment on the housing market. The socio-spatial patterns of how capital spreads out and then how it is reconcentrated overlap, showing how homogenisation and differentiation under uneven development coexist and mutually reinforce each other. I analyse this process through the intervention of corporate actors in the field, claiming that risk management on a company scale translates into uneven socio-spatial development on a broader scale; and that because of this the concrete mechanisms through which uneven development can be practically grasped on the scale of the everyday functioning of the housing market are articulated in the terminology of corporate governance.

Currently, housing in Hungary is undergoing important shifts (this volatility is, in part, a necessary characteristic of a semiperipheral housing market), which makes research in this field difficult and subject to a potentially quick loss of relevance. For this reason, I do not consider the value of my research to be in the empirical description of the precise current situation on the housing market, rather in the way I sought to uncover systematic tendencies and characteristic mechanisms of how the unevenness of housing is (re)produced in Hungary. 


\section{MAGYAR NYELVÜ ÖSSZEFOGLALÓ}

\section{A kutatás motivációja, céljai}

Doktori dolgozatomban a magyar lakáspiac egyenlőtlen térbeli-társadalmi fejlődését vizsgáltam az 1990-es évek végétől kezdődően. Elemzésem középpontjában a lakáspiaci cégek stratégiái, a lakáspiacra való befektetés logikája állt. Különös figyelmet fordítottam arra, hogy a 2008-as gazdasági válság magyar lakáspiacra és annak intézményeire gyakorolt hatásait vizsgáljam. Fő kérdésfeltevésem az volt, hogy a lakáspiacon aktív piaci szereplők intézményi, cégen belüli stratégiái milyen módon fordítódnak le egyenlőtlen térbeli-társadalmi fejlödésre.

A kutatást a „RegPol²: Társadalmi-gazdasági és politikai válaszok a kelet-közép-európai regionális polarizációra“ címü, Marie Curie ITN (vagyis Alapképzési hálózatok”) kutatási program keretében végeztem, mely a kutatás empirikus fókuszát és fogalmi keretét is jelentősen befolyásolta. A kutatási program központi kérdésfeltevése a kelet-közép-európai országokon belül növekvő területi egyenlőtlenségek, polarizálódó centrum-periféria viszonyok okainak feltárása volt (Lang et al. 2015). Az országon belüli egyenlötlenségek kérdését hangsúlyosan tágabb gazdasági keretbe helyeztem; amellett érvelve, hogy a növekvő belső fragmentáltság nem érthető meg az ország tágabb gazdasági helyzetének, függő beágyazottságának megértése nélkül.

A 2008-as gazdasági válság felszínre hozta a lakáspiac és a kapitalista befektetési ciklusok szoros összefüggéseit; a lakáspiac tőkemegkötésben játszott szerepét. Ezért a válság után megszaporodtak a lakáspiaci jelenségeket kritikai, politikai-gazdaságtani szempontból vizsgáló elemzések (lsd. pl. Bohle 2013, Aalbers 2017). Ezek többsége azonban centrumtérségek-beli empirikus anyagok alapján jut tágabb elméleti következtetésekre, és a lakáspiac tőkemegkötésben játszott szerepének növekedését (vagyis a lakhatás financializációját) elsősorban az 1970-es évek óta tartó gazdasági szerkezetváltás következményeként írják le. Ezért a válság utáni „kritikai mainstream” irodalmának keretein két szempontból is túl kívánok menni kutatásommal: egyrészt értelmezési keretemben kiemelt jelentőséget tulajdonítok a makrogazdasági függőségi viszonyoknak (Becker et al. 2015), ezáltal hangsúlyosan kezelem Magyarország globálisan félperifériás pozícióját a lakáspiaci folyamatok magyarázatában; másrészt pedig a lakhatás financializációjának jelenségét tágabb történelmi perspektívában értelmezem, a kapitalizmus hosszútávú ciklikus fejlődéséhez kapcsolódóan (Arrighi 1990).

Három fő tényező mentén járul hozzá a kutatásom a magyar lakáspiacról való empirikus tudás bővítéséhez: egyrészt annak makrogazdasági folyamatokba való beágyazottságának feltárásával, másrészt a szektor piaci szereplői szempontjából végzett vizsgálattal, harmadrészt pedig a lakáspiac térbeliségének a szereplök viszonyrendszerén keresztül, különböző léptékekhez köthető elemzésével.

Jelenleg fontos átrendeződések zajlanak a magyarországi lakáspiacon. Ez egyszerre bizonyítja a téma aktualitását és jelent nehézségeket a kutathatóság szempontjából. 2017 során, mikor kutatásom kvalitatív adatgyüjtő részét végeztem, jelentős piaci és közpolitikai változások voltak folyamatban, melyek kifutása máig sem látszik világosan. Épp ezért fontosnak tartom kiemelni, hogy kutatásomban a folyamatok és mechanizmusok megértésére koncentráltam egyes, földrajzilag lehatárolt terepek konkrét lakáspiaci helyzetével kapcsolatos mélyfúrások helyett. Úgy véltem, hogy utóbbiak gyorsan változhatnak, viszont egy-egy lakáspiaci szereplöcsoport mozgatórugóinak, stratégiáinak megértése, illetve ezek területi következményeinek feltárása esetleg könnyebben vonatkoztatható későbbi helyzetek megértésére is. 


\section{A kutatás elméleti eredményei}

\section{A lakáspiac szerepe a kapitalizmusban és annak térbeli lecsapódásában}

Ezen a területen a disszertáció fó állítása, hogy financializációs ciklusokban (vagyis amikor a befektetésre váró tőke mennyisége világszerte megnő) a lakáspiacnak kiemelt szerepe lesz, mint tökemegkötési forma (mely folyamat megragadásában központi a térbeli kiigazítás, vagyis spatial fix fogalma). Ennek következménye pedig a társadalmi és térbeli egyenlőtlenségek növekedése a lakáspiacon. A disszertációban áttekintettem azon kutatók kapcsolódó érveit, akik munkáját a legrelevánsabbnak tekintettem a magyarországi lakáspiac politikai-gazdaságtani elemzése szempontjából (Aalbers 2017, Bohle 2017, Sokol 2017). Mindhármuk munkássága fontos támpontokat ad azzal kapcsolatban, hogy milyen konkrét intézményi mechanizmusok közvetítik a tökebefektetési nyomást (például egy adott ország lakáspiacának tulajdonosi struktúrája vagy az elérhető finanszírozási csatornák szerint), viszont mindhárom szerző esetében hiányoltam a tágabb gazdasági integráció hierarchikus, függő jellegének felismerését.

\section{Külsö függöségek és belső egyenlötlenség összefüggései}

Ezen a téren a dolgozat legfontosabb megállapítása, hogy a lakásfinanszírozás számára elérhető forrásokat alapvetően meghatározza az ország Európán (illetve a globális gazdaságon) belüli pozíciója. Ennek következménye, hogy az európai perifériákon, így Magyarországon is, alapvetően hiányoznak a lakhatás finanszírozására elérhető hosszútávú források. Ez elsősorban abból fakad, hogy azok a szereplők, melyek ezeken a piacokon fektetnek be, magasabb mértékü és gyorsabb megtérülést várnak a befektetésük után. Ennek olyan praktikus következményei vannak, mint például a magasabb kamatokkal elérhető hitelek, vagy a bérlakások fenntartásában érdekelt szereplők hiánya/ finanszírozhatatlansága.

A külső függőségek és az ezekből fakadó korlátok felismerésének a magyar lakáspiac országon belüli mintázatainak megértésében is jelentősége van. A lakásfinanszírozás ilyen struktúrája növekvő belső fragmentáltságot, térbeli és társadalmi egyenlőtlenséget okoz, hiszen az országos és lokális centrumokban sokkal jobb feltételekkel lehet forrásokhoz jutni, illetve több léptéken érvényesül a perifériákról centrumok felé való tőkekivonás mechanizmusa.

Elméleti szempontból fontosnak gondolom a függőségek szempontjának kiemelését, mert rávilágít arra, hogy a kortárs politikai-gazdaságtani megközelítések, kritikai érzékenységük ellenére is gyakran homogenizáló módon láttatják a kapitalista folyamatok következményeit.

\section{Vállalatok, mint a kapitalizmus mechanizmusainak közvetitői}

A kortárs kritikai elméletek egyik fontos megközelítésbeli alapvetése, hogy bár a kapitalizmus rendszerszintü összefüggéseit helyezik elemzésük középpontjába, fontosnak tekintik azoknak az intézményi mechanizmusoknak a feltárását, amik a rendszerszintű nyomásokat a gazdaság hétköznapi müködésének szintjére lefordítják. Ebben a fordítási tevékenységben kiemelt szerepe van a vállalatoknak. A vállalati stratégiák és a térbeli folyamatok közötti kapcsolat a gazdaságföldrajz hagyományosan hangsúlyos területe, ezért ezen a téren tudtam a legközvetlenebbül ennek a diszciplínának az eszköztárára támaszkodni. Elemzésem során kiemelt figyelmet fordítottam arra, hogy a vállalati stratégiák, döntések területi következményeit feltárjam.

\section{A kutatás empirikus eredményei}


A tőkebefektetések lakáspiacra való ciklikus beáramlásnak és visszahúzódásnak területi mintázatait a lakáshitelezésen keresztül vizsgáltam, a pénzügyi túlzott bevonás (financial overinclusion), illetve az ennek nyomán kialakuló pénzügyi kirekesztés (financial exclusion) fogalmi keretén belül (mellyek az ezen a téren jelentkező egyenlötlen fejlödést tudtam megragadni). A válság előtti felfutó hitelezés időszakában ez azt jelentette, hogy folyamatosan bővült a lakáshitelezésbe bevont háztartások és települések köre. A legkiterjedtebb hitelezés földrajza nagyban átfed a későbbi nemteljesítő hitelek, majd befagyott lakáspiacok földrajzával. A lakáspiacra való tőkebefektetések ciklikus kiáramlásának majd visszahúzódásának a társadalmi hatásait ez a jelenség rendkívül jól mutatja. A jelenlegi periódusban újra fellendülö hitelezés mind társadalmi, mind térbeli szempontból jóval szelektívebb, mint a korábbi időszakokban volt, ezzel tovább növeli a lakáspiac egyenlőtlen térbeli fejlödését országos szinten.

Különböző léptékeken vizsgálva is igaz, hogy a perifériák lakáspiacai volatilisebbek és kiszolgáltatottabbak a válságciklusoknak. Európai léptéken vizsgálva a dél- vagy kelet-európai lakáspiacok a tökebefektetések kiterjedésének időszakában új befektetési célponttá válnak, viszont válságidőszakban nagyon hirtelen leállnak az ide irányuló tőkebefektetések. Ez a volatilitás alapvetően kiszámíthatatlanná teszi a perifériák lakásfinanszírozási rendszereit, és a nagy ingadozással megjelenő, befektetésre váró tőke a lakásárak és tranzakciószámok jelentős ingadozásához is vezet. A perifériák volatilitásának érve ugyanakkor alacsonyabb léptéken is igaz: azokon a területeken, ahol a lakáshitelezésnek a legnagyobb jelentősége van a lakáspiaci folyamatok alakításában (melyek jellemzően nagyvárosok agglomerációs területei); a hitelezési csatorna befagyásakor (mely a külső függőségek miatt nagyon hirtelen meg tud történni) a lakáspiaci tevékenység szintén rendkívül hirtelen módon leáll. Ezeken a területeken tapasztalhatóak a legjelentősebb ingadozások a lakásárak tekintetében is.

A lakáspiacra való tőkebefektetés ciklikussága jellegzetes helyi tereket hoz létre az elérhető finanszírozási csatornák szerint. Az így kirajzolódó területi mintázat (a jelenlegi időszakra vonatkozóan) nagy vonalakban a következő: a centrum lakáspiacokon (nagyvárosok jobb lokációi) meghatározóak a befektetési célú lakásvásárlások és általában gyakoriak a hitelfelvétel nélküli tranzakciók. Ezekben az esetekben a lakáspiaci befektetés egyértelmüen más befektetési formák alternatívájaként jelenik meg és közvetlen módon függ a makrogazdasági környezettől. A másik véglet a hitelezési rezsimböl kiszoruló területek és háztartások köre, ahol jellemző a lakásvásárlások megtakarításokból és intergenerációs transzferekből való finanszírozása. A két véglet közötti területeken (melyeket a disszertációban „köztes tereknek” neveztem) hatnak a legerőteljesebben a lakáshitelezés illetve az állami lakástámogatások változásai. Ezeket a területeket elsősorban funkcionálisan definiáltam; a lakáspiacon betöltött szerepüknek megfelelően, melyben a legfontosabb az, hogy a nagyvárosi munkaerőpiacok és a centrumokban meredeken emelkedő lakásárak zónájának szélén még megfizethető lakhatás között egyensúlyoznak. Ezért a háztartási mobilitási pályákban ezeknek a területeknek kiemelt jelentőségük van, és a lakáspiaci aktivitás is jellemzően átlag feletti.

\section{Vállalatok beágyazódása a centrum-periféria viszonyokba}

A lakáspiaci cégek köre jelentősen függ a lakáspiac helyi jellemzőitől - és ennek megfelelően hierarchikusan strukturált. Ez legkönnyebben az újlakásépítés területén ragadható meg. A centrumok lakáspiacain vannak csak jelen a nagyobb és tőkeerősebb szereplők, míg a periférikusabb lakáspiacokon jellemzően kisebb és hibrid profilú (többféle tevékenységet ötvözö) vállalkozások építenek lakásokat. Az ingatlan- és hitelközvetítő cégek esetében is jellemzö, hogy a nagyobb profitabilitással és szükebb profillal dolgozó ügynökségek a centrumterületekre koncentrálnak, míg a kiterjedtebb tevékenységet végzö, helyi kis- és 
középvállalkozói hálózatokban intenzívebb módon részt vevő ügynökségek a kisebb településekre jellemzőek. A pénzintézetek esetében a hierarchikus területi tagozódás egyrészt abban tükröződik, hogy egyes pénzintézeteknek (fiókjaikon keresztül) milyen területi jelenléte van, másrészt pedig hangsúlyosan megjelenik hitelezési politikájukban. A területileg szelektívebb pénzintézetek jellemzően szigorúbb hitelkihelyezési feltételeket állapítanak meg, míg a széles körben hitelező pénzintézetek kockázatkezelési stratégiája a minél nagyobb volumen elérése. Ezek a vállalati jellemzők a fö ügyfélkörökkel és termékprofillal, illetve kockázatvállalási hajlandósággal kapcsolatban hozott stratégiai döntések következményei.

A piaci szereplők alapvető logikájából következően arányaiban nagyobb mértékben csatornáznak anyagi és szervezeti erőforrást a centrum lakáspiacok felé. Ez különböző módon nyilvánul meg a vállalati gyakorlatokban, de egyik legplasztikusabb megjelenési formája talán az, ahogyan a profitábilisabb piacokon müködő cégek (illetve itt vásárolni tudó háztartások) szisztematikusan jobb feltételekkel jutnak finanszírozáshoz, mint a periférikusabb lakáspiacokon müködő megfelelőik. Az ingatlanügynökök müködési logikájából is az fakad, hogy tevékenységük során a centrum lakáspiacokra fókuszálnak. Ezek a tendenciák (melyik elsősorban a lakáspiaci cégek profitabilitási szempontjaiból fakadnak) tovább mélyítik a lakáspiac területi egyenlötlenségeit. A lakáspiaci szereplök körének áttekintése, viszonyaik feltárása lehetőséget ad a lakáspiaci erőforrások, piaci lehetőségek és viszonyrendszerek jobb megértésére.

A válság hatására jelentősen átrendeződött a lakáspiaci szereplők köre minden piaci szegmensben. A lakásépítési cégek köre jelentősen leszükült, és a lakáspiaci fellendülés 2015 óta tartó időszakában is erösödött a koncentráció. Ennek fö oka, hogy az újabb cégek jelenleg nehezen tudnak finanszírozáshoz jutni, illetve az építőipar is kapacitáshiányokkal küzd, ezért egyértelmü versenyelőnyben vannak a nagyobb, válságot túlélt cégek. Az ingatlan- és hitelügynökségek körében is egyértelmü centralizációnak vagyunk tanúi, melynek egyrészt szabályozási, másrészt pedig piaci okai vannak. A pénzintézetek körében tapasztalható a legjelentősebb átrendeződés: egyrészt a válság utáni években (a 2010 óta zajló kormányzati törekvések hatására) jelentősen eltolódtak a lakásfinanszírozás forrásai a külfölditől a hazai források felé, mely egyrészt a pénzügyi intézményrendszer államosításán és hazai kézbe vételén, másrészt pedig egy hazai tőkés réteg helyzetbe hozásán, harmadrészt pedig egy megtakarítani képes középosztály megerősítésén keresztül történik.

A magyar lakáspiac alapvető jellemzője, hogy hiányoznak az olyan intézmények, melyek kifejezetten a lakáspiacon való hosszútávú, stabil jelenlétben lennének érdekeltek, és melyeknek módjában és érdekében állna hosszabb megtérüléssel, alacsonyabb profitabilitással lakásokat fejleszteni vagy árulni. Hiányoznak továbbá az olyan szereplők is, melyek lakások tulajdonlását és kezelését tennék meg fő profiluknak. Ezek az intézményi hiányosságok elsősorban a magyar lakáspiac strukturális sajátosságaiból (mint például az elérhető pénzügyi források) fakadnak, és egyértelmüen hatással vannak annak térbeli és társadalmi egyenlötlenségeire.

\section{Egyenlötlen fejlödés újratermelése a lakáspiacon}

A magyar lakáspiac egyenlőtlen fejlődésével kapcsolatos egyik legfontosabb érvem annak (elsősorban a lakásfinanszírozáson keresztül való) függő beágyazódásával kapcsolatos. A válság utáni intézményi átrendeződések hatására a magyar lakásfinanszírozás külső függősége látszólag jelentősen csökkent. Ha azonban ezt a folyamatot a magyar gazdaság általános globális beágyazottságának tágabb kontextusában értelmezzük, megállja a helyét az az érv, hogy a lakásfinanszírozásban a hazai források súlyának megnövekedése pusztán egy intézményi átrendeződést jelent, mely az általános függőséget nem csökkenti, viszont az 
erőforrásokat más szereplök köréhez, más intézményi csatornák felé tereli. Ennek a belső egyenlőtlenségekre nézve nincsen mérséklő hatása (épp ellenkezőleg). Ez a folyamat osztálypolitika szempontjából is értelmezhető, mely szempontból egyértelmünek tünik, hogy a magyar félperifériás pozíciójú állam a hazai tőkés réteg megerősítésére törekszik a lakásfinanszírozás eszközein keresztül is. Területi dinamikák szempontjából ez a lokális centrumok lakáspiacainak megerősödéséhez vezet.

A tőkebefektetés és -kiáramlás hullámai térben egymásra rakódnak, melynek legjobban megragadható példája a válság előtti lakáshitelezés által indukált, válság utáni területi, társadalmi és piaci jelenségek jelzik. A válság előtti túlterjeszkedő hitelezés hatására kialakultak a lakáspiacnak olyan szegmensei, melyeket a teljes immobilitás jellemez, és melyeket a legtöbb pénzintézet jelenleg is finanszírozhatatlannak minősít. Ez hozzájárul a lakáspiac területi egyenlötlenségeinek további növekedéséhez, társadalmi szempontból pedig adósságcsapdába zárt háztartások területi koncentrációját jelenti. A korábbi lakáshitelezési hullámnak a piaci szereplök körére nézve is van hatása, hiszen a nemteljesítő hitelek fedezeteként szolgáló ingatlanok egy teljes piaci szegmenst jelentenek, mely a befektetési céllal vásárlók számára előnyös lehetőségeket jelent. Ezt kihasználva egy új vállalkozói kör alakul ki, akik a lakáspiac hagyományos szereplői mellett egyre nagyobb súllyal jelennek meg.

Kutatásom további fontos eredménye, ahogy kirajzolódott, hogy a lakáspiac, mint befektetési forma és a lakhatás, mint reproduktív tér közötti frontvonalnak kiemelt jelentősége van. Ez a frontvonal a lakáspiaci vállalati szereplők szempontjából úgy jelenik meg, mint a kockázatkerülés és a befektetésre, profitabilitásra való törekvés közötti egyensúlyozásból adódó határ, a lakáspiac „felvevői” oldalán levő háztartások szempontjából pedig a saját erőforrásaik kihasználásának, reproduktív kapacitásaik megőrzésének határa. E frontvonal mozgása határozza meg a lakáspiac térbeliségének alapvető jellemzőit is, ezért ennek minél pontosabb feltárása mind a közpolitikai beavatkozások lehetősége, mint piaci szempontból kiemelten releváns. Területileg ezt a frontvonalat az agglomerációs zónákban lehet a legjobban megragadni, ahol emiatt mind az egyéni lakáshitelezés, mind a tulajdonszerzést támogató kormányzati támogatásoknak jelentős a súlya a lakáspiaci folyamatokban. 